\title{
Combustion analysis and particulate mutagenicity characterization for a single-cylinder diesel engine fueled by Fischer -Tropsch derived liquids
}

Michael Hayden McMillian

West Virginia University

Follow this and additional works at: https://researchrepository.wvu.edu/etd

\section{Recommended Citation}

McMillian, Michael Hayden, "Combustion analysis and particulate mutagenicity characterization for a single-cylinder diesel engine fueled by Fischer -Tropsch derived liquids" (2002). Graduate Theses, Dissertations, and Problem Reports. 2426.

https://researchrepository.wvu.edu/etd/2426

This Dissertation is protected by copyright and/or related rights. It has been brought to you by the The Research Repository @ WVU with permission from the rights-holder(s). You are free to use this Dissertation in any way that is permitted by the copyright and related rights legislation that applies to your use. For other uses you must obtain permission from the rights-holder(s) directly, unless additional rights are indicated by a Creative Commons license in the record and/ or on the work itself. This Dissertation has been accepted for inclusion in WVU Graduate Theses, Dissertations, and Problem Reports collection by an authorized administrator of The Research Repository @ WVU.

For more information, please contact researchrepository@mail.wvu.edu. 
Combustion Analysis and Particulate Mutagenicity Characterization for a Single-Cylinder Diesel Engine Fueled by Fischer-Tropsch Derived Liquids

Michael H. McMillian, P.E.

\author{
Dissertation submitted to the \\ College of Engineering and Mineral Resources \\ at West Virginia University \\ in partial fulfillment of the requirements \\ for the degree of \\ Doctor of Philosophy \\ in \\ Mechanical Engineering \\ Mridul Gautam, Ph.D., Chair \\ Nigel Clark, Ph.D. \\ John Loth, Ph.D. \\ Gary Morris, Ph.D. \\ William Wallace, Ph.D.
}

Department of Mechanical and Aerospace Engineering

Morgantown, West Virginia

2002

Keywords: Diesel, Combustion, Diesel Particulate Matter, Bioassay, Genotoxicity, Mutagenicity 


\section{Abstract \\ Combustion Analysis and Particulate Mutagenicity Characterization for a Single-Cylinder Diesel Engine Fueled by Fischer-Tropsch Derived Liquids \\ Michael H. McMillian, P.E.}

Further growth of diesel engines in the light-duty and heavy-duty vehicular markets is closely linked to the potential health risks of diesel exhaust. Cleaner burning fuels, such as those derived from natural gas via the Fischer-Tropsch (FT) process, offer a potentially economically viable alternative to standard diesel fuel. As part of this study, a two-liter, single-cylinder, four-stroke direct-injected engine was instrumented for in-cylinder pressure measurements. The emissions and performance data from engine operation with Federal low sulfur No. 2 diesel fuel (DF) and natural gas derived FT fuel were compared. Also as part of the study, an investigation was carried out on the mutagenic characteristics of particulate matter (PM) derived from FT and DF fuel combustion by relating the in-vitro mutagenic activity of the particulate matter to engine operating conditions and particle size via the Ames Salmonella typhimurium bioassay (Maron and Ames, 1983). Particulate matter from two engine conditions were gathered using a Micro-Orifice Uniform Deposition Impactor (MOUDI) for size selective mutagenic analysis.

Results of the mutagenicity study indicate differences in the mutagenic response of the PM soluble organic fraction (SOF) of both Federal diesel No. 2 and FT fuel as functions of engine operating conditions, fuel type and particle size. The extracted solubles from particles of aerodynamic diameters greater than $100 \mathrm{~nm}$ were found to exhibit significantly greater mutagenic effect than their smaller counterparts $(<100 \mathrm{~nm})$ for both fuels. Results of the combustion and emission study revealed a general trend for lower emissions for FT fuel compared to DF fuel. $\mathrm{NO}_{\mathrm{x}}$ emissions correlated well with ignition delay and the amount of heat 
released in the premixed combustion phase. With the exception of two high load engine conditions, lower CO and total hydrocarbon (THC) emissions were the general trend for FT fuel. Engine test facilities were located at the U.S. DOE's National Energy Technology Laboratory (NETL) in Morgantown, WV. Particulate matter samples were collected in the NETL engine test cell. Measurement and extractions were also performed at NETL. The extracted PM was analyzed at the National Institute of Occupational Safety and Health (NIOSH), also in Morgantown, WV, to determine particulate matter in-vitro mutagenicity via the AMES bioassay method. 


\section{DEDICATION}

I dedicate this work to the memory of my loving father:

John Daniel McMillian (April 1, 1927 - November 18, 2001).

He was the inspiration in my life to pursue higher education and in many ways helped instill in me a life long passion to learn. He taught me to always ask "Why?" and to seek the answers to questions that I might have. He was always there to listen or advise and was truly interested in all that I did. I love you and miss you deeply. 


\section{ACKNOWLEDGMENTS}

I would like to express my gratitude to Dr. Mridul Gautam, a friend, teacher and advisor, for his guidance and support. Dr. Gautam combines technical expertise with the wisdom of the master without letting the ego rule.

My sincere appreciation goes to Dr. William Wallace, who served on my committee, for his technical expertise, advice and humor. The same goes to Mr. Michael Keane and Dr. Tong-man Ong who helped share the burden with Dr. Wallace in regards to the Ames bioassay analyses.

Many, many thanks to Dr. Mingzhen Cui for her diligent effort in performing the detailed analysis of over two thousand petri dishes containing Salmonella typhimurium as part of the Ames bioassay analysis. This work would never have been completed without Dr. Cui's effort and the guidance she received from Dr. Wallace, Dr. Ong and Mr. Michael Keane. I wish you all the best.

I would also like to thank Dr. Gary Morris, Dr. Nigel Clark and Dr. John Loth who served as members of my committee and whose advice and valuable suggestions significantly improved the quality of my work.

I must also thank Mr. Sandeep Mehta of West Virginia University for his advice with MOUDI operation and data analysis.

I must also thank the many people I have worked with at the National Energy Technology Laboratory during this period for the support and the lessons I've received. I have learned much from so many. A special thanks must be given to Mr. Ed Robey whose advice and guidance on statistical matters is non paralleled. Also, to number one technician, Mr. Richard Madden for putting up with me during the hundreds of hours we spent in the engine lab testing 
and testing (we've both concluded that MOUDI is not an acronym!). Thanks also to Debbie, Linda, Tami and Carol at OASIS for your help with the manuscript.

I must reserve my deepest thanks to my family. The support and love that I received from my wife Deanna, my daughter Sarah, my son Matthew during this time was what gave me the strength to succeeded. Thanks for putting up with me, I could not have done without you. Thanks to you too Mom, you've always supported me and loved me no matter what.

I thank our creator and all the tankashilas and I pray that I will somehow find the wisdom to put what I've learned to use for the betterment of all living things.

Mitakuye Oyacin 


\section{TABLE OF CONTENTS}

$\underline{\text { Page }}$

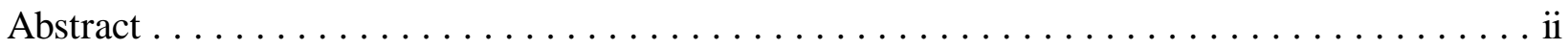

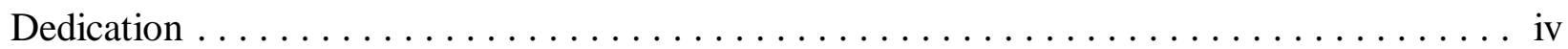

Acknowledgments $\ldots \ldots \ldots \ldots \ldots \ldots \ldots \ldots \ldots \ldots \ldots \ldots \ldots \ldots \ldots \ldots$

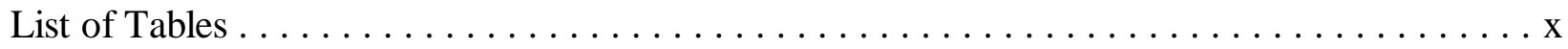

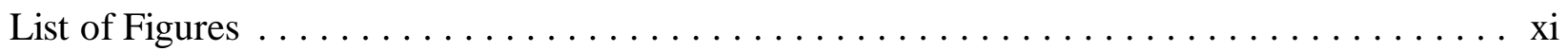

Nomenclature $\ldots \ldots \ldots \ldots \ldots \ldots \ldots \ldots \ldots \ldots \ldots \ldots \ldots \ldots \ldots \ldots \ldots \ldots \ldots$

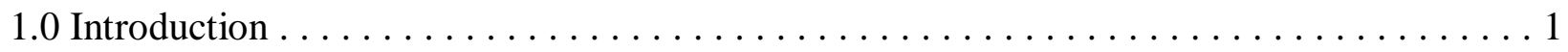

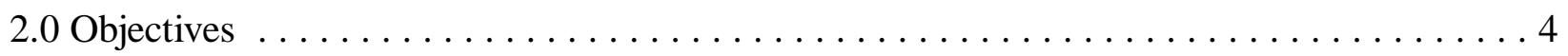

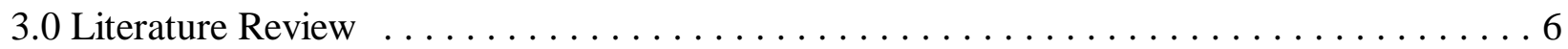

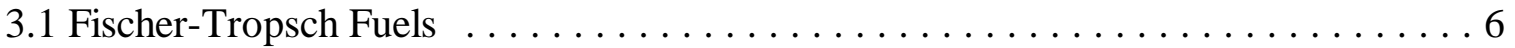

3.1.1 Introduction: The Fischer-Tropsch Processes $\ldots \ldots \ldots \ldots \ldots \ldots$

3.1.2 Fuel Properties and Fuel Effects on Exhaust Emissions . . . . . . . . . 11

3.1.2.1 Carbon/Hydrogen $(\mathrm{C} / \mathrm{H})$ Ratio . . . . . . . . . . . . . . 11

3.1.2.2 Cetane Number . . . . . . . . . . . . . . . . . . . . 13

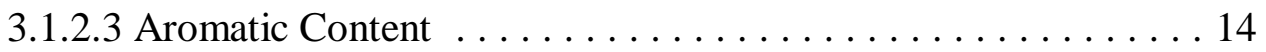

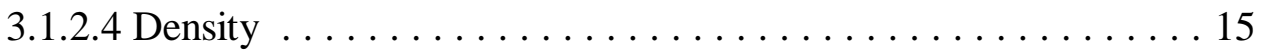

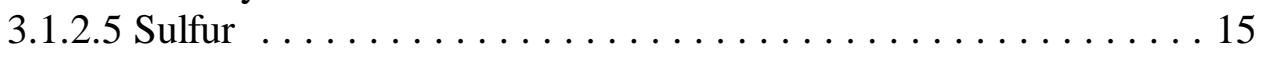

3.1.3 Fischer Tropsch Fuels and Their Emission Effects . . . . . . . . . 16

3.1 .4 Particulate Matter $(\mathrm{PM})$. . . . . . . . . . . . . . . . . . . . . . . 19

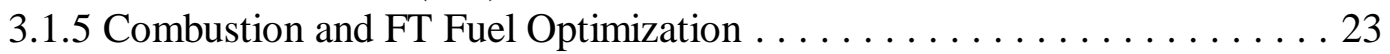

3.2 Dilution Tunnels and Particulate Measurement $\ldots \ldots \ldots \ldots \ldots \ldots \ldots \ldots \ldots$

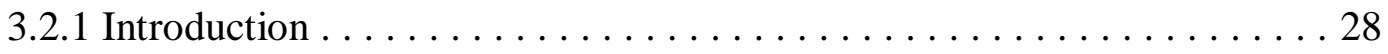

3.2.2 Sampling Methodology and Instrumentation $\ldots \ldots \ldots \ldots \ldots \ldots \ldots \ldots$

3.2.3 Effects of Fuel Formulation on Size Resolved Particulate Matter

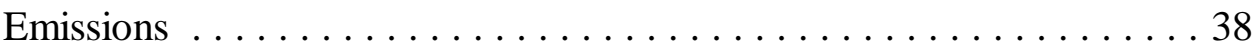

3.2.4 Effects of Dilution Tunnel Operation on Size Resolved Particulate Matter

Emissions . . . . . . . . . . . . . . . . . . . . . . . 39

3.3 Speciation of Diesel Particulates and Their Health Effects $\ldots \ldots \ldots \ldots \ldots \ldots 41$

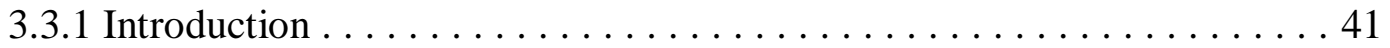

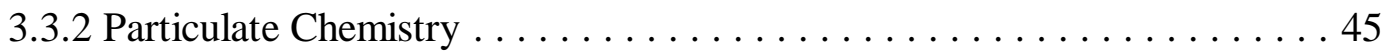

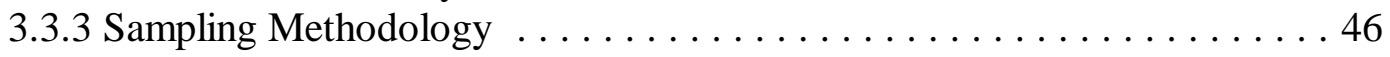

3.3.4 Sample Preparation . . . . . . . . . . . . . . . . . . . 48

3.3 .5 Analysis . . . . . . . . . . . . . . . . . . . . . . 49 


\section{TABLE OF CONTENTS}

(continued)

$\underline{\text { Page }}$

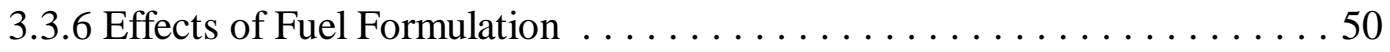

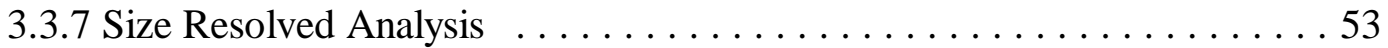

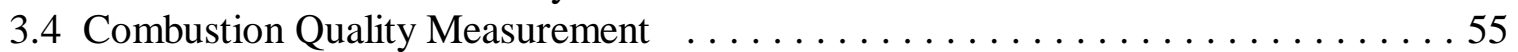

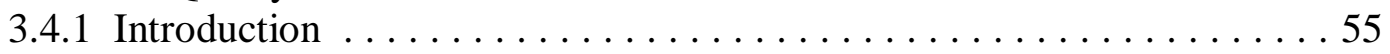

3.4.2 Measured Combustion Parameters . . . . . . . . . . . . . . 56

3.4.3 Calculated Combustion Parameters . . . . . . . . . . . . . . 62

3.4.3.1 Heat Release Rate . . . . . . . . . . . . . . . . . . . . 62

3.4.3.2 Burn Duration ... . . . . . . . . . . . . . . . . . 65

3.4.4 Fischer-Tropsch Combustion Analysis . . . . . . . . . . . . . 68

4.0 Experimental Equipment and Procedure $\ldots \ldots \ldots \ldots \ldots \ldots \ldots \ldots \ldots \ldots \ldots \ldots$

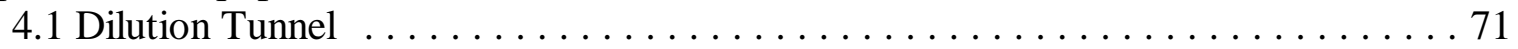

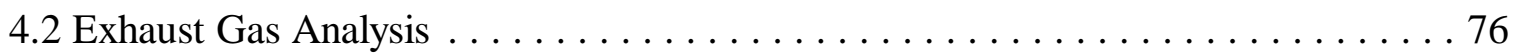

4.2.1 Total Hydrocarbon Analysis . . . . . . . . . . . . . . . . . . 76

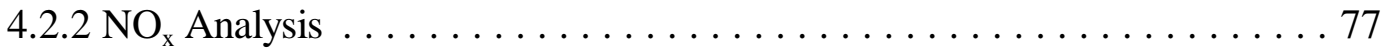

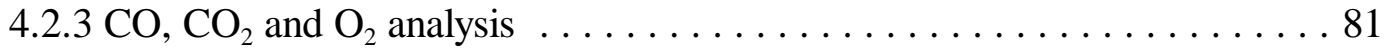

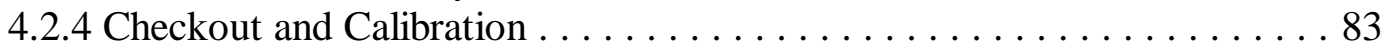

4.3 High Speed Data Acquisition and Combustion Analysis Equipment and

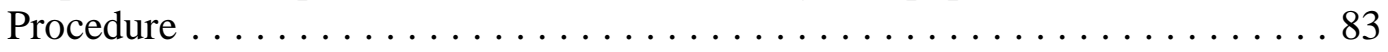

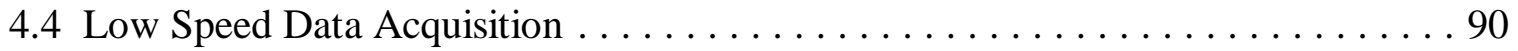

4.5 The Micro-orifice Uniform Deposition Impactor (MOUDI) $\ldots \ldots \ldots \ldots \ldots \ldots \ldots 9$

4.6 Uncertainty Analysis . . . . . . . . . . . . . . . . . . . . . . . . . . . 94

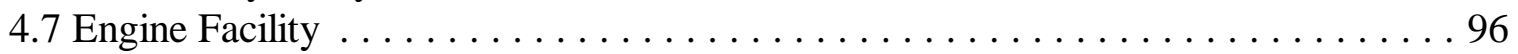

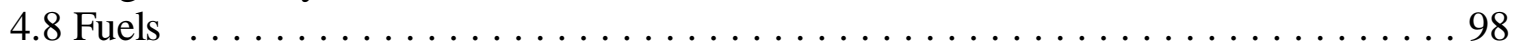

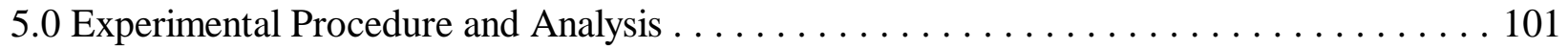

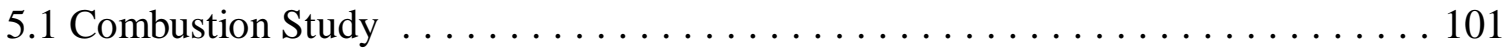

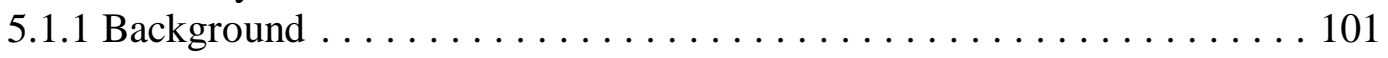

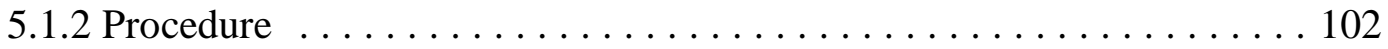

5.2 Particulate Matter Source Analysis . . . . . . . . . . . . . . . . . . . . . . 104

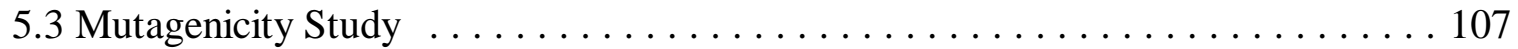

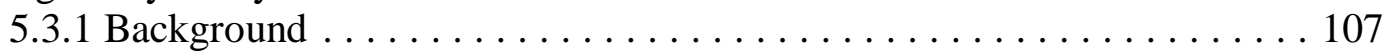

5.3 .2 Engine Injection Timing . . . . . . . . . . . . . . . . 108

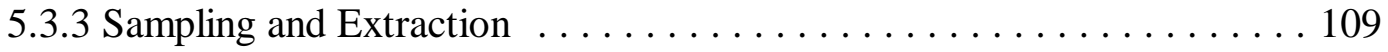

5.3 .4 Bioassay Analysis . . . . . . . . . . . . . . . . . . . . . . . 112

5.3 .5 MOUDI Samples . . . . . . . . . . . . . . . . . . . 116

5.3.6 Determination of the Soluble Mass for Ames Bioassay Dosages Using for Size Segregated (MOUDI) Samples . . . . . . . . . . . . 118

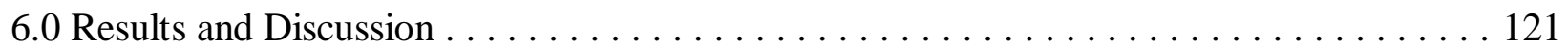

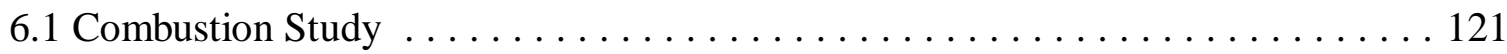




\section{TABLE OF CONTENTS}

(continued)

$\underline{\text { Page }}$

6.2 Particulate Matter Source Analysis . . . . . . . . . . . . . . . . . . . . 134

6.3 Mutagenicity Study . . . . . . . . . . . . . . . . . . . . . . 138

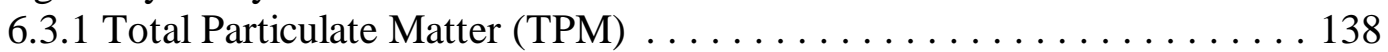

6.3.1.1 Mass Measurements . . . . . . . . . . . . . . . . . 138

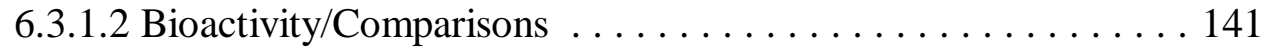

6.3.2 Size Dependent Particulate Matter Analysis . . . . . . . . . . . . . 146

6.3.2.1 Mass Distribution . . . . . . . . . . . . . . . . . 146

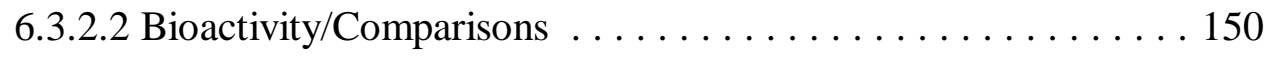

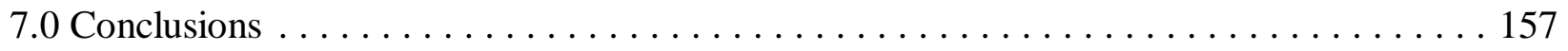

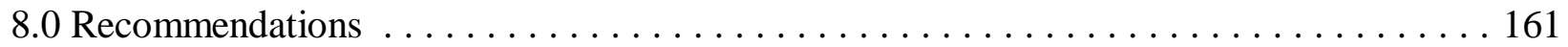

Appendix A. Flow and Mixing Analysis of a Diesel Engine Mini-Dilution Tunnel Using

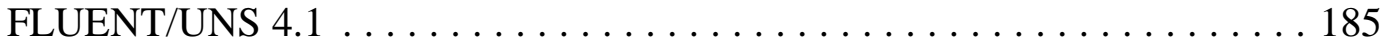

Appendix B: Engine Low-Speed Data Acquisition and Control Procedures . . . . . . . . 200

Appendix C. Uncertainty Analysis Calculations . . . . . . . . . . . . . . . . . . 219

Appendix D: Annotated Example of Ames Test Data Analysis Using MathCAD . . . . . . 238 


\section{LIST OF TABLES}

$\underline{\text { Page }}$

Table 3-1. Typical Approximate Values for Various Fuel Parameters . . . . . . . . . . . 10

Table 4-1. Measurement or Calculation Intervals $\ldots \ldots \ldots \ldots \ldots \ldots \ldots \ldots \ldots$

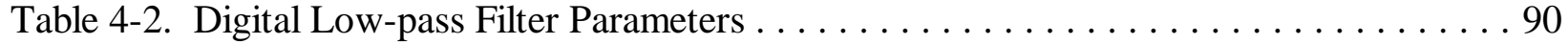

Table 4-3. MOUDI Design and Operation Parameters $\ldots \ldots \ldots \ldots \ldots \ldots \ldots$

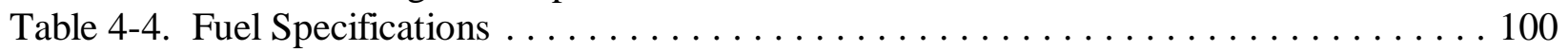

Table 5-1. Key State (KS) Timing Points $\left({ }^{\circ} \mathrm{btdc}\right) \ldots \ldots \ldots \ldots \ldots \ldots \ldots \ldots \ldots$

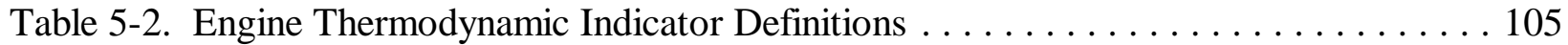

Table 5-3. Steady-State Engine Operating Conditions . . . . . . . . . . . . . . . . . . . . . 109

Table 5-4. Steady-State Operating conditions for MOUDI Sampling . . . . . . . . . . . . 117

Table 6-1. Thermodynamic Indicators . . . . . . . . . . . . . . . . . . . 122

Table 6-2. Mutagenicity (Rev/ug) and averages at each key state, for each fuel type, bacterial strain and activation*. . . . . . . . . . . . . . . . . . . . . . . 143

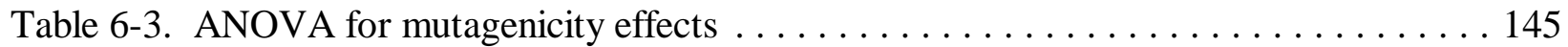

Table 6-4. Mutagenicity (Rev/ug) and averages at each key state, for each fuel type, bacterial strain and activation for the MOUDI size fractions . . . . . . . 151

Table 6-5. ANOVA for mutagenicity effects of MOUDI samples $\ldots \ldots \ldots \ldots \ldots \ldots \ldots$

Table A-1. Velocity Inlet Flow Conditions . . . . . . . . . . . . . . . . . . . . . . 186

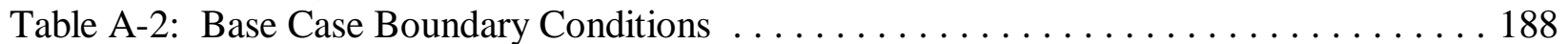

Table A-3: Number of Iterations and CPU Time for Each Case . . . . . . . . . . . . . . . . . . 199

Table C-1. Engine Air and Tunnel Flow Measurement Errors . . . . . . . . . . . . . . 225

Table C-2. Nominal Values, Errors, and Uncertainty Sources for Flow Calibration . . . . . . 228

Table C-3. Spreadsheet Calculation Descriptions $\ldots \ldots \ldots \ldots \ldots \ldots \ldots \ldots \ldots \ldots \ldots$

Table C-4. Nominal Measurement Uncertainties . . . . . . . . . . . . . . . . . . . . . . . . . 237 


\section{LIST OF FIGURES}

$\underline{\text { Page }}$

Figure 3-1. Natural Gas Reforming and Indirect Liquefaction to Produce Fischer-Tropsch

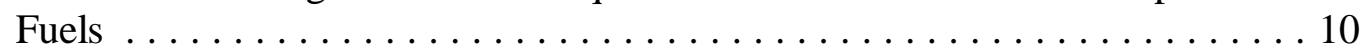

Figure 3-2. Typical DI Engine Heat Release Rate Diagram Identifying Different Diesel

Combustion Phases and Improvement Trends . . . . . . . . . . . . . 24

Figure 3-3. Effect of Pilot Injection on Heat Release Rate . . . . . . . . . . . . . . . . . . . . . . . . . . . . . . . . .

Figure 3-4. Typical Pollutant Response to Injection Timing Retard . . . . . . . . . . . 26

Figure 4-1. Mini-Dilution Tunnel Schematic . . . . . . . . . . . . . . . . . . 72

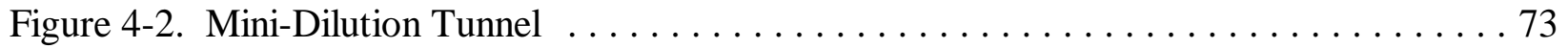

Figure 4-3. Microorifice Uniform Deposition Impactor (MOUDI) $\ldots \ldots \ldots \ldots \ldots \ldots . \ldots 92$

Figure 4-4. Engine Test Bed Schematic . . . . . . . . . . . . . . . . . . . . . 99

Figure 6-1. Percent change of FP emission Relative to Federal No. 2 diesel fuel

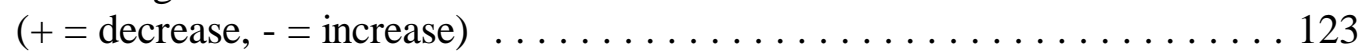

Figure 6-2. Brake specific $\mathrm{NO}_{\mathrm{x}}$ as a function of Maximum heat release rate $\left(\mathrm{J} / \mathrm{m}^{3}-{ }^{\circ} \mathrm{CA}\right)$ during the premixed combustion phase for all key states and fuel types. . . . 123

Figure 6-3. Diffusion vs. Premixed Maximum Heat Release Rate for All Key States . . . . . . 125

Figure 6-4. Maximum Heat Release Rate $\left(\mathrm{J} / \mathrm{m} 3-{ }^{\circ} \mathrm{CA}\right)$ During the Diffusion Combustion Phase for Key State 3 (FT fuel is represented by the top curve) . . . . . . . 125

Figure 6-5. Opacity as a Function of Injection Timing for Key State 3 (The lower curve is

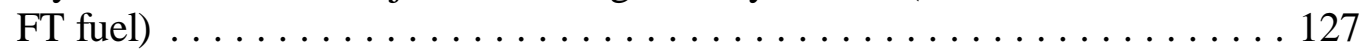

Figure 6-6. Comparison of heat release rate $\left(\mathrm{kJ} / \mathrm{m}^{3}{ }^{\circ} \mathrm{CA}\right)$ at key state 2 for DF and FT fuels at common timing (FT fuel is on the left in each of the two groups of curve

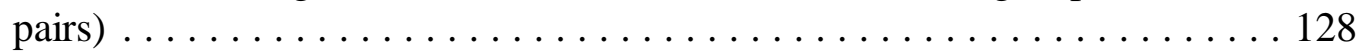

Figure 6-7. Comparison of heat release rate $\left(\mathrm{kJ} / \mathrm{m}^{3}{ }^{\circ} \mathrm{CA}\right)$ at key state 3 for DF and FT fuels at common timing (FT fuel is on the left in each of the two groups of curve

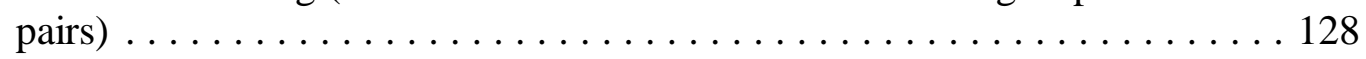

Figure 6-8. Comparison of heat release rate $\left(\mathrm{kJ} / \mathrm{m}^{3}{ }^{\circ} \mathrm{CA}\right)$ at key state 4 for DF and FT fuels at common timing (FT fuel is on the left in each of the two groups of curve pairs $\ldots \ldots \ldots \ldots \ldots \ldots \ldots \ldots \ldots$. . . . . . . . . . . . . . . 129

Figure 6-9. Comparison of heat release rate $\left(\mathrm{kJ} / \mathrm{m}^{3}{ }^{\circ} \mathrm{CA}\right)$ at key state 5 for DF and FT fuels at common timing (FT fuel is on the left in each of the two groups of curve

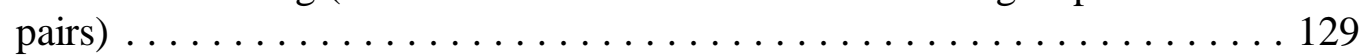

Figure 6-10. Comparison of heat release rate $\left(\mathrm{kJ} / \mathrm{m}^{3}{ }^{\circ} \mathrm{CA}\right)$ at key state 6 for DF and FT fuels at common timing ( FT fuel is on the left in each of the two groups of curve

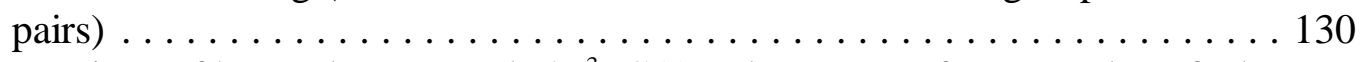

Figure 6-11. Comparison of heat release rate $\left(\mathrm{kJ} / \mathrm{m}^{3}{ }^{\circ} \mathrm{CA}\right)$ at key state 7 for DF and FT fuels at common timing (FT fuel is on the left in each of the two groups of curve

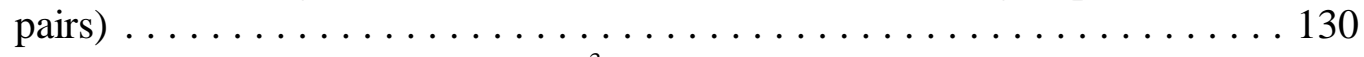

Figure 6-12. Comparison of heat release rate $\left(\mathrm{kJ} / \mathrm{m}^{3}{ }^{\circ} \mathrm{CA}\right)$ at key state 8 for DF and FT fuels at common timing (FT fuel is on the left in each of the two groups of curve

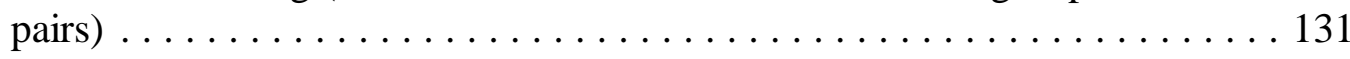




\section{LIST OF FIGURES}

(continued)

$\underline{\text { Page }}$

Figure 6-13. Total Hydrocarbon emissions (g/hp hr) (ungrouped) for all key states as a function of ignition delay. . . . . . . . . . . . . . . . . . . . 132

Figure 6-14. CO emissions ( $\mathrm{g} / \mathrm{hp} \mathrm{hr}$ ) (ungrouped) for all key states as a function of ignition delay. . . . . . . . . . . . . . . . . . . . 132

Figure 6-15. Diesel particulate matter composition by key state and fuel type. . . . . . . 135

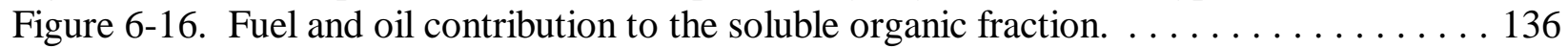

Figure 6-17. Fuel and Oil Contributions to the Soluble Portion vs. Engine Load (the curve visually represents the oil contribution trend). . . . . . . . . . . 137

Figure 6-18. Fuel and Oil Contributions to the Soluble Portion vs. Engine Speed (the curve visually represents the oil contribution trend). . . . . . . . . . . . 137

Figure 6-19. Total particulate matter production at each engine operating condition and fuel type. The error bars represent the $95 \%$ confidence interval. . . . . . . . 140

Figure 6-20. Average total particulate matter production (g/hp-hr) at each engine operating condition. The error bars represent the $95 \%$ confidence interval. . . . . . . . . 140

Figure 6-21. Average total particulate matter production $(\mathrm{g} / \mathrm{hr})$ at each engine operating condition. The error bars represent the $95 \%$ confidence interval. . . . . . . . 141

Figure 6-22. Average total particulate matter (g/hp-hr) for each fuel averaged over key operating states $3,4,7$ and 8 . The error bars represent the $95 \%$ confidence interval. . . . . . . . . . . . . . . . . . . . . . . 142

Figure 6-23. Mutagenicity (Rev/ug) at each operating condition and each fuel type. The error bars represent the $95 \%$ confidence interval for the slope of the dose response. . . . . . . . . . . . . . . . . . . . . . . . . 142

Figure 6-24. Engine revertant production rate (Revertant/hp-hr) for each key operating state and fuel type. The error bars represent the $95 \%$ confidence interval with errors due to dose response and PM measurement propagated using the root-sum-square method . . . . . . . . . . . . . . . . . . . . . . . . 144

Figure 6-25. Engine revertant production rate (Revertant/hr) for each key operating state and fuel type. The error bars represent the $95 \%$ confidence interval with errors due to dose response and PM measurement propagated using the root-sum-square method. . . . . . . . . . . . . . . . . . . . . . . . . . . . 144

Figure 6-26. Quadratic response surface of mutagenicity (slope of revertants/ug does) as a function of engine speed and load. . . . . . . . . . . . . . . . . 147

Figure 6-27. MOUDI size distribution for key state 2 engine conditions (MMAD is the mass median aerodynamic diameter; GSD is the geometric standard deviation and $\mathrm{W}$ is the fraction of the total mass in the upper (1) or lower (2) size fraction). . . . . . . . . . . . . . . . . . . . . . . . . 148

Figure 6-28. MOUDI size distribution for key state 4 engine operating conditions (MMAD is the mass median aerodynamic diameter; GSD is the geometric standard deviation and $\mathrm{W}$ is the fraction of the total mass in the upper (1) or lower (2) size fraction). . . . . . . . . . . . . . . . . . . . . . . . 149 


\section{LIST OF FIGURES}

(continued)

$\underline{\text { Page }}$

Figure 6-29. Mutagenicity at each key state, for each fuel type and DPM size range. The error bars represent the $95 \%$ confidence interval of the dose response slope. . . . . . . . . . . . . . . . . . . 151

Figure 6-30. Average mutagenicity each key state and size fraction. The error bars represent the $95 \%$ confidence interval of the dose response slope . . . . . . . . . 154

Figure 6-31. Scatterplot of mutagenicity (slope of revertants/ug dose) as a function of fuel type and particle size for the MOUDI samples. . . . . . . . . . . . . . 154

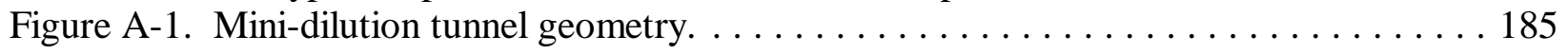

Figure A-2. Variation of function $Y$ with Peclet Number . . . . . . . . . . . . . . . . 193

Figure A-3. Typical $\mathrm{CO}_{2}$ axial concentration along the dilution tunnel centerline. . . . . . . 194

Figure A-4. Temperature contours near the inlet of the dilution tunnel. . . . . . . . . . 195

Figure A-5. Temperature contours over the entire dilution tunnel length. . . . . . . . . 196

Figure A-6. Velocity contours near the outlet of the dilution tunnel. . . . . . . . . . . . 198

Figure A-7. Velocity profile at the outlet of the dilution tunnel. . . . . . . . . . . . . 198 


\section{Nomenclature}

\begin{tabular}{|c|c|}
\hline APmax & -Location of Maximum rate of Pressure Rise $\left({ }^{\circ} \mathrm{CA}\right)$ \\
\hline BMEP & -Brake Mean Effective Pressure (bar) \\
\hline BSFC & -Brake Specific Fuel Consumption \\
\hline BurnDur & -Burn Duration $\left({ }^{\circ} \mathrm{CA}\right)$ \\
\hline BurnMaxLoc & -Location of Maximum Burn Rate $\left({ }^{\circ} \mathrm{CA}\right)$ \\
\hline $\mathrm{C} / \mathrm{H}$ & -Carbon/Hydrogen Weight Ratio \\
\hline CARB & -California Air Resources Board \\
\hline CFD & -Computational Fluid Dynamics \\
\hline $\mathrm{CO}$ & -Carbon Monoxide \\
\hline $\mathrm{CO}_{2}$ & -Carbon Dioxide \\
\hline CombDur & -Combustion duration $\left({ }^{\circ} \mathrm{CA}\right)$ \\
\hline DBE & -Double bond Equivalence \\
\hline $\mathrm{DF} 2$ & -Diesel Fuel Number 2 \\
\hline EOI & -End of Injection \\
\hline FMEP & -Friction Mean Effective Pressure (bar) \\
\hline FT & -Fischer-Tropsch \\
\hline GC & -Gas Chromatography \\
\hline $\mathrm{H}_{2}$ & -Hydrogen \\
\hline $\mathrm{H}_{2} \mathrm{SO}_{4}$ & -Sulfuric Acid \\
\hline $\mathrm{HHC}$ & -Heavy Hydrocarbons \\
\hline HHV & -Higher Heating Value \\
\hline
\end{tabular}




\begin{tabular}{|c|c|}
\hline HPLC & -High Performance Liquid Chromatography \\
\hline IgnDel & -Ignition Delay $(\tau)$ \\
\hline IMEP & -Indicated Mean Effective Pressure \\
\hline $\mathrm{Kn}$ & -Knudsen Number \\
\hline LHV & -Lower Heating Value \\
\hline LPP & -Location of Peak Pressure $\left({ }^{\circ} \mathrm{CA}\right)$ \\
\hline MFB & -Location of Mass Fraction Burned $\left({ }^{\circ} \mathrm{CA}\right)$ \\
\hline $\mathrm{nm}$ & -Nanometer $\left(10^{-9}\right.$ meter $)$ \\
\hline NMHC & -Non-Methane Hydrocarbons \\
\hline $\mathrm{NO}_{\mathrm{x}}$ & -Oxides of Nitrogen \\
\hline NR & -Nitroreductase \\
\hline $\mathrm{O}_{2}$ & -Oxygen \\
\hline${ }^{\circ} \mathrm{CA}$ & -degrees crank angle \\
\hline PAH & -Polynuclear Aromatic Hydrocarbon \\
\hline Peak & -Peak Pressure Value (bar) \\
\hline $\mathrm{PM}$ & -Particulate Matter \\
\hline $\mathrm{QCM}$ & -Quartz Crystal Microbalance \\
\hline Qmax & -Maximum Heat Release $\left(\mathrm{kJ} /{ }^{\circ} \mathrm{CA}\right)$ \\
\hline QmaxLoc & -Maximum Heat Release Location $\left({ }^{\circ} \mathrm{CA}\right)$ \\
\hline $\mathrm{R}^{2}$ & -Coefficient of Determination \\
\hline $\mathrm{SFC}$ & -Supercritical Fluid Chromatography \\
\hline SMPS & -Scanning Mobility Particle Sizer \\
\hline $\mathrm{SO}_{2}$ & -Sulfur Dioxide \\
\hline
\end{tabular}


SOF -Soluble Organic Fraction

St $\quad$-Stokes Number

SUV -Sport Utility Vehicle

$\mathrm{T} \quad$-Engine Torque (newton-meter)

THC -Total Hydrocarbons

TLC -Thin Layer Chromatography

$\mathrm{V}_{\text {disp }} \quad$-Engine Displacement Volume

VOF -Volatile Organic Fraction 


\subsection{Introduction}

Further growth of diesel engines in the light-duty and heavy-duty vehicular market has continued to focus attention on the health risks of diesel exhaust. From a regulatory perspective, particulate matter (PM) in diesel engines is undesirable. The California Air Resources Board and the Office of Environmental Health Hazard Assessment classified Diesel Exhaust as a "Toxic Air contaminant." The International Agency for Research on Cancer concluded in 1989 that diesel particulate is a probable human carcinogen (IARC, 1989) while the National Institute for Occupational Safety and Health (NIOSH) concluded that it is a potential occupational carcinogen (NIOSH, 1988). The soluble organic fraction (SOF) constituents, particularly the polynuclear aromatic hydrocarbons $(\mathrm{PAH})$ and the nitro-PAH are strong contributors to the overall mutagenicity (Johansen et al.; 1997). Even as regulations continue to tighten, the benefits of the diesel engine in transportation applications continues to influence their growth. Efforts aimed at addressing concerns related to diesel exhaust emissions require a wide knowledge about the effect of fuel formulation on particulate matter emissions, their composition and their health effects.

The diesel engine emits extremely low levels of hydrocarbons and carbon monoxide that do not require aftertreatment to comply with currently projected standards (Khair, 1997). Further, diesel engines continue to enjoy $25 \%$ to $40 \%$ higher thermal efficiency over their gasoline fueled counterparts (McMillian and Gautam, 1998). It is however, very difficult for diesel engines to simultaneously meet $\mathrm{NO}_{\mathrm{x}}$ and particulate matter emissions standards. Exhaust aftertreatment technologies for lean burn systems such as diesels in transportation applications are still in the development phases. Development and application of catalytic exhaust aftertreatment technologies are hampered by the inherently high sulfur content in currently 
available diesel fuel. The high aromatic content and sulfur content of currently available diesel fuel also influences both $\mathrm{NO}_{\mathrm{x}}$ and $\mathrm{PM}$ emissions.

Fuel reformulation has been used as a pollution control technique and continues to be considered as one of the more preferred avenues for realigning emissions in future transportation applications. Significant reformulation of diesel fuel ( $<15 \mathrm{ppm}$ sulfur) has been legislated to enable aftertreatment technologies so that heavy-duty engines can meet 2007 and beyond emission regulations (Walsh, 2001). Market penetration of light-duty diesels has the potential for a significant impact on $\mathrm{CO}_{2}$ emissions and a reduction in demand for imported crude oil due to offsets in overall thermal efficiency. In this regard, Fischer-Tropsch (FT) fuel is attractive due to its low sulfur content, low $\mathrm{C} / \mathrm{H}$ ratio and because it may be derived from natural gas or coal thus offering future economic and strategic alternatives to U.S. oil importation.

Fischer-Tropsch (FT) fuels are made by first reforming a hydrocarbon fuel by partial combustion with steam to form a gas rich in hydrogen and carbon monoxide. The gas stream is then introduced to a reactor where catalysts promote reactions to form highly paraffinic $\left(\mathrm{C}_{n} \mathrm{H}_{2 \mathrm{n}+2}\right)$ fuels. FT fuels have high cetane number, low aromatics, low $\mathrm{C} / \mathrm{H}$ ratio and relatively low specific gravity. Their value in reducing regulated emissions in diesel engines has been demonstrated (McMillian and Gautam, 2001, Schaberg et. al; 1997, Schaberg et.al; 2000, Payri et al.; 2000, others).

Fischer-Tropsch fuels are a strong candidate for fuel blending and for use as a "neat fuel" in future transportation markets. Their impact on catalyst development due to their low sulfur content is attractive and their potential to reduce diesel engine particulate emissions is attractive. Further benefits of FT emissions reduction may be realized with both a better understanding of 
the FT engine combustion process and by understanding the differences in health effects between particulate matter derived from FT fuel and that derived from typical diesel fuel.

The present study focuses on two aspects of FT fuel utilization in diesel engines. First, the mutagenicity of particulate matter derived from FT fuel combustion in a diesel engine is investigated. By understanding diesel particulate matter (DPM) mutagenicity effects with respect to engine operating conditions and particle size, engine developers may be able to "tune" engine operation to avoid promoting mutagenic emissions. Secondly, further benefits of FT emissions reduction may be realized with a better understanding of the FT engine combustion process. This study investigates engine emissions as functions of a suite of derived thermodynamic indicators. In order to accomplish these general objectives, engine data acquisition equipment and analysis hardware and software systems had to be designed and built. Emissions monitoring equipment had to be designed, selected and built. Further, a mini-dilution tunnel was designed and built for sampling and quantifying PM emissions. This introduction is followed by a brief review of the published literature, a discussion of the experimental equipment and procedure and finally the results and conclusions of this study. 


\subsection{Objectives}

The global objective of this study was to investigate the mutagenic potential of particulate matter (PM) derived from the combustion of FT fuel and $0.05 \%$ S Federal Diesel No. 2 fuel in a diesel engine and to express the in-vitro mutagenic activity as a function of engine operating conditions and particle size. In concert with this objective, engine emissions and performance are investigated using a suite of thermodynamic indicators derived from dynamic cylinder pressure measurement. Specific objectives are given below with a brief discussion relating each to the study objective.

Objective 1: Conduct Ames bioassay testing, on exhaust particulate extract from engine operating with Federal diesel No. 2 and FT fuel at seven steady-state engine operating conditions (key states) at injection timings corresponding to optimum BSFC and on two PM size fractions at two engine operating conditions.

Discussion: Particulate matter from each key state operation for the test fuels were sampled and solvent-extracted for bioassay analysis. Further, two key states that offer high and low bio-active potential were identified. These two key states are repeated for each fuel. Fractionated PM samples are collected using a Micro-orifice Uniform Deposition Impactor (MOUDI). Size fractionated PM samples were then separated into two size groups of less than $100 \mathrm{~nm}$ and greater than $100 \mathrm{~nm}$ aerodynamic diameter for bioassay analysis. Understanding the relationship between bio-potential and particle size will not only provide new information on "face value" but may also help to deconvolute engine combustion effects on bio-activity.

Objective 2: Compare exhaust particulate matter (PM) concentration and size distributions for diesel No. 2 and F-T fuel and determine the origin of PM emissions. 
Discussion: To fully understand the bio-activity of the emitted particulates, their source should be identified. By identifying the fraction of particulate derived from lube oil or the fuel, their relative contributions to bio-activity may be better understood.

Objective 3: Determine engine output, emissions and combustion performance on a Federal diesel No. 2 and F-T fuel.

Discussion: Exhaust emissions and combustion data were acquired during engine testing to determine optimum timing for best thermal efficiency. The purpose was to establish a comparison between the engine combustion and emissions characteristics operating on both Federal diesel No. 2 and FT fuel. This provided an insight into the FT combustion process and provided some baseline information regarding engine operation and exhaust PM bio-potential activity. 


\subsection{Literature Review}

\subsection{Fischer-Tropsch Fuels}

\subsubsection{Introduction: The Fischer-Tropsch Processes}

The best-known technology for producing hydrocarbons from synthesis gas is the Fischer-Tropsch process. This technology was first demonstrated in Germany in 1902 by Sabatier and Senderens when they hydrogenated carbon monoxide (CO) to methane, using a nickel catalyst. In 1926 Fischer and Tropsch were awarded a patent for the discovery of a catalytic technique to convert synthesis gas to liquid hydrocarbons similar to petroleum (Perry et al., 1997). The basic reactions in the Fischer-Tropsch synthesis are:

$$
\text { Paraffins: } \quad(2 \mathrm{n}+1) \mathrm{H}_{2}+\mathrm{nCO} \rightarrow \mathrm{C}_{\mathrm{n}} \mathrm{H}_{2 \mathrm{n}+2}+\mathrm{nH}_{2} \mathrm{O}
$$

$$
\text { Olefins: } \quad 2 \mathrm{nH}_{2}+\mathrm{nCO} \rightarrow \mathrm{C}_{\mathrm{n}} \mathrm{H}_{2 \mathrm{n}}+\mathrm{nH}_{2} \mathrm{O}
$$

$$
\text { Alchohols: } \quad(2 \mathrm{n}) \mathrm{H}_{2}+\mathrm{nCO} \rightarrow \mathrm{C}_{\mathrm{n}} \mathrm{H}_{2 \mathrm{n}+1} \mathrm{OH}+(\mathrm{n}-1) \mathrm{H}_{2} \mathrm{O}
$$

Fuels very similar to petroleum based gasoline and diesel fuel can be produced through hydrocracking or catalytic cracking of the FT wax product. Due to the exothermic nature of the FT process, temperature control of the synthesis gas production step is critical to end product chemistry and yield. High temperatures provide high yields of methane, but adversely high temperatures promote coking and sintered catalysts. Three types of reactors (tubular fixed bed, fluidized bed, and slurry) provide good temperature control, and all three types are being used for synthesis gas conversion. The first plants used tubular or plate-type fixed-bed reactors. Later, Sasol, in South Africa, used fluidized-bed reactors, and most recently, slurry reactors have 
come into use. The Synthol reactor developed by Sasol is typical of high-temperature operation. Using an iron-based catalyst, this process produces a very good automotive gasoline product with high olefin content and a low boiling range. Low-temperature operation, typically in fixedbed reactors, produces a much more paraffinic and straight-chain product. The primary diesel fraction, as well as the diesel-range product from hydrocracking of the wax, is an excellent diesel fuel (Perry et al., 1997).

Shell Oil operates a gas-based middle distillate synthesis plant at Bintulu in Malaysia. This plant, commissioned in 1993, has the capacity to produce 11,000 barrels a day of jet fuel cut, diesel fuel, specialty waxes, and other products (Stiegel and Srivastava, 1994). Diesel fuel produced in this manner is currently sold as a blending stock in California. The California Air Resources board (CARB) has mandated a maximum fuel aromatics content of 10\% (polyaromatics $<1.4 \%)$. Fuel producers are given the option of either marketing the fuel which meets the CARB specifications or marketing fuel with a higher aromatics content, provided that equivalent emissions can be demonstrated. Blends of ordinary diesel fuel and diesel synthesized from natural gas meet the toughest emissions standards imposed by the California Air Resources Board (CARB).

Beginning in October 1993, a low-sulfur reformulated diesel fuel was required for all on-highway use in the 49 states excluding California. Specifically, this fuel allows for a maximum of 0.05 weight percent sulfur, a minimum of 40 cetane number, and a maximum of 35 volume percent aromatics. The effect on $\mathrm{NO}_{\mathrm{x}}$ is minimal with these reformulated fuels. $\mathrm{NO}_{\mathrm{x}}$ remains the hardest of all regulated emissions to alter by fuel reformulation. Studies are currently under way to determine the emissions effects with more aggressively reformulated diesel fuels. Perhaps, the best reformulated hydrocarbon-based diesel fuel is represented, not by 
a petroleum derived fuel, but, rather, by fuels now being produced in pilot plant operations using the Fischer-Tropsch (FT) process with natural gas feed stock. For example, Sasol has reported that diesel fuels with over 70 cetane number, less than $0.1 \%$ aromatics, and less than $10 \mathrm{ppm}$ sulfur can be produced using their "Slurry Phase Distillate" version of the FT process (PETC Report, 1991; Gray and Tomlinson, 1997).

The global potential for making synthetic fuels from natural gas is significant. Proven natural gas reserves are currently estimated at $140 \times 10^{12} \mathrm{~m}^{3}$. However, there are no known dependable estimates for worldwide reserves of discovered, undeveloped, un-marketable gas, although the number is believed to be large. One recent study suggests that as much as $400 \mathrm{x}$ $10^{12} \mathrm{~m}^{3}$ of conventional natural gas may be available worldwide (Choi et al., 1996, Carson and Roberts, 1995). If this estimate is accurate, it means that the world's natural gas reserves could potentially be converted into 1.4 trillion bbl of syncrude, more than doubling the world's current oil reserves (Perry et al., 1997).

The term "proven" when referring to gas reserves is usually defined as economically recoverable with present technology and prices. Natural gas discoveries are generally not considered proven when they are too remote for economic transportation, too small to justify development or when their quality is sub-par (contaminated with nitrogen, carbon dioxide, or hydrogen sulfide in excess of pipeline specifications). The transportation barrier can, in many cases, be eliminated by converting the gas into syncrude liquids which can then be moved economically through existing liquid pipelines or in conventional crude oil tankers. Sub-quality gas, particularly gas with high levels of nitrogen or carbon dioxide, benefits from the unique ability of the process to convert it, without removing the contaminants, to a marketable and cost competitive liquid fuel via the FT process. Today, at plants such as Shell's, natural gas can be 
converted to liquid fuels at prices that are only about 10 percent higher per barrel than crude oil. Their low aromatic content, high cetane number, and low sulfur content make them desirable even in today's market (Stiegel and Srivastava, 1994; Agee, 1997).

Another technology that produces a synthetic FT liquid fuel is indirect liquefaction of coal. In indirect coal liquefaction, coal is fed to a gasifier, where it is reacted at high temperatures under moderate pressures in the presence of oxygen and steam. This partial combustion of the coal generates a gas consisting mainly of carbon monoxide $(\mathrm{CO})$ and hydrogen $\left(\mathrm{H}_{2}\right)$. Particulates are removed prior to entering a shift reactor where steam is added to increase the hydrogen yield, then sulfur is removed prior to entering the FT synthesis reactor. Further processing produces mixes of high end fuels including diesel fuel. A synthetic liquid similar to crude oil can be made using a process called direct liquefaction. As the name implies, coal is converted directly into a liquid product. Using today's best available direct liquefaction technology, a high-quality synthetic crude oil can be produced from coal. This product would be competitive with crude oil (West Texas Intermediate) priced at between $\$ 35$ and $\$ 40$ per barrel. However, in indirect liquefaction, the end products are liquids that are ready for use. Consequently, indirect liquefaction products carry a higher value, which is not easily measured in terms of crude oil equivalent prices (Agee, 1997). A schematic depicting NG reforming and indirect coal liquefaction to FT fuels is given below in Figure 3-1.

In general, FT derived fuels are characterized by their low aromatic content, low sulfur and high cetane number. Typical values for these properties are provided in Table 3-1 for a typical No. 2 diesel fuel (DF2), a "CARB" fuel which conforms to California fuel specifications and a hypothetical FT fuel. The effects of these and other fuel properties are discussed in the 


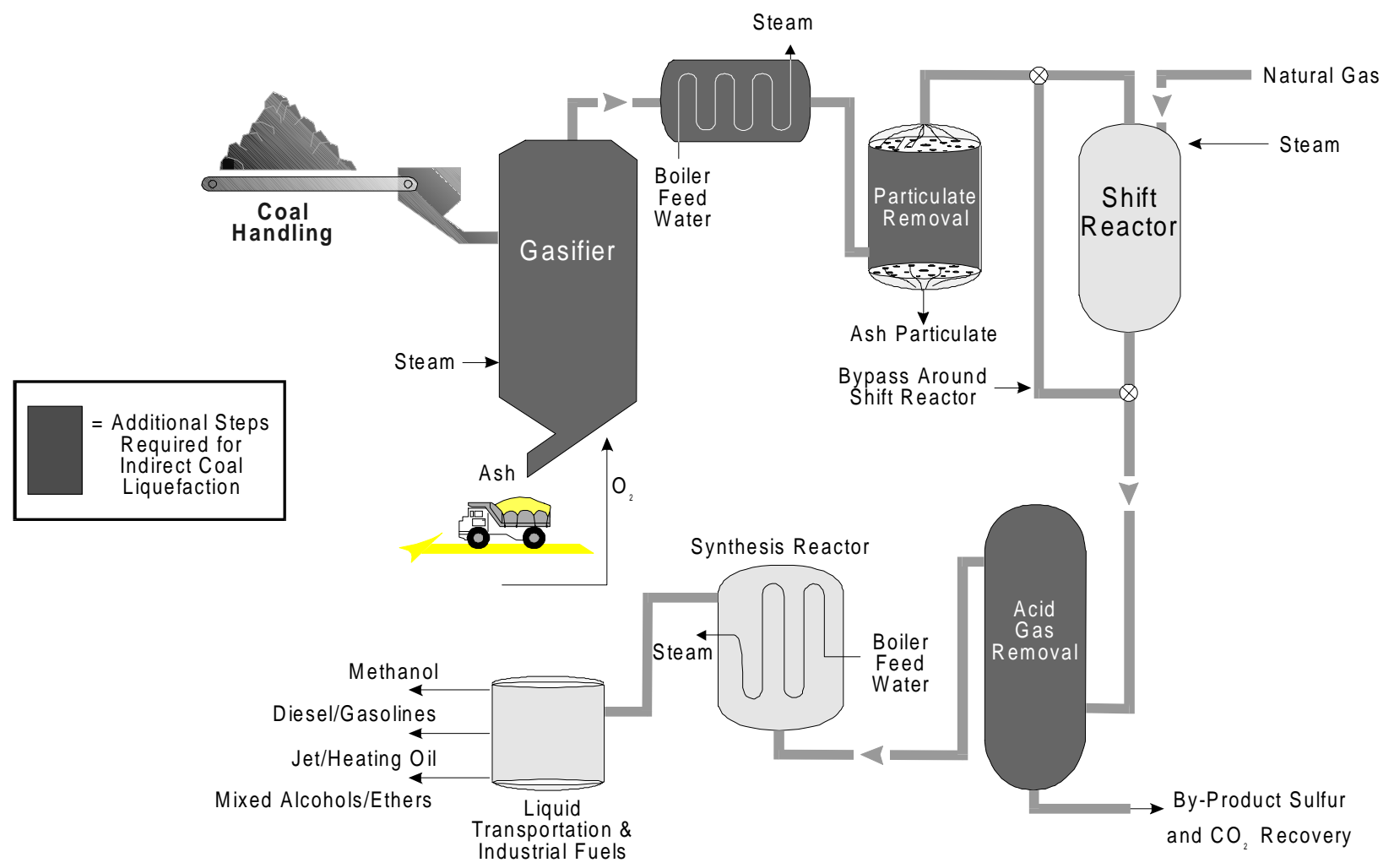

Figure 3-1. Natural Gas Reforming and Indirect Liquefaction to Produce Fischer-Tropsch Fuels

Table 3-1. Typical Approximate Values for Various Fuel Parameters

\begin{tabular}{|r|c|c|c||}
\hline & DF2 & $\begin{array}{c}\text { CARB } \\
\text { Diesel }\end{array}$ & $\begin{array}{c}\text { Typical } \\
\text { Straight } \\
\text { Run FT }\end{array}$ \\
\hline Cetane No. & 46 & 49 & $60-80$ \\
\hline Specific Gravity & 0.85 & 0.83 & 0.78 \\
\hline C/H wt Ratio & 6.5 & 5.95 & 5.8 \\
\hline Aromatics wt\% & $28-32$ & $<10$ & 1 \\
\hline Saturates wt\% & 65 & 88 & 98 \\
\hline Sulfur wt\% & $<0.05$ & $<0.05$ & 0 \\
\hline
\end{tabular}


following sections. Further, an excellent summary of the physical and chemical properties, formulations and chemical compatibility of FT fuels is provided by Stavinoha et al., (2000).

\subsubsection{Fuel Properties and Fuel Effects on Exhaust Emissions}

Concerning the fuel properties given in Table 3-1 above, higher values of cetane number and lower values of the other parameters are desirable from an emissions perspective. Various performance aspects of these fuel parameters are discussed below.

\subsubsection{Carbon/Hydrogen (C/H) Ratio}

The carbon to hydrogen ratio $(\mathrm{C} / \mathrm{H})$ ratio as well as aromatic content has been shown to correlate with particulate emissions. The $\mathrm{C} / \mathrm{H}$ ratio is typically lower in FT fuels due to their high paraffinic content. The range of carbon numbers observed for diesel fuel is typically C9 to approximately C26, with most of the mass lying between $\mathrm{C} 12$ and C18. Overall, more than 178 species have been identified as typical diesel fuel species (Gulder et al., 1985).

Glavincevski et al., (1984), showed that Proton NMR (Nuclear Magnetic Resonance) spectroscopy is well suited to obtain the average carbon type structural composition of the diesel engine fuels. Their correlations were valid under the following conditions: (a) fuels are nonolefinic (less than one percent) and the hetero-atom $(\mathrm{O}, \mathrm{S}, \mathrm{N})$ content is less than three percent, (b) the fraction of cyclo-alkanes is small as compared to other paraffins and fuels do not contain ignition improvers. The relationship between ignition quality and fuel composition was reviewed by Glavincevski et al., (1984) and showed that each member of an homologous series of hydrocarbons does not have the same ignition characteristics as the other members of the series. They emphasized that the belief that the paraffins have relatively high cetane ratings compared to aromatics and cyclo-paraffins is not always correct. A basic flaw in the "cetane 
index" equations, which use the easily measurable physical properties of the fuels as independent parameters, was explained by Guilder et al., (1985), in this manner.

Ogawa et al., (1995), performed emission studies and detailed fuel chemistry analysis of nine types of diesel fuels using thin layer chromatography (TLC), and gas chromatography/mass spectrometry (GC/MS). The complete spectrum of hydrocarbons in diesel fuels was expressed on a three-dimensional graph: the $\mathrm{X}$-axis as the carbon number, the $\mathrm{Y}$-axis as the $\mathrm{H} / \mathrm{C}$ ratio and the Z-axis as the amount of hydrocarbons of identical molecular formula. Traditional methods were utilized to separate diesel fuel hydrocarbons according to polarity (that is, high performance liquid chromatography (HPLC), supercritical fluid chromatography (SFC) and thin layer chromatography (TLC)). Likewise, gas chromatography (GC) using a non-polar capillary column was used for hydrocarbon separation. The results showed that diesel fuel consists of hydrocarbons whose double bond equivalence value (DBE) ranges from 0 to 13 where:

$$
\mathrm{DBE}=\text { Double Bond Equivalence }=(n+1)-\mathrm{m} / 2
$$

and $\mathrm{n}$ is the number of carbons and $\mathrm{m}$ the number of hydrogens in a hydrocarbon $\left(\mathrm{C}_{\mathrm{n}} \mathrm{H}_{\mathrm{m}}\right)$. Hydrocarbons in a given boiling point window are dealt with as if they were a single component in gas chromatography when using a non-polar capillary column.

Since it requires n-times dehydrogenations to produce hydrocarbons of DBE $=\mathrm{n}$ than $\mathrm{DBE}=0$, Ogawa et al., (1995), hypothesized that the back end fraction that consists of mainly higher DBE PAH compounds, is more apt to yield soot than the fractions consisting mainly of paraffins $(\mathrm{DBE}=0)$. Also, since hydrocarbons tend to cyclize and be stable as they undergo dehydrogenation, the hydrocarbon compound that has a higher DBE is thermally more stable. Therefore, the backend fraction which has a higher $\mathrm{C} / \mathrm{H}$ ratio tends to yield more $\mathrm{SOF}$ derived 
from unburned or partially burned fuel. From this viewpoint, the product of the volumetric quantity of the backend fraction at a given temperature and $\mathrm{C} / \mathrm{H}$ ratio was used as a new indicator for estimating particulate emission.

Shibuya et al., (1993), investigated the effects of aromatic ring number by blending normal paraffin, isoparrafin, alkyl benzene and 1-methylnaphthalene as test fuels. Their results showed that at the same equivalence ratio and regardless of the aromatic ring number of the fuel, particulate emission increased linearly with the $\mathrm{C} / \mathrm{H}$ ratio. The degree of increase in particulate emission with increasing $\mathrm{C} / \mathrm{H}$ ratio decreased with lower equivalence ratios. The aromatic content, aromatic type, and equivalence ratio seemed to have a smaller effect on the SOF emission level. At the same equivalence ratio, the particulate matter tended to increase linearly with the $\mathrm{C} / \mathrm{H}$ ratio of the fuel. The authors suggest a strong correlation between particulate emission level and the $\mathrm{C} / \mathrm{H}$ ratio regardless of the number of aromatic rings. Hence, the increase in particulate matter with aromatic content for di-aromatics compared to mono-aromatic fuels may be explained simply by the difference in the $\mathrm{C} / \mathrm{H}$ atomic ratio.

\subsubsection{Cetane Number}

Fuel cetane number influences combustion quality which is also strongly influenced by engine design. Therefore, it can be expected that hardware design, particularly of the fuel injection and combustion systems, will largely determine the sensitivity that the emissions of a particular engine will display relative to fuel cetane number. An increase in cetane number results in a reduction in the ignition delay period. This results in a smaller volume of fuel being injected during the ignition delay period thus resulting in less premixed combustion, forcing a larger portion of the injected fuel undergoing mixing-controlled combustion. The combustion pressure rises at a lower rate, allowing more time for cooling by means of heat transfer and 
dilution. Localized gas temperatures may be lower, resulting in lower $\mathrm{NO}_{\mathrm{x}}$ formation rates. This result is countered somewhat by the reduction in ignition delay period and its effect of advancing the start of combustion. Advancing the start of combustion essentially has the same effect as advancing the start of injection timing, which results in higher peak combustion pressures and temperatures, thereby increasing $\mathrm{NO}_{\mathrm{x}}$ formation rates. The amount of fuel subjected to this effect is dependent on the amount of fuel injected during the ignition delay period, and is therefore also affected by the cetane number of the fuel.

The effect of cetane number on $\mathrm{HC}$ and $\mathrm{CO}$ emissions has been confirmed in a number of studies using 1991 and older engine technologies, while studies involving more recent (1994 and later) engine technology have found cetane number to have a reduced effect, or no effect, thereby highlighting the advances made in engine design in order to meet ever stricter emissions legislation (Schaberg et al., 1997). The $\mathrm{NO}_{\mathrm{x}}$ response has been found to be non-linear with diminishing returns as cetane number reaches 60 and higher. The effect of increasing cetane number on particulate emissions is less clear, with most studies indicating decreasing PM and some exhibiting the opposite trend (Li et al., 1996), and some showing no effect (Lange, 1991). Much of this is certainly due to the fuel injection equipment and fuel scheduling used in a particular engine. As reported by Schaberg et al., (1997), a number of studies have found that the soluble organic fraction of the PM was reduced when cetane number was increased, but the benefit was offset by an increase in the insoluble portion of the PM, with the net result that total PM was either unaffected or increased.

\subsubsection{Aromatic Content}

Fuel aromatic content has also been found to reduce each of the regulated emissions (Erwin et al., 1994; Schaberg et al., 1997; Cowley et al., 1993). In the case of PM, it has been 
shown that at low engine speeds and loads particulate PAH emissions can be accounted for by unburned fuel PAH, although at high speeds and loads, there is evidence of additional sources of PAH. The effect of reducing total aromatic content will be to slightly reduce emissions. While removing poly-aromatics is more effective, there is also likely to be a beneficial effect on BSFC. Combustion efficiency is affected by changes in the rate and timing of heat release, as well as heat transfer. The LHV of aromatic hydrocarbons is lower than the equivalent carbon number paraffin. Paraffinic content therefore increases the lower heating value (LHV) of the fuel, having a beneficial effect on BSFC (Ryan and Montalvo, 1997).

\subsubsection{Density}

Fuel density is dependent on chemical make up. Separating physical effects of density from chemical effects on combustion and emissions is difficult. Theoretically, with a lower density fuel, the instantaneous fuel mass flowrate into the combustion chamber is lower, and a longer injection period is required to meet the fuel energy demand of the engine. This results in lower heat release rates, with an associated reduction in $\mathrm{NO}_{\mathrm{x}}$ formation rates. At high speeds and loads, the longer injection time may result in a degree of incomplete combustion resulting in increased $\mathrm{HC}$ and $\mathrm{CO}$ emissions. During transient engine operation, over fueling accentuated by turbocharger lag, is reduced with lower density fuels resulting in lower PM, HC, and CO emissions (Cowley et al., 1993).

\subsubsection{Sulfur}

Fuel sulfur is converted to $\mathrm{SO}_{2}$, and further oxidized to form sulfates which, along with bound water manifest themselves as PM emissions. Generally, there is a linear relationship between fuel sulfur consumption and the sulphate portion of particulate mass emissions, with a fuel sulfur to particulate mass conversion rate of between 1 and $2 \%$. Fuel sulfur content is also 
an important parameter where exhaust oxidation catalysts are employed for the reduction of HC, $\mathrm{CO}$, and $\mathrm{PM}$ emissions, as oxidation of $\mathrm{SO}_{2}$ in the exhaust gas over the catalyst may lead to a dramatic increase in PM in the form of sulfates and will "blind" the catalyst (Mori, 1997). EPA regulations are now in place that mandate reduced sulfur levels in diesel fuel $(<15 \mathrm{ppm})$ by 2007.

\subsubsection{Fischer Tropsch Fuels and Their Emission Effects}

FT fuels benefit in all of the fuel properties given in Table 1 above. Some recent work with FT fuels in diesel engines is briefly highlight below. These highlighted results are general in nature but serve to illustrate the "cleaner burning" aspect of FT fuels.

Erwin and Ryan (1993), reported on fuel assay work which included two FischerTropsch feedstocks, one from hydrocracking of wax, the other a straight-run product from modern slurry reactor technology. They were distilled into a diesel range cut $\left(350^{\circ}-650^{\circ} \mathrm{F}\right)$ $\left(177^{\circ} \mathrm{C}-343^{\circ} \mathrm{C}\right)$ for comparison with other diesel stocks. The second FT sample was made by Air Products under a U.S. Department of Energy (DOE) contract. The materials were supplied as hydrocarbon liquid and light wax. These samples were combined in a ratio of 1.6:1 according to the proportion in production. The hydrocarbon liquid, being lower in boiling range than the Arge wax, contained light process oils and oxygenates. They derived a $350^{\circ} \mathrm{F}-650^{\circ} \mathrm{F}\left(177^{\circ} \mathrm{C}-\right.$ $343^{\circ} \mathrm{C}$ ) straight run diesel sample from this mixture. The boiling point distribution and viscosity become more important at the lighter loads, where the injection process might be more affected by the physical properties than at the higher load conditions (Erwin and Ryan, 1993). In total, their efforts produced a set of 80 test fuel blend samples for the program. The FT materials were almost all paraffins and represent a high cetane-number candidate blend that requires no processing. The fuels were tested at six different speed-load conditions in a direct-injected, variable compression ratio (VCR) test engine. The FT samples made by Air Products were made 
from coal by gasification and followed by reaction over a polymerization catalyst bed which produces almost entirely normal paraffins. The ignition quality and emissions characteristics were found to be related to boiling point as indicated by the strong functional relationships between these parameters and the average boiling point of each fraction and were directly related to aromatic content and type of fuel. A linear regression of the cetane number was dependent on the alkylbenzenes, T50\%, indenes, paraffins, specific gravity, and viscosity. Within their range of variation, the relationships between emissions and fuel composition were linear thus allowing linear programming techniques to be used to design low-emission blends. They concluded that the then newly proposed specifications for reformulated diesel fuel, which limit both the end point and aromatics content, may not be compatible with each other and may lead to increased particulate emissions. Reducing the end point will reduce the cetane number in some feedstocks and can also reduce the effectiveness of hydrogenation in reducing the aromatics content. This overall cetane number reduction could have an adverse effect on $\mathrm{NO}_{\mathrm{x}}$.

Ryan and Montalvo (1997), in later work, reported that FT fuels produced 38\% less HC, 46 percent less $\mathrm{CO}, 8$ percent less $\mathrm{NO}_{\mathrm{x}}$ and 30 percent less particulate than the national average diesel fuel (Federal No. 2 diesel fuel) when tested in a Detroit Diesel Series 60 engine, when following a protocol similar to the CARB procedure for evaluation of reformulated diesel fuels. They tested three FT fuels, one "national average diesel fuel" with a cetane number of 45.5 and total aromatic content of 32 percent and a "California reference fuel" with a cetane number of 50.2 and total aromatic content of 8.7 percent. In these tests, the types of aromatics were found to be more important than simply the total mass of aromatic material. Because an engine's full load performance is proportionally dependent on the mass of fuel injected into the engine (assuming similar heating values in energy per unit mass), engine performance levels on any fuel 
can be expected to vary in direct proportion to the fuel's density, relative to the density of the reference fuel. Average torque readings with the FT fuels were correspondingly from 5 - 9 percent lower than DF2, apparently because these fuels were less dense than DF2 although max. torque timing was not optimized for FT fuel. Emissions of volatile organic fraction (VOF) and unburned oil using FT fuels were generally lower than those associated with the diesel fuels. The best FT fuel produced $0.018 \mathrm{~g} / \mathrm{hp}-\mathrm{hr}$ of VOF and $0.007 \mathrm{~g} / \mathrm{hp}-\mathrm{hr}$ of unburned oil.

Schaberg et al., (1997), compared emissions of FT fuels from natural gas reforming with standard diesel fuel and other blends. Transient emissions tests were performed to compare emissions using fuels produced by the Sasol Slurry Phase Distillate Process (SSPD), to those with US diesel fuels. A heavy 4-stroke, 1991 technology diesel engine was used. It was found that the SSPD fuels produced significantly lower emissions than the standard and CARB fuels in all four regulated emission categories $\left(\mathrm{NO}_{x}, \mathrm{HC}, \mathrm{CO}, \mathrm{PM}\right)$. The blended fuels generally reduced emissions in proportion to the amount of SSPD fuel in the blend. The Sasol Slurry Phase Distillate fuel has a very high cetane number, very low aromatics and sulphur content, and lower density than the standard fuel. $\mathrm{HC}, \mathrm{CO}, \mathrm{NO}_{\mathrm{x}}$, and PM emissions were lower by 49\%, 33\%, 27\%, and $21 \%$ respectively, when compared to the DF2 fuel. The VOF of PM was reduced by $34 \%$, relative to the standard fuel. Tests were also performed at retarded injection timing settings with the SSPD fuel, which had a cetane number in excess of 70. It was found that a further reduction in $\mathrm{NO}_{\mathrm{x}}$ emissions could be obtained, without significantly compromising particulate emissions or specific fuel consumption. These results are important when considering fuel injection variables and FT fuels.

Schaberg et al., (1997), again compared emissions of FT fuels from natural gas reforming with standard diesel fuel and other blends. This time they used a 1999 model year Detroit Diesel 
Series 60 engine with hot-start and cold-start transient test cycles. Engine emissions were commensurately lower with FT fuel in both cold and hot-start emissions. The reduction in $\mathrm{NO}_{\mathrm{x}}$ with FT fuel was smaller in the 1999 engine than noted from their previous work in a 1991 engine. In the previous work the FT fuel reduced PM emissions primarily via equal reductions in both VOF and carbon, while in the 1999 engine the reduction in PM was primarily a result of reduction of the carbon portion of the PM.

\subsubsection{Particulate Matter (PM)}

Recently, more than ever, particulate matter in diesel engines is becoming more undesirable. Due to the recent attention to PM and the fact that FT fuels have the potential to reduce PM, this section discussing PM is included to provide background information to the reader.

Typical particle size distributions in diesel engines are bi-modal with a nuclei mode (0.0075 to 0.042 microns in diameter) and an accumulation mode ( 0.041 to 1.0 microns in diameter). Primary carbon spherules are formed in the combustion chamber by nucleation and a large percentage of these carbonaceous cores (soot) are oxidized during the expansion stroke. The particles that survive oxidation typically agglomerate together to form the long chain aggregates or clusters associated with diesel particulate matter emission. Once the exhaust enters the atmosphere or a dilution tunnel, organic compounds adsorb or condense onto the surface of the carbon particles to form the soluble organic fraction (SOF) (Kittleson, 1998).

Baumgard and Johnson (1996), investigated diesel particle size distributions from a 1988 and a 1991 Cummins 10 liter engine using three different fuels and two exhaust control technologies (a ceramic trap and an oxidation catalytic converter). Their results indicate a clear shift towards more nuclei mode particles and less accumulation mode particles using the 1991 engine 
as compared to the same fuel on the 1988 engine. These results suggest that as higher injection pressures are used, in this case $154 \mathrm{MPa}$ in the 1991 engine versus $124 \mathrm{Mpa}$ in the 1988 engine, smaller nuclei mode particles begin to dominate.

Recent flame investigations have shown that soot is primarily formed at temperatures exceeding $1500 \mathrm{~K}$ and equivalence ratios above $(\phi \approx 1.6)$ (Arcoumanis and Schindler, 1997). Initial soot formation is rapid and is completed in a few milliseconds in both premixed and in diffusion flames. The particles first appear in a fuel rich area where the soot formation rate and the soot volume fraction increases. As more combustion air is entrained into the flame a decrease in the mixture fraction and a slowing down of the soot formation rate occurs. Finally, the particles reach fuel lean areas where soot oxidation and negative formation rates dominate.

A simple mechanistic scheme for the soot formation in molecular terms using extensive reduces global mechanisms was first presented by (Frenklach and Wang, 1990). The theoretical description of the auto-ignition process for non-premixed fuels under diesel conditions includes and extensive list of elementary reactions (1011 reactions with 171 species for the component nheptane). The mechanism may be described by first oxidizing the fuel molecules in the premixed gas phase This results in the formation of smaller molecules including acetylene which is the basis for the formation of higher hydrocarbons and aromatics. These form in a planar structure by an H-abstraction-acetylene-addition mechanism. In diffusion flames, the reaction of the fuel takes place in very fuel rich areas under pyrolysis conditions. In this case the chemical portion of the model has to be extended by including pyrolysis. Because of the low volume which results from the formation of new soot particles, the soot formation rate can be considered to be equal to the surface growth rate. Surface growth is the most important 
mechanism for most of the soot mass formed during combustion (Arcoumanis and Schindler, 1997).

Soot formation correlates with percent fuel injected after 8 degrees ATDC (Chen et al., 1997). When soot is formed during the later part of the expansion stroke, insufficient time is available for the oxidation of soot by the available oxygen radicals. A falling injection pressure profile is recommended to produce the least soot emissions. The falling injection profile can be produced by a medium pressure common rail system with an intensifier accumulator injector or a front loaded split injection of a high pressure common rail system. Based on KIVA projections, a falling injection profile plus pre or pilot injection has the potential to provide the optimal tradeoff (Chen et al., 1997).

Past and, to a lesser extent present, practice is to raise injection pressure in order to further reduce PM. Injection rate control is also essential to controlling PM with instantaneous fuel cut-off at the end of injection. $\mathrm{NO}_{\mathrm{x}}$ formation can be correlated with the percent of fuel injected before 5 degrees ATDC (Han et al., 1996). This is due to the fact that $\mathrm{NO}_{\mathrm{x}}$ reaction is most sensitive to the early part of the combustion because the combustion reactants $(\mathrm{N}, \mathrm{O}, \mathrm{OH})$ stay at a high gas temperature longer with amount injected (over 2400-2800K). Some technologies have been adopted for their impact on $\mathrm{PM}$ reduction rather than $\mathrm{NO}_{\mathrm{x}}$ reduction. However, it should be noted that reducing PM provided engineers more freedom in controlling $\mathrm{NO}_{\mathrm{x}}$ than would otherwise have been possible. For instance, increasing injection pressure led to reductions in PM through better mixing and higher air utilization. Also, higher injection pressure reduced ignition delay and allowed engineers additional injection timing retard, leading to lower $\mathrm{NO}_{\mathrm{x}}$ emissions as well. Pilot or staged injection $\mathrm{R} \& \mathrm{D}$ results indicated that an optimum injection strategy would be to slow down the injection rate (small pilot) for $\mathrm{NO}_{\mathrm{x}}$ control with the 
latter portion of the injection characterized by a fast injection rate with falling injection profile for particulate control.

Particulate traps showed some promise in 1991 as a method for engine manufacturers to meet the reduced particulate standard of $0.134 \mathrm{~g} / \mathrm{kWh}$ for urban buses. However, due to the complexity of regeneration and the development of engines that could meet the $0.134 \mathrm{~g} / \mathrm{kWh} \mathrm{PM}$ standards without a trap, the use of traps on buses was discontinued. However, there has been a resurgence of passive particulate traps as a result of the EPA urban bus retrofit rule. While some manufacturers will probably opt to meet the 2004 standards without a trap of any kind, the significantly lower particulate standard applicable to urban buses together with the proposed 2004 standard of $3.2 \mathrm{~g} / \mathrm{kWh}\left(\mathrm{NO}_{\mathrm{x}}\right.$ combined with non-methane hydrocarbons (NMHC)) will force most manufacturers to use traps for meeting the 2004 urban bus standards (Browning, 1997). Traps will certainly be required to meet 2007 EPA heavy-duty highway standards.

One promising approach to diesel particulate filter regeneration is the utilization of the capability of nitrogen dioxide $\left(\mathrm{NO}_{2}\right)$ to oxidize carbon. By using available $\mathrm{NO}_{2}$ and by using a catalyst to oxidize $\mathrm{NO}$ to $\mathrm{NO}_{2}$ upstream of the particulate filter, significant levels of $\mathrm{NO}_{2}$ may be available for oxidation of particulate matter and hence regeneration of diesel particulate filters (Hawker et al., 1998).

A recent study ( Chatterjee et al., 2001), using continuously regenerated filters in buses and truck in southern California, demonstrated the very near term practicality of using such filtration systems. Emissions testing results showed significant reductions in PM, CO and HC in the diesel exhaust when using low sulfur $(<50 \mathrm{ppm})$ diesel fuel. Particle sizing analysis exhibited a $99 \%$ reduction in particle count using scanning mobility particle sizer (SMPS) results over the range of $10 \mathrm{~nm}$ to $254 \mathrm{~nm}$ mean aerodynamic diameter. None of the test fleets used 
exhibited any operation or maintenance issues related to the filtration system. Fuel economy was also unaffected.

\subsubsection{Combustion and FT Fuel Optimization}

Heywood (1988) describes the diesel combustion process to consist of four phases. The first phase is defined as the time between start of injection (SOI) and start of combustion (SOC) and is termed the ignition delay period. Following that is the premixed combustion phase, in which fuel injected into the cylinder during the ignition delay period is burned producing a high heat release rate. The premixed phase contributes to $\mathrm{NO}_{\mathrm{x}}$ production due to higher temperatures near TDC, the readily available oxygen present and by developing a hotter environment for fuel injected in the mixing controlled phase. During the main mixing controlled phase of combustion, the remaining fuel is injected into burning or burned gases and combustion takes place as a partially premixed diffusion flame. This means that most of the fuel burns like a gaseous layered mixture cloud in which areas with different thermodynamic conditions and mixture fractions are present. The extent of these areas depends on ignition delay and burning rate of the diffusion flame of the turbulent mixture. By mixing with combustion gas, mixture elements may reach moderately high temperatures and low air/fuel ratio states at the same time yielding high soot formation rates. The late combustion phase is characterized by a slow heat release rate, rapid piston expansion and burn out of soot particles. The kinetics of the final fuel and soot burnout process become slower as the temperature of the cylinder gases decrease with piston expansion. Following the logic of Ogawa et al., (1995), FT fuels are much less likely to soot since they have low DBE values and a low $\mathrm{C} / \mathrm{H}$ ratio. Thus, FT fuels allow for a greater degree of timing retard, and lower $\mathrm{NO}_{\mathrm{x}}$ for a given PM emission index in an optimized engine. Typically, fuel injection schedules are not optimized for FT fuels as FT fuels are not widely 
distributed. Further reduction in emissions may be realized with optimization experiments with FT fuels. Figure 3-2 below gives a typical heat release rate diagram and directions in which the heat release profile should trend towards for clean, efficient combustion (Heywood, 1998).

The high cetane number characteristic of FT fuels provides a means to reduce the ignition delay period, lowering initial combustion temperature and thereby reducing $\mathrm{NO}_{\mathrm{x}}$. With injection rate control, FT fuels can provide other trade-offs too. Injection rate control is one of the means of designing combustion patterns shown in Figure 3-2. Figure 3-3 shows an example of trends for a simple pilot injection intended to control premixed combustion. This example shows a significant reduction of premixed combustion in the early part of combustion as a result of pilot injection. Initial pilot injection can also decrease ignition delay. Reducing amount of fuel entering the cylinder at low injection pressures near the end of injection (EOI) is essential to controlling PM and HC. This must also be accomplished without excessive needle bounce and fuel dribbling (Hikosaka, 1997).

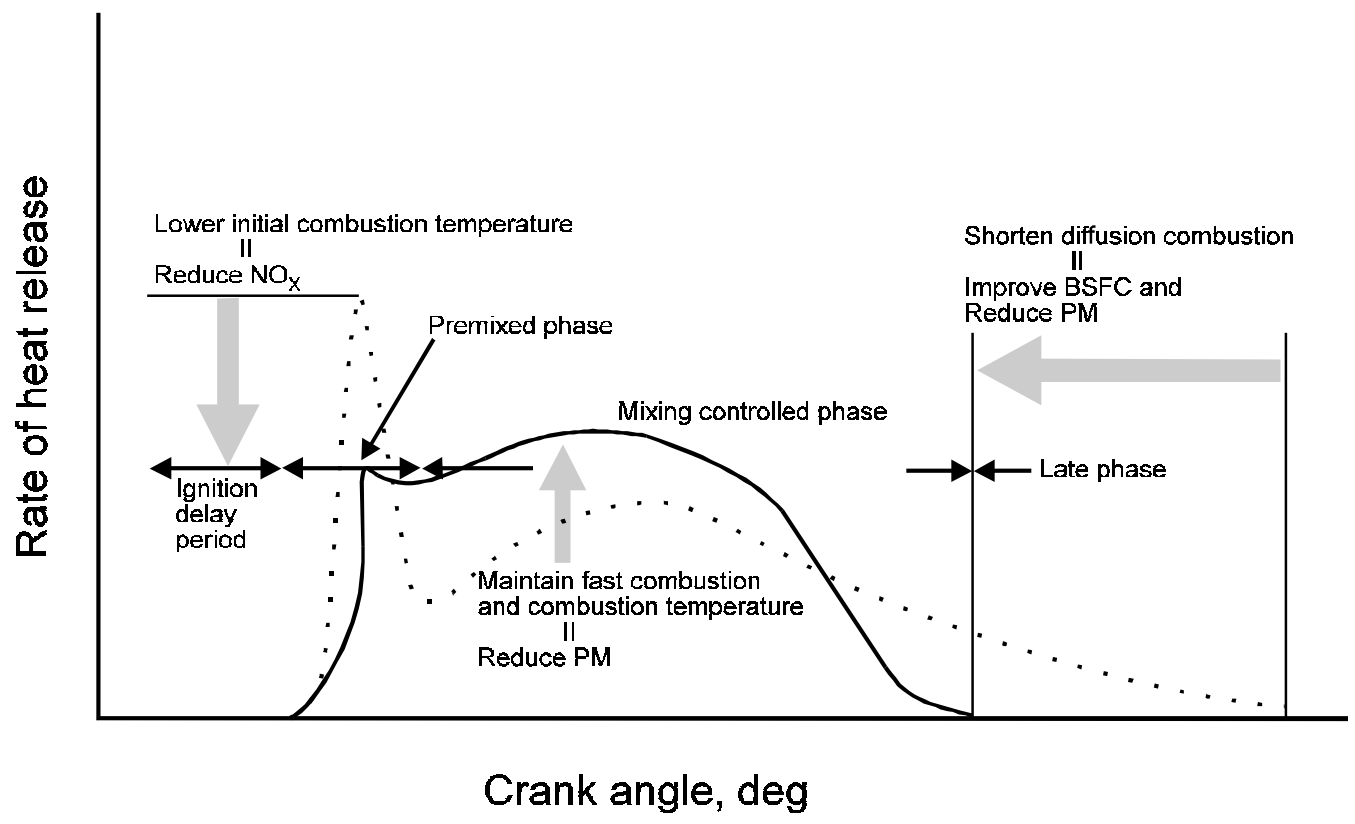

Figure 3-2. Typical DI Engine Heat Release Rate Diagram Identifying Different Diesel Combustion Phases and Improvement Trends 


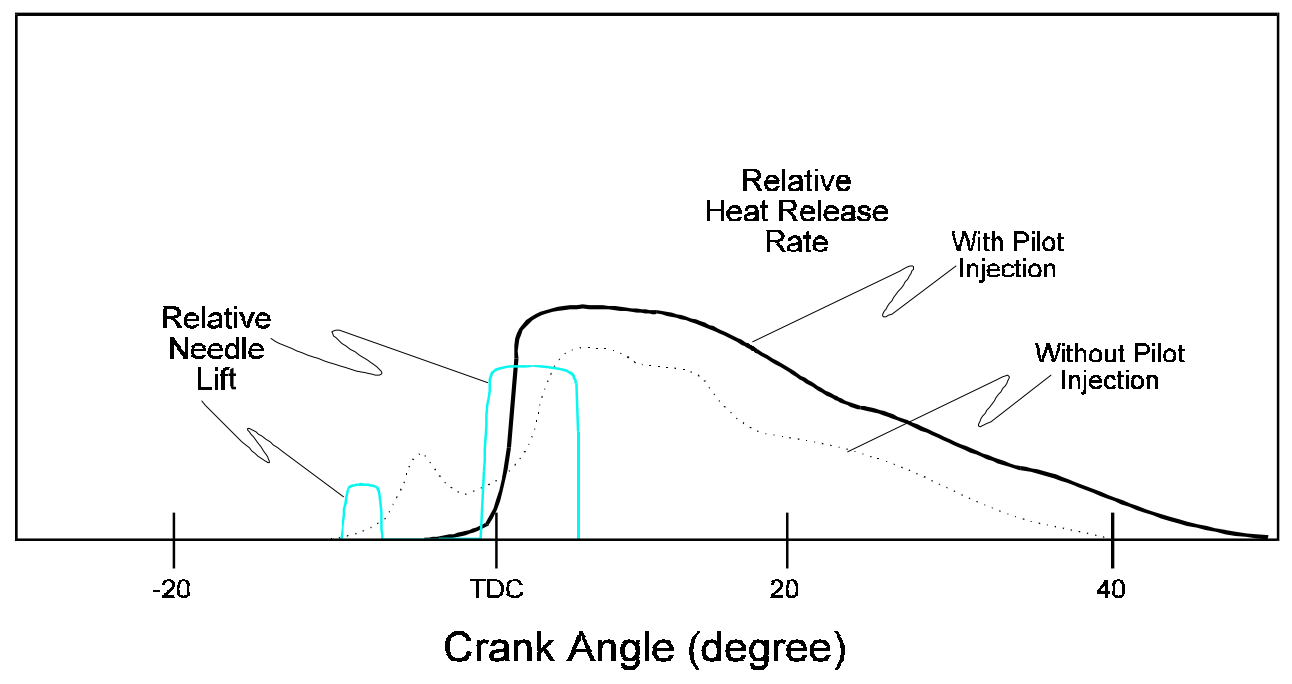

Figure 3-3. Effect of Pilot Injection on Heat Release Rate

Rail pressure and pilot injection each affect average injection rate. Emissions of $\mathrm{NO}_{\mathrm{x}}$ increase with increasing rail pressure. Pilot injection reduces injection rate by extending the time over which fuel is injected and decreasing main ignition delay which tends to lower $\mathrm{NO}_{\mathrm{x}}$. Fuels with lower density such as FT fuels provide a lower instantaneous fuel mass flowrate into the combustion chamber and a longer injection period is required to meet the fuel energy demand of the engine. This results in lower heat release rates, with an attendant reduction in $\mathrm{NO}_{\mathrm{x}}$ formation rates. The timing of the pilot injection event is also critical as excessive advanced pilot timing offsets the rate effect, resulting in higher $\mathrm{NO}_{\mathrm{x}}$. Increased injection rate, with its associated increase in burning rate, is expected to reduce smoke emissions. However, this may be offset with FT fuels. Increases in smoke with pilot injection can also occur due to shifting to more diffusion controlled burning and reduced premixed burning. Also, fuel injection during the main phase could occur in areas already depleted of oxygen from pilot combustion. High injection rate at high rail pressures increases the maximum burn rate which increases the 
rates of cylinder pressure rise. This is decreased by the amount of pilot injection (Hikosaka, 1997). Timing of pilot injection at constant overall injection volume, may be advanced with FT fuels due to their high cetane number. This will further aid in $\mathrm{NO}_{\mathrm{x}}$ reduction. Optimization with FT fuels will allow for a greater window for pilot fuel timing, duration and quantity.

Han et al., (1996), have incorporated their version of injection, combustion and emission formation models in the University of Wisconsin - Engine Research Center (UW-ERC) KIVA Computational Fluid Dynamics (CFD) engine program. Their prediction of the soot- $\mathrm{NO}_{\mathrm{x}}$ tradeoff curve and the heat release rate was in good agreement with Caterpillar 3401 single cylinder combustion and emission data using standard DF2 fuel. Their results, not surprisingly, showed that retarded timing is most effective in reducing $\mathrm{NO}_{\mathrm{x}}$. The reductions were rather dramatic with an approximate $40 \%$ increase in $\mathrm{NO}_{\mathrm{x}}$ by going from $100\left(-2^{\circ}\right)$ (that is, $100 \%$ of fuel injected at $2^{\circ}$ before top dead center) to $100\left(-10^{\circ}\right)$. They developed a correlation with $\mathrm{NO}_{\mathrm{x}}$ formation and the percent of fuel injected before $5^{\circ}$ ATDC. Han et al., (1996), also concluded that $\mathrm{NO}_{\mathrm{x}}$ reactions are most sensitive to the early part of combustion because the reactants $(\mathrm{N}, \mathrm{O}, \mathrm{OH})$ stay at a high gas temperature for a longer period, but retarded timing produced significantly greater PM emissions. Soot was correlated with percent fuel injected after $8^{\circ}$ ATDC. Again, when soot is formed during the later portion of the expansion stroke, the residence time available for oxidation is insufficient. To typify the effect of retarded injection timing on hydrocarbons, $\mathrm{CO}$, $\mathrm{NO}_{\mathrm{x}}$, and particulates the results of testing on a 1991 version of a heavy duty truck engine is depicted in Figure 3-4.

For a rising injection profile, typical of a unit pump, the soot emissions are much higher when the fuel injection duration (FID) is increased from a very short $15.2^{\circ} \mathrm{CA}$ to $21.5^{\circ} \mathrm{CA}$ at 


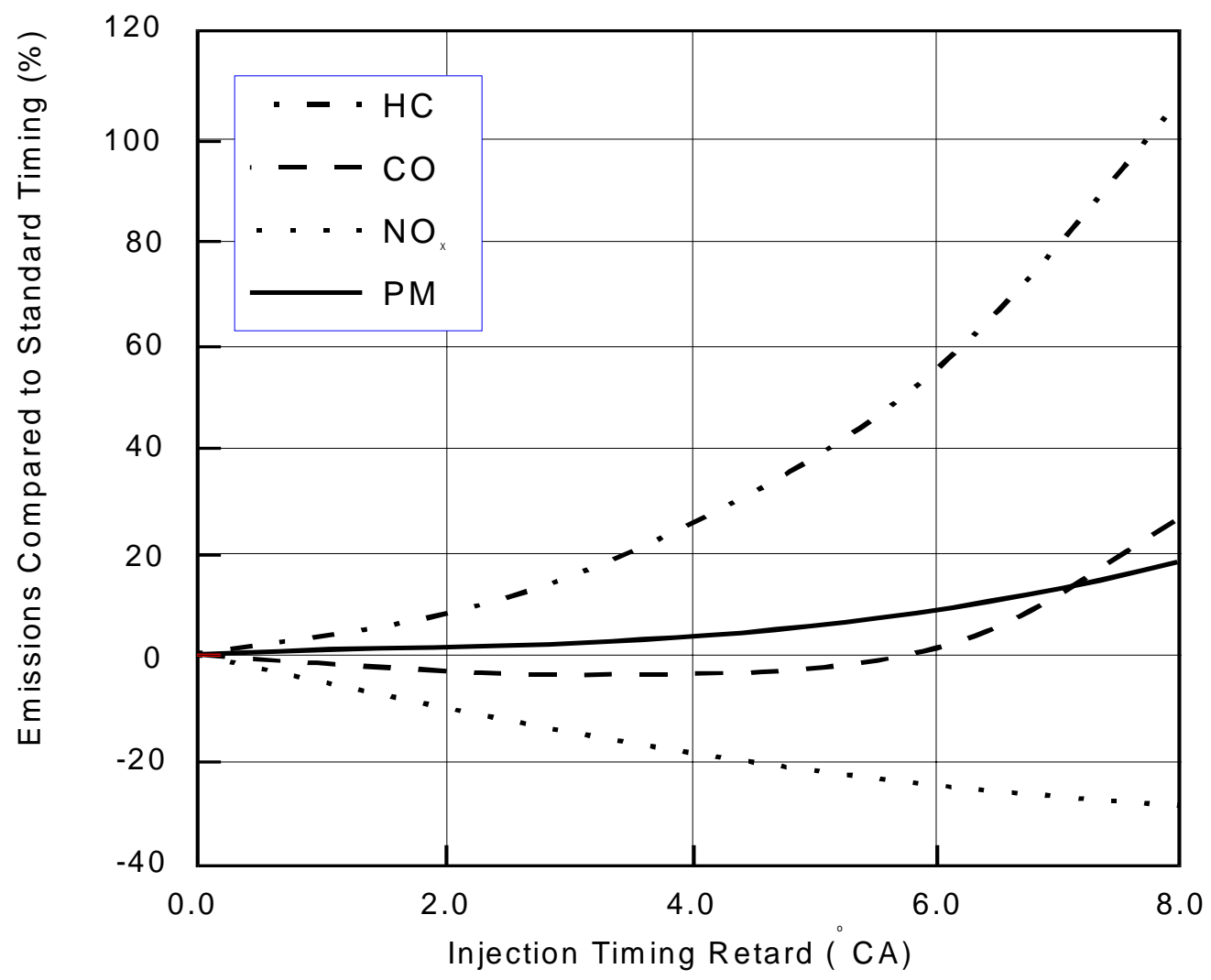

Figure 3-4. Typical Pollutant Response to Injection Timing Retard

constant start of injection (SOI) at "step function" initial and ending ramp rates. However $\mathrm{NO}_{x}$ emissions remain low. Again, this is due to the late cycle injection correlated after $8^{\circ}$ ATDC. For falling injection profiles, the soot emission remains low but $\mathrm{NO}_{\mathrm{x}}$ gets higher. Falling injection profiles allow more total fuel mass to be injected before $5^{\circ}$ ATDC and, in this case, even for long injection durations. The falling injection rate indicates a high $\mathrm{NO}_{\mathrm{x}}$ situation but the lowest soot emission even for a rather long $21.5^{\circ} \mathrm{CA}$ duration. Increasing the injection rising rate is detrimental for soot emissions. However, when using a FT fuel, less sensitivity is expected and using this as a trade-off may benefit $\mathrm{NO}_{\mathrm{x}}$. This also agrees well with the correlation made in the split injection study, that soot emission is related to fuel injection after $7^{\circ}$ 
ATDC and that $\mathrm{NO}_{\mathrm{x}}$ emission to fuel injection before $4^{\circ}$ ATDC for this particular engine arrangement (Han et al., 1996; Ricert et al., 1997).

\subsection{Dilution Tunnels and Particulate Measurement}

\subsubsection{Introduction}

The Code of Federal Regulations (CFR) 40, Part 86, Subpart N delineates the conceptual design and methodology for dilution tunnel measurement for engine systems operating on diesel fuel. Tunnels may be classified as single dilution tunnels or double dilution tunnels. Double dilution tunnels involve a two-stage dilution of the exhaust by first diluting the total exhaust in the primary tunnel and then further diluting a sample of this exhaust in the secondary dilution tunnel. Other tunnel types are in common use today which offer added convenience or improvement. A partial-flow dilution tunnel (or "mini-dilution" tunnel) is an alternative to full flow dilution tunnel for diluting and sampling diesel engine emissions. Some of the advantages of partial-flow dilution tunnels include smaller size and lower capital cost what make them suitable for transportable sampling systems. Partial dilution tunnels are an accepted method for the measurement of particulate emission from heavy duty diesel engines in Europe and Japan. These standards and regulations define a sequence of steady-state set-points for the steady state cycle. Partial dilution systems are not accepted by any standard or regulation for transient measurements of gaseous and particulate matter emission measurements.

Silvis et al., (1999) developed a mini-dilution tunnel system that uses critical flow venturis to provide a stable and repeatable exhaust dilution at a constant dilution ratio. The design is unique in that it uses a dome loaded regulator between the sample inlet and dilution air inlet thus controlling the dilution air pressure. The venturis used to control dilution air and 
sample flow are temperature controlled by mounting them in the same temperature controlled chamber.

Graze (1993) designed a mini-dilution tunnel of a porus tube design with an extremely short dilution section $(30 \mathrm{~cm})$. The system coefficient of variation values ranged from $\pm 10 \%$ or less at low idle to less than $\pm 3 \%$ at rated power. These results were consistent with uncertainty analysis outlined in their work.

Yoda and Uchida (1999) developed a mini-dilution tunnel based on mass flow controller (MFC) techniques. The system was designed for ultra-low emission vehicle work and used zero grade gas for dilution to prevent the influence of pollutants in the atmospheric air to influence the measurements. The authors used a pitot tube for flow measurement and used several novel techniques for correcting MFC gas specific heat errors and transient time alignment.

Gautam et al., (1999) designed and tested a mini-dilution tunnel concept employing a 91 tube exhaust splitter for transient particulate matter testing. In their concept, 90 tubes were led to a surge tank and then vented, the remaining tube transferred the raw exhaust sample (representing 1/91 of the total exhaust flow) to the mixing zone in a mini-dilution tunnel where it was diluted with fresh air. A pressure based split ratio control unit was incorporated into the system to maintain the sample and total exhaust mass flow rate ratio. This pressure based control system was successful for steady-state as well as transient testing although further refinements in PID control were recommended.

Diesel particulate matter is essentially sub-micrometer in diameter $(98 \%<1 \mu \mathrm{m})$. The particle count and mass distributions appear to have a unimodal or bimodal log-normal form (Pataky et al., 1994; Rickeard et al., 1996) depending on engine type and test conditions. Three morphological modes can be expected. The modes are classified as nuclei, agglomeration and 
coarse. The nuclei mode contains particles with diameter range from approximately 5 to $40 \mathrm{~nm}$ (Pataky et al., 1994; Rickeard et al., 1996; Abdul-Khalek et al.; 1998, Kittelson et al., 1999). The chemical composition and mechanism of generation of particles in the nuclei mode is still subject of the research. The agglomeration (accumulation) diameter 100 - $300 \mathrm{~nm}$ typically consists of agglomerates formed by coagulation during the expansion stroke of primary carbonaceous nuclei generated early in the exhaust or by particle re-entrainment from combustion and exhaust system deposits. The coarse mode contains particles with volume diameter of $1 \mu \mathrm{m}$ to $10 \mu \mathrm{m}$ (Kittelson et al., 1999).

Treating particles as amorphous agglomerates with nonuniform density makes the task of particle size classification extremely complicated. Therefore, when dealing with the particles of unknown morphology and density, it is common practice to express their behavior in aerosol samplers in terms of an equivalent diameter. The particles are then related to spheres through particle density and shape factor. Several different equivalent diameters are defined in literature.

An electrostatic classifier classifies particles according to their mobility equivalent diameter. The mobility equivalent diameter is the diameter of a sphere that has the same dynamic mobility as the particle in question. The MOUDI, an inertial impactor, classifies particles according to their aerodynamic equivalent diameter. The aerodynamic equivalent diameter is the diameter of a unit density sphere which settles at the same speed as the particle.

Dynamic nature of processes governing formation and transformation of particulate matter make concept of effective particle density inadequate for diesel exhaust particles. Therefore, diesel exhaust particles are usually treated as spheres of unit density. 


\subsubsection{Sampling Methodology and Instrumentation}

Diesel exhaust aerosols are a highly dynamic system. Particles may change size, mass, and composition as a result of aging, heating, cooling, and dilution. Coagulation, nucleation, condensation, evaporation, adsorption, desorption, and filter/substrate related gas-to-particle conversion are some of the processes influencing diesel aerosol measurements. Since numerous physical and chemical processes influence the sampling of diesel exhaust, obtaining representative samples and interpreting results of measurements requires meticulous work and close consideration of all parameters.

Ahlvik et al., (1998), studied effects of non-isokinetic sampling and found that the penetration of the majority of diesel particles, above 95 percent, is satisfactory even for nonisokinetic conditions. Velocity plays a very important role in any sampling procedure. It is important to maintain a sufficiently small Stokes number $\left(-\tau \mathrm{U}_{\mathrm{o}} / \mathrm{D}_{\mathrm{p}}\right)$ in the sampling system, since particles above a critical Stokes number will not accurately follow the fluid. Sampling inlets with larger diameters are less susceptible to deposition caused by free steam turbulence. Gravitation settling velocities cause inertial losses but they are rather insignificant for particles typical of diesel exhaust. Turbulent deposition results from particles being thrown from turbulent eddies, through laminar sub-layer into the wall. The turbulent deposition depends upon the inertia of the particles and is not important for particles smaller than several microns in diameter and does not effect the combustion generated particles.

Particles experience phoretic forces when they are exposed to either temperature or concentration gradients. Thermophoretic force is exerted on the particles when a temperature gradient is present in the surrounding gas. This force tends to drive the particles down the temperature gradient. In general it can be stated that for typical insulated raw exhaust lines and 
dilution tunnels operating at dilution ratios in order of 10:1, thermophoresis could be responsible for 1-2\% deposition loss of fine particles (Ahlvik et al., 1998). Diffusiophoretic force is exerted on particles when a concentration gradient is present in the surrounding gas. Diffusiophoretic force does not play a very important role in diesel exhaust sampling (Kittleson, 1990).

The dilution process plays an important role in measuring diesel exhaust aerosols by affecting the saturation ratio, temperature and volatile fractions of diluted exhaust. In steady-state and transient testing of engines and vehicles a dilution tunnel is most often used concept for diluting the exhaust. The dilution process considerably affects the particulate matter measurements and presents a potential source for artifact generation. On the other hand, the dilution air decreases particle concentration making it difficult to collect enough mass for accurate measurements. Cooling by dilution is also desirable in order to minimize thermophoretic deposition. In the Federal Test Procedure, the role of dilution air is to decrease primary mixing zone and filter face temperatures to $375^{\circ} \mathrm{F}\left(191^{\circ} \mathrm{C}\right)$ and less than $125^{\circ} \mathrm{F}\left(52^{\circ} \mathrm{C}\right)$, respectively (CFR 40, Part 86, Subpart N, 1996). It should be noted that the filter face temperature requirements are expected to change to $116.6^{\circ} \mathrm{F} \pm 9^{\circ} \mathrm{F}\left(47^{\circ} \mathrm{C} \pm 5^{\circ} \mathrm{C}\right)$ begining in 2007.

Mayer et al., (1995), compared size distribution of diesel particulate matter for different particulate trap systems. They employed an iso-kinetic type partial dilution tunnel the Smart Sampler (SS) manufactured by AVL, for integral and size-selective measurements of PM. The Swiss Federal Material Testing Labs estimated that the total scatter in the particulate measurements with SS system, including engine emission scatter, to be approximately $+/-15 \%$.

Rickeard et al., (1996), studied the influence of vehicle and fuel on exhaust particulate size distribution by performing tests on European diesel light-duty vehicles using a range of 
production diesel fuels. The results obtained on the diesel vehicles were compared with simultaneously tested gasoline vehicles. A Quartz Crystal Microbalance (QCM) Cascade impactor and a scanning mobility particle sizer (SMPS) were used for size-selective measurements. The mass recovery of the QCM impactor was found to be very low, and was susceptible to diffusion losses of particles with aerodynamic diameters smaller than $500 \mathrm{~nm}$. It should be noted that the exhaust sample was not charge neutralized prior to entering the impactor. Additionally, the impactor had long residence times and did not provide a means to keep the PM adhered to the crystal. The median size range for steady state vehicle operating conditions ranged from 70 to $100 \mathrm{~nm}$, with tendency to be larger at the highest test speed. For some test conditions, some vehicles showed a second peak in the distribution at smaller size range, around $40 \mathrm{~nm}$. Transient size selective measurements were performed for five discrete sizes, namely 25, 50, 100, 200, and $400 \mathrm{~nm}$ with the largest number of particles collected at $100 \mathrm{~nm}$. Particles emissions were highest under accelerating and high speed conditions. The variation in diesel fuel quality had no systematic effect on the median size of particulate matter emissions. Hence, the authors concluded that size selective measurements did not introduce any new factor in evaluating relative fuel performance. The diesel fuels used were commercial European grades.

Some of the problems with the QCM have been resolved . Recently, the Mid-Atlantic Research Institute LLC (MARI) began offering a commercial real-time particulate mass monitor with an integrated sample conditioning system based on the QCM concept. Tests conducted with the MARI system on the exhaust from a modern heavy-duty diesel engine have shown the PM mass emissions data to be well within $10 \%$ of the EPA CVS gravimetric method. The 
system is insensitive to engine exhaust flow pressure fluctuations as well as environmental vibrations due to its high natural resonant frequency of $5 \mathrm{MHz}$ (MARI, 2002).

Abdul-Khalek et al., (1998) performed measurements on the exhaust of medium-duty, turbocharged and aftercooled direct injection diesel engine using mini-dilution system using test modes of the Cl8 Mode and the type B Universal 11 Mode. The diluted exhaust streams were characterized using electrical size classification (SMPS and EAA). The bimodal distribution function fit particles sizes for steady-state 11 Mode test and 18 Mode test used in the study. The nuclei mode contained more than $50 \%$ particles by number and less than $1.5 \%$ by volume. It appeared that the nuclei mode particles emitted by that engine contained very little SOF. They also noticed that catalytic converter produced extremely tiny particles composed primarily of sulfuric acid with diameters in the 7 to $15 \mathrm{~nm}$ range downstream of the catalyst.

Maricq et al., (1999) used an SMPS and an Electrical Low Pressure Impactor (ELPI) for transient measurements of particulate matter emissions from a series of late model gasoline engines. The study reported that it is feasible to make reliable and reproducible transient measurements of particle size distributions for gasoline vehicles. The authors used an ELPI and claimed excellent agreement with transient, number weighed, size distributions that were obtained from different individual SMPS measurements. They found that majority of particles, based on a number weighted distribution, ranged from 10 to $300 \mathrm{~nm}$. The mean diameters for the gasoline test vehicles was found to range from 45-80 nm. The corresponding mass-weighted mean diameters were in vicinity of $200 \mathrm{~nm}$. The transient particle measurements revealed that spark ignition vehicles emit particles principally during very specific short times, and primarily under heavy acceleration. 
Graskow et al. (1998) studied exhaust particulate emissions from a spark ignition engine equipped with catalytic converter. They employed an ejector pump for dilution of the portion of the exhaust and catalytic stripper, CNC, and SMPS for size-selective measurements of PM under steady-state operating conditions. They found that emissions were periodically unstable during the steady-state operating conditions (baseline emissions and unsteady spiking emissions). The authors suggest that the small particles $(<30 \mathrm{~nm})$ detected in the spikes are formed through the homogeneous nucleation of gas-phase heavy-hydrocarbons. After comparison of the size distribution of PM emissions from gasoline and diesel engine the authors concluded that the mechanism for aerosol formation may be different for these two engines types.

As mentioned above, (Kittleson, et al., 1999), a fraction of measured PM in dilution tunnels may come from re-entrainment of material on the walls of the measurement system and combustion system. The principal mechanism of soot deposition during combustion is thermophoresis. A particle suspended in a gas in which a temperature gradient exists is subjected to a force due to the temperature gradient. This force is termed the thermophoretic force. The concept was described in the 1870's as a dark dust free zone surrounding a hot body (Li et al., 1996). This dark space was determined to result from a balance between thermal repulsion and Brownian motion and convection. For most practical applications it is the thermophoretic velocity, not the force, that is important. The thermophoretic velocity can be determined by equating the thermal force to the drag force on the particle. The thermophoretic constant and thus the thermophoretic velocity exhibits only a minor dependence on particle size. For particles that are small compared to the mean free path, the Knudsen number, which is a dimensionless number defined as the mean free path divided by the characteristic length of the particle, $(\mathrm{Kn}) \gg>1, \mathrm{~K}_{1}$, and thus velocity is independent of particle size and the thermal 
conductivity ratio. For particles considerably larger than the mean free path, $\mathrm{Kn}<<1, \mathrm{~K}_{1}$ shows a minor dependence on particle size. This affect is enhanced by a high ratio of thermal conductivities (Kittleson et al. 1990). Results suggest that the gross rate of in-cylinder deposition in the indirect injection diesel engine is between 20 and 45 percent of the net soot emission rate. Thus, a significant fraction of the soot emitted may be stored on combustion chamber surfaces and protected from oxidation. Further evidence of wall deposition and subsequent re-entrainment has been obtained by making time-resolved measurements of soot concentrations in the exhaust. These measurements show higher particle concentrations during blowdown than during the remainder of the exhaust stroke. Inertial effects must not be neglected. The importance of inertial deposition effects depends upon the Stokes Number (St), which is the ratio of the inertia force acting on a particle to the viscous force. Particles above a critical Stokes Number, which will depend on the details of the flow, will not accurately follow the fluid (Kittleson et al. 1990).

A series of Round Robin test of emissions from heavy-duty diesel engines were conducted under the guidance of the Engine Manufacturers Association Calibration Task Force and the Coordinating Research Council Smoke and Particulate Panel during the mid to late 1980's. These test showed significant intra- and inter-lab variability in particulate measurements using the Heavy Duty Transient Test (40 CFR Subpart N) (Kittleson and Johnson, 1991). A number of sources of variability were discovered. Some of the major and/or more surprising are listed here. An unexpected source of variability is thermophoretic deposition of particulate matter onto walls of the sampling system followed by subsequent re-entrainment in an unpredictable manner. For typical conditions the model predicts that more than $5 \%$ of the material is re-entrained. Engine and tunnel conditioning prior to running a test appear to 
stabilize this process and reduce variability. A source of variability which has been a matter of concern for some time is the influence of dilution and cooling upon the soluble organic fraction. Under typical conditions, the model predicts (and experiments in several laboratories have confirmed) that soluble organic matter, and thus total particulate matter, increases with increasing dilution ratio.

Kittleson and Johnson's report highlighted the following from their examinations of various facilities. These data are somewhat dated but still highlight many effects that influence PM measurement in dilution tunnels. The highlights of their examination follows.

Caterpillar did significant conditioning before testing. The engine was mapped into the tunnel and a conditioning cycle was run before going through the actual test cycle. Conditioning consists of running for 10 minutes of rated speed and load. Care was taken to minimize the use of flexible tubing in the exhaust system. Under certain conditions, resonances in the exhaust system have been found to be associated with blowoff of soot from the walls and apparently higher particulate emissions.

Cummins observed significant conditioning effects in the transfer line between the primary and secondary tunnels. A new transfer line gives significantly lower particulate emissions until it is conditioned.

Ford reports that when a series of essentially identical transient test are run, particulate emissions occasionally jump up by 10 to $20 \%$ for a single run and then return to the baseline. This is consistent with the idea of occasional re-entrainment from the walls of the dilution system. On the other hand, when they collect blank filters from the dilution tunnel without running the engine, the levels are low. Ford does not have any humidity control on either the 
engine air or the dilution air. They report generally lower particulate numbers in the winter in generally low humidity conditions.

\subsubsection{Effects of Fuel Formulation on Size Resolved Particulate Matter Emissions}

In heavy-duty diesel engines testing, both steady-state and transient, sulphur was found to be dominant fuel property affecting particulate emissions (Den Ouden et al., 1994). Sulfur content in current diesel fuels in the USA is $<0.05 \%(500 \mathrm{ppm})$ and will be reduced to less than $15 \mathrm{ppm}$ by 2007. The sulfur oxidizes to produce sulfur dioxide, $\mathrm{SO}_{2}$, of which a fraction can be oxidized to sulfur trioxide, $\mathrm{SO}_{3}$, which combines with water to form a sulfuric acid aerosol (Heywood, 1988). Studies with low sulfur fuel revealed that the number of relatively large particles $(>0.040 \mu \mathrm{m})$ remain unaffected when using fuel with low sulfur content. In contrast, low sulfur content is found to reduce concentration of nanoparticles $(<0.040 \mu \mathrm{m})$ by several orders of magnitude, implying that the majority of particles of this size are sulfur related (Mostafa et al., 2002). Opris et al., (1993), as well as Baumgard et al., (1996) concluded that most nuclei particles were formed in the dilution tunnel via heterogenous nucleation of $\mathrm{H}_{2} \mathrm{SO}_{4^{-}}$ $\mathrm{H}_{2} \mathrm{O}$.

Den Ouden et al. (1994) established empirical correlation between fuel sulfur content and particulate emissions for heavy-duty and light-duty diesel vehicles. The authors used these correlations to predict changes in particulate emissions with changes in fuel sulfur content. They considered other fuel effects on emissions from heavy-duty vehicles to be small in comparison to contribution of sulfur and the combination of cetane number and density. This is in contrast to others (Ryan, 1997; Erwin 1993 and 1994; Schaberg, 1997; Cowley 1993) who have concluded that aromatics have a strong effect on PM emissions. 


\subsubsection{Effects of Dilution Tunnel Operation on Size Resolved Particulate Matter Emissions}

Evidence presented in published literature shows that variation in the dilution ratio significantly affects the mass and number concentration of particles by changing the adsorption, condensation, and coagulation rates. Ahlvik et al., (1998), experienced a higher number of ultra-fine particles $(<100 \mathrm{~nm}$ ) during operation of the tunnel at high dilution ratios although the differences were very slight over a narrow range of relatively low dilution ratios (1.0 - 6.8). In contrast, larger particles (170-1000 nm) increased in number at low dilution, but their number concentration remains several order of magnitude below that of the small particles. The total number concentration was thus higher when higher dilution was applied. Hydrocarbon adsorption is more likely than condensation in causing increasing in mass concentration with reduced dilution ratio (MacDonald et al., 1980). Condensation may be a factor when heavy hydrocarbon species are present in the exhaust gas. The saturation ratio is ratio of partial pressure of condensible species to the local vapor pressure. At low values of saturation ratio an increase in saturation ratio results in an increase in organic adsorption (heterogeneous condensation). At high values of saturation ratio new particles may also form by homogeneous nucleation. Homogeneous nucleation and heterogeneous condensation of hydrocarbons affect both the number and the mass concentration. Dilution ratio also affects number but not the mass concentration by coagulation. Low dilution ratio should result in lower number concentration for the same mass of collected particles. Kittelson et al., (1990) suggested that the effects of dilution ratio on the soluble organic fraction can be estimated from known saturation ratio of representative hydrocarbon as a function of dilution ratio.

Abdul-Khalek et al., (1998) used partial iso-kinetic mini-dilution system with the primary and secondary dilution to study effect of dilution ratio on the number and volume concentration 
of diesel particulate matter. Ejector pumps were used for primary and secondary dilution of exhaust, providing overall dilution ration ranging from 65 to 3000 . For dilution ratio above about 60 , number and volume concentrations for their system were essentially independent of dilution ratio. For dilution ratios under 60 , number as well as volume concentrations increased with decreasing dilution ratio. Nucleation was favored by lower dilution ratios and likely increased the number concentration in the nuclei mode under those conditions. The authors expected coagulation to have the opposite effect.

Plee and MacDonald (1980) examined varying dilution ratio and varying filter temperature in an IDI diesel engine. The concluded that the condensation and an evaporation mechanism may be important at high hydrocarbon concentrations in the exhaust. Adsorption and desorption are generally the dominant mechanism at lower hydrocarbon concentrations. Recent work by Qiag et al., (2001) showed that for an engine running at ISO Mode 8 (Idle, noload) conditions with standard Federal No. 2 diesel fuel that the nuclei mode exhaust particulate number concentration increased from $3 \times 10^{7}$ to $3 \times 10^{8}$ part. $/ \mathrm{cm}^{3}$ as the dilution air temperature was decreased from $42.5^{\circ} \mathrm{C}$ to $15^{\circ} \mathrm{C}$. This sensitivity is also demonstrated by Hall et al., (2000). They showed accumulation mode particles to be relatively insensitive to changes in dilution tunnel conditions while nuclei mode particles were very sensitive. They concluded that there was no clear indication how to accurately measure nucleation particles due to their extreme sensitivity to minor changes in engine and tunnel conditions.

Pagán (1999), studied particle size distributions from a heavy-duty diesel engine equipped with a common rail injection system. It was shown that the number mean diameter of the particle size distributions decreased with increasing dilution ratios and that the total number concentration of particles did not change with dilution ratio. Further, fuel injection pressures 
affected the size distribution of PM with some engine conditions. Generally increased fuel injection pressure resulted in increased number density of nuclei mode particles.

Hall et al.,(2000) investigated number and size distributions from heavy-duty diesel engines. They concluded that larger particles (agglomeration mode and above) were measurable to a satisfactory level. However, nucleation mode particles are extremely sensitive to sampling conditions. They concluded that there was no clear indication how to accurately quantify size distributions of nucleation particles.

\subsection{Speciation of Diesel Particulates and Their Health Effects}

\subsubsection{Introduction}

The International Agency for Research on Cancer (IARC) concluded that diesel particulate is a probable human carcinogen. The soluble organic fraction (SOF) constituents, particularly the polynuclear aromatic hydrocarbons $(\mathrm{PAH})$ and the nitro-PAH may contribute to the overall carcinogenic effects. Genotoxicity of the exhaust particles from engines operating on high and low sulfur standard diesel fuels has also been studied (Bagley et al., 1996). They looked at the effects of an oxidation catalytic convertor (OCC) at three steady-state engine operating conditions on emissions and mutagenic PM activity with two engines operating on low-sulfur and high sulfur fuel. They concluded that the OCC effects on particle associated mutagenic activity were mode-related with reductions in activity from the OCC from about $30 \%$ to $84 \%$ depending on engine mode operation. Vapor phase hydrocarbons were also tested; mutagenic effects decreased for some engine conditions and increased for others resulting for OCC use.

Donaldson (1994) suggested that particles smaller than $100 \mathrm{~nm}$ in diameter, are toxic by virtue of their size and cause stress of the epithelial cells lining the lung, which can lead to lung irritation and inflammation. Laboratory studies have shown that, for deposition of given 
material in the lung, toxicity varies conversely with particle size. This is due to a better penetration into the cell, greater surface area, and more rapid dissolving of the finer particles (Mauderly et al., 1995).

Acute effects of diesel exhaust exposure include odor, eye irritations, lung function decrements, cardiovascular symptoms, and some non-specific effects. Most of these effects are reported among persons highly exposed to diesel exhaust. Lung function decrements are reported as chronic effects. Another chronic effect that has been studied extensively among occupationally exposed persons is lung cancer. In addition to lung cancer, but at a less frequent rate, an enhanced incidence of bladder cancer is reported. The particles trapped in the lungs may prolong the residence time of particulate organics or induce the generation of reactive oxygen species. These compounds are known to react with macro molecules causing lipid peroxidation, DNA damage and or activation of other genotoxic substances such as PAHs. However, these results have not yet been confirmed in mammals in vivo. A direct interaction of particles with lung tissue is also suggested as a cause of cancer but mechanism for this interaction has not yet been defined. Persons occupationally involved in the operation and maintenance of diesel powered engines form a group potentially exposed to products derived from the combustion of diesel fuel. Persons working in the vicinity of such engines are also exposed. Since most diesel engines are used as power suppliers for vehicles, people working along busy roads are potentially inhaling diesel exhaust emissions. Even the general public, such as inhabitants of urban areas, are potentially at risk although their exposure levels are much lower (Scheepers et al., 1992).

Data from rodents suggest that ultrafine particles can move from lung to the liver in particulate form. Existing epidemiological and laboratory animal data on the toxicity of diesel 
particulate emissions are derived from exposures to emissions from older technology engines. It is possible for changes in emissions to result in either greater or lesser toxicity. For example, it has been suggested that emission of increased numbers of ultrafine $(<0.1$ micron $)$ particles of organic condensate may accompany the reduction of elemental carbon particles, yet the health impact of such an increase in ultrafine particles is unknown. However, ultrafine particles are thought to penetrate lung tissues more rapidly, translocate to other organs to a greater degree, and have greater toxicity per unit of mass than larger fine particles, but existing information is largely anecdotal (Bagley, 1996).

Nikula et al., (1999) suggested that overall, intratracheal installation into the lungs of intact rats followed by bronchoalveolar lavange and histopathology was likely to give the most reliable assay of relative particle toxicity. Currently, dose-response and time-response relationships in the A549 cell cultures are being examined further (Nikula et al., 1999). In addition, the use of cultured lung macrophages is being explored. Macrophages are cells that are important to response because they engulf particles and release cytotoxic and inflammatory mediators.

Nikula et al., (1999) concluded that it does not appear that lung slice assays offer any advantage over cell culture or lung instillation. Initial results of Nikula et al., (1999) confirm the fact that a significant portion of poorly soluble ultrafine particles leaves the lungs rapidly after deposition. Questions have been raised about the potential toxicity of ultrafine particulate emissions and some have suggested that the majority of the ultrafine particulate material in emissions from new diesel engines consists of organic condensate. If this claim is proven true by experts in emissions analyses, the next step will be to evaluate the behavior of ultrafine organic particles after inhalation. At this time, it is not known if they will behave as particles or as vapors because of their rapid solubility. 
Barale et al., (1992) tested one light and three heavy duty diesel engines representing past present and future production, under steady state and transient conditions. They concluded that a correlation between engine load and mutagenic activity may be shown from the particulate extracts and that water port injection reveals a dramatic decrease of mutagenicity at high load conditions. It is theorized by the authors that the production of hydroxyl radical at the high combustion temperatures associated with the maximum engine load inhibits PAH formation. The insensitivity at low load conditions is attributed to the lower combustion temperatures hence lower $\mathrm{OH}^{--}$radical production.

Christensen et al., (1996), using the Ames test, noted that mutagenicity decreased with increasing load for both direct and indirect mutagenicity and that the direct and indirect mutagenicity was not found to be controlled by the $\mathrm{NO}_{\mathrm{x}}$ concentration of the exhaust gas, but rather by the PAH concentration. Here, direct mutagenicity refers to Salmonella typhimurium response without activation by $\mathrm{S} 9$ activation while indirect mutagenicity refers to activation with S9 liver extract. Emissions from most combustion processes show higher mutagenicity in the Ames test when prepared with a proportion of rat liver homogenate (S9). The rate liver contains enzymes that convert many compounds into metabolites that are more mutagenic than the parent compound.

Bond et al., (1990) suggested that the formation of lung DNA adducts by metabolites of soot associated organic compounds is one step in the initiation of diesel exhaust-induced, pulmonary carcinogenesis in rats. Data that support this statement include the observation that DNA adduct levels are highest in the region of the respiratory tract where tumors occur. It is possible that the role of particles in the carcinogenic response to diesel exhaust may be related to their ability to induce an inflammatory response in the lung. The inflammatory response, 
coupled with an increase in lung cell turnover that is induced by diesel exhaust may be important in carcinogenesis following exposure to diesel exhaust.

Griffis et al., (1993) studied clearance rates of PM from rats. The long-term clearance rates of soot had estimated half times of $87 \pm 28,99 \pm 4$ days, for the low and medium exposure groups respectively. The clearance half-time for the high level exposure group of $165 \pm 8$ days was significantly longer than those of the other two groups.

\subsubsection{Particulate Chemistry}

The hydrocarbon fraction of the exhaust emissions from an internal combustion engine is a complex mixture of burned and unburned fuel and lubricating oil compounds. Cartellieri and Herzog, (1988) showed that for typical late 80's engine technology, the source of particulate matter composition was $43 \%$ insoluble fuel (dry soot), $29 \%$ soluble lube oil, $13 \% \mathrm{SO}_{4}$ and $\mathrm{H}_{2} \mathrm{O}$ (using $0.3 \% \mathrm{~S}$ fuel), $10 \%$ soluble fuel residue and $5 \%$ insoluble lube oil residue. To fully assess the environmental impact of the $\mathrm{HC}$ fraction it is necessary to do speciation of individual $\mathrm{HC}$ compounds. The speciation of hydrocarbon fraction in diesel exhaust represents a particular challenge to the analytical chemistry as numerous compounds of varying functionalities are adsorbed on particulate matter or dispersed in the gaseous phase.

Most studies on diesel exhaust hydrocarbons focus on PAHs, nitro-PAHs and oxy-PAHs because they are potentially mutagenic and carcinogenic. Another health concern related to diesel exhaust hydrocarbons is their potential for ozone formation. Clark et al., (1995), found that the major portion of the ozone forming potential of the volatile hydrocarbon species was a sum of the contributions from ethene, propene, and 1,3-butadiene, and BTEX compounds. These species according to authors accounted for 90 and $95 \%$ of volatile hydrocarbons ozone 
forming potential. The semi-volatile hydrocarbons contributed between 5 and $15 \%$ to the overall ozone forming potential.

Gautam et al., (1994) concluded that aldehydes, ketones, esters, olefins and other hydrocarbon components of high concentration in diesel exhaust should be of the major concern regarding ozone forming potential.

Hammerle et al., (1995) observed that the range of carbon numbers for diesel fuel was typically $\mathrm{C}_{9}$ to $\mathrm{C}_{26}$, with most mass lying between $\mathrm{C}_{12}$ and $\mathrm{C}_{18}$. They found that the composition of the hydrocarbons in the total hydrocarbon exhaust portion for the tested vehicle and fuel consisted of methane, light hydrocarbons (LHC), heavy hydrocarbons (HHC), aldehydes, and particulate soluble organic fraction. Similar aliphatic fuel components found in the exhaust led the authors to conclude that most of heavy hydrocarbons exhaust fraction was composed of unburned fuel. The $\mathrm{C}_{12}, \mathrm{C}_{13}, \mathrm{C}_{14}, \mathrm{C}_{15}$ paraffins accounted for $34 \%$ of the HHC mass, and the methyl- and dymethylnaphtalenes account for another $21 \%$. Fifty-three percent of the HHC mass was identified as aliphatic and $31 \%$ as aromatic. The 20 most abundant species accounted for $85 \%$ of the HHC mass.

\subsubsection{Sampling Methodology}

Filter collected PM is often used for chemical analysis and bioassay analysis. The most important factor for consideration in selecting filter media for analysis are the quantity of particulate matter required for analysis and minimization of (1) interference arising from the background response of the blank filters and (2) artifact formation from chemical transformations occurring on the filter during and after filter sampling. Glass fiber filters suffer from a positive artifact mass in ambient air sampling due to their slight alkalinity that results in the in situ conversion of sulfur dioxide to sulfate. Artifact particulate nitrate can also be formed on 
glass fiber filters depending on the gaseous nitric acid concentration. Prewashing is efficient way for removal of any possible contaminants from the filters.

Glass fiber Teflon (Polytetrafluoroethylene, PTFE) coated filter is most commonly used filter media in engine and vehicle testing (Bagley et al., 1993, Opris et al., 1993, Pataky et al., 1994). These filters have relatively high collection efficiency (greater than $99 \%$ for particles $>0.3 \mu \mathrm{m}$ at $3.20 \mathrm{~m} / \mathrm{s}$ ), cause relatively low pressure drop, have good thermal stability, have low trace contamination level, and are relatively inert. Quartz fiber filter are type of filter customary used for collection of the ambient organic aerosol samples.

Barale et al., (1993) noted that the mutagenetic activity of diesel exhaust can be influenced either by modifications to the combustion process or by the choice of the diesel fuel formulation. Products resulting from incomplete diesel combustion, contain a complex mixture of organic chemicals such as aromatic and aliphatic hydrocarbons, polycyclic aromatic hydrocarbons (PAHs), plus substituted PAHs and other polar organic compounds. Part of the organic matter was adsorbed onto submicron carbonaceous particles and were identified as soluble organic fraction (SOF) and dry soot as constituents of diesel engine particulate. Diesel particulate collected on filters were extracted with dichloromethane and solvent partitioned into organic acids organic bases and neutral compounds. Bioassays of these three fractions show that the activity is largely isolated into the organic neutral fraction which is further fractionated into paraffins, aromatics and moderately polar and highly polar fractions. The two polar fractions together account for $90 \%$ of the mutagenic activity but only $30 \%$ of the mass. Comparative studies with and without nitroreductase-deficient (NR) strains of Salmonella typhimurium show a reduction in the mutagenicity of these organics with NR strains suggesting that nitrated polycyclic aromatic hydrocarbons contribute to this mutagenicity. For diesel soot, over $90 \%$ of 
the mutagenic activity is detected in the aromatic and polar neutral fractions and $\mathrm{NO}_{2}-\mathrm{PAHs}$ account for a significant portion of this fraction.

\subsubsection{Sample Preparation}

The following process for particulate sample preparation was followed by Bagley et al., (1996). All filters used to collect particulate matter were equilibrated in a constant relative humidity chamber $(42 \pm 3 \%$ relative humidity 25 degrees \pm 1 degree $C)$ and weighed prior to exposure. After exposure, the filters were ammoniated for one hour in a covered Plexiglas chamber containing an open Petri dish of ammonium hydroxide. The filters were then reequilibrated in the constant relative humidity chamber and reweighed to obtain the mass of TPM. The filters were ultrasonically extracted in distilled, deionized water (after SOF extraction) to obtain the $\mathrm{SO}_{4}$ fraction. Sulfate concentrations were determined on these extracts using ion chromatography with a conductance detector by comparison to an aqueous standard curve consisting of solutions having known concentrations of potassium sulfate. The particle associated solid fraction (SOL) emissions were defined as the mass left on the filter after extractions with dichloromethane (DCM) and deionized water. The SOL levels were therefore determined by the difference in TPM, SOF, and $\mathrm{SO}_{4}$ masses as: $\mathrm{SOL}(\mathrm{mg})=\mathrm{TPM}(\mathrm{mg})-\mathrm{SOF}(\mathrm{mg})-$ $\mathrm{SO}_{4}(\mathrm{mg})$. Mutagenic activity of the SOF and XOC samples was determined using a version of the microsuspension (micro-preincubation) modification of the Salmonella typhimurium microsome mutagenicity bioassay or Ames test (Kado et al., 1983; Maron and Ames 1983; Bagley et al., 1993). This modified Ames test resulted in increased sensitivity, lower sample mass requirements, and lower media and supply requirements than the standard plate incorporation Ames test. In order to stabilize filter weights, it was recommended that the filters be ammoniated after the particulate matter is collected (SAE Handbook 1990). The 
ammoniation process theoretically converts the $\mathrm{SO}_{4}$ on the filter to ammonium sulfate; because this compound is fairly stable at room temperature, more stable filter weights should be obtainable, resulting in more repeatable results. The ammoniation should not affect the TPM levels as long as the amount of ammonium sulfate added to the filter is corrected from the filter weight after the $\mathrm{SO}_{4}$ analysis. However, it was not known what effect the ammoniation process might have on the mutagenicity of the SOF, XOC, or PAH levels in these same fractions. Ammoniation was necessary when fuel sulfur levels were of the order of $0.3 \%$ as ued in the Bagley et al., (1993) work. Now fuel sulfur is fairly low and will decrease further in the future.

\subsubsection{Analysis}

Keane et al., (1991) reported the results of genotoxicity testing of diesel exhaust particles dispersed in aqueous mixtures of a major compound of pulmonary surfactant, as compared to samples from the same sources extracted with dichloromethane. Both types of extractions yielded similar results in both the Salmonella mutagenicity assay and the sister chromatid exchange (SCE) assay.

Nussear et al., (1992), investigated diesel exhaust from a Caterpillar 3304 diesel engine. This engine type is representative of those found in underground mines. The exhaust was diluted in multitube mini-dilution tunnel and the particulate matter collected on $70 \mathrm{~mm}$ fluorocarbon coated glass fiber filters as well as on $8 "$ x 10" hi-volume filters. A six mode steady state duty cycle was used to relate engine operating conditions to the genotoxic potential. Diesel exhaust particles were dispersed in aqueous mixtures of dipalmitoyl phosphatidyl choline, a major component of pulmonary surfactant, and were tested for genotoxicity. Diesel sample from the same source were extracted with dichloromethane and transferred into dimethyl sulfoxide and subjected to the same assays. Both types of extractions yielded similar results with the Ames 
Salmonella mutagenicity assay and the sister chromatid exchange assay using V79 cells. After separation of the samples into supernatant and sediment fractions, the activity of both diesel samples was shown to reside exclusively in the supernatant fraction for the solvent-extracted samples, and exclusively in the sedimented fraction for surfactant dispersed samples. These findings indicate that genotoxic activity associated with diesel particles inhaled into the lung may be made bioavailable by virtue of the solubilization and dispersion properties of pulmonary surfactant components.

Christensen et al., (1996), found that emissions from most combustion processes show higher mutagenicity in the Ames test when preparation of rat liver homogenate (S9-mis) is added to the bacterial incubation mixture. The rat liver contains enzymes, that convert many compounds into metabolites that are more mutagenic than the parent compound. In general PAHs are only mutagenic in the Ames test in the presence of S9-mix. Compounds requiring metabolic activation are termed indirect mutagens. In contrast many nitro-PAHs are strong mutagens in the Salmonella/microsome assay, without addition of S9-mix. Such compounds are mainly metabolized by nitro-reduction.

\subsubsection{Effects of Fuel Formulation}

Numerous investigations have been carried out to clarify the relationship between fuel properties and emissions using various combinations of engines and fuels. A number of fuel properties affect emissions, but most prominent and investigated are specific gravity, viscosity, distillation temperature, cetane number, aromatics content, and sulfur content.

Fuel composition affects many aspects of engine performance, including economy and exhaust emissions. Diesel fuels are a mixture of alkane, alkene, aliphatic and aromatic compounds, with boiling points in the approximate range $200-370^{\circ} \mathrm{C}$. Fuels with high alkane 
contents are preferable and this is reflected in their high cetane number. The aromatic components are considered to degrade the fuel, giving rise to extended ignition delays, leading to high initial heat release rates with consequently high noise and particulate matter and nitrogen oxide emissions (Mills et al., 1983).

Mills et al., (1983) used six specially blended gas oil having aromatic content of $10 \%$, $30 \%, 40 \%, 50 \%, 60 \%$, and $70 \%$ for studying the effects of diesel fuel aromaticity on the polynuclear aromatic hydrocarbon exhaust emissions. The sampling stream was filtered on a high efficiency filter for collection of the PM and than transferred to condensation traps for the removal of the vapor-phase PAHS. They found that total PAH emissions increased with increasing fuel aromatics for all engine operating conditions and no-load and that low speed full load operating conditions produced the greatest PAH exhaust concentrations. Higher loads also tended to produce larger molecular mass, more biologically active PAHs.

Bagley et al., (1996) noted that the PM size distribution is bimodal and consists of a nuclei mode ( 0.0075 to $0.056 \mathrm{um}$ in diameter) and an accumulation-mode ( 0.056 to $1.0 \mathrm{um}$ in diameter). The number distribution for the low sulfur fuel indicated more than one order of magnitude decrease in the nuclei mode from the conventional sulfur fuel; however, the accumulation-mode number concentrations were nearly the same. The volume distribution indicated similar results; for example, $9.5 \%$ of the volume is in the nuclei mode for the conventional sulfur fuel compared to only $2.2 \%$ for the low sulfur fuel. It was apparent after analyzing the low sulfur and conventional sulfur fuel data that the differences in emissions might be due not only to the fuel sulfur level, but also possibly due to different cetane numbers and aromatic contents and to differences in the specific chemical composition of the fuels. The size distributions for the conventional sulfur and the doped sulfur fuels measured from the engine 
raw exhaust and the dilution tunnel had similar accumulation modes, but the dilution tunnel distributions had higher number and volume concentrations in the nuclei mode. This indicated that the majority of the nuclei-mode particles were formed during the dilution process and originated from the fuel sulfur.

At the temperature and pressure in the combustion chamber, most of the fuel sulfur is converted to $\mathrm{SO}_{2}$ (Heywood, 1988). When exhaust is diluted and cooled, some $\mathrm{SO}_{2}$ is converted to $\mathrm{SO}_{3}$, which combines with water from the combustion process or inlet air and forms $\mathrm{H}_{2} \mathrm{SO}_{4}$ vapor. Baumgard (1995) showed that heteromolecular nucleation of $\mathrm{H}_{2} \mathrm{O}$ and $\mathrm{H}_{2} \mathrm{SO}_{4}$ vapor can occur during dilution tunnel sampling and can form particles of nuclei-mode size range. These particles are collected on the filter as part of the TPM. Whether or not heteromolecular nucleation occurs is dependent upon the $\mathrm{H}_{2} \mathrm{O}$ and $\mathrm{H}_{2} \mathrm{SO}_{4}$ vapor pressures. A comparison presented by Bagley et al., (1996) of the low sulfur and doped sulfur mutagenic activity data appeared to indicate that the increase in fuel sulfur might be related to a decrease in mutagenic activity in vapor phase hydrocarbon samples. This observation is in general agreement with the findings of Rasmussen (1990), for which the fuel sulfur contents also were adjusted using ditert-butyl disulfide. Assays of this compound at concentrations higher than those used in the fuel showed neither mutagenic activity nor toxicity, indicating that the decrease in activity was not directly related to the presence of the sulfur additive.

The performance of the diesel fuel is improved by various additives such as amine detergents, polymeric dispersant, metal deactivators, emulsifiers, cetane improvers or ignition accelerators, flow improvers, antistatics, smoke suppressants, antioxidants, and biocides in the 1-1000 ppm concentration range. Collectively these chemicals are usually referred to as fuel additives. Many chemical structures with toxicological significance are found among the 
additives: esters, phenols, amines, organic nitrates, both inorganic and organic metal compounds, etc. (Scheepers I, 1992). The influence of these additives on exhaust composition is an area of active study.

Crebelli et al., (1995) also found that the mutagenicity of diesel exhaust is largely dependent on the aromatic content of the fuel. They tested six different fuels of varying sulfur and aromatic content in light duty truck engine operating steady state in the 13th mode of the ECE 15 schedule (3.9 bar IMEP and $2000 \mathrm{rpm}$ and used Ames Salmonella typhimurium strains TA100 and TA98 using S9 activation for bioassay analysis. The comparative mutagenic investigation of the exhaust demonstrated that the genotoxic potential of diesel emissions can be drastically reduced by lowering the aromatic content of the fuel.

Johansen et al., (1997) determined the genotoxic activity of the organic solvent extraction fraction from PM and vapor phase diesel exhaust was determined in a bacterial mutagenesis assay using Salmonella thyphimurium TA 98 with and without metabolic activation S9 and TA98. Four test fuels were used including a base fuel with $18.3 \%$ aromatics. Two fuels were produced by catalytic upgrading of raw diesel fuels. These fuels were treated using hydrodesulphurization. In nearly all cases the activity followed the aromatic content rather than the sulfur content of the fuels.

\subsubsection{Size Resolved Analysis}

Several researchers (Leonardy et al., 1992; Venkataraman et al., 1994; and Abdul-Khalek et al., 1998) have reported work on the size-resolved chemical analysis of diesel particulates. Their work was based on the chemical analysis of particulate matter collected in the laboratory conditions or road tunnels. 
Venkataraman et al., (1994) measured ten polycyclic aromatic hydrocarbons (PAHs) in size-segregated aerosol sample from two traffic tunnels. The particles were collected using a low pressure impactor. The ultrasonication as method and high-pressure liquid Chromatography (HPLC)-grade methylene chloride as solvent were employed for PAH extraction. Ten PAHs were analyzed using an HPLC. The elemental carbon size distribution in both tunnels were unimodal with over $80 \%$ of the mass in particles smaller than $0.12 \mu \mathrm{m}$. Over $80 \%$ of the PAH mass was in particles smaller than $0.12 \mu \mathrm{m}$ aerodynamic diameter.

Abdul-Khalek et al., (1998) used rapid dilution to prevent nucleation and growth of particles and concluded that nuclei mode appeared to be solid, formed by volatilization of lube oil metallic ash components and subsequent nucleation of these materials during the expansion stroke. The authors also found that for full load, rated speed testing mode use of converter resulted with increased number concentration, mostly particles under $10 \mathrm{~nm}$. These particles were attributed to the oxidation of $\mathrm{SO}_{2}$ and $\mathrm{SO}_{3}$ by the catalyst and the production of sulfuric acid particles during dilution and cooling of the exhaust.

Leonardy et al., (1992) used an alternative method to make size-dependent measurement of PAH concentration on particles in diesel exhaust. They used the aerosol photoemission (APE) method suitable for in-situ measurement of amount of hydrocarbons adsorbed on the surface of the particulate matter. Method is based on the emission of electrons by irradiation with ultraviolet light at a wavelength close to the ionization threshold. The size-dependent measurements of the photoelectric yield of diesel particles indicated that with an increase in engine load, the PAH concentration on the very small-inhalable-particles showed a strong increase, and increased only slightly on the larger particles. The authors concluded that observed distribution of PAH on diesel particles was not in agreement with a model that assumes 
that the PAH concentration was controlled by diffusion flux to particles but rather related to the way in which particles were created in the high-pressure combustion.

\subsection{Combustion Quality Measurement}

\subsubsection{Introduction}

Cylinder pressure information has been in use for decades for investigating combustion processes in internal combustion engines. It is an effective and easy to implement method to track the combustion process on a cycle resolved basis. Accurate, rapid response piezo-electric pressure transducers are available that are designed for the harsh environment in the combustion chamber of an internal combustion engine. Digital data acquisition systems, triggered by a crankshaft mounted incremental encoder, sample voltages produced from the charge amplified signal of a piezo-electric pressure transducer.

The evolution of cylinder pressure in an internal combustion engine is a complicated process involving the heat release due to combustion, heat transfer by convection, conduction and radiation, as well as the changing combustion chamber volume. Cylinder combustion pressure may be used as a direct measurement of parameters such as the maximum combustion

pressure, $\left(\mathrm{P}_{\max }\right)$, the crank angle of occurrence of this maximum pressure, $\left(\theta_{\mathrm{Pmax}} \cdot\right)$ and the indicated mean effective pressure (IMEP). There are a number of important parameters that are derived from the measurement of cylinder pressure. These parameters are based on combining the cylinder pressure measurements with thermodynamic models. By utilizing the cylinder pressure, cylinder volume, and the derivatives of these functions, quantitative measures of the combustion quality can be derived. These include the heat release rate, overall heat release, as well as combustion or "burn" duration. 


\subsubsection{Measured Combustion Parameters}

The indicated mean effective pressure (Work/Vol.) is a very important measure of engine performance, due to its relative invariance with engine size, and is an excellent measure of the overall performance of the engine. By definition the mean effective pressure (MEP) is the work for a given cycle divided by the displaced volume of the engine:

$$
\mathrm{MEP}=\frac{\mathrm{W}_{\mathrm{c}}}{\mathrm{V}_{\mathrm{d}}}
$$

Where $W_{c}$ is the work per cycle and $V_{d}$ is the displaced volume of the engine.

The indicated mean effective pressure, IMEP, is the work delivered to the piston by the cylinder gases during a given engine cycle divided by the engine displacement. This quantity neglects frictional and all other losses and measures only the PdV work delivered to the piston. Pumping losses during the intake and exhaust strokes are neglected. The net indicated mean effective pressure for a given cycle is defined as:

$$
\operatorname{IMEP}_{n}=\frac{\int_{-\pi}^{\pi} P d V}{V_{d}}
$$

Where $\mathrm{P}$ is the cylinder gage pressure and $\mathrm{dV}$ is the incremental change in volume.

Because the cylinder pressure will be the sampled data, the integral given above will become a summation over all the data points collected during the compression and expansion strokes. Thus Eqn. 6 can be replaced as follows: 


$$
\operatorname{IMEP}=\frac{\sum_{\theta=-\pi}^{\theta=\pi} \mathrm{P} \frac{\mathrm{dV}}{\mathrm{d} \theta} \mathrm{d \theta}}{\mathrm{V}_{\mathrm{d}}}
$$

The incremental change in the angle, $\mathrm{d} \theta$, is the resolution of the encoder used to trigger the data acquisition system. Brundt and Lucas (1991), found that the deviation of the mean IMEPs was found to vary only slightly with CA resolution. The error in the gross IMEPs at $10^{\circ} \mathrm{CA}$ resolution in their study was only $-0.9 \%$. Even at $20^{\circ} \mathrm{CA}$ resolution the error is less that $-3 \%$. The sensitivity to CA resolution error is only about $0.1 \%$ per degree as compared to $5 \%$ per degree for CA phasing errors. There are two main reasons for the relative small errors incurred when using coarse crank angle resolution and noisy pressure data. First, there is a low sensitivity to cylinder pressure fluctuation around TDC due to the low rate of change of volume and second the errors produced for individual steps and sections of the cycle tend to cancel out over the integration period. The contribution to the IMEP is thus small near to TDC and reaches a maximum typically 40 degrees ATDC when the maximum combination of pressure and volume change rate occur together. The rate of change of the cylinder volume can be found as a function of engine geometry. The cylinder volume (Heywood, 1988) at any given crank angle is given by:

$$
\mathrm{V}(\theta)=\mathrm{V}_{\mathrm{c}}+\frac{\mathrm{V}_{\mathrm{c}}}{2}\left(\mathrm{r}_{\mathrm{c}}-1\right)\left[\mathrm{R}+1-\cos \theta-\left(\mathrm{R}^{2}-\sin ^{2} \theta\right)^{1 / 2}\right]
$$

Where $\mathrm{V}(\theta)$ is the cylinder volume at crank angle $\theta, V_{c}$, is the clearance volume of the engine, $r_{c}$ is the compression ratio, and $\mathrm{R}$ is the ratio of connecting rod length to crank radius. The rate of 
change of the cylinder volume is found by differentiating this function with respect to crank angle:

$$
\frac{d V}{d \theta}=\frac{V_{c} \sin \theta}{2}\left(r_{c}-1\right)\left(1+\frac{\cos \theta}{\sqrt{R^{2}-\sin ^{2} \theta}}\right)
$$

Substituting this expression for $\mathrm{dV} / \mathrm{d} \theta$ into Equation 7 gives an expression for the net indicated mean effective pressure as a function of the sampled pressure:

$$
\operatorname{MEP}_{n}=\frac{\sum_{\theta=-\pi}^{\theta=\pi} P(\theta) \frac{V_{c} \sin \theta}{2}\left(r_{c}-1\right)\left(1+\frac{\cos \theta}{\sqrt{R^{2}-\sin ^{2} \theta}}\right)}{V_{d}}
$$

The net indicated mean effective pressure can be calculated for any single engine cycle (assuming adequate $\mathrm{CA}$ resolution), and used as a measure of the efficiency of the combustion process. IMEP takes into account the magnitude of the pressures in a given cycle and the accuracy of the phasing of the cycle with respect to the maximum brake torque timing. Brundt and Emtage, (1996) found that calculated IMEP is extremely sensitive to errors in the phasing between cylinder pressure and cylinder volume. The phasing errors can vary from 5\% to $10 \%$ per CA degree for gasoline and diesel engines respectively. Phase errors are most commonly caused by positioning error with the crank angle marker shaft encoder, although filters and smoothing functions can also contribute to the error. These are also inherent errors induced due to torsional strain during engine operation. Induced torsional strain in the crankshaft may be as high as $0.3^{\circ} \mathrm{CA}$ at some engine speeds or during transient loading conditions (Morita and Okamura, 1995). 
Brundt and Emtage, (1996) revealed that the magnitude of the \% IMEP error per degree of crank angle phase shift was mainly a function of four parameters, compression ratio, heat release per unit mass of charge, ignition/injection timing and overall combustion duration. It increases linearly with compression ratio. Advanced injection or ignition timing, increasing $\mathrm{A} / \mathrm{F}$ ratio, and fast burn will also increase IMEP error for a given amount of phasing error. Volumetric efficiency has little effect.

IMEP values are frequently estimated from dynamometer measurements (Lancaster et al., 1975). For the fired engine using a dynamometer, the brake mean effective pressure (BMEP) is that used from the dynamometer. For a 4-stroke engine with BMEP measured in bar:

$$
\mathrm{BMEP}=\left(\frac{\text { Torque }}{\mathrm{V}_{\mathrm{d}}}\right)\left(\frac{2 \mathrm{rev}}{\text { cycle }}\right)\left(\frac{2 \pi \mathrm{rad}}{\mathrm{rev}}\right)\left(\frac{10^{-2}}{\mathrm{~Pa}}\right)
$$

BMEP may be considered to be a function of indicated mean effective pressure (IMEP), pumping mean effective pressure (PMEP) and friction mean effective pressure (FMEP):

$$
\text { BMEP = IMEP + PMEP - FMEP }
$$

For the motored engine:

$$
\mathrm{BMEP}_{\mathrm{m}}=\mathrm{IMEP}_{\mathrm{m}}+\mathrm{PMEP}_{\mathrm{m}}-\mathrm{FMEP}_{\mathrm{m}}
$$

BMEP is considered positive when the engine is doing work. The $\mathrm{BMEP}_{\mathrm{m}}$ of the motored engine is a negative quantity because work is being done on the engine by the dynamometer. The motored mean effective pressure (MMEP) is normally used as the measure of engine motoring load, 


$$
\mathrm{MMEP}=-\mathrm{BMEP}_{\mathrm{m}}
$$

Then:

$$
-\mathrm{BMEP}_{\mathrm{m}}=-\mathrm{IMEP}_{\mathrm{m}}-\mathrm{PMEP}_{\mathrm{m}}+\mathrm{FMEP}_{\mathrm{m}}
$$

Typically one makes the assumption that motored indicated mean effective pressure may be neglected. This is not always true, but makes for a useful estimate. Further if one assumes:

$$
\mathrm{PMEP}=\mathrm{PMEP}_{\mathrm{m}}
$$

$$
\text { FMEP }=\text { FMEP }_{\mathrm{m}}
$$

then:

$$
\mathrm{MEP}_{\text {dyna }}=\mathrm{IMEP}
$$

IMEP $_{\mathrm{dyna}}$ should be constantly above the fired IMEP. The primary reason for this is the non-zero value of the motored IMEP and failure of the equivalent FMEP and PMEP assumption. If one carefully equilibrated the engine to firing conditions and quickly shut off the fuel to take a motored IMEP measurement, then a reasonable estimate of $\mathrm{IMEP}_{\mathrm{dyna}}$ may be obtained.

As previously mentioned, maximum cylinder pressure is a very simple means of quantifying the combustion process as it requires no calculation, and represents the combustion quality with a single parameter. The maximum cylinder pressure that occurs in a given cycle is a function of both the total amount of energy that is released during combustion, and the timing of 
that release relative to TDC of the engine. It is also an important parameter in engine mechanical design.

With all other parameters held constant, the maximum pressure increases with increasing heat release and increases as the effective injection timing is advanced. As the effective injection timing is advanced, the heat release occurs earlier in the cycle, when the cylinder volume is smaller, leading to a higher maximum cylinder pressure. The injection timing which corresponds to the maximum cylinder pressure is not necessarily coincident with the maximum brake torque (MBT) timing. MBT is a function of crank angle and cylinder pressure. Pressure may be developed by combustion before the piston reaches TDC doing negative work on the piston, resulting in lower overall torque. Further, the total heat release is a function of both the mass of fuel trapped in the cylinder and the combustion efficiency. The combustion efficiency accounts for the unburned fuel fraction.

The crank angle at which the maximum cylinder pressure occurs, $\theta_{\mathrm{Pmax}}$ is also an indication of the intensity and duration of the premixed combustion period. As with maximum cylinder pressure, one of the main advantages of using $\theta_{\mathrm{Pmax}}$ is its simplicity. It requires no additional calculation to extract it from the pressure data, and it can be stored as a single parameter which quantifies the combustion quality through the impact of ignition delay for any given cycle.

Ignition delay is an important parameter in that it gives an indication of the duration of the premixed combustion phase. The duration of the delay between the needle lift and the first noticeable sign of pressure increase from motored operation is how ignition delay is defined. 


\subsubsection{Calculated Combustion Parameters}

While the direct pressure measurements discussed above offer a simple means of quantifying the combustion quality in internal combustion engines, they measure the overall effect of several competing phenomenon. For example, the indicated mean effective pressure takes into account the total heat release, the timing of the heat release, and the variation in heat transfer from cycle to cycle. More specific information is often required regarding the parameters that make up the cylinder pressure data. These methods are based on simple combustion models and require several simplifying assumptions in order to allow calculation from only the cylinder pressure. The two most prevalent combustion related parameters that are calculated are the heat release rate and the combustion or "burn" duration.

\subsubsection{Heat Release Rate}

The rate of heat release is an excellent means by which to characterize the combustion process. Cylinder pressure data may be used to estimate heat release rate by treating the cylinder during combustion as a closed system of varying volume. By neglecting heat transfer effects and flows into and out of crevice volumes in the combustion chamber, an energy balance on the combustion chamber control volume yields:

$$
\Delta \mathbf{Q}_{\text {chem }}=\mathrm{mc}_{\mathrm{v}} \mathrm{dT}+\mathrm{PdV}
$$

Where $\Delta \mathrm{Q}_{\text {chem }}$ is the incremental amount of chemical energy released, $\mathrm{m}$ is the total mass of the system, $\mathrm{c}_{\mathrm{v}}$ is the specific heat at constant volume of the gas, $\mathrm{dT}$ is the incremental change in the gas temperature, $\mathrm{P}$ is the cylinder pressure, and $\mathrm{dV}$ is the incremental change in the cylinder volume. Equation 19 neglects heat transfer, which accounts for approximately $15 \%$ of the total 
heat release. This leads to significant error in the absolute value of the heat release although quantitative comparisons of cycle to cycle heat release are possible.

A number of technical papers (Karim and Khan, (1971); Callahan et al., (1985); Brundt et al., (1998) and Brundt and Platts (1999)) have studied the main sources of errors associated with heat release calculations. Most recently, Brundt and Platts (1999) indicated that the most significant sources of heat release errors have been shown to be due to cylinder pressure measurement errors caused by incorrect phasing, absolute pressure referencing offset, noise, heat release model errors, deficiencies in modeling spatial variations in heat release models, unaccounted gas property variations and charge to wall heat transfer. In addition to such errors producing incorrect numerical values for heat release quantities, misleading and non-physical heat release characteristics can also result, such as the occurrence of negative heat release rates during the post-combustion period. Heat release analysis is also known to be more sensitive to errors as compared to burn calculations because the normalizing process has the effect of reducing the impact of calculation errors. Brundt et al., (1998) investigated measurement errors using simulated and measured gasoline fueled spark-ignited engine pressure data. Their results showed that the highest error sensitivity is associated with crank angle phasing and absolute pressure referencing. Sensitivities of up to $8 \%$ per ${ }^{\circ} \mathrm{CA}$ for phasing error and $5 \%$ per 0.1 bar for pressure referencing error were identified.

Applying the ideal gas law to Eqn. 3-19 gives the expression shown in Eqn. 3-20. The treatment of the cylinder gas as an ideal with a constant value of $\mathrm{R}$ leads to small additional errors but is consistent with the purpose of the derivation.

$$
\delta Q_{\text {chem }}=\frac{c_{v}}{R} V d P+\left(\frac{C_{p}}{R}+1\right) P d V
$$


Where $\mathrm{R}$ is the average gas constant for the cylinder constituents and $\mathrm{c}_{\mathrm{p}}$ is the specific heat at constant pressure. Substituting the ratio of specific heats and taking the rate of change with respect to crank angle yields a measure for the heat release rate as a function only of the measured pressure, volume, and the rate of change of these properties:

$$
\frac{\mathrm{dQ}_{\text {chem }}}{\mathrm{d} \theta} \cong\left(\frac{1}{\gamma-1}\right) \mathrm{VdP}+\left(\frac{\gamma}{\gamma-1}\right) \mathrm{PdV}
$$

Where $\gamma$ is the ratio of specific heats.

The ratio of specific heats can be either taken as a constant value throughout the process or can be estimated as a function of temperature. The heat release rate can also be integrated and normalized to yield a measure of the burned gas fraction, this provides one method of estimating burn duration as discussed in Section 3.4.3.2 below. Heat release rate is important because it is a direct link between the collected cylinder pressure data and the actual cycle resolved combustion events. It is a measure of the burning rate in the engine, which is directly related to the properties of the combusting mixture.

Neglecting heat transfer in any in-cylinder thermodynamic calculation induces significant error. Heat transfer corrections to heat release models, such as Equation 3-22, have been developed by numerous investigators (Annand, (1963); Woschni, (1967); LeFeuvre et al., (1969); Dent and Souliaman, (1977); Sihling and Woschni, (1979); Gatowski et al., (1984); Morel and Keribar, (1985); Wahiduzzaman et al., (1987); Callahan et al., (1985); Brundt et al., (1998); and Brundt and Platts (1999)). There are many correlations for both convective and radiative heat transfer. With correction for wall heat transfer Equation 3-21 may be expressed as: 


$$
\frac{d Q_{\text {chem }}}{d \theta} \cong\left(\frac{1}{\gamma-1}\right) \mathrm{VdP}+\left(\frac{\gamma}{\gamma-1}\right) P d V+d Q_{\text {wall }}
$$

\subsubsection{Burn Duration}

The number of crank angle degrees required for the combustion of the cylinder charge is an important parameter for the operation of internal combustion engines. The burn duration can be estimated using the heat release rate, or by application of a simple two-zone combustion model. In the two-zone model, the compression and expansion strokes in the engine are assumed to be essentially isentropic. The combustion chamber is divided into two regions, a burned gas region and an unburned gas region, separated by a thin flame front. From the polytropic relation applied to the burned and unburned volumes given in Equations 3-24 and 3-23 respectively:

$$
V_{u}=V_{u, 0}\left(\frac{P_{0}}{P}\right)^{1 / n}
$$

Where $\mathrm{V}_{\mathrm{u}}$ is the volume of the unburned mixture, $\mathrm{V}_{\mathrm{u}, 0}$ is the volume the unburned mixture would have occupied at point of ignition, $\mathrm{P}_{\mathrm{o}}$ is the pressure in the combustion chamber at ignition, $\mathrm{n}$ is the polytropic exponent and $\mathrm{P}$ is the cylinder pressure.

$$
V_{b}=V_{b, 0}\left(\frac{P_{f}}{P}\right)^{1 / n}
$$


Where $\mathrm{V}_{\mathrm{b}}$ is the volume of the burned mixture, $\mathrm{V}_{\mathrm{b}, \mathrm{f}}$ is the volume which the burned mixture would occupy at the end of combustion, and $\mathrm{P}_{\mathrm{f}}$ is the pressure in the combustion chamber at the end of combustion.

Because the flame front is considered to occupy a negligible volume:

$$
\mathrm{V}=\mathrm{V}_{\mathbf{u}}+\mathrm{V}_{\mathbf{b}}
$$

Where, $\mathrm{V}$ is the total cylinder volume.

Clearly, the burned gas fraction can be written in terms of either the burned or unburned mixture volume ratio:

$$
\mathrm{x}_{\mathrm{b}}=1-\frac{\mathrm{V}_{\mathrm{u}, 0}}{\mathrm{~V}_{0}}=\frac{\mathrm{V}_{\mathrm{b}, \mathrm{f}}}{\mathrm{V}_{\mathrm{f}}}
$$

Where $\mathrm{V}_{\mathrm{o}}$ is the cylinder volume at ignition, and $\mathrm{V}_{\mathrm{f}}$ is the cylinder volume at the end of combustion. Combining Equations 3-23 through 3-25 yields an expression for the burned gas fraction in terms of the cylinder pressure and the conditions at the beginning and end of combustion:

$$
x_{b}=\frac{P^{1 / n} V-P_{o}^{1 / n} V_{o}}{P_{f}^{1 / n} V_{f}-P_{o}^{1 / n} V_{o}}
$$

This is only an approximation of the actual mass fraction burned for several reasons including the fact that heat transfer was neglected and the variation of the polytropic index over the large temperature range which occurs during combustion was neglected.

Brundt and Emtage (1997) compared five MFB models including one which considered heat transfer effects. The Rassweiler and Withrow MFB model was found to produce the best 
results in comparative tests (spark ignited engines) with simulated and experimental pressure data. Absolute pressure referencing offset caused the largest error in the calculated MFB and burn angles, particularly at low engine load. The Rassweiler and Withrow MFB equation is given as:

$$
\mathrm{MFB}_{\theta}=\frac{\sum_{\mathrm{i}=\mathrm{ign}}^{\mathrm{i}=0} \Delta \mathrm{p}_{\mathrm{c}, \mathrm{i}}}{\sum_{\mathrm{i}=\mathrm{EEOC}}^{\mathrm{i} g \mathrm{gn}} \Delta \mathrm{p}_{\mathrm{c}, \mathrm{i}}}
$$

Where, $\mathrm{MFB}_{\theta}$ is the mass fraction burned at crank angle $\theta, \Delta \mathrm{p}_{\mathrm{c}}$ is the corrected pressure rise due to combustion, $\mathrm{i}$ is the integer crank angle location, ign is the ignition crank angle location and EEOC is the crank angle for estimated end of combustion.

The corrected pressure rise due to combustion is calculated from the difference between the incremental measured pressure rise and the pressure rise corresponding to a polytropic compression/expansion process and then referenced to the cylinder volume at TDC:

$$
\Delta \mathrm{p}_{\mathrm{c}, \mathrm{i}}=\left[\mathrm{p}_{\mathrm{i}}-\left(\frac{\mathrm{V}_{\mathrm{i}-1}}{\mathrm{~V}_{\mathrm{i}}}\right)^{\mathrm{n}} \mathrm{p}_{\mathrm{i}-1}\right]\left(\frac{\mathrm{V}_{\mathrm{i}-1}}{\mathrm{~V}_{\mathrm{r}}}\right)
$$

Where: $\mathrm{n}$ is the assumed polytropic index, $\mathrm{V}$ is the cylinder volume and $\mathrm{V}_{\mathrm{r}}$ is the reference volume at TDC. Here the polytropic index is based on values calculated from least squares fits to the log pressure versus log volume data usually over a 40 degree period. The angles used depend on the ignition timing, EEOC and EVC. 
Brundt and Emtage (1997) summarized errors with respect to burn rates. The largest errors will occur under the following conditions:

1. when absolute pressure referencing errors are present under low load conditions and polytropic indices are calculated directly from the pressure data

2. when burn angles of less than $10 \%$ and more then $90 \%$ are used and there are any errors in the pressure data and/or assumed compression ratio or signal noise is present

3. when less than 100 cycles are being used under conditions such as idle where cyclic variations are high and

4. when slow burns, partial burns or misfires are present.

The optimum trade-off regarding the minimum number of cycles and maximum crank angle resolution for best burn angle and IMEP accuracy differs. Assuming that the pressure data are being acquired and analyzed for both IMEP and burn angle analysis, the minimum number of cycles will be dictated by IMEP requirements and the maximum crank angle resolution will be controlled by burn angle considerations.

There are several burn durations that are in common use in internal combustion engine research. The total burn duration $\theta_{0-100}$ is not typically used due to the difficulty in determining accurately the exact beginning and ending points of combustion. The two most commonly used burn durations are the number of crank angle degrees between ignition and $2 \%$ mass fraction burned, $\theta_{0-2}$ and the duration of the bulk of combustion, between $10 \%$ and $90 \%, \theta_{10-90}$.

\subsubsection{Fischer-Tropsch Combustion Analysis}

There have been many papers written regarding combustion analysis of diesel engine operating on a variety of liquid, gaseous and even solid fuel (Kakwani and Kamo, (1989); Mtui and Hill, (1996); Zhang and Van Gerpen (1996), and many others). The only detailed 
combustion analysis known to this author is that of Atkinson et al., (1999). In their study, a Sasol slurry-phase derived from natural gas using the Fischer-Tropsch process fueled a Navistar T444E (V8, 7.3 liter) directed-injected diesel engine. Twelve separate engine load and speed conditions were chosen to span a wide range of the engines performance map.

Atkinson et al., (1999) found that at all operating conditions, the Sasol FT yielded a shorter ignition delay that the diesel fuel, as a result of its higher cetane rating. The Sasol FT fuel ignition delay period was one tenth of a millisecond $\left(1^{\circ} \mathrm{CA} @ 1500 \mathrm{rpm}\right)$ less than diesel. This enabled a reduced physical evaporation period before ignition. The Sasol FT fuel also yielded a more consistent heat release rate shape. There was no difference in ignition delay trend between the two fuels related to load.

The Sasol FT fuel had a slightly longer burn duration than the diesel fuel, however the sum of the ignition delay and the combustion duration for each fuel is roughly equivalent.

The peak combustion pressure generated by the Sasol FT fuel was lower than the peak pressure for diesel at each speed and load set point. The authors concluded that this was naturally explained by the fact that the piston has passed farther down the expansion stroke by the time the peak pressure is encountered. The Sasol FT fuel displayed a 35\% average lower maximum burn rate than diesel fuel for the same speed and load.

The benefit of Sasol FT in yielding less $\mathrm{NO}_{\mathrm{x}}$ at similar power densities is evident when the diesel and Sasol FT data are collapsed into a single trend, with $\mathrm{NO}_{\mathrm{x}}$ versus peak combustion pressure, and $\mathrm{NO}_{\mathrm{x}}$ versus measured exhaust temperature considered. For the same measured exhaust temperature (assuming similar in-cylinder temperature) both Sasol FT and diesel fuel produce the same levels of $\mathrm{NO}_{\mathrm{x}}$. This does not suggest any difference in the mechanism behind 
the $\mathrm{NO}_{\mathrm{x}}$ formation reaction but merely that for the same net power output at any speed, the Sasol FT results in a lower average in-cylinder temperature.

The authors concluded that while Sasol FT derates an unmodified compression ignition engine by a small amount at its highest load settings, the brake specific emissions on Sasol FT fuel are significantly lower than on diesel fuel. Lower peak in-cylinder temperatures, are chiefly responsible for the lower $\mathrm{NO}_{\mathrm{x}}$ reduction benefits for Sasol FT while the lower sulfur content of the fuel results in lower PM emissions.

Just as in the case of diesel fuel, Fischer-Tropsch fuel represents a generic fuel. There are potentially an infinite number of FT formulations and specifications with respect to density, cetane number, sulfur level, aromatic content and boiling point fractions. Combustion behavior depends greatly upon these specifications. 


\subsection{Experimental Equipment and Procedure}

\subsection{Dilution Tunnel}

The Code of Federal Regulations (CFR) 40, Part 86, Subpart N delineates the conceptual design and methodology for recommended dilute exhaust measurement for engine systems operating on diesel fuel. The recommended dilution tunnels are either primary, or primary with secondary dilution. However, other tunnel types, in common use today, offer added convenience or improvement. A partial-flow dilution tunnel is an alternative to full flow dilution tunnel for diluting and sampling diesel engine emissions. Some of the advantages of partial-flow dilution tunnel include smaller size and lower capital cost thereby making them suitable for transportable sampling systems.

In this study a mini-dilution tunnel was designed and constructed. A mini-tunnel design was opted over the full flow design due to site constraints for plant dilution air and for siting a full size blower. Further, the convenience of having a portable dilution tunnel has its advantages. Modeling of the flow and mixing in a dilution tunnel system is given in detail in appendix A. The system is designed to sample raw exhaust from the diesel engine exhaust. The system, shown schematically in Figure 4-1 and pictorially in Figure 4-2, incorporates a minidilution tunnel, pump, mass flow and temperature measurement and control instrumentation, and accompanying transfer lines. The tunnel was built from 3.25" ID (82.6 mm), sch 10, 316 stainless steel pipe. Temperature controlled dilution air is introduced at one end of the tunnel at four circumferentially, equidistantly spaced points. This arrangement assures uniform flow and concentration distribution profiles for the diluted exhaust by the time it reaches the $\mathrm{CO}_{2}$ tunnel sampling probe and $90 \mathrm{~mm}$ particulate sample filter. The dilution tunnel, the pumps, and the mass flow measurement instrumentation were designed for achieving repeatable and accurate 


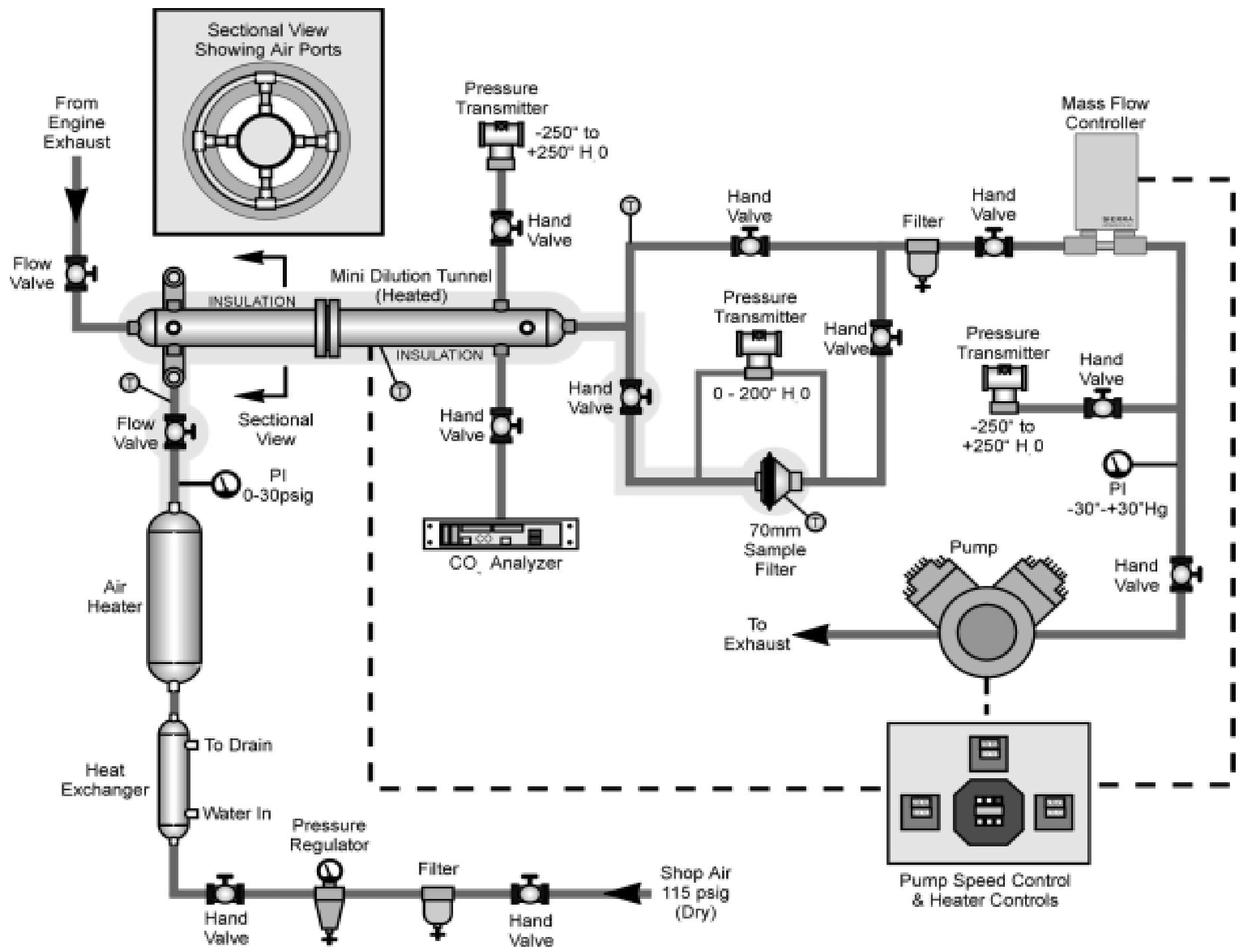

Figure 4-1. Mini-Dilution Tunnel Schematic 


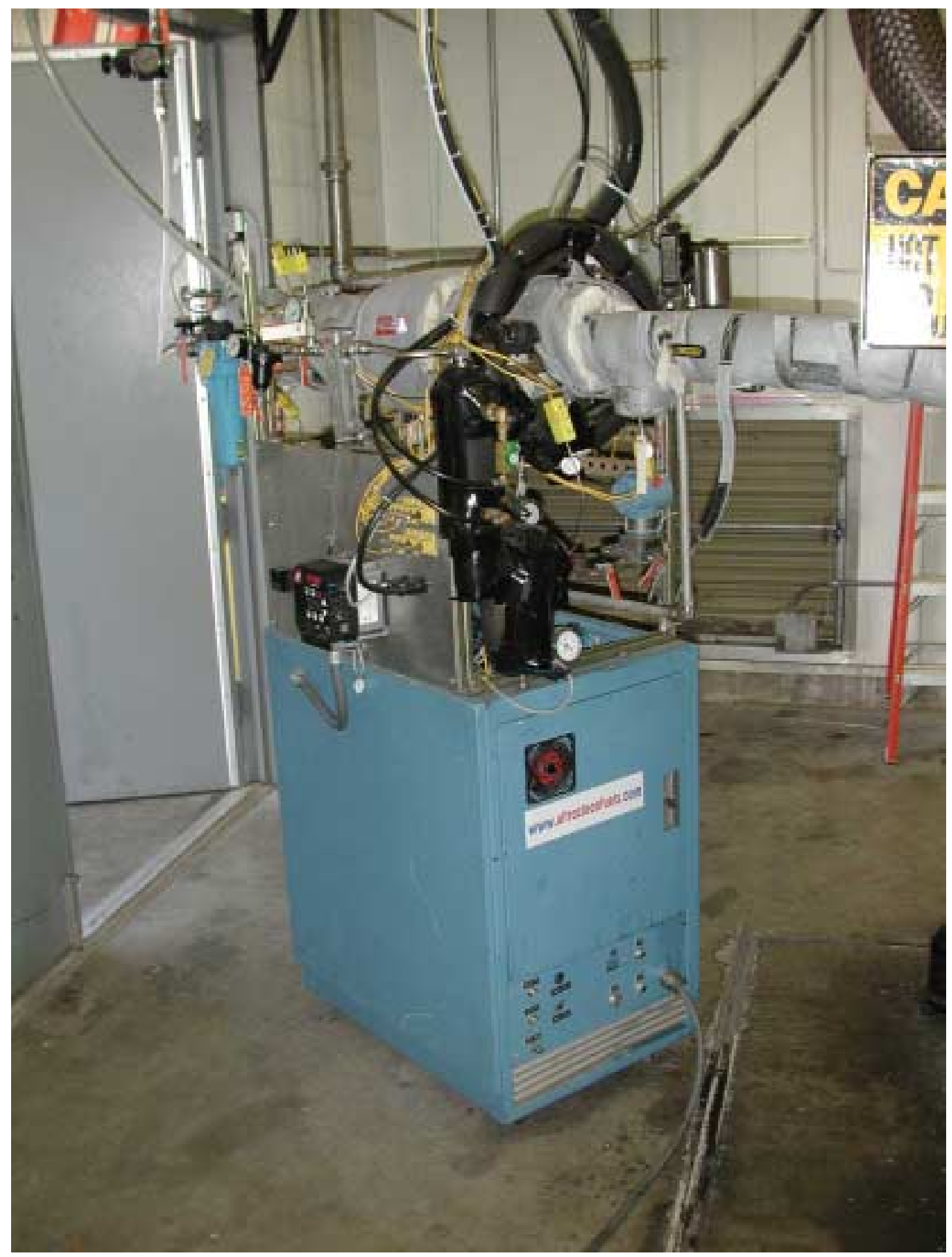

Figure 4-2. Mini-Dilution Tunnel 
dilution ratios of up to $30: 1$. Note that the dilution ratio is defined as ratio of mass flow rates of raw and diluted exhaust. The mass flow rate of exhaust is measured indirectly from the split ratio and the total mass flow rate through the dilution tunnel. The total mass flow rate through the dilution tunnel is measured with a Sierra Series 840 mass flow controller with accuracy of $\pm 1 \%$ of full scale including linearity over $15-25^{\circ} \mathrm{C}$ and 0.3 to $4 \mathrm{~atm}$, and time constant of $600 \mathrm{~ms}, 2$ seconds to within $\pm 2 \%$ of final value with repeatability of $\pm 0.15 \%$ full scale. All flow rates measured by the Sierra mass flow controllers are compensated for temperature and pressure effects and expressed in terms of standard conditions. The mass flow controller is protected by a 0.01 micron Hankison coalescing filter. The filter has the role of preventing potential damage on the mass flow controllers due to excessive particulate matter or water vapor load.

The amount of sampled engine exhaust is then calculated from the dilution ratio. The dilution ratio is determined from levels of $\mathrm{CO}_{2}$ in the tunnel and the sampled engine exhaust. The dilution ratio is defined by

$$
\text { Dilution Ratio }=\left[\frac{\left(\mathrm{CO}_{2_{\mathrm{ex}}}-\mathrm{CO}_{2_{\text {back }}}\right)}{\left(\mathrm{CO}_{2_{\mathrm{tum}}}-\mathrm{CO}_{2_{\text {back }}}\right)}\right]
$$

where the subscripts "ex," "tun" and "back" identify samples taken from the engine exhaust, the dilution tunnel and background respectively. The total engine exhaust mass sampled is then given by:

$$
\text { Total Engine Exhaust Mass Sampled }=\frac{\dot{\mathrm{M}}_{\text {tunnel }}}{\text { Dilution Ratio }}
$$

Constant diluted exhaust flow rates are maintained throughout the experiments. Selected dilution ratios are obtained by adjustments of pump speed and dilution air flow rate. The dry dilution air is filtered and pressure regulated before passing through a counterflow water to air 
heat exchanger to help maintain constant dilution air temperature conditions. The dilution air flow rate is then controlled by a needle valve.

The tunnel was designed to satisfy the major criteria for achieving uniform mixing prior to the $\mathrm{CO}_{2}$ sampling zone and filter. Calculated values of the Reynolds number $\left(\mathrm{Re}=\mathrm{vd}_{\mathrm{l}} / v\right)$ for the different anticipated flow conditions indicate turbulent regime and good mixing. Further, CFD modeling was performed to map the flow fields and the results indicated thorough mixing prior to the $\mathrm{CO}_{2}$ sample probe and filter. A discussion of the modeling effort is presented in Appendix A. The tunnel is heated and well insulated for maintaining constant wall temperature. The inlet to the dilution tunnel consists of a probe constructed from 3/4" (19 mm) stainless steel tubing which is inserted into the engine exhaust flow. The sampled exhaust then flows through a short straight section of 1/4" $(6.3 \mathrm{~mm})$ well insulated stainless steel flexible transfer pipe. The length of the transfer line is maintained as short as possible and walls well insulated to minimize any sample losses, particularly diffusion and thermophoretic deposition to the tube walls. Sharp bends and other restrictions in the transfer line were avoided.

Sample is drawn through the dilution tunnel by a KNF Neuberger twin head diaphragm pump rated at 300 liters per minute free flow. It is certified at less than 0.005 Torr-liter/sec leakrate. Stainless steel is used for all sample wetted system components.

Temperatures of the dilution air at the inlet to the tunnel, sampled engine exhaust, bypass line, pump inlet and filter temperature were continuously monitored. The filter face temperature wsa maintained below $125^{\circ} \mathrm{F}\left(51.7^{\circ} \mathrm{C}\right)$, in accordance with CFR 40, Part 86, Subpart N, 1996. Maximum and minimum filter temperatures were recorded during each sampling period. Fluid temperatures at the mass flow controllers locations were maintained in the range recommended for maximum accuracy of the mass flow controllers. 


\subsection{Exhaust Gas Analysis}

A gas analysis system was designed and fabricated at the NETL facility to measure the concentration of gaseous components in the diluted or raw exhaust gas stream for diesel or other reciprocating engines. The gas analysis system was used to measure concentrations of $\mathrm{CO}_{2}$ in the diluted exhaust and raw engine exhaust for the purpose of calculating the dilution ratio. Total hydrocarbons, $\mathrm{NO}_{\mathrm{x}}$ and $\mathrm{CO}$ concentrations were measured in the raw exhaust. Total Hydrocarbon and $\mathrm{NO}_{\mathrm{x}}$ measurements were originally made in the mini-dilution tunnel. However, an uncertainty analysis revealed that measurement error is greatly reduced if the concentration measurements are made in the raw exhaust (See Appendix C: Uncertainty Analysis Calculations).

Three heated stainless steel probes were inserted into the raw engine exhaust to a depth of 1.5" (38 mm) in a 4" (101 mm) exhaust line. These probes were connected to heated lines which transfer the sampled exhaust. The hydrocarbon line and probe were kept at a wall temperature of $375^{\circ} \mathrm{F} \pm 10^{\circ} \mathrm{F}\left(191^{\circ} \mathrm{C} \pm 5.5^{\circ} \mathrm{C}\right)$ while the other probes and lines were heated to $175^{\circ} \mathrm{F} \pm 10^{\circ} \mathrm{F}\left(79^{\circ} \mathrm{C} \pm 5.5^{\circ} \mathrm{C}\right)$. The temperatures must be kept high in order to prevent water condensation and higher molecular weight hydrocarbon condensation in the THC line.

There was one sample probe in the mini-dilution tunnel which was used solely for $\mathrm{CO}_{2}$ measurement. The exhaust sample passed through heated filters before it was transferred though approximately 30 feet $(9 \mathrm{~m})$ of heated sample line to the gas analysis cabinet.

\subsubsection{Total Hydrocarbon Analysis}

Gases were transferred directly into the heated Horiba FIA-236 flame ionization analyzer. No other conditioning was required since cooling of the gases would result in condensation and loss in sample. The FIA 236 was heated internally to $375^{\circ} \mathrm{F}\left(191^{\circ} \mathrm{C}\right)$ to 
eliminate the potential loss of condensed hydrocarbons. The analyzer employed a burner/sensor where a regulated flow of sample gas entered a flame produced by reactions of a $40 \%$ hydrogen in helium fuel and hydrocarbon free air. The hydrocarbon components of the sample stream underwent a complex ionization that produced electrons and positive ions as given below

$$
\begin{gathered}
\mathrm{CH}+\mathrm{O} \rightarrow \mathrm{CHO}^{+}+\mathrm{e}^{-} \\
\mathrm{CHO}^{+}+\mathrm{H}_{2} \mathrm{O} \rightarrow \mathrm{H}_{3} \mathrm{O}^{+}+\mathrm{CO} \\
\mathrm{H}_{3} \mathrm{O}^{+}+\mathrm{e}^{+} \rightarrow \mathrm{H}_{2} \mathrm{O}+\mathrm{H}
\end{gathered}
$$

Polarized electrodes then collect the ions that are produced, causing current to flow through the associated electronic measuring circuitry. The current flow was proportional to the carbon atom concentration. The model FIA-236 measured in set ranges from $10 \mathrm{ppm}$ up to 30,000 ppm, with a $\mathrm{T}_{90}$ of 1.5 seconds. Sensitivity was $0.5 \%$ of full scale on each range while repeatability and linearity were both less than $1 \%$ full scale. Zero span drift was less than $1 \%$ full scale per eight hours. The analog output was 0 -5 VDC non-isolated (Horiba FIA-236 Flame Ionization Instruction Manual, March 1997).

\subsection{2 $\mathrm{NO}_{\mathrm{x}}$ Analysis}

Prior to entering the $\mathrm{NO}_{\mathrm{x}}$ analyzer, significant sample conditioning is required to obtain an accurate and repeatable $\mathrm{NO}_{\mathrm{x}}$ measurement. As mentioned above, all sample lines prior to the water condenser must be heated to above the dew point of the sample gases. All of the $\mathrm{NO}_{\mathrm{x}}$ lines are heated to $175^{\circ} \mathrm{F} \pm 10^{\circ} \mathrm{F}\left(79^{\circ} \mathrm{C} \pm 5.5^{\circ} \mathrm{C}\right)$ which is greater than the dewpoint of the raw exhaust. 
After traveling the length of the sample line the sample gases first pass through a Horiba Model COM11, $\mathrm{NO}_{2}$ to $\mathrm{NO}$ convertor. It is important to convert the $\mathrm{NO}_{2}$ to $\mathrm{NO}$ before the water condenser. Tidona et al., (1988), report that a substantial amount of $\mathrm{NO}_{2}$ is absorbed by water. In their experiments an average of $26.4 \%$ of the $\mathrm{NO}_{2}$ was removed via two bubblers in an ice bath. After exiting the $\mathrm{NO}_{2}$ to $\mathrm{NO}$ convertor, the sample travels a very short distance to the water condenser. Hilliard and Wheeler (1977), determined that type 316 stainless steel tubing typically used in sample tubes or sample probes, is extremely active in the $\mathrm{NO}$ to $\mathrm{NO}_{2}$ oxidation reaction at a temperature of $470^{\circ} \mathrm{C}$. The presence of $\mathrm{CO}$ competes for these active catalytic centers and therefore inhibits the production of $\mathrm{NO}_{2}$, but the effect is negligible below $\mathrm{CO}$ concentrations of $1000 \mathrm{ppm}$. CO is often expected in concentrations less than $1000 \mathrm{ppm}$, therefore a short sample line is preferred between the $\mathrm{NO}_{2}$ to $\mathrm{NO}$ converter and the water condenser just to minimize any possible oxidation catalysis reactions. The water condenser used in this study was a Baldwin Model 8210 sample conditioner designed to remove water from the sample stream. This unit is rated to remove less than $10 \%$ of any remaining $\mathrm{NO}_{2}$ from the sample stream while removing greater than $98 \%$ of the moisture during the condensation process. After moisture removal, the sample enters the $\mathrm{NO}_{\mathrm{x}}$ analyzer.

It is important to note the significance of removing moisture from the sample stream prior to chemiluminescence analysis. Matthews et al., (1977) report that in typical automobile exhaust, the chemiluminescent type analyzers may indicate $\mathrm{NO}_{\mathrm{x}}$ concentrations up to $30 \%$ lower due to third body quenching effects primarily due to $\mathrm{H}_{2} \mathrm{O} \cdot \mathrm{CO}_{2}$ was also found to have a strong positive effect, while $\mathrm{CO}$ and Argon had small negative effects. Conversion of other nitrogenous species such as $\mathrm{NH}_{3}, \mathrm{CH}_{3} \mathrm{NH}_{2}$, and $\mathrm{HCN}$ was also reported to be significant. Fortunately, the other nitrogenous species are present in very low concentrations in typical diesel or spark ignited 
engine exhaust. $\mathrm{N}_{2}$ and $\mathrm{N}_{2} \mathrm{O}$ were also investigated but their quenching was very inefficient. Tidona et al. (1988), carried this type of study further. They measured the effects of various third body quenching efficiencies and from first order curve fits, they attempted to predict relative indicated NO concentrations versus actual concentrations. They reported that actual NO to indicated NO concentrations were as much as $41 \%$ greater for stoichiometric methane/air mixtures. These values are about 7.6\% greater than those of Matthews et al., (1977). The difference is due primarily to the difference in the $\mathrm{H}_{2} \mathrm{O}$ correction.

Zabielski et al., (1984) investigated the effects of the transport properties of the carrier gases along with kinetic quenching effects. They noted that when a chemiluminescent analyzer is spanned with calibration gas with a known concentration of $\mathrm{NO}$ and $\mathrm{N}_{2}$, it is usually assumed that the sample gas will have similar quenching and transport properties. This assumption is generally invalid. They further concluded that transport effects are important for major species and offered calculation techniques to try to account for the transport effects. Note that "transport effects" here implies changes to actual chamber pressures or flowrate of species through capillaries due to differing transport properties between the carrier gases of the span gas and sample gases.

Fortunately, water has been identified as having an overwhelming third body quenching effect but can be removed via appropriate conditioning. However, there are other effects to consider such as chemiluminescence from other species. Tidona et al., (1988), also investigated this interference phenomenon and concluded that the effect of $\mathrm{CO}$ chemiluminescence is important for concentrations of about 5 - 10\%. Since CO has far higher propensity for chemiluminescence of any of the higher concentration background gases, chemiluminescent interference should not be a problem for this study (Tidona, et al., 1988). 
Careful monitoring of the chamber pressure is important in this study. Tidona et al., (1988) also carried out experiments with $\mathrm{NO}$ in $\mathrm{N}_{2}$ and Ar to investigate the effect of chamber pressure. The indicated concentration was determined to be approximately inversely proportional to the reaction chamber pressure. It is therefore important to monitor and control the reaction chamber pressure. This is accomplished by using a needle valve at the outlet of the analyzer upstream of the vacuum pump in this study.

The ThermoEnvironmental Model 42C operation is based upon the concept that nitric oxide (NO) and ozone $\left(\mathrm{O}_{3}\right)$ react to produce a characteristic luminescence with an intensity linearly proportional to the NO concentration. Infrared light emission results when electronically excited $\mathrm{NO}_{2}$ molecules decay to lower energy states. Specifically,

$$
\begin{gathered}
\mathrm{NO}+\mathrm{O}_{3} \rightarrow \mathrm{NO} *_{2}+\mathrm{O}_{2} \\
\mathrm{NO} *_{2} \rightarrow \mathrm{NO}_{2}+\mathrm{hv} \\
\mathrm{NO} *_{2}+\mathrm{M} \rightarrow \mathrm{NO}_{2}+\mathrm{M}
\end{gathered}
$$

In Equation 4-6, ozone reacts with nitric oxide to produce electronically excited nitrogen dioxide. This $\mathrm{NO}_{2}$ * can reach equilibrium either through photoemission (Equation 4-7) or by collisional energy transfer (Equation 4-8). The intensity of the photoemission is given by:

$$
I=\frac{k_{1} k_{2}[N O]\left[O_{3}\right]}{k_{2}+\sum k_{3 M}[M]}
$$


where $\mathrm{k}_{3 \mathrm{M}}$ is a function of the specific third body. Because chemiluminescence analyzers measure this intensity, it is advantageous to decrease the probability of collisional de-excitation. This is conventionally accomplished by operation at sub-atmospheric pressures, typically less than $10 \mathrm{~mm}$ of $\mathrm{Hg}$. Since $\mathrm{k}_{3}$ is a function of the third body, $\mathrm{M}$, the chemical composition of the carrier gas also effects the measured intensity (Matthews et al., 1977).

Nitrogen dioxide must first be transformed into NO before it can be measured using the chemiluminescent reaction. $\mathrm{NO}_{2}$ is converted to $\mathrm{NO}$ (Equation 4-6) by a stainless steel $\mathrm{NO}_{2}$ to $\mathrm{NO}$ converter heated to about $635^{\circ} \mathrm{C}$.

The sample is then drawn into the analyzer through a particulate filter, a capillary, and then to the mode selection valve. The valve routes the sample either directly to the reaction chamber when the unit is operating in the $\mathrm{NO}$ mode or to the $\mathrm{NO}_{2}$ to $\mathrm{NO}$ converter and then to the reaction chamber when the analyzer is in the $\mathrm{NO}_{\mathrm{x}}$ mode. $\mathrm{The}_{\mathrm{NO}}$ mode was used in this study.

Dry filtered air enters the analyzer through a flow sensor and then through a silent discharge ozonator which generates ozone for the chemiluminescent reaction. A photomultiplier tube (PMT) housed in a thermoelectric cooler detects the $\mathrm{NO}_{2}$ chemiluminescence (ThermoEnvironmental Model 42C Instruction Manual, 1995). The detector operates in pre-set ranges from $10 \mathrm{ppm}$ up to $5,000 \mathrm{ppm}$. Response time $\left(\mathrm{T}_{90}\right)$ is 5 seconds. Repeatability and linearity are both less than $1 \%$ full scale. Zero drift is less than 0.05 ppm in 24 hours. Span drift is less than $1 \%$ full scale per 24 hours. The analog output is $4-20 \mathrm{~mA}$.

\subsection{3 $\mathrm{CO}, \mathrm{CO}_{2}$ and $\mathrm{O}_{2}$ analysis}

After traveling through a heated filter and heated sample line, sample gases enter a Baldwin Environmental Model 20410 thermoelectric sample gas conditioner. Thermoelectric 
cooling or the "Peltier Effect" is a solid-state method of transferring heat from one ceramic surface to another using dissimilar semiconductor materials. These dissimilar ceramics act like the vapor and liquid phases of conventional refrigerants. The cold junction becomes cold through absorption of heat energy by the electrons as they pass from one semiconductor to another. The compressor is replaced by a DC power source which pumps the electrons from one semiconductor to another. A heat sink replaces the conventional condenser fins. The model 20410 lowers the sample dew point to $+5^{\circ} \mathrm{C}\left(41^{\circ} \mathrm{F}\right)$. It should be noted that the moisture concentration in the sample gases can range from $1 \%$ up to $10 \%$ for diesel operation with FT fuel. A dew point of $41^{\circ} \mathrm{F}$ represents a moisture concentration of approximately $0.1 \%$ by mass. Particulate matter that may have made it through the upstream heated filter was removed by a Baldwin sample prefilter located downstream from the cooler. The sample thus conditioned, was directed to the gas analyzers. The conditioner was designed for a maximum flowrate of 20 liters per minute (lpm) which is over twice the necessary capacity. The reported soluble gas removal rates as percent of inlet gas concentration are $\mathrm{NO}: 0 \%$ loss, $\mathrm{NO}_{2}:<2 \%$ loss, $\mathrm{CO}: 0 \%$ loss, and $\mathrm{CO}_{2}:<1 \%$ loss.

There are two $\mathrm{CO}$ analyzers, two $\mathrm{CO}_{2}$ analyzers and one $\mathrm{O}_{2}$ analyzer in the analyzer bay. The $\mathrm{CO}$ and $\mathrm{CO}_{2}$ analyzers are Horiba Model VIA-510 infrared units. They are based on infrared absorption of the measured component. By determining the amount of attenuation of infrared beam, the component concentration can be determined. The infrared radiation from a light source is passed through a rotating chopper and into the detection cell. Infrared radiation is absorbed as it passes through the sample. The light then impacts a detection cell which vibrates thereby generating an electric current. The current is amplified and provided as a $4-20 \mathrm{~mA}$ analog output. The light is also filtered allowing only the frequencies corresponding to the 
measured component gas to pass. The Horiba VIA-510 has a reproducibility of $\pm 0.5 \%$ of fullscale and a zero and span drift of $\pm 1.0 \%$ of full-scale per 24 hours.

Oxygen concentration was measured by a Illinois Instruments Model 6000 Precision Oxygen Analyzer. Its measurement is based on an electrochemical reaction between $\mathrm{O}_{2}$ and zirconia. When heated to a temperature of about $650^{\circ} \mathrm{C}\left(1200^{\circ} \mathrm{F}\right)$, the zirconia produces a logarithmic output voltage signal related to the concentration of oxygen in the sample gas. The output signal is conditioned and amplified to provide sensitivity from $0.01 \%$ to $100 \%$. The reported accuracy is $<1 \%$ of measured value with $0.2 \%$ repeatability of the measured value.

\subsubsection{Checkout and Calibration}

All gas analyzers were calibrated with seven to nine-point calibration curves generated using least squares regression in accordance with the requirements of CFR 40, part 86, subpart N. This was accomplished by feeding a span gas through a Peus Systems Model PGD 15/63 63step gas divider with $\pm 0.4 \%$ accuracy and \pm 0.4 repeatability of the span step. All calibration gases are NIST traceable with analytical uncertainty of less than $\pm 1.0 \%$.

Also, the conversion efficiency of the $\mathrm{NO}_{2}$ to $\mathrm{NO}$ convertors in the in-line convertor and the internal converter on the ThermoEnvironmental Model $42 \mathrm{C} \mathrm{NO}_{\mathrm{x}}$ analyzer was verified in accordance with CFR 40, Part 86, Subpart N using a ThermoEnvironmental Model 100B $\mathrm{NO}_{\mathrm{x}}$ generator.

Leak checks on all analytical lines were performed in accordance with NETL engine research laboratory leak check procedures.

\subsection{High Speed Data Acquisition and Combustion Analysis Equipment and Procedure}

The technique of using cylinder pressure information for investigating combustion processes in internal combustion engines has been in use for decades. It is an effective method 
to track the combustion process on a cycle resolved basis. Not only are robust, rapid response piezo-electric pressure transducers required, but high-speed digital data acquisition systems, triggered by a crankshaft mounted incremental encoders are also required.

This study employs the use of a multiple channel indicating system for recording cylinder pressure, fuel line pressure and needle lift all in relation to crank angle. Data is recorded at an overall throughput rate of up to $1 \mathrm{MHz}$. The indicating system, sensors and software are manufactured by AVL North America, Inc.

An AVL GU21D uncooled gallium orthophosphate $\left(\mathrm{GaPO}_{4}\right)$ piezoelectric pressure transducer was used for in-cylinder pressure measurement. $\mathrm{GaPO}_{4}$ was chosen for its thermal stability at high temperatures. An AVL 3066 piezo amplifier was used to condition the output of the GU21D. The amplifier employed integral drift compensation with an accuracy of $< \pm 0.1 \%$ and linearity of $< \pm 0.01 \%$ full scale output. Gain error (accuracy) is $< \pm 0.1 \%$ full scale output. The piezoelectric transducer was ranged at 200 bar with a linearity of $< \pm 0.3 \%$ full scale output. Its thermal sensitivity shift in the $200^{\circ} \mathrm{C}$ to $300^{\circ} \mathrm{C}$ range is $< \pm 0.5 \%$. Its cyclic temperature drift and IMEP stability over a 10 hour test period is less than \pm 0.4 bar and $2 \%$ respectively.

Fuel line pressure was measured with an AVL 31DP2000 strain gage pressure transducer ranged at 0 to 2000 bar. It has a combined non-linearity and hysteresis of $<0.5 \%$. The signal was conditioned by a AVL 3009 multi-purpose amplifier. The amplifier has a gain error of < $\pm 0.8 \%$ max. and a linearity of $< \pm 0.01 \%$ max. Zero point drift is typically less than $0.8 \mu \mathrm{V} /{ }^{\circ} \mathrm{C}$.

Needle lift was measured using an inductive measurement transducer in a half-bridge connection scaled at 10 volts per millimeter of needle lift displacement. An AVL 3076 carrier half-bridge frequency amplifier is used to condition the inductive signal. It has an adjustable 
sensitivity a linearity of $\pm 0.5 \%$ of maximum amplitude. Zero drift is less than $0.001 \% /{ }^{\circ} \mathrm{C}$ of maximum amplitude.

Engine speed and crank angle $\left({ }^{\circ} \mathrm{CA}\right)$ positions were measured using an AVL 364C highprecision optical encoder mounted on the crankshaft end. The angle information is transmitted by light pulses from the encoder through an optical cable to a light-to-current converter. The signal was then conditioned and sent to the data acquisition system. Crank angle measurement was selectable down to $0.05^{\circ} \mathrm{CA}$. The uncertainty, over in the range of speeds employed in this study, was less than $\pm 0.02^{\circ} \mathrm{CA}$.

Top dead center determination is of critical importance for thermodynamic calculations based on pressure in internal combustion engines. Brundt and Emtage (1996), report extremely high sensitivity of the indicated mean effective pressure (IMEP) calculation to crank angle phasing. An error of up to $10 \%$ per degree was reported. An AVL 428 TDC sensor unit was used for dynamic TDC measurement with $< \pm 0.1^{\circ} \mathrm{CA}$ error. The system employs a capacitance sensor inserted into the injector bore and connected to the data acquisition system. The engine is motored and the TDC is recorded. Static determination of top dead center was performed and found to be in good agreement with the dynamic measurement from the AVL 428 TDC sensor unit.

Combustion analysis was supported by an AVL software package called "IndiWin." IndiWin uses the cylinder pressure, fuel line pressure and needle lift to determine maximum cylinder pressure (bar) and its location $\left({ }^{\circ} \mathrm{CA}\right)$, maximum rate of pressure rise (bar/deg) and its location $\left({ }^{\circ} \mathrm{CA}\right)$, maximum fuel line pressure (bar) and it's location $\left({ }^{\circ} \mathrm{CA}\right)$, needle lift location and duration. It calculates thermodynamic values based on heart release using a simplified first law analysis and employing a constant polytropic coefficient as recommended by Randolph, 1990. 
Surface heat transfer losses are neglected, hence the displayed values are accordingly lower than the actual heat released. The heat lost through the system boundary is significant near the end of combustion when temperatures are highest. Studies have shown that the energy lost due to heat transfer doesn't significantly affect the ignition delay parameter (Heywood, 1988; Brundt and Emtage, 1997). However, errors in heat transfer calculation can influence the absolute values of these parameters. These errors are minimized when comparing fuels at known operating conditions in the same engine.

The heat release calculation is based on the first law of thermodynamics and is given by:

$$
Q_{i}=\frac{C}{\kappa-1}\left[\kappa p_{i}\left(V_{i+n}-V_{i-n}\right)+V_{i}\left(p_{i+n}-p_{i-n}\right)\right]
$$

where, $\mathrm{n}$ is the interval measurement, $\mathrm{\kappa}$ is the polytropic coefficient (related to the ratio of specific heats, $\mathrm{k}$ ), $\mathrm{p}$ is the cylinder pressure and $\mathrm{V}$ is the cylinder volume.

Pressure correction was made by calculating a pressure offset, $\mathrm{P}_{\text {off }}$ from the following equation.

$$
P_{\text {off }}=P_{1}-\frac{\left(P_{2}-P_{1}\right)}{\left[\left(\frac{V_{1}}{V_{2}}\right)^{k}-1\right]}
$$

Suffices 1 and 2 refer to two crank angle locations in the compression stroke and $\mathrm{n}$ is the assumed polytropic index. The earliest crank angle must always be after intake valve closing (IVC) and the latest crank angle must be before ignition, hence values of $100^{\circ}$ and $65^{\circ} \mathrm{BTDC}$ are recommended by AVL. In addition, to reduce the sensitivity to noise and ADC resolution effects, the pressure offset is normally calculated over a number of crank angle intervals and the 
average value used. The pressure offset or referenced pressure, $\mathrm{P}_{\text {off }}$, is then subtracted from all of the cycle pressure values to achieve the absolute pressure, that is, the whole cycle pressure data displaced by $\mathrm{P}_{\text {off }}$. However, one disadvantage is that some index has to be specified. This approach is in concert with information and recommendations by Randolf (1990), and Brundt and Pond (1997). The polytropic index is defined by the equation

$$
\mathrm{p} \mathrm{V}^{\mathrm{k}}=\mathrm{C}
$$

Where $\mathrm{p}$ and $\mathrm{v}$ are cylinder pressure and volume respectively. The polytropic index ( $\kappa)$ is related to the ratio of specific heats and the rate of heat transfer between the cylinder charge and walls. Brundt and Emtage (1996), reported that although the polytropic index reduces slightly during the compression stroke due to reducing $\mathrm{k}$ and heat transfer effects, it is common to assume a constant value. AVL recommends a polytropic coefficient of 1.37 .

Based on the work of Lancaster et al., (1975) and Brundt and Pond (1997), the following measurement parameters (Table 4-1) were chosen.

Table 4-1. Measurement or Calculation Intervals

\begin{tabular}{|l|l|}
\hline \multicolumn{1}{|c|}{ Measurement Type } & \multicolumn{1}{c|}{ Measurement or Calculation Interval } \\
\hline Needle Lift & $0.5^{\circ} \mathrm{CA}$ resolution from $-30^{\circ} \mathrm{CA}$ to $+30^{\circ} \mathrm{CA}$ \\
\hline Fuel Line Pressure & $0.5^{\circ} \mathrm{CA}$ resolution from $-30^{\circ} \mathrm{CA}$ to $+30^{\circ} \mathrm{CA}$ \\
\hline Maximum Cylinder Pressure and Location & $0.5^{\circ} \mathrm{CA}$ resolution from $-30^{\circ} \mathrm{CA}$ to $+30^{\circ} \mathrm{CA}$ \\
\hline $\begin{array}{l}\text { Maximum Cylinder Pressure Rise Rate } \\
\text { and Location }\end{array}$ & $0.5^{\circ} \mathrm{CA}$ resolution from $-30^{\circ} \mathrm{CA}$ to $+30^{\circ} \mathrm{CA}$ \\
\hline IMEP & $1.0^{\circ} \mathrm{CA}$ resolution from $-360^{\circ} \mathrm{CA}$ to $+360^{\circ} \mathrm{CA}$ \\
\hline Crank Angle Resolution & $\begin{array}{l}0.1^{\circ} \mathrm{CA}(1800 \text { pulses, both edges, } 2 \text { triggers per } \\
\text { cycle })\end{array}$ \\
\hline Heat Release & $1.0^{\circ} \mathrm{CA}$ resolution from $-30^{\circ}$ to $+90^{\circ} \mathrm{CA}$ \\
\hline Burn Duration & $1.0^{\circ} \mathrm{CA}$ resolution from $-30^{\circ}$ to $+90^{\circ} \mathrm{CA}$ \\
\hline
\end{tabular}


Brundt and Pond (1997), considered 100 cycle averaging and $1{ }^{\circ} \mathrm{CA}$ resolution as being adequate for burn duration analysis. Brundt and Emtage (1996), found IMEP variance only slightly dependent on CA resolution. For this study, cycle averaging of 100 cycles and $0.5^{\circ} \mathrm{CA}$ resolution is employed.

Further filtering of cylinder pressure data is required for accurate combustion analysis as rapid changes in pressure (dp) resulting from signal noise and in-cylinder acoustical resonance are highly amplified in the resulting heat release calculations. This "corruption" of the heat release data may be easily understood by examining Equation 3-21 in Section 3.4.3.1. Pressure signal conditioning is accomplished using a low-pass digital filter as recommended by Theobald and Alkidas (1987). Their work looked at a suite of cylinder pressure data from a direct injected single cylinder diesel engine with simulated turbocharger conditions. They found that spline filtering was ineffective in removing combustion-generated ripples in the pressure data and in addition, important details of the combustion history were altered. They found that digital lowpass filtering was highly effective in removing ripples in the pressure data and at making the heat-release history recognizable. However, while many of the thermodynamic variables such as IMEP were not altered by the filtering, the value of the peak rate of the heat release during the premixed combustion phase could in many cases be reduced significantly in comparison to the unfiltered data.

The simple digital low-pass filter provided by AVL's Concerto software was used for signal conditioning in the present study. It's inputs were the cutoff frequency $\left(f_{c}\right)$ and calculation resolution (n), (measured in $\left.{ }^{\circ} \mathrm{CA}\right)$. The digital low-pass filter is of the type given in Equation 4-13. 


$$
c(j)=\frac{\sin \left(2 \pi \frac{f c}{f s} j\right)}{\pi \cdot j}
$$

In order to somewhat optimize the signal conditioning process, both filtered and unfiltered data at key states 3, 4, and 7 were compared. Key states 3, 4 and 7 represent the most noisy data at the engine speeds of 16, 24 and 36 revolutions per second, respectively. Calulation resolutions from 0.3 to $0.9{ }^{\circ} \mathrm{CA}$ were compared at cutoff frequencies from $2000 \mathrm{~Hz}$ to $5000 \mathrm{~Hz}$. The parameters that were considered were the change in peak heat release rates in both the premixed and the difusion control burn phases, the decrease in amplitude between the maximum and minimum pressure occilations in the pre-combustion portion of the heat release curve and the amount of decrease in slope approaching the peak of the diffusion controlled burn phase heat release peak. Low reductions of heat release rate peaks and high reductions in noise amplitude and slope were valued. More weight was given to reduction in premixed peak than to the other factors. The level of detail used in this analysis is deemed acceptable due to the fact that the combustion analysis used in this study is a comparison of the combustion of two fuel types. The difference in signal noise was not significant between fuel types. Therefore, when comparing within engine operating conditions the chosen method was certainly adequate. A more detailed analysis considering spectral analysis may be considered for future applications.

After considering a suite of pressure data representing the range of timing conditions the digital low pass filter parameters were chosen and are given in table 4-2 below. 
Table 4-2. Digital Low-pass Filter Parameters

\begin{tabular}{|c|c|c|}
\hline Engine Speed & Resolution $\left({ }^{\circ} \mathbf{C A}\right)$ & Cutoff Frequency $(\mathbf{H z})$ \\
\hline 16 & 0.3 & 2500 \\
\hline 24 & 0.5 & 3500 \\
\hline 36 & 0.9 & 2500 \\
\hline
\end{tabular}

\subsection{Low Speed Data Acquisition}

Where convenient, calculated values were derived using the Microsoft Excel spreadsheet. However, because time average values were required for measuring PM emissions in the dilution tunnel, most calculations are done using Paragon TNT. This allowed the use of counter/timer/ reset blocks within Paragon which were used to initialize and integrate key values over the duration of the sample, while still locking minimum and maximum values.

Paragon TNT employs an architecture, which partitions program functions into multiple servers and multiple clients. This allows TNT's client and server subsystems to function independently or in combination. Paragon TNT also provides open links to third party software such as relational databases, spreadsheets and statistical analysis packages through dynamic data exchange (DDE). From the viewpoint of other Paragon TNT subsystems, the DDE subsystem is considered a "client;" however, from the viewpoint of a third party package, it is a "server." This means that any third party system such as MS Excel can initiate a conversation with the DDE subsystem and then perform data exchange in real time. Hence, the Excel spreadsheet is used as the "final line" for low-speed data acquisition. Listed below are data acquisition features inputted into Paragon TNT or Excel for data analysis and documentation purposes. These numbers are reported in the test summary log and most are calculated values. Descriptions of 
the calculation methods are not included in this section for the sake of brevity. A detailed description of the calculation method is given in Appendix B: Engine Low-Speed Data Aquisition and Control Procedures. The list of data either derived or reported as part of the lowspeed data acquisition system is numerous and rather detailed. The reader is also referred to Appendix B for the data reported as part of the low-speed data acquisition system.

\subsection{The Micro-orifice Uniform Deposition Impactor (MOUDI)}

The MOUDI is an inertial 10-stage impactor with each stage or "substrate" collecting particle matter with cutoff diameters as given below in Table 4-3. At each stage, jets of particle laden gas pass through nozzles accelerating the particles toward the down stream substrate stage. Particles larger than the cut size of the stage cross the air streamlines and are collected on the impaction substrate. The smaller particles with less inertia do not cross the streamlines (i.e., follow the gas flow) and proceed onto the next stage where the nozzles are smaller, the velocity through the nozzles are higher, and a smaller cut size of particles are collected. This is continued through the MOUDI until the smallest particles are finally collected at the afterfilter. A picture of the assembled MOUDI is given in Figure 4-3.

The substrates are greased "light," "medium," or "heavy." This nomenclature refers to the amount of grease applied to the substrate and not to the viscosity or density of the grease. Stages 0,1 , and 2 are coated with a thicker (heavy) grease with nominal grease mass between 5.0 and $6.0 \mathrm{mg}$. Stages 4, 5, and 6 are greased to approximately $3 \mathrm{mg}$ (medium) and stages 7 through $10 \mathrm{~m}$ are greased at approximately $1.5 \mathrm{mg}$ each (light). The grease (dimethlpolysiloxane, GE product VISC-100M)) was checked for mutagenicity by first applying a known amount of grease on a substrate medium, then extracting the grease using the standard soxhlet process followed by 


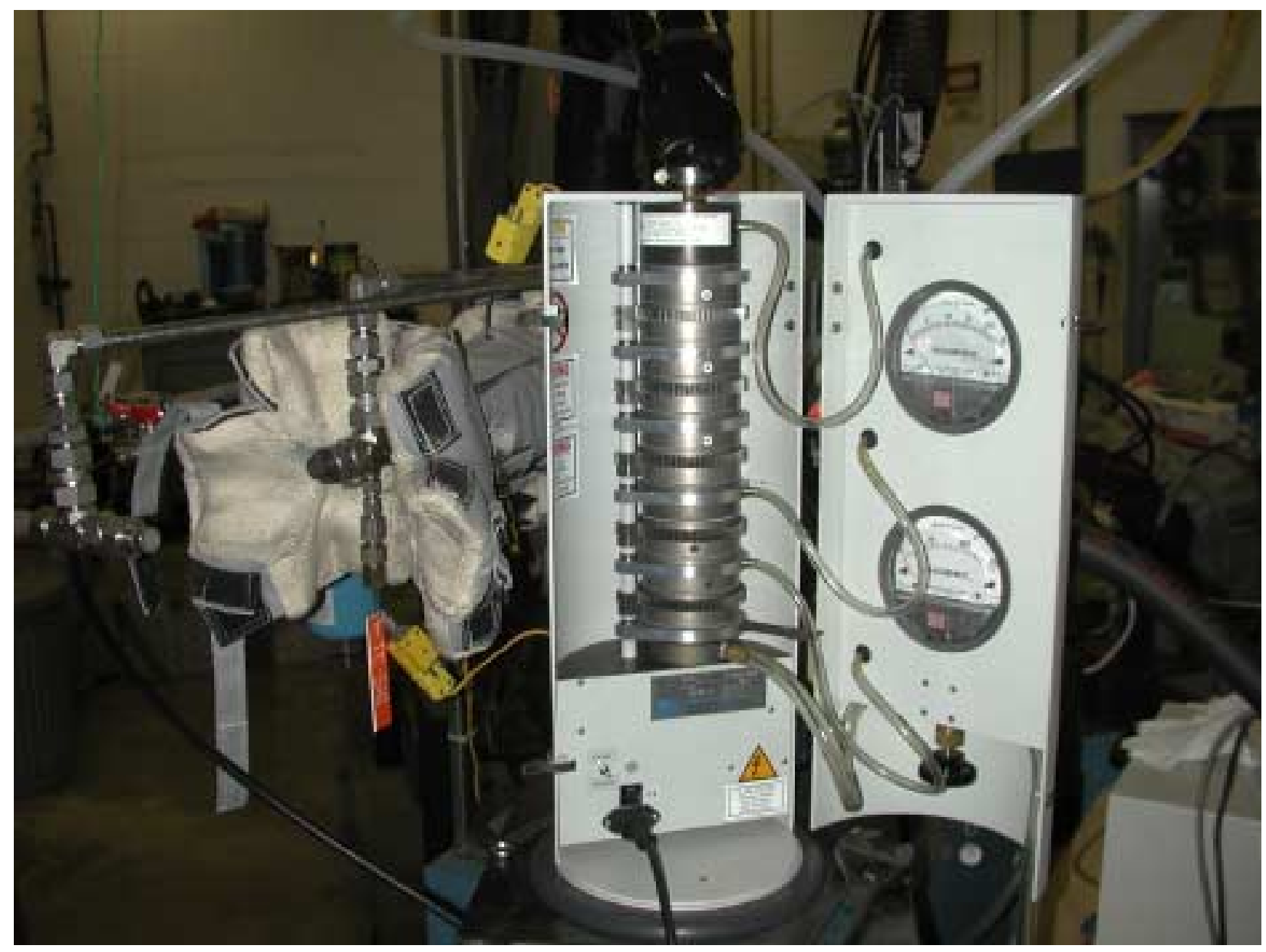

Figure 4-3. Microorifice Uniform Deposition Impactor (MOUDI)

the Ames bioassay. The results indicated no mutagenic activity (activity was no higher than the background level). This result allowed us to use the greased substrates in lieu of ungreased substrates to ensure high particle capture efficiency with no "particle bounce" (Cheng and Yeh, 1979).

In this study, the measured mass size distributions obtained on the MOUDI substrates were expressed in a $\log$-normal form $\mathrm{dM} / \mathrm{d}(\log \mathrm{D})$. The mass distribution is then fitted to a bimodal distribution, via the method of $\mathrm{Xu}$ et al., (2002), with each mode being log-normal as given by: 


$$
\frac{d M}{d(\log D)}=\sum_{j=1}^{n} \frac{M_{j}}{\log \sigma_{j} \sqrt{2 \pi}} \exp \left[\frac{\left(\log D-\log M M A D_{j}\right)^{2}}{-2 \log ^{2} \sigma_{j}}\right]
$$

Where $\mathrm{D}$ is the aerodynamic particle diameter, $\mathrm{M}_{\mathrm{j}}$ is the mass fraction of particles for mode $\mathrm{j}$ (substrate $\mathrm{j}$ ), MMADj is the mass median aerodynamic diameter of the distribution and $\sigma_{\mathrm{j}}$ is the distribution's geometric standard deviation.

A 30 liter/min sample is drawn through the MOUDI during sampling of the exhaust gases extracted from the mini-dilution tunnel. The MOUDI was calibrated at a flow rate of 30 liter/min by the manufacturer prior to testing. The "as calibrated cut points" values given in Table 4-3 were determined during the manufacturer's calibration using the same 30 liter/min MOUDI flow rate. Operation, assembly and disassembly, and preparation of the impactor/ rotator column is performed in accordance to the procedures outlined in Marple et al., (1991).

Table 4-3. MOUDI Design and Operation Parameters

\begin{tabular}{|c|c|c|c|c|c|c|c|}
\hline Stage & $\begin{array}{c}{ }^{\text {a}} \text { Nominal } \\
\text { Cut-Point } \\
(\mu \mathrm{m})\end{array}$ & $\begin{array}{c}{ }^{\text {a Calibrated }} \\
\text { Cut-Point } \\
(\mu \mathrm{m})\end{array}$ & $\begin{array}{c}\text { Nozzle } \\
\text { Diameter } \\
(\mathbf{c m})\end{array}$ & $\begin{array}{c}\text { Number } \\
\text { of } \\
\text { Nozzles }\end{array}$ & $\begin{array}{c}{ }^{\mathrm{b}} \mathrm{S} / \mathrm{W} \\
\mathbf{W}=\text { nozzle } \\
\text { diameter }\end{array}$ & ${ }^{\mathbf{c}} \mathbf{P} / \mathbf{P}_{\mathrm{o}}$ & $\begin{array}{c}\text { Nozzle } \\
\text { Reynolds } \\
\text { No. }\end{array}$ \\
\hline Inlet & 18 & 18 & 1.71 & 1 & 0.75 & 1.00 & 2420 \\
\hline 1 & 10.0 & 9.9 & 0.889 & 3 & 0.5 & 1.00 & 1560 \\
\hline 2 & 5.6 & 6.2 & 0.380 & 10 & 1.0 & 1.00 & 1090 \\
\hline 3 & 3.2 & 3.1 & 0.247 & 10 & 1.0 & 1.00 & 1680 \\
\hline 4 & 1.8 & 1.8 & 0.137 & 20 & 1.0 & 1.00 & 1510 \\
\hline 5 & 1.0 & 1.0 & 0.072 & 40 & 1.0 & 0.99 & 1440 \\
\hline 6 & 0.56 & 0.56 & 0.040 & 80 & 1.5 & 0.97 & 1340 \\
\hline 7 & 0.32 & 0.35 & 0.0140 & 900 & 4.1 & 0.95 & 350 \\
\hline 8 & 0.18 & 0.20 & 0.0090 & 900 & 6.4 & 0.89 & 580 \\
\hline 9 & 0.10 & 0.092 & 0.0055 & 2000 & 10.6 & 0.76 & 500 \\
\hline 10 & 0.056 & 0.05 & 0.0052 & 2000 & 11.1 & 0.53 & 750 \\
\hline
\end{tabular}




\subsection{Uncertainty Analysis}

The objective of uncertainty analysis or "error analysis" discussed in this section, is to examine the experimental uncertainty in the particulate matter mass emissions rates from the Ricardo Proteous engine and to assess the contribution of individual measurement uncertainties to the final brake specific mass emissions in $\mathrm{g} / \mathrm{hp}-\mathrm{hr}$ units. The results of this analysis were initially used as a design tool, first to screen three different configurations for the dilution tunnel design, and second, to investigate sensitivity to various component measurements. A spreadsheet program was written, allowing easy variation of parameters and easy graphical representation of sensitivities.

Uncertainty determination was approached by considering a calculated or measured

$$
\mathrm{N}=\mathrm{f}\left(\mathrm{u}_{1}, \mathrm{u}_{2}, \mathrm{u}_{3}, \ldots \mathrm{u}_{\mathrm{n}}\right)
$$

quantity $\mathrm{N}$, where $\mathrm{N}$ is a function of known independent variables.

The absolute error is given by:

$$
\mathrm{E}_{\mathrm{a}}=\Delta \mathrm{N}=\left|\Delta \mathrm{u}_{1} \frac{\partial \mathrm{f}}{\partial_{\mathrm{u}_{1}}}\right|+\left|\Delta \mathrm{u}_{2} \frac{\partial \mathrm{f}}{\partial_{\mathrm{u}_{2}}}\right|+\ldots+\left|\Delta \mathrm{u}_{\mathrm{n}} \frac{\partial \mathrm{f}}{\partial_{\mathrm{u}_{\mathrm{n}}}}\right|
$$

The measurement errors $\left(\Delta \mathrm{u}_{\mathrm{n}}\right)$ for each instrument consists of a fixed bias and some multiple of the random (precision) error. A normal distribution is considered for the random errors. These errors are described below.

$$
\begin{gathered}
\Delta \mathrm{u}_{\mathrm{n}}= \pm \mathrm{B}_{\mathrm{n}}+\mathrm{k}_{\alpha} \mathrm{S}_{\mathrm{n}} \\
\mathrm{B}_{\mathrm{n}}=\left[\mathrm{B}_{1}^{2}+\mathrm{B}_{2}^{2}+\ldots+\mathrm{B}_{\mathrm{n}}^{2}\right]^{1 / 2}
\end{gathered}
$$




$$
S_{n}=\left[S_{1}^{2}+S_{2}^{2}+\ldots+S_{n}^{2}\right]^{1 / 2}
$$

Where $B_{n}$ are the bias errors (fixed errors) and $S_{n}$ are the random (repeatability) errors. The parameter $\mathrm{k}_{\alpha}$ is a constant that depends on the type of distribution and the confidence level $(1-\alpha)$ required. A 95\% $( \pm 2 \sigma)$ confidence level is used throughout this analysis. Also, in this analysis, uncertainty propagation is addressed using the root-sum-square (RSS) method (Kline, 1985). In this consideration, the $\Delta \mathrm{u}_{\mathrm{i}}$ 's are the total uncertainties of measurement "i." The RSS error is given by:

$$
\mathrm{E}_{\mathrm{a}}=\Delta \mathrm{N}=\left[\left(\Delta \mathrm{u}_{1} \frac{\partial \mathrm{f}}{\partial \mathrm{u}_{1}}\right)^{2}+\left(\Delta \mathrm{u}_{2} \frac{\partial \mathrm{f}}{\partial \mathrm{u}_{2}}\right)^{2}+\ldots+\left(\Delta \mathrm{u}_{\mathrm{n}} \frac{\partial \mathrm{f}}{\partial \mathrm{u}_{\mathrm{n}}}\right)^{2}\right]^{1 / 2}
$$

Sensitivity Analysis is a powerful tool to improve data quality. A spreadsheet program was written using Microsoft Excel ${ }^{\mathrm{TM}}$, allowing easy variation of parameters and easy graphical representation of sensitivities. The spreadsheets are used for "what if" analysis, identification of error sources and their total contribution to error as well as their sensitivity. Identifying sensitivity is also very useful for control purposes.

All of the "Measurement Uncertainty" spreadsheets were also linked through Dynamic Data Exchange protocol to the Paragon control and data acquisition system. This allowed a "real time" estimate of measurement error during engine testing. Changes in gas composition and hence ranges were handled analytically using "if" statements in the spreadsheets which search the instrument error spreadsheet for the proper errors. This provided a point source error estimation, which was used in considering the uncertainty in overall engine measurements. The details of the uncertainty analysis are given in Appendix C: Uncertainty Analysis Calculations. 
Uncertainty analysis was performed for the dilution tunnel particulate mass measurement, emission analysis and flow calibrations.

\subsection{Engine Facility}

The engine facility is located at the U.S. Department of Energy's National Energy Technology Laboratory (NETL). The NETL engine, a Ricardo Proteus, and test bed were produced by G. Cussons Ltd. of Manchester, England. The design of this two-valve, four-cycle engine was based on the Volvo TD120 with a toroidal combustion bowl in the piston. The engine's bore and stroke is $130 \mathrm{~mm}(5.1 \mathrm{in})$ and $150 \mathrm{~mm}$ (6 in) respectively and it's swept volume is 1.997 liters (122.4 $\mathrm{cu}$ in). The engine has a compression ratio of 13.3:1 and a maximum power output of $55 \mathrm{~kW}(74 \mathrm{hp})$ at $36.7 \mathrm{rev} / \mathrm{sec}$. It was configured in the directinjection configuration for this study. Startup and engine load were controlled by a 420 volt, $100 \mathrm{hp}(75 \mathrm{~kW})$ McClure Model 4999, DC dynamometer with an estimated measurement uncertainty of $0.53 \mathrm{~N}-\mathrm{m}$ torque. Engine speed was measured at the dynamometer with an estimated measurement uncertainty of $0.135 \mathrm{~Hz}$. Turbocharger conditions were simulated by using filtered, dried, preheated and regulated $115 \mathrm{psi}(775 \mathrm{KpaG})$ pressurized NETL site air source and by using a back pressure control valve in the exhaust.

Fuel handling was accomplished using a gravimetric system. The fuel was supplied from a secondary container (used for test fuels) or day tank located outside the facility building. The fuel was drawn from the gravimetric measuring container by a mechanical lift pump integral with the injector pump. The Bosch A700 injector pump has four plunger elements (12 mm, $12 \mathrm{~mm}, 12 \mathrm{~mm}$ and $9 \mathrm{~mm}$ ) which were operated in unison. The injector pump and integral lift pump were flange mounted on a timing plate allowing the operator to rotate the pump assembly thereby adjusting the static injection timing from $30^{\circ}$ retard to TDC to $30^{\circ}$ advance. Fuel flow 
rate was calculated from the rate of change in weight of a small fuel reservoir in the gravimetric fuel flow unit. When the fuel weight reached a specified minimum, a solenoid opened a valve and admitted more fuel to the reservoir, thus causing the holding weight to increase. The solenoid closed when the weight of fuel reached a specified maximum. Calculation of fuel flow rate began by identifying and isolating those portions of holding weight data for which the fill valve was closed. The cumulative mass of fuel consumed between consecutive observations was then calculated. The time between successive calculations depended on the time for a given mass of fuel to be consumed. The gravimetric fuel flow unit was manufactured by AVL North America and is capable of up to $80 \mathrm{~kg} / \mathrm{hr}$ flow rate with a total measurement uncertainty of $0.12 \%$ of measurement value plus $0.015 \mathrm{~kg} / \mathrm{hr}$ (signal noise).

Air mass flow rate measurement was made with an "Alcock Viscous Air Flow Meter." The following equation was used to calculate the air mass flow rate $(\mathrm{g} / \mathrm{sec})$

$$
\dot{\mathrm{m}}_{\mathrm{air}}=\alpha \cdot \Delta \mathrm{P} \cdot \gamma_{\mathrm{visc}} \cdot\left[\frac{\left(\mathrm{P}_{\mathrm{fm}}+\mathrm{P}_{\mathrm{ba}}\right)}{\mathrm{P}_{\mathrm{atm}}}\right] \cdot\left[\frac{\mathrm{T}_{\mathrm{std}}}{\left(\mathrm{T}_{\mathrm{abs}}+\mathrm{T}_{\mathrm{fm}}\right)}\right]
$$

Where $\alpha$ is a conversion factor.

A least-squares linearization was determined during flow proving using sonic flow nozzles. The equation for the viscosity correction factor $(\gamma)$ was derived from second-order regression of the viscosity data in the air properties table of the Alcock Viscous Air Flow Meter operating instructions. The viscous correction factor $\left(\gamma_{\text {visc }}\right)$ was calculated as:

$$
\gamma_{\text {vise }}=1.05525-0.00288 \cdot \mathrm{T}+6.29018 \times 10^{-6} \cdot \mathrm{T}^{2}
$$

Where the temperature $\left({ }^{\circ} \mathrm{C}\right)$ was measured with a type $\mathrm{k}$ thermocouple at the flowmeter. $\Delta \mathrm{P}$ was measured by Rosemount model 3051 differential pressure transmitter ranged at $254 \mathrm{~mm} \mathrm{H}_{2} \mathrm{O}$ 
with an estimated manufacturers total error of $0.19 \%$ of span. $\mathrm{P}_{\mathrm{fm}}$ was measured by a Rosemount model 1144 pressure transducer which was ranged at $200 \mathrm{KpaG}$ and had an estimated total error of $0.26 \%$ of span.

A schematic depicting both the process and instrumentation of the engine test bed is given in Figure 4-4.

\subsection{Fuels}

A standard research grade diesel fuel refined by Phillips Chemical Company was chosen as the baseline fuel for this study. This fuel meets the specifications set forth by the EPA in 1993 which was enacted to enforce a $0.05 \%$ sulfur limit on diesel fuel sold in the U.S. The Fischer-Tropsch fuel was produced by the Shell refinery in Bintulu, Malaysia. It was derived form natural gas and contains virtually no sulfur. The physical and chemical specifications of these fuels are given below in Table 4-4.

The FT fuel that was analyzed did not contain the $0.02 \%$ Paradyne 655 lubricity additive. NETL measurements of density, carbon (wt. \%), hydrogen (wt.\%) and heat of combustion are also included and reported in parentheses in the table. The NETL values were derived from sample with the lubricity additive. Gross heat of combustion was measured at NETL using a Parr $^{\circledR}$ bomb calorimeter. Net calorific value was calculated using ASTM D-2015-14.2 procedures. Carbon and hydrogen were determined using a Perkin Elmer $2400 \mathrm{CHN}$ elemental analyzer. Fuel density was determined using a Mettler DA-110 density/specific gravity meter. All other data were provided by the fuel supplier. Heating value, density and carbon (wt.\%) and hydrogen (wt.\%) are used in engine combustion calculations. NETL and manufacturers values were combined and averaged for engine calculations. 


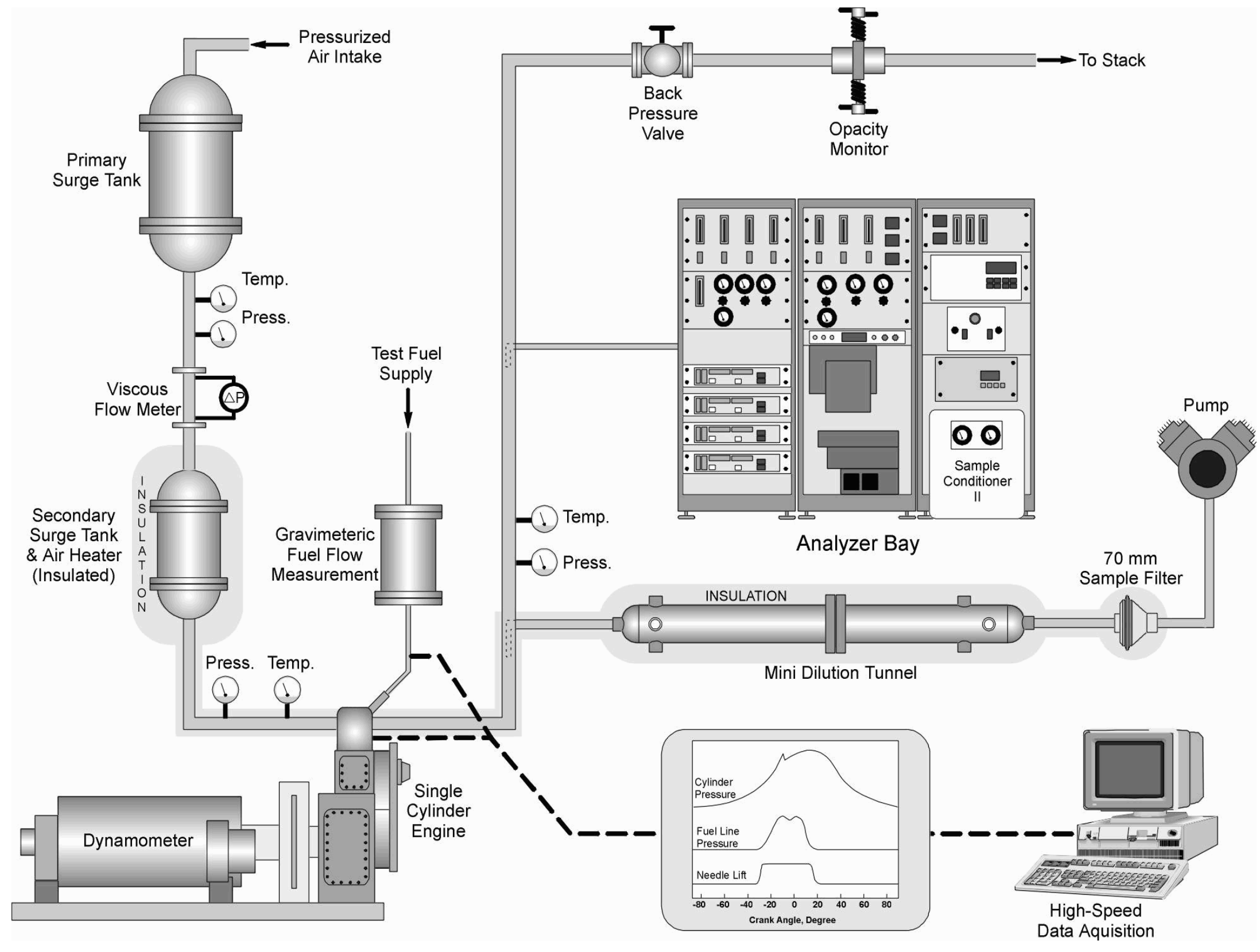

Figure 4-4. Engine Test Bed Schematic 
Table 4-4. Fuel Specifications

\begin{tabular}{|c|c|c|}
\hline Analysis & Malaysian FT & $\begin{array}{c}\text { Std. Diesel Fuel } \\
\text { Phillips Lot D-538) }\end{array}$ \\
\hline Density, kg/L @ 15 $\mathrm{C}$ & $0.7845(.782)$ & $.8455(.843)$ \\
\hline API Gravity @ 60F (API) & 54 & 35.86 \\
\hline Cetane No. & 73.7 & 46.7 \\
\hline Sulfur Content (\% mass) & $\mathrm{NR}(\mathrm{TBD})$ & .03 \\
\hline \multicolumn{3}{|l|}{ Heat of Combustion } \\
\hline Gross Heat Value (BTU/lb) & $20273.8(20264)$ & $(19514)$ \\
\hline Net Heat Value (BTU/lb) & $18883.5(18921)$ & $(18322)$ \\
\hline Aromatic $(\% \mathrm{v} / \mathrm{v})$ & 0.1 & 28.3 \\
\hline Saturates (\% v/v) & 99.8 & 70.3 \\
\hline Olefins (\% v/v) & 0.1 & 1.4 \\
\hline Flash Point $\left({ }^{\circ} \mathrm{C}\right)$ & 72 & 69.4 \\
\hline Cloud Point $\left({ }^{\circ} \mathrm{C}\right)$ & 3 & -17.8 \\
\hline Water \& Sediment (\%) & $<0.02$ & 0 \\
\hline Carbon Residue (\% mass) & 0.02 & $\mathrm{NR}$ \\
\hline Ash (\% mass) & $<0.001$ & NR \\
\hline Viscosity (cSt @ 40º & 3.57 & 2.54 \\
\hline Corrosion & $1 \mathrm{~A}$ & $1 \mathrm{~A}$ \\
\hline Pour Point $\left({ }^{\circ} \mathrm{C}\right)$ & 0 & -20.6 \\
\hline Gums \& Resins (mg/100 ml) & 0.2 & NR \\
\hline Lubricity SDBOCLS (grams) & 1700 & $\mathrm{NR}$ \\
\hline Lubricity HFRR (micron) & $420 / 540 / 570$ & NR \\
\hline \multicolumn{3}{|l|}{ Carbon/Hydrogen (\% mass) } \\
\hline Carbon & $84.91(83.73)$ & NR (86.74) \\
\hline Hydrogen & $14.94(14.49)$ & $\mathrm{NR}(12.86)$ \\
\hline Nitrogen & 0.57 & NR \\
\hline Residual & -1.09 & NR \\
\hline Oxygen (by difference) & Negligible & NR \\
\hline
\end{tabular}

NR (not reported).

( ) Values in parentheses are from measurements made at NETL. The fuel analyzed at NETL contained the Paradyne 655 lubricity additive. 


\subsection{Experimental Procedure and Analysis}

This section delineates the experimental procedure and analysis for this effort. The description which follows is divided into three sections representing the combustion study, particulate matter source analysis and the mutagenicity study.

\subsection{Combustion Study}

Exhaust emissions and combustion data were acquired during engine testing. The purpose was to establish a comparison between the engine combustion and emissions characteristics operating on both Federal diesel No. 2 and FT fuel. This section discusses the experimental procedure and analysis for the combustion study.

\subsubsection{Background}

There have been several papers written on the relative emissions performance of FT fuel in various engines (Schaberg et al., (1997) and Schaberg et al., (2000)). The only detailed combustion analysis known to this author is that of Atkinson et al., (1999). Recently, Venkatesan and Abraham (2000) did a combustion analysis of an engine operating on diesel fuel, which indirectly supports some of the $\mathrm{NO}_{\mathrm{x}}$ emissions conclusions of Atkinson et al., (1999).

In the Atkinson study, a natural gas derived slurry-phase FT fueled a Navistar T444E (V8, 7.3 liter) directed-injected diesel engine. Twelve separate engine load and speed conditions spanned the range of the engine performance map. They found that at all operating conditions, the FT fuel yielded a shorter ignition delay, generally $0.1 \mathrm{~ms}$ shorter $\left(1^{\circ} \mathrm{CA}\right.$ at $\left.1500 \mathrm{rpm}\right)$, than diesel fuel as a result of its higher cetane rating. This enabled a reduced physical evaporation period before ignition. The FT fuel had a slightly longer burn duration than the diesel fuel, however the sum of the ignition delay and the combustion duration for each fuel was roughly equivalent. The benefit of $\mathrm{FT}$ in yielding lower $\mathrm{NO}_{\mathrm{x}}$ at similar power densities was well 
demonstrated. For the same measured exhaust temperature (assuming similar in-cylinder temperature) both FT and diesel fuel produced equivalent levels of $\mathrm{NO}_{\mathrm{x}}$. The authors suggested that there is no "new" mechanism behind the $\mathrm{NO}_{\mathrm{x}}$ formation reaction but merely that for the same net power output at any speed, the FT results in a lower average in-cylinder temperature. The Atkinson study concluded that while FT derates an unmodified compression ignition engine by a small amount at its highest load settings, the brake specific emissions on FT fuel are significantly lower than on diesel fuel. This derating is due to the lower density of FT fuel as fueling was not adjusted to compensate for lower fuel energy flux in their study.

In the study by Venkatesan and Abraham (2000), unlike the Atkinson study, timing was varied over a moderate range of timing conditions but load was again allowed to change in response to timing changes. They used a Cummins single cylinder N-14 direct injected diesel engine. In agreement with the Atkinson study, they concluded that the $\mathrm{NO}$ emissions correlate with the phasing of the heat release rate curve with respect to TDC. The authors suggested that the whole question of combustion phasing and its relationship to temperature was a strong primary effect on $\mathrm{NO}$ emissions.

\subsubsection{Procedure}

A test matrix consisting of three sets of eleven randomized timing points as given in table 5-1 was followed. 
Table 5-1. Key State (KS) Timing Points ( ${ }^{\circ}$ btdc)

\begin{tabular}{|c|c|c|c|c|c|c|}
\hline KS 2 & KS 3 & KS 4 & KS 5 & KS 6 & KS 7 & $\overline{\text { KS } 8}$ \\
\hline 5 & 16 & 18 & 20 & 9 & 14 & 5 \\
\hline 19 & 10 & 24 & 18 & 23 & 22 & 7 \\
\hline 5 & 6 & 24 & 6 & 19 & 24 & 15 \\
\hline-1 & 2 & 18 & 10 & 15 & 30 & 13 \\
\hline 11 & 10 & 10 & 6 & 21 & 16 & 9 \\
\hline 15 & 18 & 12 & 12 & 7 & 16 & 11 \\
\hline 3 & 4 & 14 & 2 & 19 & 10 & 23 \\
\hline 7 & 6 & 24 & 16 & 11 & 12 & 17 \\
\hline-1 & 22 & 20 & 14 & 9 & 26 & 23 \\
\hline 3 & 20 & 16 & 4 & 21 & 18 & 21 \\
\hline 13 & 12 & 28 & 20 & 11 & 30 & 25 \\
\hline 13 & 12 & 10 & 14 & 25 & 12 & 13 \\
\hline 17 & 2 & 16 & 0 & 13 & 26 & 17 \\
\hline 17 & 4 & 14 & 2 & 17 & 18 & 7 \\
\hline 5 & 14 & 22 & 10 & 21 & 10 & 9 \\
\hline 3 & 10 & 26 & 0 & 5 & 12 & 25 \\
\hline 7 & 20 & 10 & 12 & 23 & 20 & 21 \\
\hline 19 & 12 & 18 & 8 & 25 & 14 & 19 \\
\hline 1 & 22 & 12 & 12 & 25 & 26 & 15 \\
\hline 7 & 16 & 22 & 2 & 13 & 28 & 11 \\
\hline 1 & 8 & 14 & 18 & 7 & 14 & 17 \\
\hline 15 & 14 & 12 & 20 & 9 & 22 & 13 \\
\hline 17 & 14 & 8 & 16 & 15 & 28 & 19 \\
\hline 11 & 18 & 20 & 14 & 19 & 22 & 21 \\
\hline 13 & 2 & 20 & 6 & 23 & 16 & 15 \\
\hline 15 & 22 & 22 & 16 & 17 & 18 & 23 \\
\hline 19 & 4 & 16 & 18 & 13 & 30 & 5 \\
\hline 1 & 18 & 8 & 0 & 15 & 20 & 5 \\
\hline 9 & 8 & 28 & 10 & 5 & 24 & 11 \\
\hline-1 & 8 & 26 & 8 & 17 & 28 & 25 \\
\hline 9 & 16 & 26 & 4 & 11 & 24 & 7 \\
\hline 9 & 6 & 28 & 8 & 7 & 10 & 9 \\
\hline 11 & 20 & 8 & 4 & 5 & 20 & 19 \\
\hline
\end{tabular}

The procedure calls for setting the fueling to give the required load. The engine emissions were then allowed to stabilize and data were recorded. The timing was then set at the next timing point. This procedure was repeated allowing the emissions to stabilize at each setting. For this study, the engine was brought to equilibrium conditions at the beginning of each key state. As timing was changed, the emissions were again allowed to stabilize. The time 
required for stabilization was maintained constant for each timing change, thus aiding measurement repeatability. Oil and coolant temperatures were kept constant at each key state condition.

This combustion study is intended to further add to the understanding of FT emissions and combustion relationship. Variations of FT emissions and combustion data with such wide variation of timing has not been presented in the literature.

$\mathrm{NO}, \mathrm{CO}$, and THC are considered as functions of the thermodynamic indicators given in Table 5-2 for each steady-state condition (key state). Opacity was also considered at key state 3 but was not considered for the other key states due to inconsistencies in the data at the very low end of the opacity monitor's operating range. The engine steady-state operating conditions or "key states" are given below in Table 5-3 of Section 5.3.2.

\subsection{Particulate Matter Source Analysis}

Understanding the source of particulate matter is important if a researcher is to better understand how to control its formation. The source of particulate matter is primarily the fuel or the lubrication oil. The present study attempts to determine the relative quantities of soluble and insoluble fractions, $\mathrm{SO}_{4}$ and water as well as the contributions of fuel and lube oil to the soluble portion of the particulate matter emissions. Once the soluble and sulfate portions are identified, the insoluble portion is given by the difference between the total sample mass and those portions.

A $10 \mathrm{ml}$ portion of the soxlet extracted sample containing the soluble organic fraction (SOF) of the diesel particulate matter was concentrated via drying to $1 \mathrm{ml}$ and used for further analysis to determine its source. The concentrated sample was injected into a chromatographic 
Table 5-2. Engine Thermodynamic Indicator Definitions

\begin{tabular}{|c|c|c|}
\hline Abbreviation & Parameter & Definition \\
\hline PMAXS & Peak Pressure Value & $\begin{array}{l}\text { Maximum pressure of an average over } 100 \text { engine } \\
\text { cycles (bar) }\end{array}$ \\
\hline APMAX & Location of Peak Pressure & $\begin{array}{l}\text { Location of the maximum pressure encountered } \\
\left({ }^{\circ} \mathrm{CA}\right) .\end{array}$ \\
\hline RMAXS & $\begin{array}{l}\text { Maximum Burn Rate or Pressure Rise } \\
\text { Rate }\end{array}$ & $\begin{array}{l}\text { Maximum rate of pressure rise calculated from a } \\
5 \text {-pt. Central difference. }\end{array}$ \\
\hline ARMAX & $\begin{array}{l}\text { Maximum Burn Rate or Pressure Rise } \\
\text { Rate Location }\end{array}$ & Location of maximum burn rate $\left({ }^{\circ} \mathrm{CA}\right)$. \\
\hline Ign Delay & Ignition Delay & $\begin{array}{l}\text { Time, measured in crank angle degrees, from start } \\
\text { of fuel injection to point heat release rate reaches } \\
5 \mathrm{~kJ} / \mathrm{m}^{3}-{ }^{\circ} \mathrm{CA} \text {. }\end{array}$ \\
\hline SOI & Start of injection & Point in which needle lift reaches $0.2 \mathrm{~mm}$ \\
\hline EOI & End of Injection & $\begin{array}{l}\text { Point at which needle closes to within } 0.2 \mathrm{~mm} \text { of } \\
\text { seat }\end{array}$ \\
\hline Inj Dur & Injection duration & Difference between SOI and EOI (oCA) \\
\hline SOC & Start of Combustion & $\begin{array}{l}\text { Point at which the heat release rate reaches } \\
5 \mathrm{~kJ} / \mathrm{m}^{3}-{ }^{\circ} \mathrm{CA} \text {. }\end{array}$ \\
\hline CombDur & Combustion Duration & $\begin{array}{l}\text { Time, measured in crank angle degrees, from } 10 \% \\
\text { to } 90 \% \text { of the mass fraction burned }\left({ }^{\circ} \mathrm{CA}\right) .\end{array}$ \\
\hline MFB50\% & $\begin{array}{l}\text { Location of Mass Fraction } \\
\text { Burned- } 50 \%\end{array}$ & $\begin{array}{l}\text { Location of } 50 \% \text { of the integrated mass fraction } \\
\text { burned curve }\left({ }^{\circ} \mathrm{CA}\right) .\end{array}$ \\
\hline $\begin{array}{l}90-50 \text { (Diff. } \\
\text { Burn) }\end{array}$ & Mixing Burn & $\begin{array}{l}\text { Measure in crank angle degrees of the time from } \\
50 \% \text { to } 90 \% \text { of the mass fraction burned }\left({ }^{\circ} \mathrm{CA}\right) \text {. } \\
\text { This is an indication of the mixing phase burn rate }\end{array}$ \\
\hline Premixed Peak & $\begin{array}{l}\text { Maximum Heat Release Rate of the } \\
\text { pre-mixed combustion phase }\end{array}$ & $\begin{array}{l}\text { Maximum value of the instantaneous heat release } \\
\left(\mathrm{kJ} / \mathrm{m}^{3}-{ }^{\circ} \mathrm{CA}\right) \text {. }\end{array}$ \\
\hline $\begin{array}{l}\text { Premixed Peak } \\
\text { Loc }\end{array}$ & $\begin{array}{l}\text { Maximum Heat Release Location of } \\
\text { the pre-mixed combustion phase }\end{array}$ & Location of the maximum heat release $\left({ }^{\circ} \mathrm{CA}\right)$. \\
\hline Diffusion Peak & $\begin{array}{l}\text { Maximum Heat Release Rate of the } \\
\text { diffusion controlled combustion phase }\end{array}$ & $\begin{array}{l}\text { Maximum value of the instantaneous heat release } \\
\left(\mathrm{kJ} / \mathrm{m}^{3}-{ }^{\circ} \mathrm{CA}\right) \text {. }\end{array}$ \\
\hline $\begin{array}{l}\text { Diffusion Peak } \\
\text { Loc }\end{array}$ & $\begin{array}{l}\text { Maximum Heat Release location of } \\
\text { the diffusion controlled combustion } \\
\text { phase }\end{array}$ & Location of the maximum heat release $\left({ }^{\circ} \mathrm{CA}\right)$. \\
\hline
\end{tabular}

column to determine either a lube oil or fuel source via the method outlined in the Institute of Petroleum method IP442, “Analysis of fuel and oil-derived hydrocarbons in diesel particulates on filters - Gas Chromatography Method." In this method, the calculation relies on the assumption that all the hydrocarbons present in the particulate are either from unburned fuel or 
unburned oil. The method uses the chromatogram from the neat fuel and oil as "standards" to which chromatograms of the soluble matter are later compared. In our case, samples of the extracted solvent and/or MOUDI grease were used in combination with a thermal background that was subtracted from the chromatogram of each sample. Repeatability as a percentage of total sample is reported in IP442 to range from $9 \%$ to $10 \%$ while reproducibility ranged from $19 \%$ to $33 \%$.. Accuracy and repeatability were minimized by standardizing the injection technique into the gas chromatograph. Gas tight Dynatech Precision Sampling, C160-FN, $5 \mu \mathrm{L}$ syringes were used for manual injections. This is important since, inherently during the injection, a small portion of the sample irreducibly blows past the plunger and never reaches the column when using non-gas tight syringes. The syringes were cleaned and dried before loading it with sample. Dichloromethane was used to clean the syringe between injections. The syringes were aspirated with clean filtered nitrogen at room temperature to remove residual traces of the cleaning solvent. All GC chromatograms were corrected back to a nominal $2 \mu \mathrm{L}$ injection volume. The procedure follows:

1. Pull the plunger back $1 \mu \mathrm{L}$ from the bottom to create an air gap.

2. Place the needle into the sample.

3. Draw the sample into the syringe barrel slowly until the tip of the plunger reaches the 4 $\mu \mathrm{L}$ mark.

4. Depress the plunger slowly until it bottoms out.

5. Repeat steps 3 and 4 several times to work the air bubbles out of the sample slug, but make sure that you have the needle submersed into the sample at all times. Also make sure that you haven't lost the original $1 \mu \mathrm{L}$ air gap. 
6. Withdraw the plunger tip to the $2 \mu \mathrm{L}$ mark. (Remember that the volume of the needle is approximately $1 \mu \mathrm{L}$.)

7. Remove the needle from the sample.

8. Further withdraw the plunger to the $4 \mu \mathrm{L}$ mark. At this point you should have approximately a $2 \mu \mathrm{L}$ slug of bubble free sample visible in the syringe barrel. Using a magnifying glass determine the actual amount in the syringe to the nearest $.025 \mathrm{ml}$.

9. Fully insert the needle into the injection port while leaving the slug of sample in step 8 fully in the barrel. Rapidly and smoothly depress the plunger so as to push the plug of sample through the needle and into the injection port liner.

\subsection{Mutagenicity Study}

An Ames bioassay was conducted on the exhaust particulate extract from engine operation with both Federal diesel No. 2 and FT fuel at seven steady-state engine operating conditions (key states) and on two PM size fractions at two engine operating conditions. This section delineates the experimental procedure and analysis leading to the final bioassay results.

\subsubsection{Background}

The present study investigated the mutagenic activity of particulate matter derived from FT fuel combustion in the single-cylinder diesel engine as functions of engine operation and particle size. Particulate samples were gathered at seven steady-state operating conditions (key states) for both Federal diesel No. 2 and the FT fuel at optimized thermal efficiency timing points. The term "optimized" is used here to mean that the engine was optimized for maximum thermal efficiency by adjusting fuel injection timing at constant speed and torque at each key operating state. Samples were also collected for size dependent analysis using a MOUDI impactor at two steady state operating conditions. The PM collected by the MOUDI were 
analyzed in two size groups corresponding to particles of aerodynamic diameter less than $100 \mathrm{~nm}$ and aerodynamic diameter greater than $100 \mathrm{~nm}$.

To date, a clear mechanism has not been established to explain the interactions that fuel properties and engine operation have on the bio-potential of diesel exhaust. Several published literature reports suggest that higher load conditions promote bioactivity while others point to low load (Christiansen et al., 1996) or even moderate load (Nussear et al., 1992) promoting higher bio-activity. These efforts failed at reporting or relating detailed engine operations such as injection timing to their findings. Therefore, for purposes of comparing the emissions and performance of an engine operating on two different fuels such as Federal diesel No. 2 and FT fuel, the engine must operate on a common basis. This study began by performing an engine timing optimization for best thermal efficiency at each operating point or "key state." This effort was piggybacked with the combustion study discussed in Section 5.1.

\subsubsection{Engine Injection Timing}

A randomized test matrix was employed involving three replications of 11 independent timing points centered on an estimated optimum. The procedure for thermal efficiency injection optimization included setting the fueling to give the required load. The engine emissions were allowed to stabilize and thermal efficiency was recorded. The timing was then set at the next timing point. This procedure was repeated allowing the emissions to stabilize at each setting. The time required for stabilization was maintained constant for each timing change, thus aiding measurement repeatability. Oil and coolant temperatures were kept constant at each key state condition. Thermal efficiency vs. static injection timing) were then plotted to establish optimum timing settings for each fuel and key state. The results indicated that optimum timing for the FT fuel and the standard diesel fuels were very similar and effectively equal within the confidence 
limits. The engine steady state operating conditions or "key states" are given in Table 5-3. The static timing point, in Table 5-3, is the optimized timing determined using the above procedure. The difference between optimized timing points for DF and FT fuels were within experimental error.

Table 5-3. Steady-State Engine Operating Conditions

\begin{tabular}{|r|r|r|r|r|r|r|r|}
\hline $\begin{array}{c}\text { Key } \\
\text { State }\end{array}$ & $\begin{array}{c}\text { Engine } \\
\text { Speed } \\
(\mathbf{H z})\end{array}$ & $\begin{array}{c}\text { Engine } \\
\text { BMEP } \\
(\mathbf{b a r})\end{array}$ & $\begin{array}{c}\text { Torque } \\
(\mathbf{N m})\end{array}$ & $\begin{array}{c}\text { Boost } \\
(\mathbf{K p a G})\end{array}$ & $\begin{array}{l}\text { Inlet Air } \\
(\mathbf{C})\end{array}$ & $\begin{array}{c}\text { Static } \\
\text { Timing } \\
@\end{array}$ & $\begin{array}{c}\text { Exhaust } \\
(\mathbf{K p a G})\end{array}$ \\
\hline 2 & 16 & 2 & 31.8 & 0 & 40 & 11 & 0 \\
\hline 3 & 16 & 10 & 158.9 & 30 & 40 & 13 & 10 \\
\hline 4 & 24 & 16 & 254.3 & 125 & 40 & 17 & 42 \\
\hline 5 & 24 & 2 & 31.8 & 0 & 40 & 10 & 0 \\
\hline 6 & 32 & 2 & 31.8 & 15 & 40 & 16 & 5 \\
\hline 7 & 32 & 12 & 190 & 160 & 40 & 22 & 53.5 \\
\hline 8 & 24 & 10 & 158.9 & 70 & 40 & 15 & 23.5 \\
\hline
\end{tabular}

@ The same static timing was used for each fuel.

\subsubsection{Sampling and Extraction}

Diesel Particulate Matter (DPM) was collected for mass measurement, extraction and chromatographic analysis at NETL. The extracted SOF was provided to National Institute for Occupational Safety and Health (NIOSH) in Morgantown, WV for Ames bioassay testing.

The DPM was sampled on Pallflex TX40HI20-WW 90-mm Teflon coated glass fiber filters. The filter holder was designed to provide a leak-tight support for the filters and a uniform filter face flow velocity distribution. Filtration efficiency for the Pallflex TX40H120WW was reported as 92.6-99.99\% for particle diameter range of 35-1000 nm (Willeke and Baron, 1993). Guerrieri et al. (1996) investigated filter face velocity effects on particulate mass from 
heavy-duty diesel engines and suggested that a filter face velocity range between 40 to 100 $\mathrm{cm} / \mathrm{sec}$ would exhibit little, if any, influence on collected particulate mass. Flow rates were kept within the range of 35 to $45 \mathrm{~cm} / \mathrm{sec}$ and dilution ratios were held very near a constant 12:1 ratio for this study.

Prior to exposure, the filters were first extracted in a soxhlet apparatus for 72 hours (600 cycles) to reduce errors in sample weight associated with loss of filter material and then equilibrated in a environmentally controlled chamber at $70 \mathrm{~F}$ and $50 \%$ relative humidity $(\mathrm{RH})$ for 12 hours. After exposure, the filters were again equilibrated in the constant temperature and relative humidity chamber and weighed to obtain the PM mass. After weighing, the exposed filters were extracted for 72 hours (approximately 600 cycles) with dichloromethane (DCM) in a Soxhlet apparatus to obtain the soluble organic fraction (SOF). Six hundred cycles using DCM was chosen after considering both the need for extracted SOF for bioassay testing and for source analysis. The bulk of published soxhlet extraction methods for both bioassay and source analysis of diesel particulate matter employs 24 hour extraction which corresponds to approximately 200 cycles (Cartllieri and Herzog, 1988; Johansen et al., 1997; Bagley et al., 1996; Gautam, et al., 1994; Ensell et al., 1998 and Montreuil et al., 1992). However, recent studies (de Lucas et al., 1999) indicate that longer extraction periods result in significantly greater extraction of hydrocarbon compounds including PAHs. de Lucas et al., (1999) went on to compare various extraction methods and solvents. They concluded that an accurate determination of fuel and oil contributions require very high extraction times (close to 600 cycles). Further, they found that extraction by a mixture of DCM and benzene (70:30) would allow a reduction to 400 cycles for extraction of both high and low molecular weight hydrocarbons. After reviewing the works of Ensell et al., (1997), Montreuil et al., (1992), and 
Krishna et al., (1983), it was concluded that DCM extracts the highest proportion of mutagens from fresh diesel exhaust and that little mutagenicity is lost using DCM as the only extractant. Further, benzene was ruled out for this study as a solvent for bioassay studies since benzene is itself a known strong mutagen (IARC, 1989). Therefore, to obtain maximum extraction of both high and low molecular weight hydrocarbons for accurate source analysis and bioassay analysis, an extended soxhlet extraction process employing 600 cycles with dichloromethane as the only solvent was chosen for this study.

The mass of the SOF was determined gravimetrically on both a small (100-uL) aliquot of the total extract, which was dried and weighed at NIOSH and also by filter mass difference before and after final soxhlet extraction at NETL. The average of the SOF weight determined by each method was used to determine the dosages in the AMES tests. Meticulous and precise filter handling and weighing procedures were followed to assure reliable measurements. NIST traceable weights were used to calibrate the microbalance at both NIOSH and NETL to an uncertainty of $0.01 \mathrm{mg}$. Again, as mentioned above, filters were also thoroughly extracted before exposure to minimize background contributions on a mass basis. After soxhlet extraction, filters were extracted via sonication in distilled, deionized water to obtain the $\mathrm{SO}_{4}$ fraction. Sulfate concentrations were determined from the extracts using ion chromatography with a conductance detector by comparison to an aqueous standard curve consisting of solutions having known concentrations of potassium sulfate. The particle associated solid fraction (SF) was defined as the mass left on the filter after extractions with DCM and deionized water. 


\subsubsection{Bioassay Analysis}

For both total particulate samples and size fractionated samples using the MOUDI, the soluble organic fraction of the diesel particulate matter (DPM) was analyzed using the Ames method (Maron and Ames, 1983) (Watenabe et al., 1990). The results were used to associate mutagenic activity with engine test conditions and compare standard No. 2 diesel with FT fuels at these conditions. The Micro-orifice Uniform Deposition Impactor (MOUDI) was used to gather and classify samples by particle size for size dependent Ames bioassay analysis at two key operating states. Two sized fractions derived from engine operation at key states 2 and 4 (representing low speed-low load and intermediate speed-high load conditions respectively) for each fuel were collected producing a total of twelve samples for size-dependent Ames analysis. In all cases, the genotoxicity and mutagenicity was determined using a pre-incubation variant of the Ames Salmonella microsomal assay system (Watenabe et al., 1990). The samples were tested on both YG1024 and YG1029 bacterial tester strains in the presence and absence of 10\% concentration of $S 9$, a preparation made from the livers of laboratory rats induced with Aroclor 1254. Using both strains accounts for both frameshift and basepair substitution types of mutation. The S9 demonstrates whether the mutagens cause genetic damage directly or whether they require activation by metabolic enzymes produced in mammalian livers. Concentration (dosage) ranges were from very low dosages to, in some cases, levels in which toxicity effects are apparent. Experiments were performed using four replicates, and dose-adjustment confirmation tests were run and repeated as necessary for each sample. Known mutagens and the solvent dichloromethane (DCM) were used as positive controls and the dispersants, dimethyl sulfoxide (DMSO) and Tween 80, were used as negative controls. The numbers of revertants are determined by using an automatic counter. The average number and standard deviations of 
revertants per plate were then determined. The revertant activity was related to initial particulate mass and engine output by carefully tracking the solvent and particulate concentrations.

In the Ames test, the relationship between revertant count and dosage was used to develop a measure of mutagenicity. For small dosages, the mean revertant count was typically assumed to be a linear function of the dose of a mutagenic substance. Further, the slope of the line relating revertant count to dose was used a measure of the mutagenicity of the substance. However, at large doses, Salmonella death begins to dominate due to DPM sample extract toxicity. This effectively reduced the revertant count and reduces the slope of the revertant-vs-dose curve. If revertant count data from cases exhibiting toxicity were included in the analysis to determine mutagenicty, the slopes, and hence the mutagenicity measure, would have been biased downward. These toxicity effects were removed using the statistical method of Bernstein et al., (1982).

Bernstein et al., (1982) suggest a stepwise approach to testing for toxicity effects and removing affected data from the revertant-vs-dose analysis. To utilize their notation, there are (r) doses of the substance being tested, $\mathrm{d}_{\mathrm{i}}, \mathrm{i}=1,2, \ldots, \mathrm{r}$, including the control or "zero" dose. There are (n) replicates of each dose, producing revertant counts $\mathrm{N}_{\mathrm{i}, \mathrm{j}}, \mathrm{j}=1,2, \ldots \mathrm{n}$. The revertant counts are assumed to be random variables with a generalized Poisson distribution,

$$
P\left(N_{i, j}\right)=\frac{\xi \cdot\left(\xi+\eta \cdot N_{i, j}\right)^{n-1} \cdot e^{-\left(\xi+\eta \cdot N_{i, j}\right)}}{N_{i, j} !}
$$

with 
$\eta=1-\frac{1}{\sqrt{\gamma}} \quad$ and $\quad \xi=\frac{\mu_{\mathrm{i}}}{\sqrt{\gamma}}$ where $\mu_{\mathrm{i}}$ and $\gamma$ are parameters of the distribution. The mean

revertant count at dose $d_{i}$ is $\mu_{i}$ and is assumed to be a linear function of dose except in cases of toxicity, for example

$$
\mu_{i}=\left(\beta_{0}+\beta_{1} \cdot d_{i}\right)
$$

Here, $\beta_{0}$ represents the mean revertant count for the zero dose (i.e. control case) and $\beta_{1}$ is the measure of mutagenicity (revertants per unit dose). The procedures of Bernstein et al., (1982) employ maximum-likelihood techniques to estimate the unknown parameters and to test hypotheses concerning toxicity and mutagenicity. Under the assumption that the replicates are independently and identically distributed, the likelihood of a particular data set can be expressed as a function of the unknown parameters by,

$$
L\left(\beta_{0}, \beta_{1}, \gamma\right)=\prod_{i} \prod_{j} P\left(N_{i, j}\right)
$$

but it is more typical to use the log-likelihood function,

$$
\ln \left(\mathrm{L}\left(\beta_{0}, \beta_{1}, \gamma\right)\right)=\sum_{i} \sum_{j} \ln \left(\mathrm{P}\left(\mathrm{N}_{\mathrm{i}, \mathrm{j}}\right)\right)
$$

Estimates of the unknown parameters were derived by maximizing the likelihood function with respect to the parameters. This maximization can sometimes be done analytically but, due to the large number of cases, was performed numerically in this study using MathCAD spreadsheets. An example of the detailed MathCAD calculations is given in appendix D: Annotated Example 
of Ames Test Data Analysis Using MathCAD. The particular example is for keystate 2 engine operation using FT fuel with bacterial strain YG1024 with S9 activation.

The stepwise procedure to screen data for toxicity effects begins by considering the data at the $\mathrm{r}^{\text {th }}$ dose. The likelihood's of two different models are compared. In the first model (the "no-toxic-effects" model), the average revertant count vs. dose is assumed to be linear up to and including the rth dose as described above. The second model (the "toxic effect" model) is similar except the linear relationship is assumed to hold only through the $(r-1)^{\text {th }}$ dose and the $\mathrm{r}^{\text {th }}$ dose is assumed to have its own mean, $\mu_{\mathrm{r} .}$ A different mean for the $\mathrm{r}^{\text {th }}$ dose makes sense if the $\mathrm{r}^{\text {th }}$ dose is exhibiting serious toxic effects in which its mean count would be expected to fall below the trend followed by the first (r-1) doses. The maximum likelihood of the second model, having one more parameter, will be as high or higher than that of the first model. The difference between the maximum log-likelihood of both models, under a null hypothesis of no toxic effects, follows a Chi-squared distribution with one degree of freedom. Using an alpha level of 0.05 in testing the null hypothesis, we omit the datum from subsequent analysis upon conclusion that the revertant count data at dose " $r$ " were affected by toxicity. Otherwise, the slope from the first model is used to estimate the mutagenicity of the particulate extract. This procedure is stepwise in that if the rth dose has been rejected due to apparent toxic effects, the procedure is repeated again to examine revertant count data at the $(\mathrm{r}-1)^{\mathrm{th}}$ dose for evidence of toxicity. The procedure is repeated over and over until either it fails to reject a dose as toxic or until there is insufficient data to continue. In our case, the majority of the data sets consists of 5 doses, and it is necessary to retain at least three to estimate the mutagenicity, therefore the analytical procedure is used to test only the two highest doses for toxicity. 
Bernstein et al.; 1982 also recommend addition statistical tests on revertant count data sets. One of these is a test for mutagenic effect in which the null-hypothesis of no mutagenic effect (i.e. the mean revertant count is a constant that is independent of dosage, $\beta_{1}=0$ ) versus the alternative that the mean revertant count is a linear function of dosage. The mutagenic effect test compares the maximum likelihood of the model $\mu_{i}=\beta_{0}$ with that of $\mu_{i}=\beta_{0}+\beta_{1} * d_{i}$ in order to test the null hypothesis that $\beta_{1}=0$ (i.e., testing if the dose response differs significantly from zero). Rejecting the null hypothesis is evidence that the substance being tested is mutagenic. The other test is a lack-of-fit test for the control dose similar to that described above for toxicity effects in the higher doses. The control (zero-dose) data are compared to the linear trend established by the remainder of the data. The maximum likelihood of the model $\mu_{\mathrm{i}}=\beta_{0}+\beta_{1} * \mathrm{~d}_{\mathrm{i}}$ is compared to that of the model $\mu_{i}=\left\{\mu_{0}\right.$ for $i=1, \beta_{0}+\beta_{1} * d_{i}$ otherwise $\}$. The null-hypothesis is that the mean revertant count of the control dose is consistent with the linear dose-vs-count trend exhibited by the remainder of the data (i.e. does the negative control fit the remaining dose response slope). If the null-hypothesis was rejected, we should be suspicious that there may still be some toxicity effects or other phenomena affecting the linearity of the revertant count and, hence, our estimates of the mutagenicity.

\subsubsection{MOUDI Samples}

The test procedure for the MOUDI samples employs the engine conditions given in Table 5-4. The engine test procedure for collecting size-segregated MOUDI samples was similar to the engine tests in which total particulate filter samples were taken. The test procedure involved identical warm up and shut down before and after each day of testing. The engine load, speed, boost pressure, inlet air conditions were all set to the conditions given in table 5-4. The engine always ran at the set condition for 45 minutes allowing oil temperatures, coolent temperature and 
other engine conditions to stabilize. During this time the dilution tunnel was turned on and it too was allowed to stabilize with respect to dilution ratio, tunnel inlet temperature, dilution air temperature and tunnel wall temperature. When changing fuel, the engine was run until the fueling system was flushed with the new fuel at least two times. The fuel injector nozzles were also checked after at the end of each day to ensure integrity.

Table 5-4. Steady-State Operating conditions for MOUDI Sampling

\begin{tabular}{|c|c|c|c|c|c|c|c|}
\hline $\begin{array}{c}\text { Key } \\
\text { State }\end{array}$ & $\begin{array}{c}\text { Engine } \\
\text { Speed } \\
(\mathrm{Hz})\end{array}$ & $\begin{array}{c}\text { Engine } \\
\text { BMEP } \\
(\text { bar })\end{array}$ & $\begin{array}{c}\text { Torque } \\
(\mathrm{Nm})\end{array}$ & $\begin{array}{c}\text { Boost } \\
(\mathrm{KpaG})\end{array}$ & $\begin{array}{c}\text { Inlet } \\
\text { Air } \\
(\mathrm{C})\end{array}$ & $\begin{array}{c}\text { Static Timing } \\
(\text { used for each } \\
\text { fuel }){ }^{\circ} \mathrm{CA}\end{array}$ & $\begin{array}{c}\text { Exhaust } \\
(\mathrm{KpaG})\end{array}$ \\
\hline 2 & 16 & 2 & 32 & 0 & 40 & 11 & 0 \\
4 & 24 & 16 & 254 & 125 & 40 & 17 & 42 \\
\hline
\end{tabular}

47-mm aluminum foils (Fisher-Scientific) were used as impaction substrates for size-selective (MOUDI) measurements of PM in this study. Thirty-seven millimeter diameter, $0.1 \mu \mathrm{m}$ pore size filters (Fisher-Scientific) were used as the afterfilter. The procedures and equipment used for conditioning and weighing filters for total particulate matter gravimetric analysis were also used for treatment and weighing of the substrates and afterfilters designated for size-selective measurements of particulate matter. After exposure, the substrates were again weighed to obtain the particulate mass on each substrate. After re-weighing, the particulate laden substrates were split into three groups. One group is made up of substrates 9,10 and the afterfilter. This group represented the "Ultra-fine particles" or particles with nominal diameters less than $100 \mathrm{~nm}(0.1 \mu \mathrm{m})$. The second group consisted of substrates 3-8. This group represents particles with nominal diameters between $100 \mathrm{~nm}(0.1 \mu \mathrm{m})$ and $3.1 \mu \mathrm{m}$. The third group consists of substrates 0,1 , and 2 and was discarded due to the fact that they contained the most 
grease per substrate $(5-6 \mathrm{mg}$ ) and because negligible, if any, amounts of particulate matter were captured. Stages 0,1 , and 2 were therefore not included in the soxhlet extraction and mutagenic studies. The exposed substrates and afterfilters were then extracted for 72 hours (approximately 600 cycles) with dichloromethane (DCM) in a Soxhlet apparatus to obtain the SOF. For each

engine test (sample set consisting of 3 sample replications), separate extractions were performed, on the three combined sets of stages 3 through 8 and on the three combined sets of stages 9,10 and the afterfilter. After the extraction, the remaining DCM and SOF solution was diluted to $200 \mathrm{ml}$ and as with the total particulate matter samples, $10 \mathrm{ml}$ was taken for later chemical analysis (to determine the soluble organic fraction (SOF)) and the remaining $190 \mathrm{ml}$ was provided to NIOSH for bioassay analysis.

\subsubsection{Determination of the Soluble Mass for Ames Bioassay Dosages Using for Size Segregated (MOUDI) Samples}

For MOUDI analysis, the actual dosages for Ames bioassay analysis had to be determined using a chromatographic technique rather than the standard methods of either evaporating the solute and weighing the remaining solubles or using the difference in mass of the extracted filter and the original filter mass. The reason is that there was no way to retain the particulate material during the soxhlet extraction process since the particles only adhered to the greased surface of an aluminum disk substrate and the grease is washed away during the extraction process. Further, the greased substrates contained an unknown amount of grease, a part of which remains after any evaporative process.

A chromatographic technique was used to determine the amount of solubles and hence the dosage for the Ames tests. This technique provided only an approximation that assumes a similar distribution of compounds in the soluble fraction in both the size segregated (MOUDI) 
substrates and the total particulate matter (TPM) samples. Careful handling and control of the injection process used in the chromatographic analysis reduced the inaccuracy in determination of sample size. Chromatographic sample size was nominally $2 \mu 1$ with chromatograms adjusted for slight variations around the nominal. Estimated accuracy of the sample injection was $0.05 \mu 1$ or $2.5 \%$.

The procedure for calculating the amount of solubles in the MOUDI substrates reduced to a mathematical weighting of the known solubles in a corresponding TPM sample from the same engine operating conditions. The procedure is as follows:

1. First, the total particulate masses on both the subject MOUDI substrate sample $\left(\mathrm{W}_{\mathrm{m}}\right)$ and the corresponding total particulate sample $\left(\mathrm{W}_{\mathrm{f}}\right)$ collected at the same engine and tunnel operating conditions were determined. Then the mass of solubles in the total filter sample $\left(\mathrm{W}_{\mathrm{fs}}\right)$ was determined from the difference in the filter sample mass and the filter sample mass after soxhlet extraction.

2. Second, the area under the chromatogram for the subject MOUDI substrate sample $\left(\mathrm{A}_{\mathrm{m}}\right)$ and for the corresponding total particulate sample $\left(\mathrm{A}_{\mathrm{f}}\right)$ collected at the sample engine and tunnel operation conditions per the GC procedure was determined.

3. The area under the GC chromatogram of the MOUDI substrates was first corrected (proportionally) to the area under the GC chromatogram for the total particulate

$$
A_{m}\left(\frac{W_{f}}{W_{m}}\right)=A_{m} \text { corr }
$$

sample and is given by $\mathrm{A}_{\mathrm{m}}$ corr. 
4. The amount of solubles in the corrected MOUDI substrate sample $\left(\mathrm{W}_{\mathrm{m}}\right.$ corr $)$ was then determined by taking the ratio of the corrected MOUDI substrate sample GC area ( $\mathrm{A}_{\mathrm{s}}$ corr) to the total sample GC area and multiplying by the amount of solubles in the total

$$
\frac{A_{m} \text { corr }}{A_{f}} W_{f s}=W_{m} \text { corr }
$$

$\operatorname{sample}\left(\mathrm{W}_{\mathrm{fs}}\right)$.

5. $\mathrm{W}_{\mathrm{m}}$ corr was defined as the mass of solubles in the substrate sample if it were proportionally as large as the total particulate sample. This was corrected by multiplying by the ratio of the substrate sample mass to the total filter sample mass. This gave an estimate of actual solubles on the substrates $\left(\mathrm{W}_{\mathrm{s}} \mathrm{sol}\right)$.

$$
\mathrm{W}_{\mathrm{m}} \frac{\mathrm{W}_{\mathrm{m}} \text { corr }}{\mathrm{W}_{\mathrm{f}}}=\mathrm{W}_{\mathrm{s}} \text { sol. }
$$

6. This reduced to

$$
\mathrm{W}_{\mathrm{s}} \text { sol }=\mathrm{W}_{\mathrm{fs}} \frac{\mathrm{A}_{\mathrm{m}}}{\mathrm{A}_{\mathrm{f}}}
$$

which was an estimate of the solubles in the extracted MOUDI substrates.

7. The solubles were dissolved in $200 \mathrm{ml}$ of DCM. $10 \mathrm{ml}$ was removed for use in the GC analysis. The value of $\mathrm{W}_{\mathrm{s}} \mathrm{sol}$ accounted for that removal. This was also the case for all soxhlet-derived samples. 


\subsection{Results and Discussion}

This section provides the detailed results and discussion of the combustion study, particulate matter source analysis, and mutagenicity study.

\subsection{Combustion Study}

The change in brake-specific emissions due to FT fuel operation for each key state are given below in Figure 6-1. There was a general trend in the data for lower emissions with FT fuel in $\mathrm{NO}_{\mathrm{x}}, \mathrm{CO}, \mathrm{THC}$, and opacity with the exception of $\mathrm{CO}$ in key state 4, THC and CO in key state 7 and $\mathrm{NO}_{\mathrm{x}}$ in key state 8.

Differences in the emission rate between fuels within key states is attributable to fuel chemistry, physical properties, the combustion process and their complex interrelationship. The mean values of the thermodynamic indicators used in the present study are given in Table 6-1. They are derived from measurements over a range of common timing conditions within each key state. Measurement uncertainty of the emissions data is discussed in Appendix C.

Referring to Figure 6-1 (with the above exceptions), each operating condition displayed similar trends for each of the two test fuels. Indeed, while the general absolute emissions levels were different, their trends are similar with respect to changing engine conditions. In all cases, FT fuel yielded a shorter ignition delay in all cases due to its high cetane number. A shorter ignition delay results in less fuel energy injected during the premixed combustion phase resulting in a much smaller heat release rate. Figure 6-2 demonstrates the sensitivity and uniformity of $\mathrm{NO}_{\mathrm{x}}$ to the amount of heat released during the premixed combustion phase. The FT fuel averaged about a $30 \%$ shorter ignition delay than DF over all key states. The reduced quantity of fuel evaporation occurring before ignition reduced the amount of energy released during the premixed combustion phase. 
Table 6-1. Thermodynamic Indicators

\begin{tabular}{|c|c|c|c|c|c|c|c|}
\hline \multicolumn{8}{|c|}{ Federal Diesel No. 2/ Fischer Tropsch } \\
\hline & KS 8 & KS 7 & KS 6 & KS 5 & KS 4 & KS 3 & KS 2 \\
\hline Load (nm) & $158.6 / 158.3$ & $190.4 / 189.6$ & $31.9 / 32.3$ & 32.12 / 32.09 & $255.3 / 255.4$ & $154.6 / 158.3$ & $32.6 / 32.8$ \\
\hline Opacity (\%) & No Data & No Data & No Data & No Data & No Data & $11.90 / 8.12$ & No Data \\
\hline $\begin{array}{c}\mathrm{NO}_{\mathrm{x}} \\
(\mathrm{g} / \mathrm{hp}-\mathrm{hr})\end{array}$ & $13.43 / 14.29$ & $15.34 / 12.94$ & $22.58 / 18.39$ & $17.26 / 17.13$ & 17.09 / 15.52 & $16.81 / 15.92$ & $16.19 / 14.53$ \\
\hline $\begin{array}{c}\text { THC } \\
\text { (g/hp-hr) }\end{array}$ & $0.22 / 0.19$ & $0.54 / 0.69$ & $1.63 / 1.24$ & $3.53 / 1.53$ & $0.11 / 0.19$ & $0.22 / 0.16$ & $4.43 / 2.39$ \\
\hline $\begin{array}{c}\text { CO } \\
\text { (g/hp-hr) }\end{array}$ & $1.06 / 0.51$ & $5.56 / 5.63$ & $4.39 / 2.19$ & $7.20 / 2.64$ & $1.16 / 1.75$ & $1.48 / 1.04$ & $6.77 / 3.93$ \\
\hline $\begin{array}{c}\text { Exhaust Temp } \\
\text { (C) }\end{array}$ & 408.7 / 405.2 & $397.8 / 397.0$ & 289.3/295.8 & 269.2 / 271.3 & 474.7 / 473.4 & $531.6 / 524.6$ & $250.7 / 253.8$ \\
\hline $\begin{array}{c}\text { Thermal } \\
\text { Efficiency (\%) }\end{array}$ & $38.91 / 38.92$ & $36.68 / 36.27$ & $21.20 / 20.82$ & $22.56 / 22.25$ & 40.72 / 40.64 & $35.23 / 36.06$ & $24.74 / 24.08$ \\
\hline $\begin{array}{c}\text { Equivalence } \\
\text { Ratio }\end{array}$ & $0.47 / 0.45$ & $0.41 / 0.40$ & $0.29 / 0.29$ & $0.29 / 0.29$ & $0.54 / 0.54$ & $0.71 / 0.68$ & $0.30 / 0.29$ \\
\hline APMAX ( $\left.{ }^{\circ} \mathrm{CA}\right)$ & $6.37 / 6.91$ & $4.46 / 4.69$ & $-0.18 / 1.52$ & $5.46 / 4.29$ & $5.28 / 5.29$ & $7.16 / 7.20$ & $5.57 / 3.81$ \\
\hline ARMAX $\left({ }^{\circ} \mathrm{CA}\right)$ & $-5.80 /-6.70$ & $-11.13 /-13.75$ & $-1.67 /-3.00$ & $1.36 /-2.07$ & $-9.91 /-5.13$ & $-4.60 /-4.47$ & $-0.36 /-2.78$ \\
\hline MFB5\% $\left({ }^{\circ} \mathrm{CA}\right)$ & $\begin{array}{l}-7.64 / \\
-10.41\end{array}$ & $-13.16 /-15.52$ & $-5.16 /-7.58$ & $-0.22 /-3.11$ & $\begin{array}{c}-13.01 / \\
-15.04 \\
\end{array}$ & $-7.03 /-7.88$ & $-1.87 /-4.31$ \\
\hline MFB10\% $\left({ }^{\circ} \mathrm{CA}\right)$ & $-6.66 /-8.98$ & $-11.96 /-13.59$ & $-4.89 /-7.09$ & $0.19 /-2.71$ & $\begin{array}{c}-11.91 / \\
-13.16 \\
\end{array}$ & $-5.84 /-6.57$ & $-1.39 /-3.86$ \\
\hline MFB50\% $\left({ }^{\circ} \mathrm{CA}\right)$ & $1.09 / 1.84$ & $-1.83 /-0.95$ & $-2.80 /-1.24$ & $2.52 / 1.05$ & $-1.96 /-1.49$ & $1.80 / 1.90$ & $1.78 /-0.35$ \\
\hline MFB90\% $\left({ }^{\circ} \mathrm{CA}\right)$ & 44.24 / 41.32 & $57.66 / 57.82$ & $63.77 / 65.38$ & $53.21 / 53.91$ & 44.94 / 44.20 & $51.13 / 45.68$ & $54.68 / 52.79$ \\
\hline Comb Dur $\left({ }^{\circ} \mathrm{CA}\right)$ & $50.91 / 50.30$ & $69.63 / 71.40$ & $68.66 / 72.48$ & 53.02 / 56.62 & 56.85 / 57.37 & 56.97 / 52.25 & $56.06 / 56.66$ \\
\hline $\begin{array}{c}\text { 90-50 (Diff. } \\
\text { Burn) }\end{array}$ & 43.15 / 39.48 & $59.49 / 58.77$ & $66.57 / 66.63$ & $50.69 / 52.86$ & $46.90 / 45.70$ & $49.33 / 43.78$ & $52.89 / 53.14$ \\
\hline RMAX & $8.88 / 5.18$ & $8.91 / 5.54$ & $17.44 / 9.06$ & $6.89 / 5.42$ & $11.52 / 8.79$ & $8.61 / 5.04$ & $4.39 / 4.83$ \\
\hline PMAX & 93.06 / 91.94 & $135.20 / 134.5$ & $59.61 / 51.71$ & 41.59 / 41.13 & $140.99 / 138.56$ & $77.98 / 78.93$ & $37.51 / 38.77$ \\
\hline SOI $\left({ }^{\circ} \mathrm{CA}\right)$ & $\begin{array}{r}-14.84 / \\
-15.04 \\
\end{array}$ & $-23.1 /-23.1$ & $-18.58 /-18.47$ & $\begin{array}{r}-11.83 / \\
-11.56 \\
\end{array}$ & $\begin{array}{c}-20.03 / \\
-19.90 \\
\end{array}$ & $\begin{array}{c}-11.14 / \\
-11.23 \\
\end{array}$ & $-10.6 /-12.29$ \\
\hline $\mathrm{EOI}\left({ }^{\circ} \mathrm{CA}\right)$ & $-1.18 /-1.42$ & $1.11 / 1.59$ & $-9.92 /-9.7$ & $-7.17 /-7.77$ & $-0.83 /-0.53$ & $-2.73 /-2.68$ & $-7.36 /-8.56$ \\
\hline Inj Dur $\left({ }^{\circ} \mathrm{CA}\right)$ & $13.66 / 13.62$ & $24.21 / 24.68$ & $8.67 / 8.77$ & $4.66 / 3.79$ & $19.20 / 19.37$ & $8.41 / 8.56$ & $3.24 / 3.73$ \\
\hline $\operatorname{soc}\left({ }^{\circ} \mathrm{CA}\right)$ & $-9.02 /-11.99$ & $-14.65 /-17.31$ & $-6.67 /-9.08$ & $-1.79 /-4.57$ & $\begin{array}{c}-14.74 / \\
-17.11 \\
\end{array}$ & $-9.19 /-9.35$ & $-4.37 /-6.67$ \\
\hline Ign Delay $\left({ }^{\circ} \mathrm{CA}\right)$ & $5.82 / 3.10$ & $8.45 / 5.79$ & $11.92 / 9.38$ & $10.04 / 6.99$ & $5.29 / 2.79$ & $1.95 / 1.88$ & $6.22 / 5.61$ \\
\hline Premixed Peak & 198.14 / 98.67 & $196.87 / 107.9$ & $267.83 / 168.2$ & 153.34 / 122.64 & $237.90 / 126.19$ & $189.71 / 105.36$ & $110.2 / 111.8$ \\
\hline $\begin{array}{c}\text { Premixed } \\
\text { Location }\left({ }^{\circ} \mathrm{CA}\right) \\
\end{array}$ & $-5.92 /-9.32$ & $-11.13 /-13.69$ & $-3.98 /-6.33$ & $1.16 /-1.87$ & $-11.47 /-14.27$ & $-4.64 /-5.46$ & $0 /-2.8$ \\
\hline Diffusion Peak & 75.58 / 81.92 & $71.31 / 85.68$ & No Data & No Data & $104.33 / 116.18$ & 68.46 / 98.50 & No Data \\
\hline $\begin{array}{l}\text { Diffusion Peak } \\
\text { Location }\left({ }^{\circ} \mathrm{CA}\right)\end{array}$ & $2.28 /-0.82$ & $-2.63 /-3.5$ & No Data & No Data & $-1.96 /-5.00$ & $0.30 /-1.48$ & No Data \\
\hline
\end{tabular}




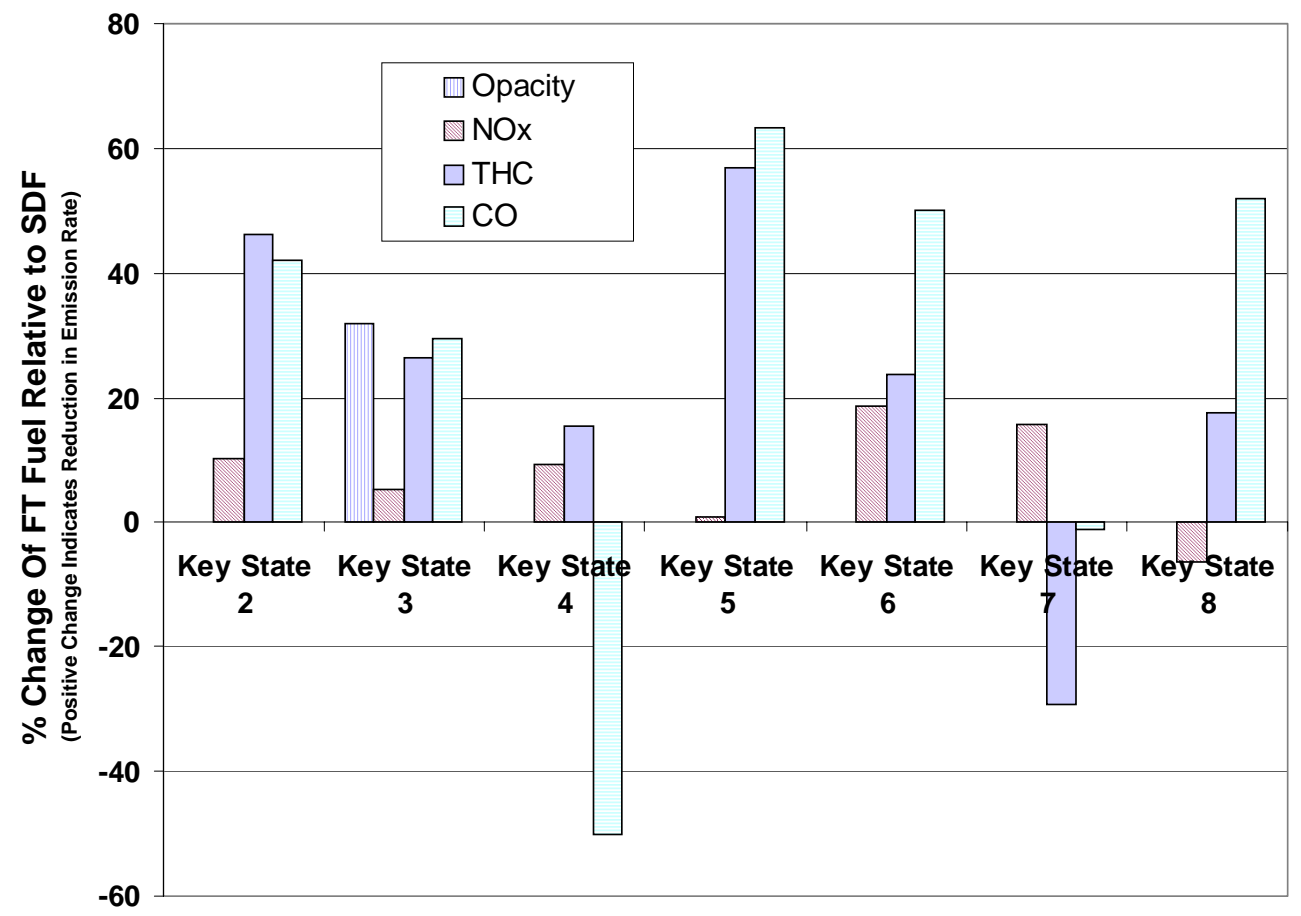

Figure 6-1. Percent change of FP emission Relative to Federal No. 2 diesel fuel $(+=$ decrease,$-=$ increase $)$.

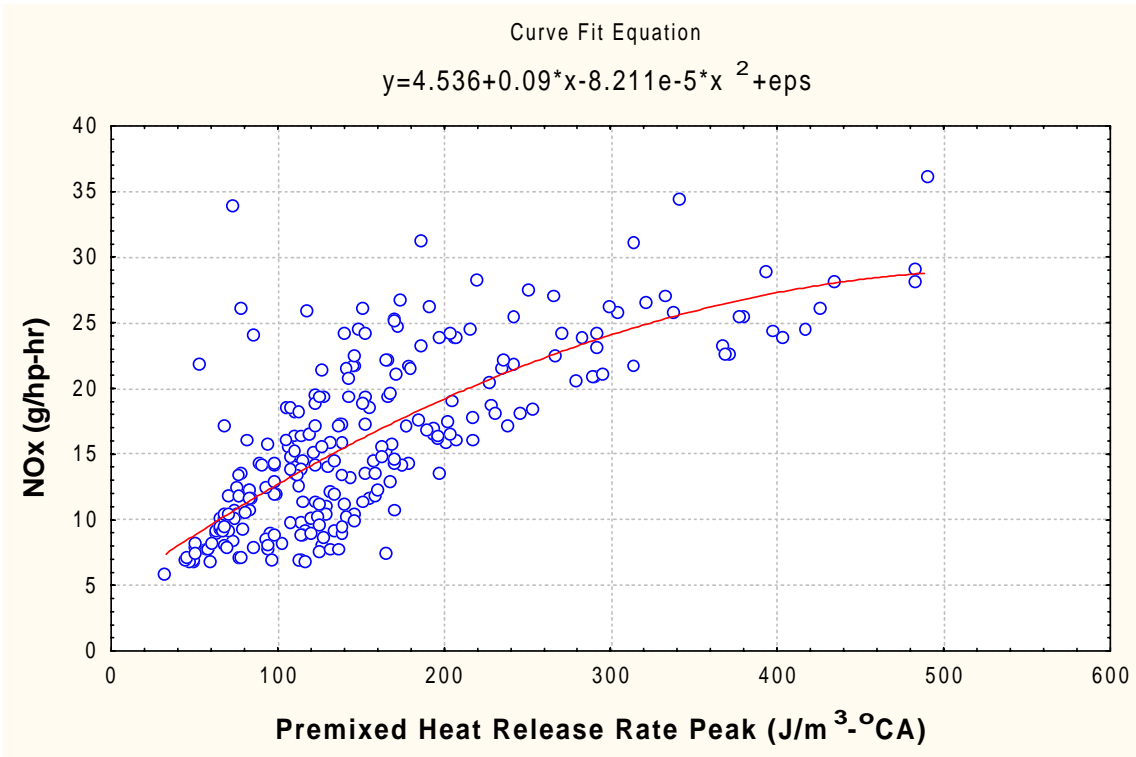

Figure 6-2. Brake specific $\mathrm{NO}_{\mathrm{x}}$ as a function of Maximum heat release rate $\left(\mathrm{J} / \mathrm{m}^{3}-{ }^{\circ} \mathrm{CA}\right)$ during the premixed combustion phase for all key states and fuel types. 
Phasing of the combustion event is important too, as heat released near TDC provides higher temperatures.

In this study, there was no apparent functional relationship between $\mathrm{NO}_{\mathrm{x}}$ and the maximum heat released in the diffusion phase. Any relationship between $\mathrm{NO}_{\mathrm{x}}$ and location of the diffusion peak appears to have been a covariant relationship with timing. Further, there is no apparent functional relationship between $\mathrm{NO}_{\mathrm{x}}$ and differences in the locations of the maximum diffusion heat release rate. $\mathrm{NO}_{\mathrm{x}}$ was not a significant function of exhaust temperature for any operating condition (key state). For both fuels and all key states, the magnitude of the premixed spike increased monotonically with increasingly advanced timing. Ignition delay decreased accordingly.

Significance has been given in the literature to the relative magnitudes of heat released in the premixed phase versus heat released in the diffusion phase. The diffusion peak of the heat release rate was consistently greater for FT fuel while the location of the diffusion peak was covariant with the location of the start of combustion as well as the $50 \%$ to $90 \%$ diffusion burn duration. This follows the logic that since the heat release rate of the premixed combustion phase was lower due to shorter ignition delay, the diffusion phase must contain more energy. This is demonstrated in Figure 6-3. Figure 6-3 shows the premixed and diffusion heat release maximum heat release rates for all key states and each fuel type. As can be seen, increasing the portion of fuel mixed in with the premixed phase naturally subtracts from the diffusion phase. The relative differences between FT and DF maximum heat release rate during the diffusion combustion phase is demonstrated by key state 3 in Figure 6-4. 


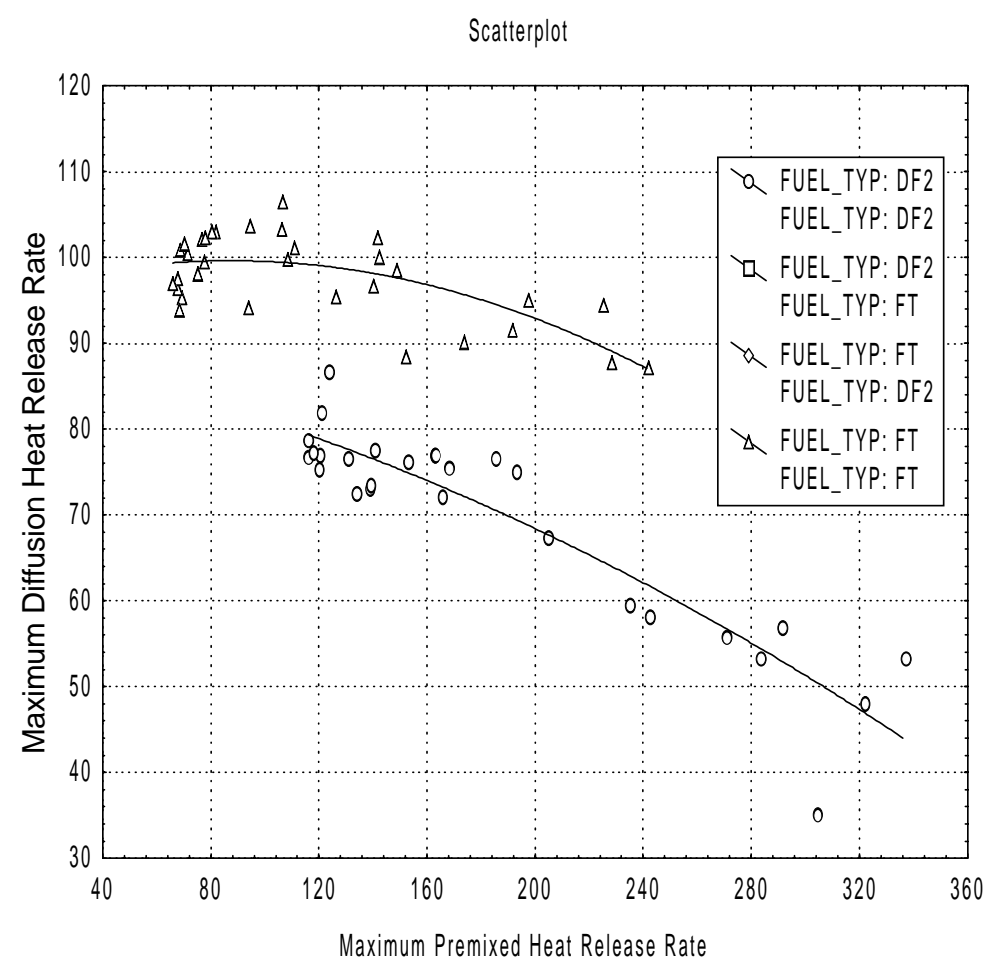

Figure 6-3. Diffusion vs. Premixed Maximum Heat Release Rate for All Key States

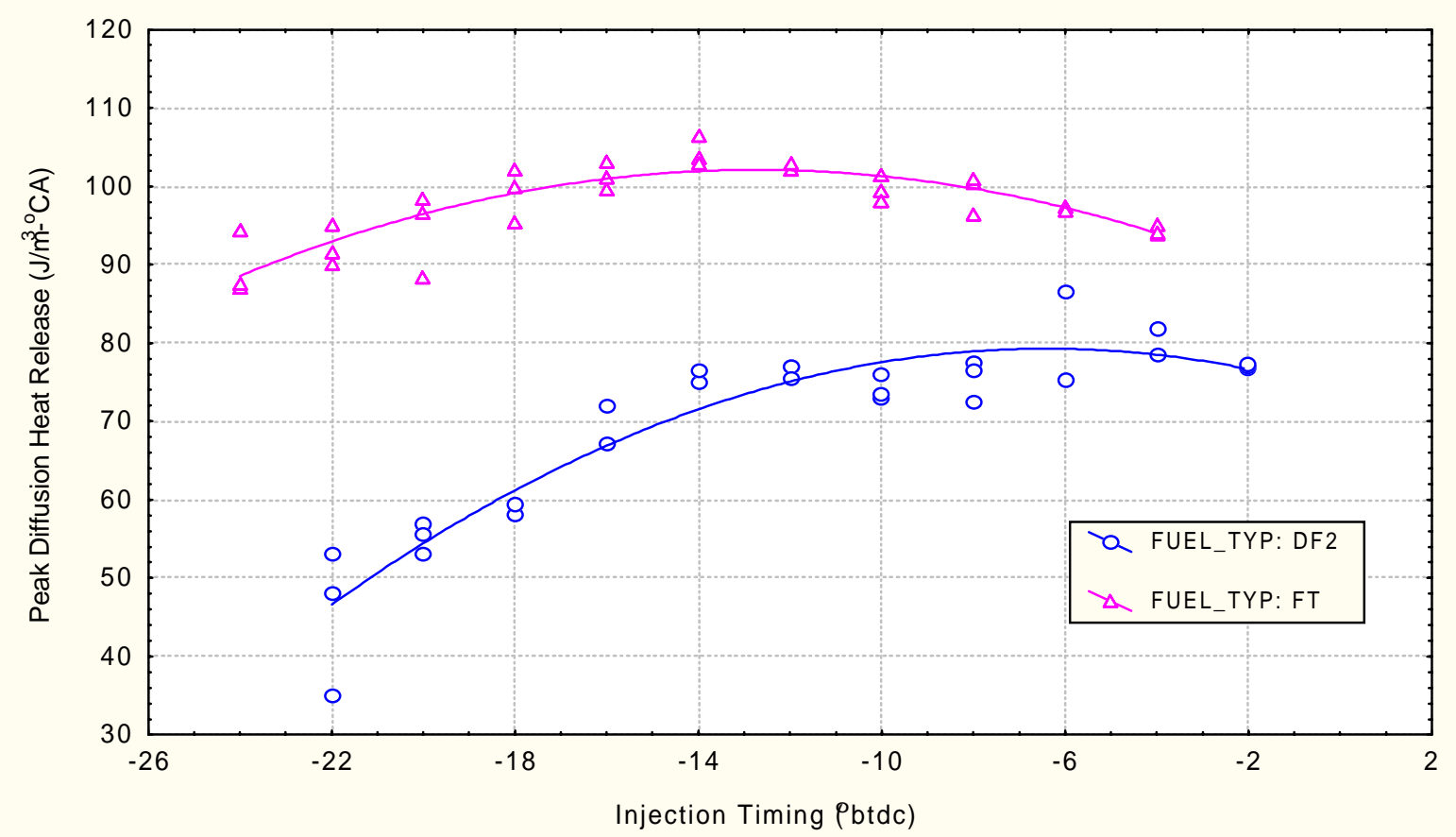

Figure 6-4. Maximum Heat Release Rate $\left(\mathrm{J} / \mathrm{m} 3-{ }^{\circ} \mathrm{CA}\right)$ During the Diffusion Combustion Phase for Key State 3 (FT fuel is represented by the top curve) 
The overall burn duration was very similar between fuels. The diffusion burn rate between the $50 \%$ and $90 \%$ MFB locations was generally shorter for FT with the exception of key state 3. Peak combustion pressures were very similar and are in agreement with findings of Atkinson et al., (1999).

Opacity was measured at key state 3 and is given as a function of timing in Figure 6-5. There appears to be a functional relationship between opacity at key state 3 and the peak energy released in the diffusion burning phase for standard diesel fuel but not for FT fuel. This may be indicative of the differences in fuel chemistry as $\mathrm{C} / \mathrm{H}$ ratio has been considered a fairly strong indicator of sooting propensity (Tosaka et al., 1989). However, in general it is difficult to correlate soot emissions with heat release characteristics. Several factors related to in-cylinder fluid dynamics and mixing probably dominate over any single factor such as temperature dominates $\mathrm{NO}_{\mathrm{x}}$ formation.

The maximum heat release rates during the diffusion combustion phase are also dependent on the fuel injection duration. In general, FT fuel had a longer injection duration due to its lower density. When considering FT fuel's lower density and slightly higher energy content per unit mass, one would expect approximately $4.5 \%$ more fuel volume to be injected per injection at the same engine output. Recall that the test procedure calls for constant torque at all timing points requiring a a fueling adjustment after each timing change. This result indicates only a slightly longer mean fuel injection duration (0.6\%) as evidenced in Table 6-1. This discrepancy is intractable from this study. 


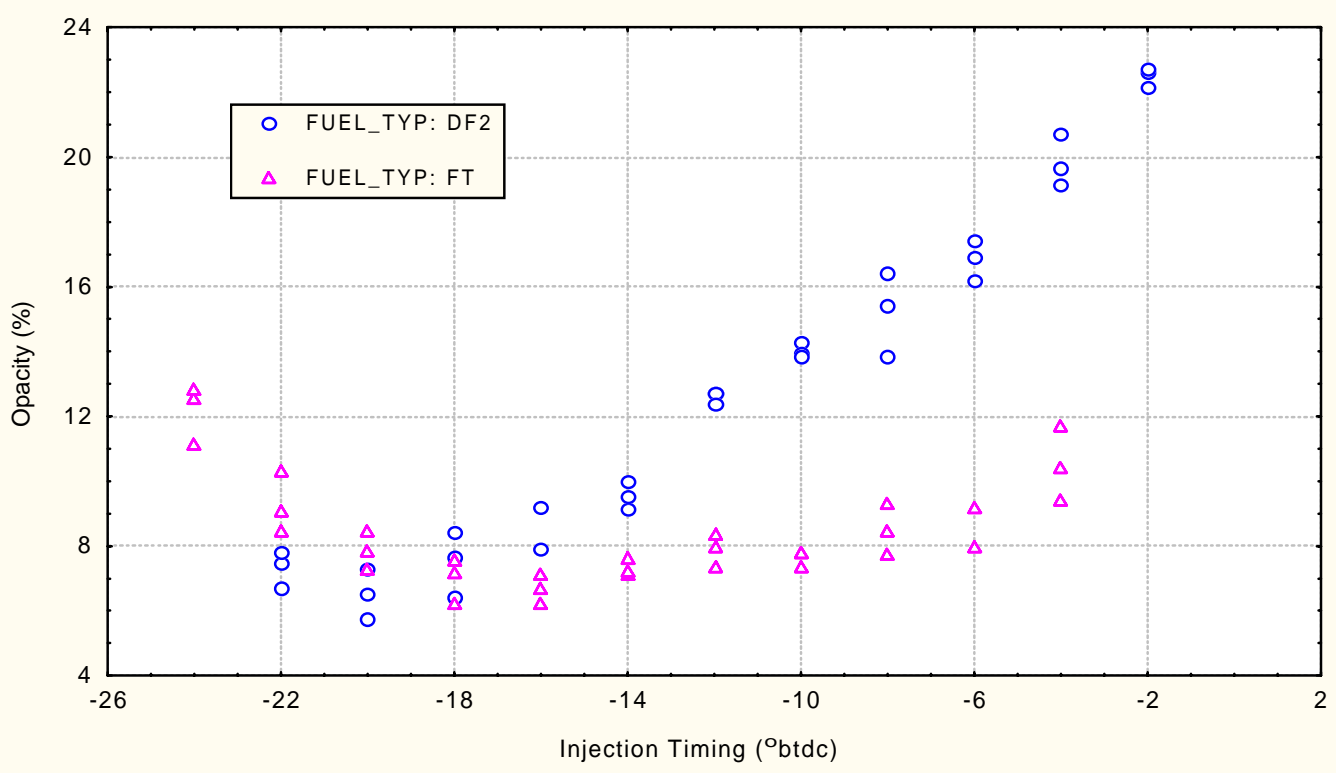

Figure 6-5. Opacity as a Function of Injection Timing for Key State 3 (The lower curve is FT fuel)

Under diffusion burning conditions and in the absence of significant differences in ignition delay, both $\mathrm{NO}_{\mathrm{x}}$ and $\mathrm{PM}$ have been found to be primarily dependent on the fuel $\mathrm{C} / \mathrm{H}$ ratio as well as a function of various aspects of fuel boiling range. The lower aromatic content of FT fuel is primarily responsible for lower $\mathrm{C} / \mathrm{H}$ ratio and for higher boiling point.

The differences in the shape of the heat release rate curves between standard diesel fuel and FT fuel are rather striking. A visual inspection demonstrates the overwhelming effect of a shorter ignition delay provided by the high cetane number of FT fuel has in the premixed combustion phase. Figures 6-6 through 6-12 give typical heat release curves. Each set of curves contain both advanced and retarded timing setting and visually typify differences between the test fuels. As mentioned above, the phasing of the heat release rate is important for the effect on maximum torque timing as well as emission phenomena. What is very apparent from each of 


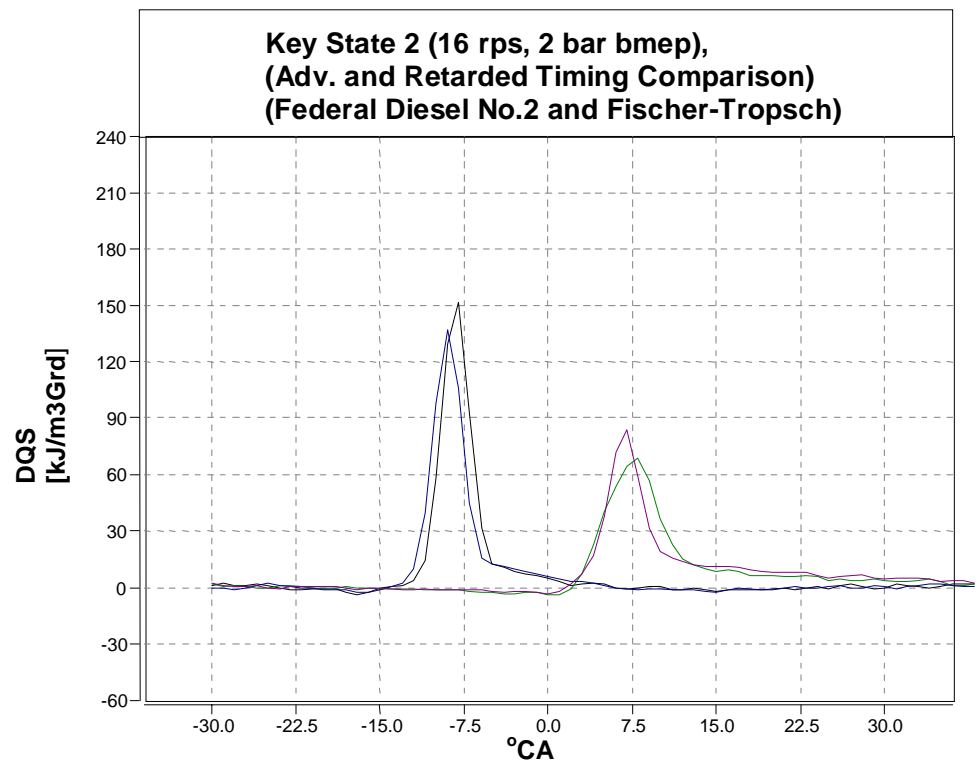

Figure 6-6. Comparison of heat release rate $\left(\mathrm{kJ} / \mathrm{m}^{3}{ }^{\circ} \mathrm{CA}\right)$ at key state 2 for DF and FT fuels at common timing (FT fuel is on the left in each of the two groups of curve pairs)

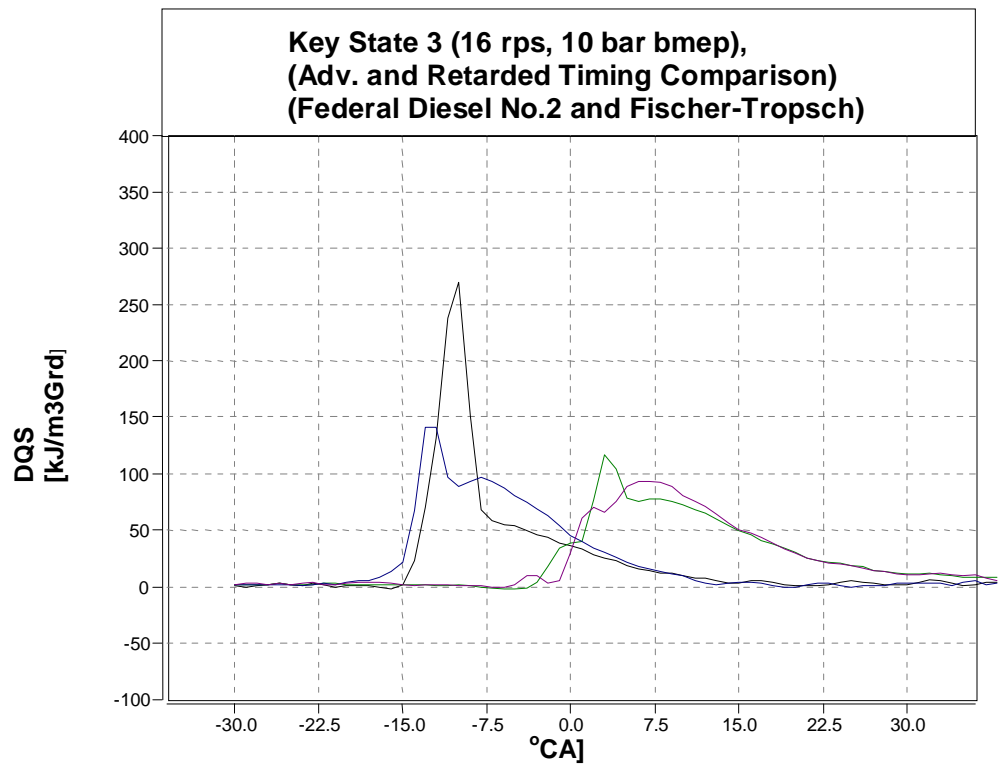

Figure 6-7. Comparison of heat release rate $\left(\mathrm{kJ} / \mathrm{m}^{3}{ }^{\circ} \mathrm{CA}\right)$ at key state 3 for DF and FT fuels at common timing (FT fuel is on the left in each of the two groups of curve pairs) 


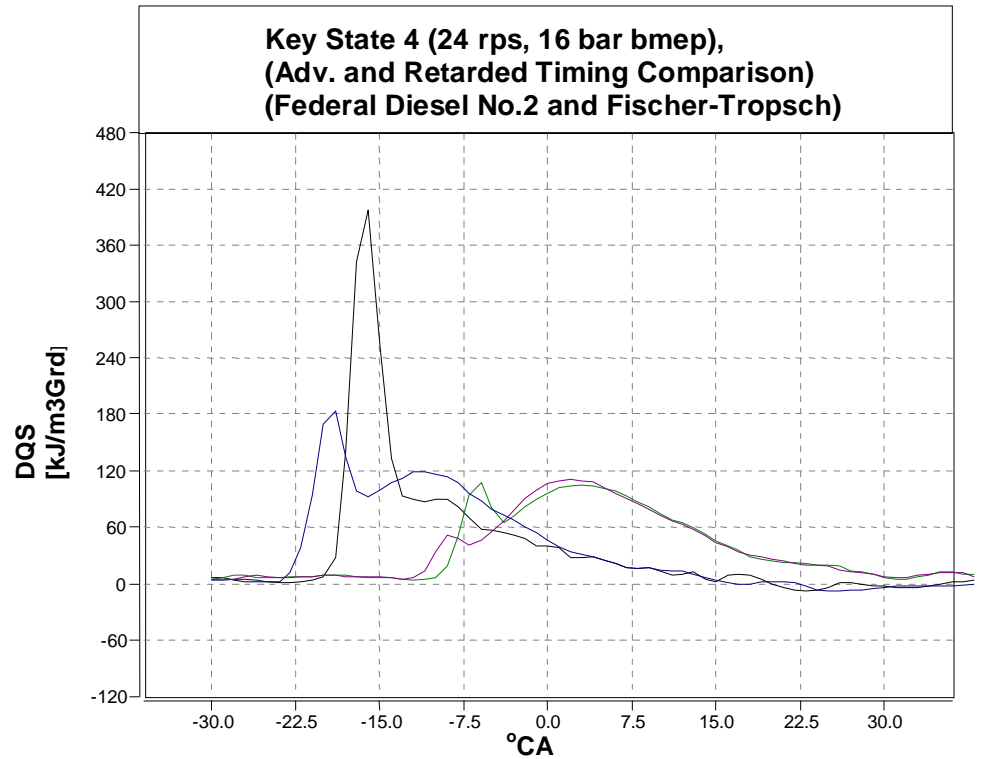

Figure 6-8. Comparison of heat release rate $\left(\mathrm{kJ} / \mathrm{m}^{3}{ }^{\circ} \mathrm{CA}\right)$ at key state 4 for DF and FT fuels at common timing (FT fuel is on the left in each of the two groups of curve pairs)

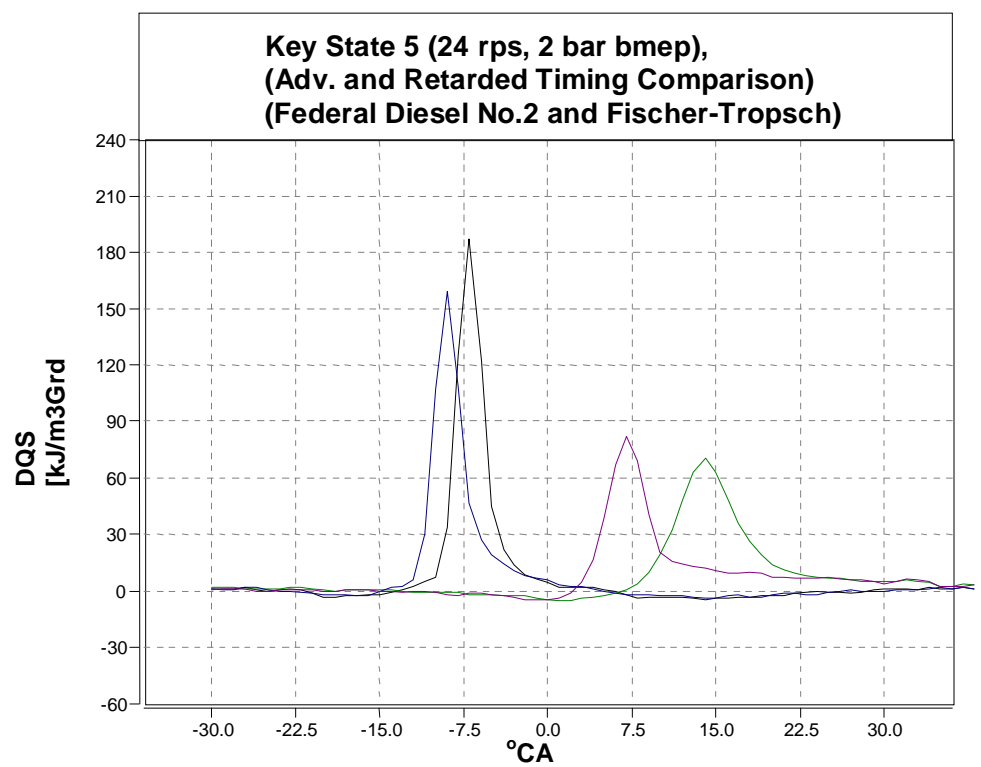

Figure 6-9. Comparison of heat release rate $\left(\mathrm{kJ} / \mathrm{m}^{3}{ }^{\circ} \mathrm{CA}\right)$ at key state 5 for DF and FT fuels at common timing (FT fuel is on the left in each of the two groups of curve pairs) 


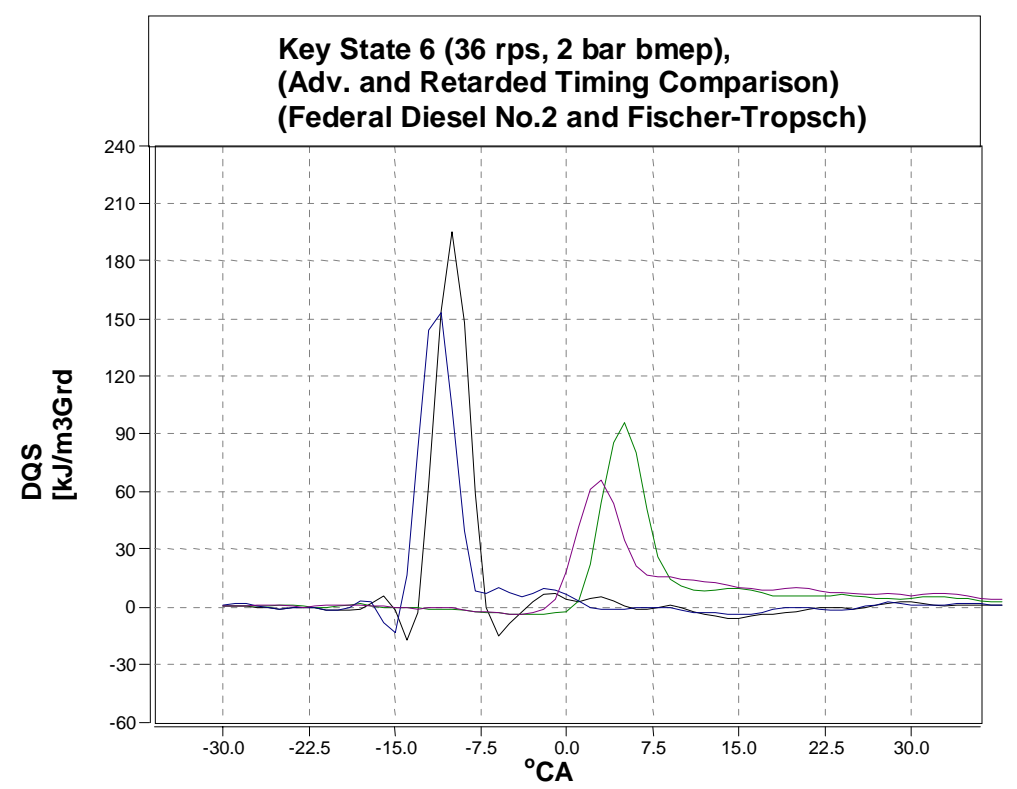

Figure 6-10. Comparison of heat release rate $\left(\mathrm{kJ} / \mathrm{m}^{3}{ }^{\circ} \mathrm{CA}\right)$ at key state 6 for DF and FT fuels at common timing ( FT fuel is on the left in each of the two groups of curve pairs)

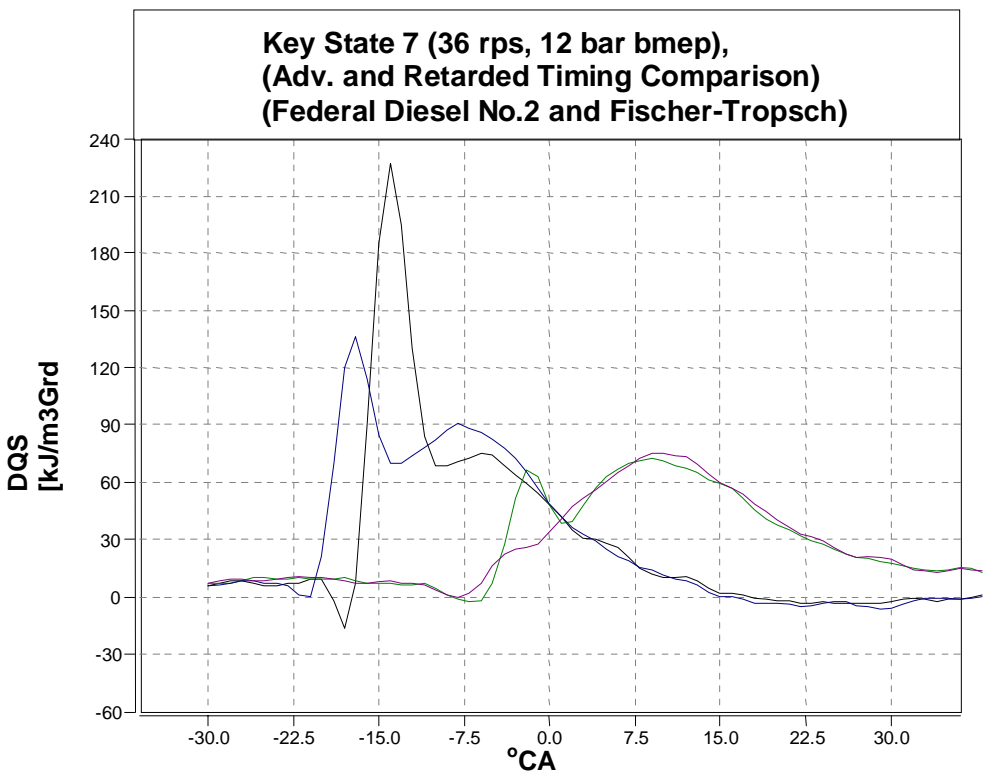

Figure 6-11. Comparison of heat release rate $\left(\mathrm{kJ} / \mathrm{m}^{3}{ }^{\circ} \mathrm{CA}\right)$ at key state 7 for DF and FT fuels at common timing (FT fuel is on the left in each of the two groups of curve pairs) 


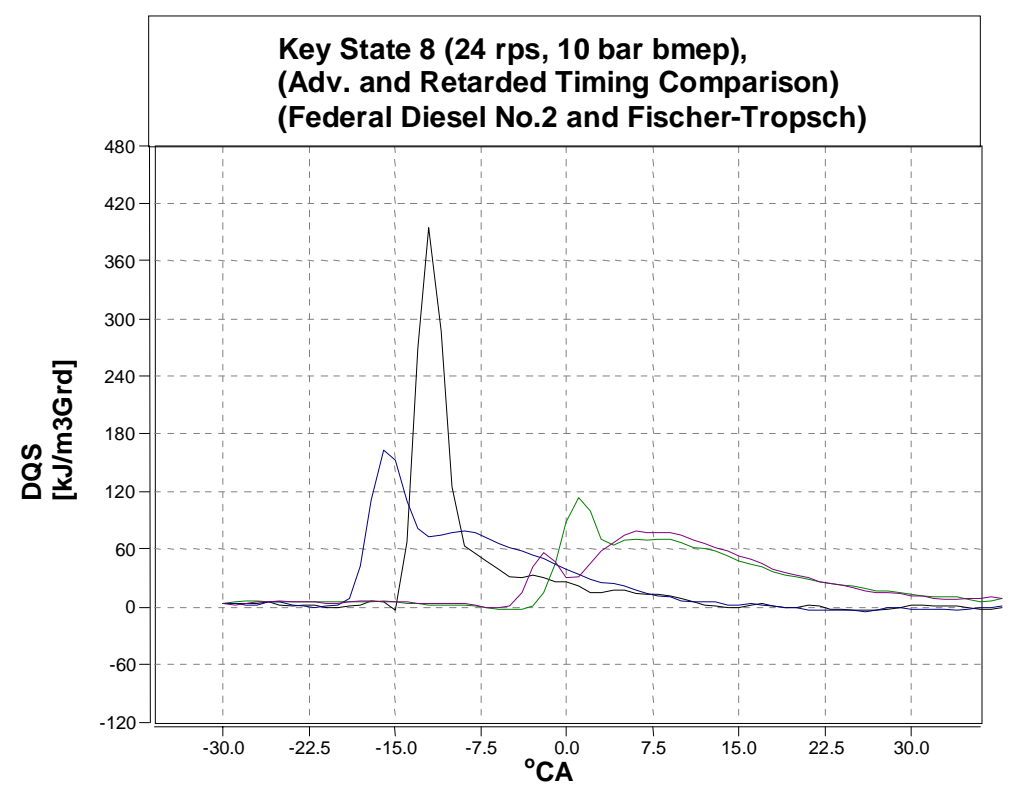

Figure 6-12. Comparison of heat release rate $\left(\mathrm{kJ} / \mathrm{m}^{3}{ }^{\circ} \mathrm{CA}\right)$ at key state 8 for DF and FT fuels at common timing (FT fuel is on the left in each of the two groups of curve pairs)

Figures 6-6 through 6-12 is the high rate of heat release during the premixed combustion phase for DF fuel and for advanced timing conditions. The ignition delay differences between fuels as well as the diffusion phase differences are also apparent. No diffusion phase is visible in the low-load key states 2, 5 and 6 . This is because at such low loads the injection duration is so short that nearly all of the fuel is injected prior to start of combustion.

Carbon monoxide (CO) brake specific emissions were lower for FT fuel at all engine conditions except at key state 4 and slightly at key state 7 . Total hydrocarbon (THC) brake specific emissions were lower for FT fuel with the exception of key state 7. Scatterplots of THC and $\mathrm{CO}$ as a function of ignition delay are given in Figures 6-13 and 6-14 respectively for all key states. The general reductions in $\mathrm{CO}$ and THC emissions are in concert with several previous 


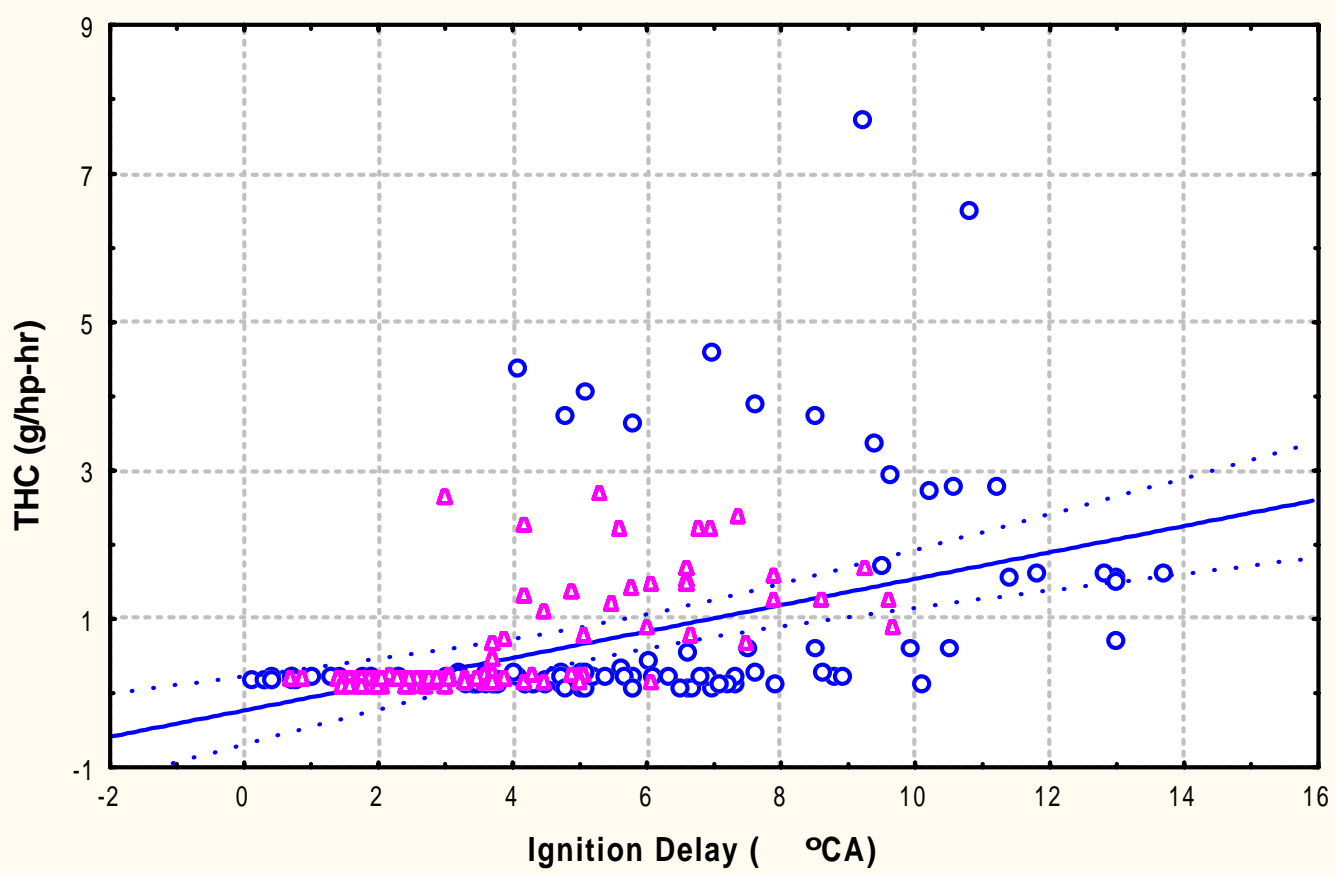

Figure 6-13. Total Hydrocarbon emissions (g/hp hr) (ungrouped) for all key states as a function of ignition delay.

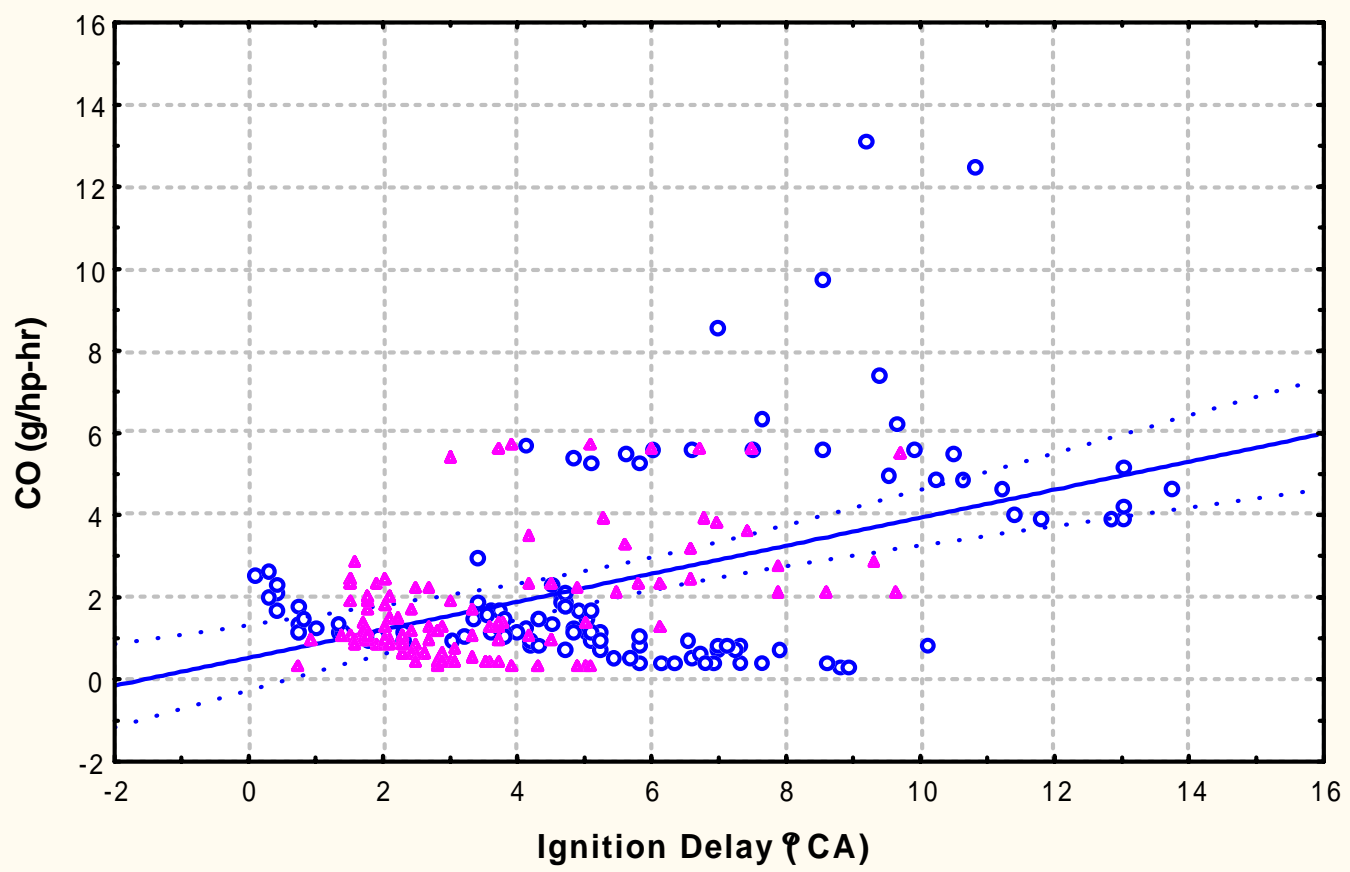

Figure 6-14. CO emissions ( $\mathrm{g} / \mathrm{hp} \mathrm{hr}$ ) (ungrouped) for all key states as a function of ignition delay. 
findings and are well represented by Schaberg et al., (1997); Schaberg et al., (2000); and Ryan and Montalvo (1997). The increase in emissions of CO and THC at key state 4 and 7 respectively is puzzling.

Several studies have attempted to correlate fuel properties with THC and CO emissions. Weidmann et al., (1988) concluded that cetane number and density had the highest effect on THC and CO reductions. Ullman et al., (1990) and Ullman et al., (1995) both linked THC emissions to the effect of cetane number. Figures 6-13 and 6-14 tend to support these conclusions since cetane number is directly correlated to ignition delay. However the mechanism as to the effect of reduce ignition delay on THC and CO emissions is not clear. Kidoguchi et al., (2000), surmised that for low loads, lower cetane fuels produce higher THC due to locally over lean mixtures. Payri et al., (2000), reports that there is no advantage for THC and CO with the FT fuels in terms of atomization and equivalence ratio in the mixture. In the present study, global equivalence ratio was very similar between fuels at each engine state with slight differences probably not nearly accountable for the changes observed.

Paraffins, which are the overwhelmingly largest constituent of FT fuel, tend to yield more reactive radicals than the cyclic compounds found in Federal No. 2 diesel fuel. This is basically the chemistry behind the shorter ignition delay. The effects on combustion rate due to chemistry are much less since the chain branching radicals and hydroxyls are more concentrated during the period leading up to ignition.

Since THC and CO each come from incomplete combustion, their emissions have similar trends in regard to emission levels versus changes in engine combustion and fuel atomization. In essence the differences in the $\mathrm{THC}$ and $\mathrm{CO}$ emissions come in part from the differences in $\mathrm{C} / \mathrm{H}$ ratio between FT and DF and from physical effects. 
The primary source of unburned fuel in the form of $\mathrm{CO}$ and THC must come from either overly rich or overly lean regions of combustion or due to flame quenching or spray cooling at the walls of the combustion chamber. Rich combustion does not appear to be a strong candidate since $\mathrm{CO}$ and $\mathrm{THC}$ is quite high for the leanest conditions of key state 5 . This conclusion is also supported by the work of Payri et al., (2000). Over mixing is a possibility as both CO and THC track will with ignition delay. Over fueling may have a bigger effect on THC than with CO. FT fuels typically have a lower boiling point than DF. The evaporation process occurs faster with FT fuel, therefor wall impingement quenching is less probable with FT fuel. The determining factors behind the differences in THC and CO levels between FT and DF will require more analysis and perhaps a more dedicated test plan designed to isolate the effects of over mixing, over fueling and flame quenching effects.

\subsection{Particulate Matter Source Analysis}

PM composition is determined using the methods outlined in Section 5.2. This method really determines from what source the PM constituents are derived. The SOF is assumed to come from either unburned fuel or unburned lube oil. Sulfates and insolubles are also accounted for via ion chromatography and via weight difference, respectively. Results of the PM source analysis for the total particulate matter samples is given in Figure 6-15.

The data in Figure 6-15 are qualitatively consistent with those from Cartellieri and Tritthart, (1984), in which several IDI diesel passenger cars were tested over the FTP75 cycle. In their study, insolubles ranged from around $50 \%$ by mass to nearly $90 \%$ by mass with lube oil making up the bulk of the soluble mass. These data are also qualitatively consistent with that of Schaberg et al., (1997) and Schaberg et al., (2000). In each study, the authors looked at 


\section{Diesel Particulate Composition}

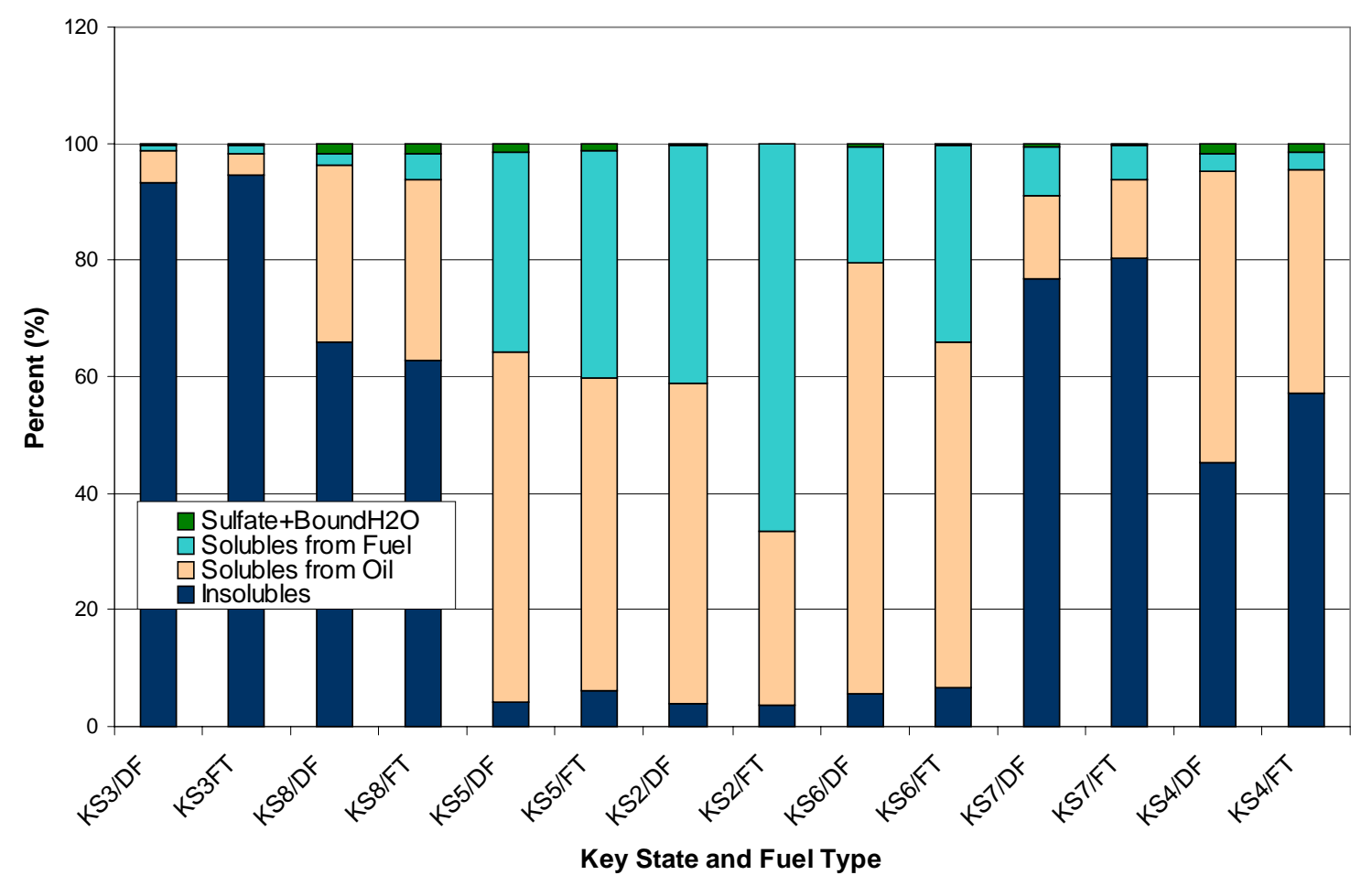

Figure 6-15. Diesel particulate matter composition by key state and fuel type.

particulate source from cold and hot start testing of several fuel blends including neat FT fuels and standard Federal No. 2 diesel fuel. They compared their results from a 1999 engine to that of a 1991 engine and concluded that in the 1991 engine the FT fuel reduced PM emissions over that of standard diesel fuel by equally reducing both solubles and insolubles while in the 1999 engine, the reduction was primarily due to the reduction of the insoluble portion. In all cases the amount of oil derived solubles exceeded the amount of fuel derived solubles. While the results of Figure 6-15 are in qualitative agreement, quantitative agreement is impossible due to differences in engine type, engine operation and fuel type. The contribution of fuel and oil to the soluble portion of the particulate matter is highlighted in Figure 6-16. Figure 6-16 also contains information based on particle size from the MOUDI samples. Insolubles and sulfate + bound 


\section{Fraction Fuel and Oil Contribution to SOF}

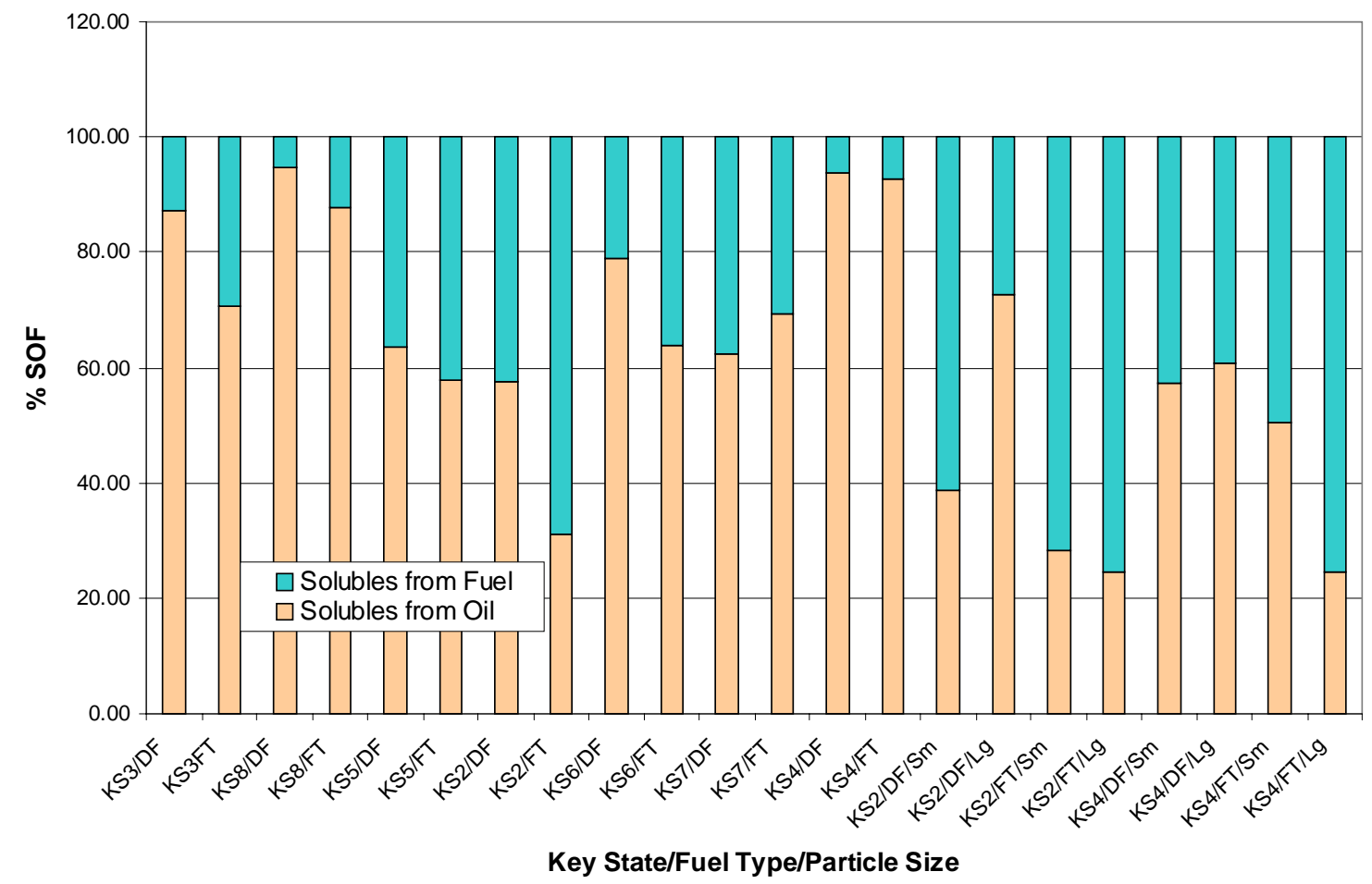

Figure 6-16. Fuel and oil contribution to the soluble organic fraction.

water information cannot be obtained from the MOUDI samples since all material was lost during the soxhlet extraction process.

A correlation between total particulate matter soluble fraction components (fuel and oil derived) and mutagenicity data was not possible in this study due to the autocorrelation of fuel and oil solubles with operating conditions. One could envision a test in which the lube oil contribution is varied by adjusting ring clearances or by controlling and varying crankcase pressure. This type of study was outside the scope of the present work. It is still interesting to note the trend of the lube oil contribution, as functions of engine speed and load, to the soluble organic fraction of the total particulate matter. Figures 6-17 and 6-18 show this qualitative trend for engine load and speed respectively. The curves presented in Figures 6-17 and 6-18 are 
Fuel and Oil Contributions to Soluble Portion vs. Engine Load

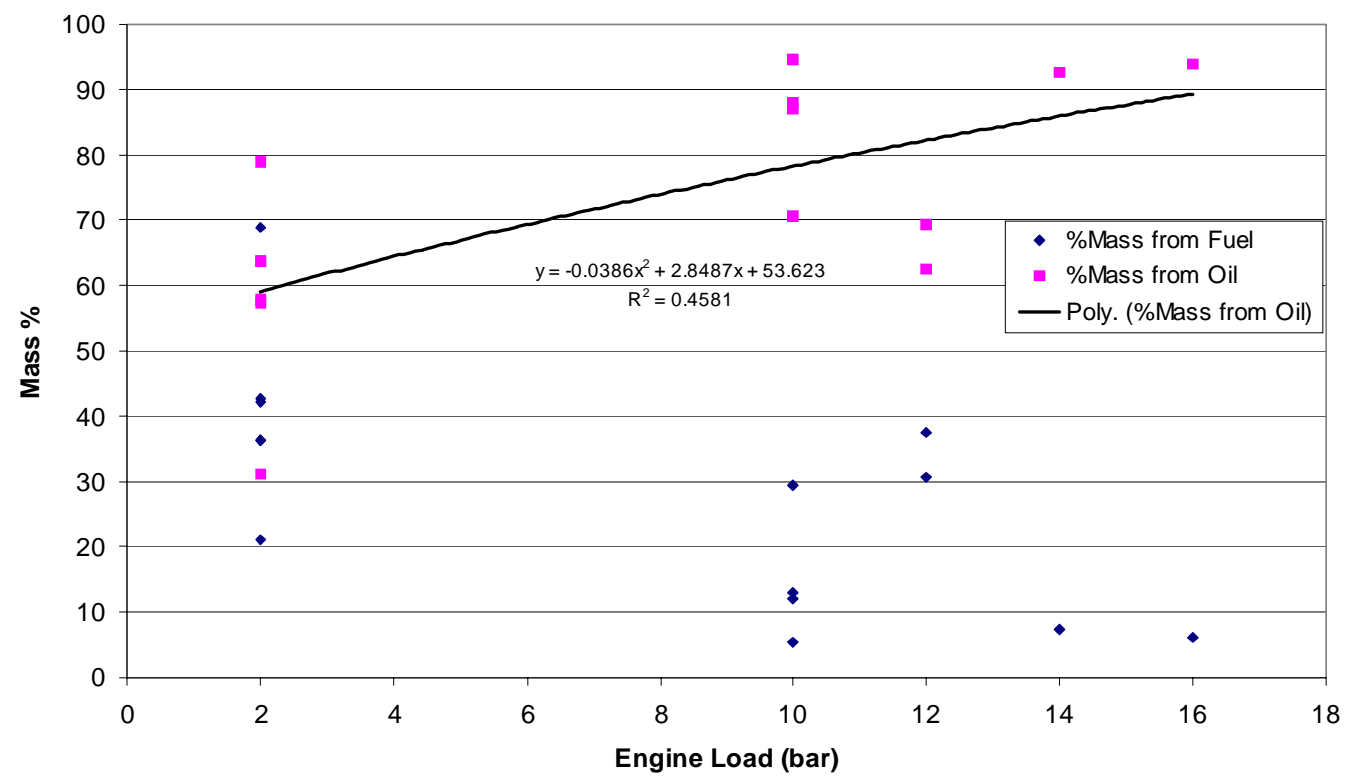

Figure 6-17. Fuel and Oil Contributions to the Soluble Portion vs. Engine Load (the curve visually represents the oil contribution trend).

Fuel and Oil Contributions to Soluble Portion vs. Engine Speed

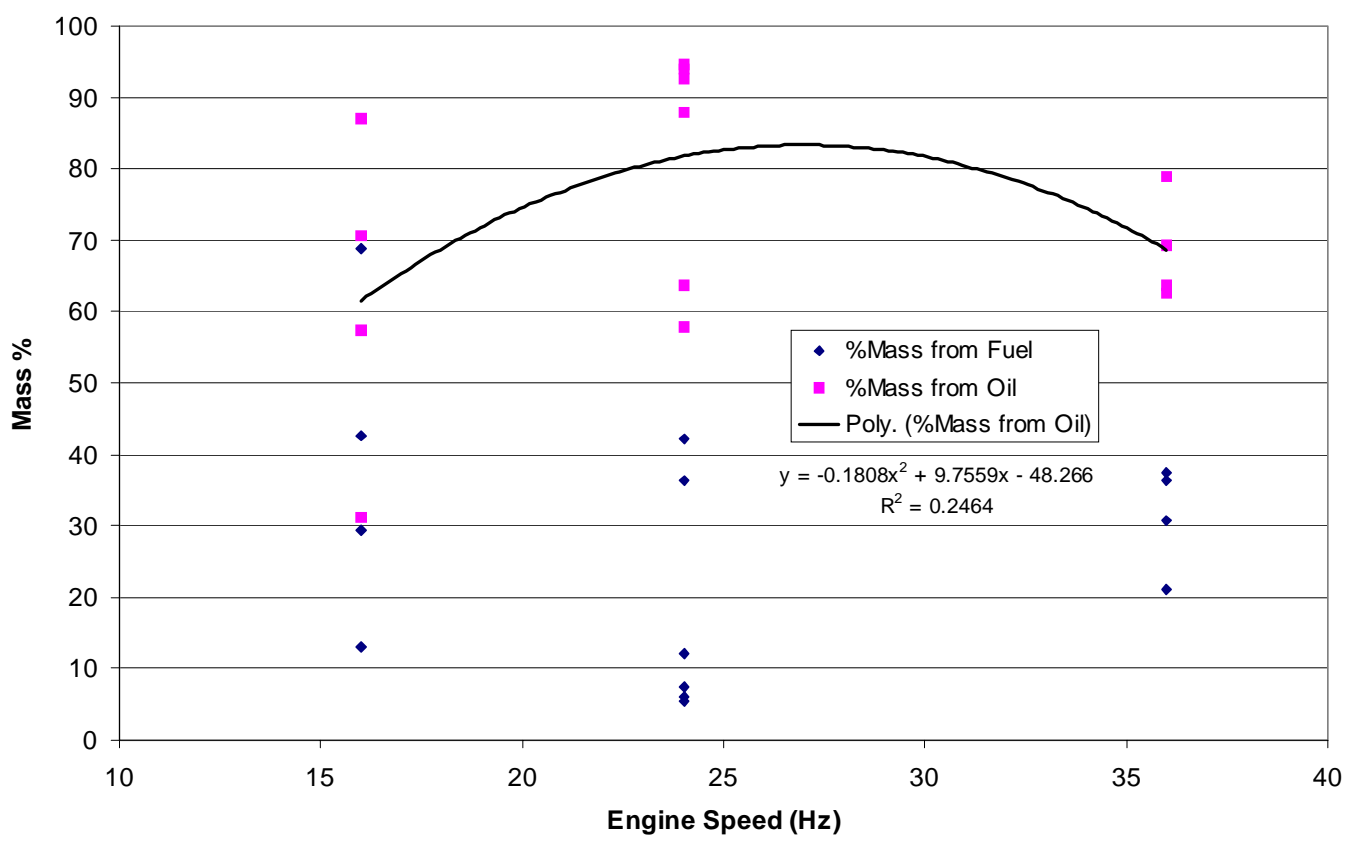

Figure 6-18. Fuel and Oil Contributions to the Soluble Portion vs. Engine Speed (the curve visually represents the oil contribution trend). 
intended to provide the reader with a visual cue as to where the data corresponding to the lube oil contribution are located. The curve is not intended to represent any significant trend.

Although no solid conclusions may be drawn from these trends, the upward trending slope indicating an increase in lube oil contribution with respect to engine load is apparent in Figure 6-17. At high load conditions, one might expect that due to the higher level of fueling the fuel component might be more dominant. However, combustion efficiency in this engine was poor at the low load conditions thus providing significant fuel contribution to the SOF. Again no conclusions can be drawn regarding engine speed effects as shown in Figure 6-18. It is apparent from reviewing the literature of Cartellieri and Tritthart, (1984) and and Schaberg et al., (2000) that the contributions of the fuel and lube oil fractions are very engine dependent. Yet, again, no conclusions regarding fuel or oil derived SOF based on engine speed or load were provided by those authors.

\subsection{Mutagenicity Study}

The mutagenicity study is separated into two major sections corresponding to the mutagenicity analysis of the total particulate matter samples and the size dependent particulate matter mutagenicity analysis.

\subsubsection{Total Particulate Matter (TPM)}

This section is further separated into two parts for discussion purposes. Total particulate mass measurements and the resulting bioassay results are discussed in the following two sections.

\subsubsection{Mass Measurements}

Total particulate filter samples were taken at the seven steady-state engine operating conditions (key states) given in Table 5-3. The engine work-specific (brake-specific) total 
particulate matter (TPM) results are given in Figure 6-19 for both Federal diesel No. 2 (DF) and the Fischer-Tropsch (FT) test fuels. Figure 6-19 shows some variability in the engine-specific (g/hp-hr) TPM with respect to both fuel type and load. The low-load conditions (key states 2, 5, and 6) generally show the highest levels of TPM emissions. This is more clearly demonstrated in Figure 6-20, which gives the average TPM over both fuels at each key state.

Key states 4 and 8 (Intermediate-speed, high-load and intermediate-speed, moderate-load respectively) demonstrate the lowest TPM. Key state 7, which represents high-speed, 75\% load yeilded about $0.46 \mathrm{~g} / \mathrm{hp}$-hr TPM. Key state 3, which is the low-speed, moderate-load case gave the highest non low-load TPM. These key states were also consistent with regard to the relative difference in TPM between each fuel type.

Again, the low-load conditions (key states 2, 5, and 6) generally produced the highest TPM. This is in part due to lower thermal efficiency at the low load conditions. When PM data are presented as mass emission rates $(\mathrm{g} / \mathrm{hr})$ the effect of thermal efficiency is reduced. Total particulate matter production at each key state in grams per hour (g/hr) is given in Figure 6-21.

The test engine, Ricardo Proteous, uses a pump-line-nozzle (PLN) type fuel injection system. It was noted in testing that the $90-\mathrm{mm}$ particulate filters from the low-load cases (key states 2,5 and 6 ) that the filters obtained a tan colored stain in addition to the dark gray or black particulate matter. This material was later shown to be primarily soluble organics and quite likely originated from partially burned fuel. Fuel injector needle lift was later shown to be incomplete at the low-load cases. This probably led to less than desirable atomization and significant carryover of unburned and partially burned fuel into the exhaust. Poor atomization at low-loads has been demonstrated in early vintage engines employing (PLN) fuel systems (Cuenca, 1993). Improper low-load atomization and its effect on TPM was in large part what 


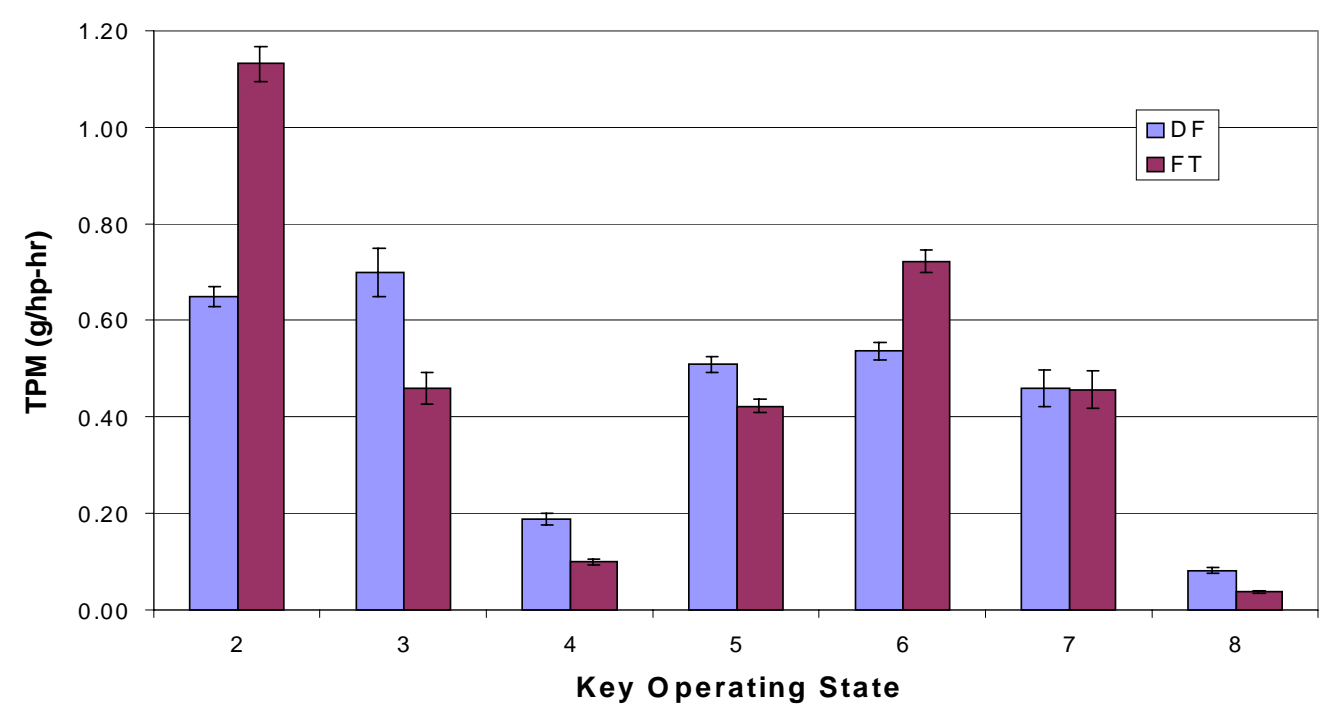

Figure 6-19. Total particulate matter production at each engine operating condition and fuel type. The error bars represent the $95 \%$ confidence interval.

Total Particulate Matter Key State Average (Both Fuels Combined)

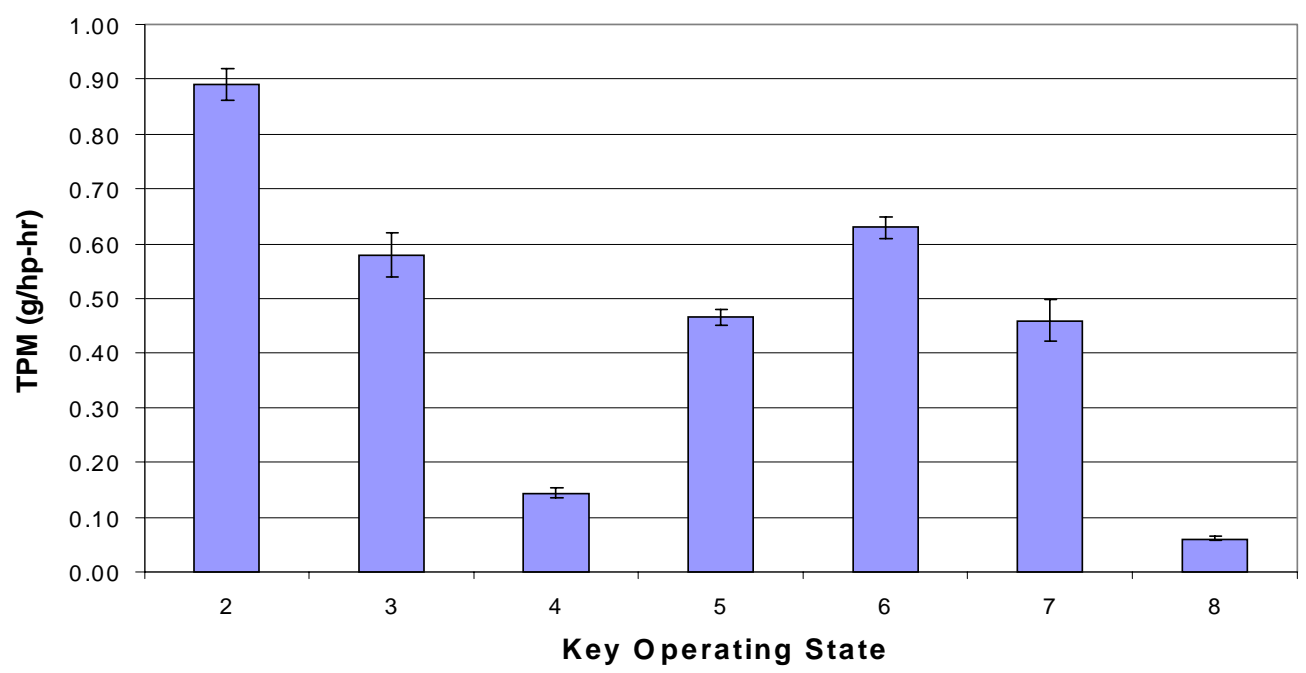

Figure 6-20. Average total particulate matter production (g/hp-hr) at each engine operating condition. The error bars represent the $95 \%$ confidence interval. 


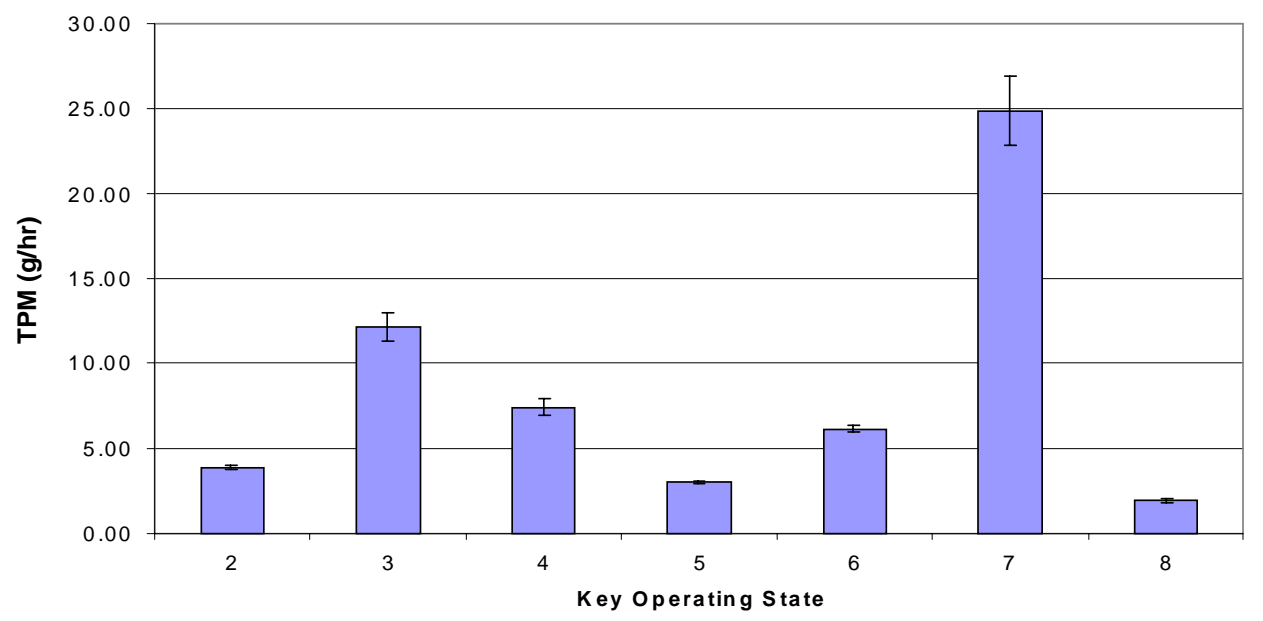

Figure 6-21. Average total particulate matter production $(\mathrm{g} / \mathrm{hr})$ at each engine operating condition. The error bars represent the $95 \%$ confidence interval.

drove the development of the modern constant, high-pressure fuel injection equipment (FIE) we see today.

When considering the differences in TPM with respect to fuel type it can clearly be seen from Figure 6-19 that the low-load cases influence the overall FT TPM rate by skewing it to the high side. The average TPM from key states 3, 4, 7 and 8 (intermediate and high load cases) is given in Figure 6-22. When considering cases other than low-load conditions the relative improvement in TPM reduction from FT fuel is $26 \%$ over the DF fuel.

\subsubsection{Bioactivity/Comparisons}

The mutagenicity (revertants/ug dose) for each fuel type and engine operating conditions is given in Figure 6-23. Recall that these are averages of the Ames test with two bacterial strains both with and without S9 activation. Each of those are the resulting slopes of the dose response curve derived from 4 replications of 3-5 dosages. The results and averages at each key state, for each fuel type, bacterial strain and activation are given in Table 6-2. 
Total Particulate Matter DF and FT Average

(Without Low Load Cases)

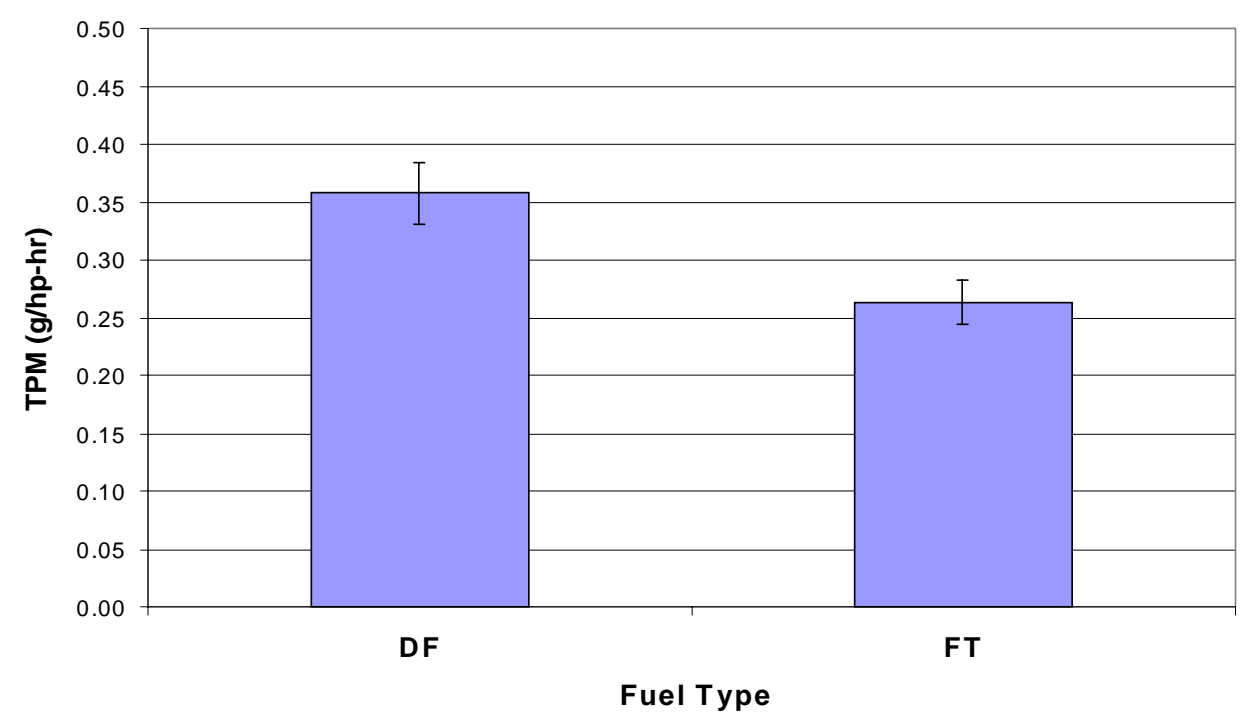

Figure 6-22. Average total particulate matter (g/hp-hr) for each fuel averaged over key operating states 3, 4, 7 and 8 . The error bars represent the $95 \%$ confidence interval.

Average Mutagenicity

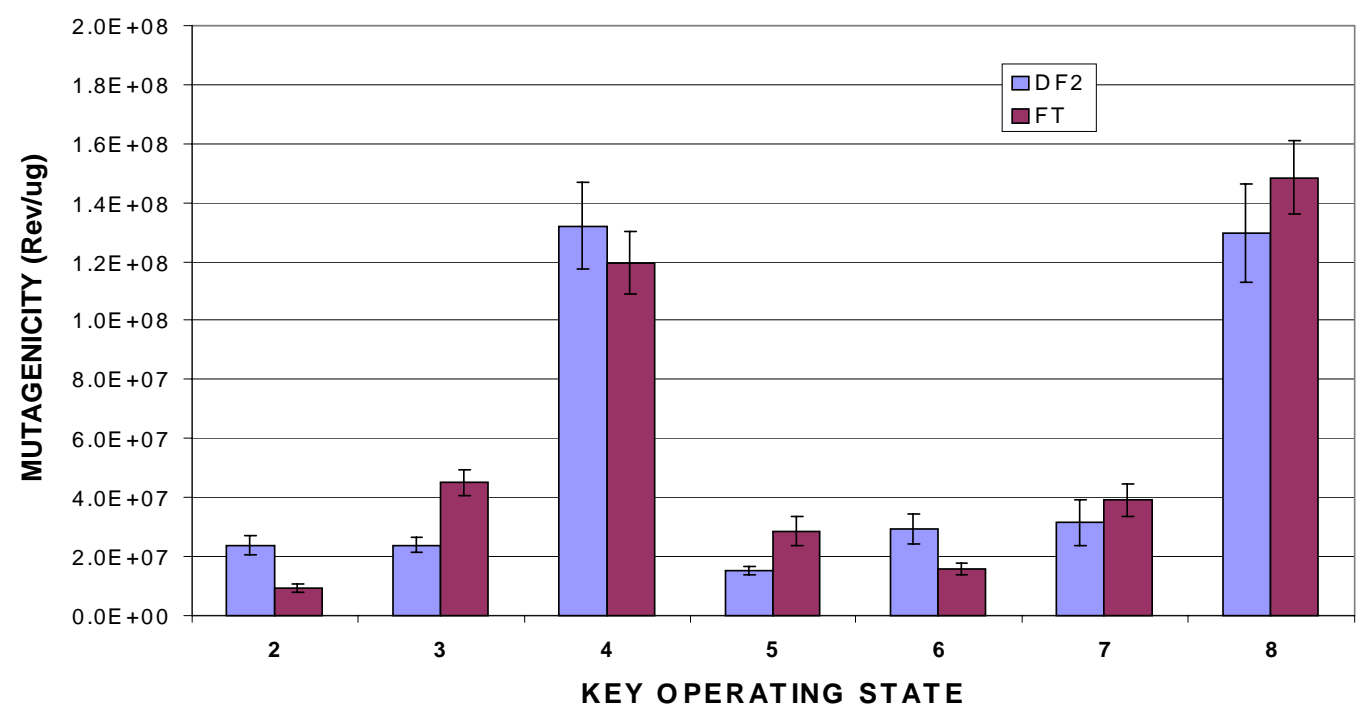

Figure 6-23. Mutagenicity (Rev/ug) at each operating condition and each fuel type. The error bars represent the $95 \%$ confidence interval for the slope of the dose response. 
Table 6-2. Mutagenicity (Rev/ug) and averages at each key state, for each fuel type, bacterial strain and activation*.

\begin{tabular}{|c|c|c|c|c|c|c|c|c|c|}
\hline \multirow{3}{*}{$\begin{array}{l}\text { Key } \\
\text { State }\end{array}$} & \multicolumn{4}{|c|}{ DF2 } & \multicolumn{4}{|c|}{ FT } & \multirow[b]{3}{*}{ Ave. } \\
\hline & \multicolumn{2}{|c|}{ YG1024 } & \multicolumn{2}{|c|}{ YG1029 } & \multicolumn{2}{|c|}{ YG1024 } & \multicolumn{2}{|c|}{ YG1029 } & \\
\hline & S9- & S9+ & S9- & S9+ & S9- & S9+ & S9- & S9+ & \\
\hline 2 & $4.59 \mathrm{E}+07$ & $1.76 \mathrm{E}-07$ & $1.27 \mathrm{E}+07$ & $3.65 \mathrm{E}+07$ & $1.70 \mathrm{E}+07$ & $7.03 \mathrm{E}+06$ & $2.68 \mathrm{E}+06$ & $1.06 \mathrm{E}+07$ & $1.65 \mathrm{E}+07$ \\
\hline 3 & $1.90 \mathrm{E}+07$ & $3.39 \mathrm{E}+07$ & $1.68 \mathrm{E}+07$ & $2.60 \mathrm{E}+07$ & $3.79 \mathrm{E}+07$ & $4.84 \mathrm{E}+07$ & $3.82 \mathrm{E}+07$ & $5.56 \mathrm{E}+07$ & $3.45 \mathrm{E}+07$ \\
\hline 4 & $2.31 \mathrm{E}+08$ & $5.00 \mathrm{E}+07$ & $1.05 \mathrm{E}+08$ & $1.42 \mathrm{E}+08$ & $2.00 \mathrm{E}+08$ & $4.73 \mathrm{E}+07$ & $6.41 \mathrm{E}+07$ & $1.66 \mathrm{E}+08$ & $1.26 \mathrm{E}+08$ \\
\hline 5 & $2.18 \mathrm{E}+07$ & $1.01 \mathrm{E}+07$ & $1.09 \mathrm{E}+07$ & $1.82 \mathrm{E}+07$ & $5.08 \mathrm{E}+07$ & $1.72 \mathrm{E}+07$ & $1.43 \mathrm{E}+07$ & $3.22 \mathrm{E}+07$ & $2.20 \mathrm{E}+07$ \\
\hline 6 & $7.16 \mathrm{E}+07$ & $2.50 \mathrm{E}+07$ & $1.30 \mathrm{E}+07$ & $7.35 \mathrm{E}+06$ & $2.50 \mathrm{E}+07$ & $1.30 \mathrm{E}+07$ & $7.35 \mathrm{E}+06$ & $1.79 \mathrm{E}+07$ & $2.25 \mathrm{E}+07$ \\
\hline 7 & $2.66 \mathrm{E}+07$ & $1.81 \mathrm{E}+07$ & $2.93 \mathrm{E}+07$ & $5.19 \mathrm{E}+07$ & $5.81 \mathrm{E}+07$ & $1.88 \mathrm{E}+07$ & $1.70 \mathrm{E}+07$ & $6.20 \mathrm{E}+07$ & $3.52 \mathrm{E}+07$ \\
\hline \multirow[t]{2}{*}{8} & $3.14 \mathrm{E}+08$ & $8.46 \mathrm{E}+07$ & $5.50 \mathrm{E}+07$ & $6.43 \mathrm{E}+07$ & $3.70 \mathrm{E}+08$ & $9.41 \mathrm{E}+07$ & $5.37 \mathrm{E}+07$ & $7.57 \mathrm{E}+07$ & $1.39 \mathrm{E}+08$ \\
\hline & $1.04 \mathrm{E}+08$ & $3.17 \mathrm{E}+07$ & $3.47 \mathrm{E}+07$ & $4.94 \mathrm{E}+07$ & $1.08 \mathrm{E}+08$ & $3.51 \mathrm{E}+07$ & $2.82 \mathrm{E}+07$ & $6.00 \mathrm{E}+07$ & \\
\hline \multirow{2}{*}{ Ave. } & \multicolumn{2}{|c|}{$6.80 \mathrm{E}+07$} & \multicolumn{2}{|c|}{$4.21 \mathrm{E}+07$} & \multicolumn{2}{|c|}{$7.18 \mathrm{E}+07$} & \multicolumn{2}{|c|}{$4.41 \mathrm{E}+07$} & \\
\hline & \multicolumn{4}{|c|}{$5.50 \mathrm{E}+07$} & \multicolumn{4}{|c|}{$5.79 \mathrm{E}+07$} & \\
\hline
\end{tabular}

* The highlights represent dose response slopes in which there was some degree of remaining toxicity effects by the method of Bernstein, et al., (1982).

The average values given in Table 6-2 indicate a slight difference in mutagenic activity with regards to fuel type. The FT fuel has on average a $5 \%$ greater mutagenic activity (revertants/ug dose). From a practical perspective this difference is minimal. These data may also be expressed in engine specific units as well as in time specific units in the same manner as Figures 6-19 and 6-21 above. Figures 6-24 and 6-25 below give the mutagenicity rate as revertants per hp-hr and revertants per hour respectively. Again, when these data are presented in purely time-rate units $(\mathrm{g} / \mathrm{hr})$ the effect of thermal efficiency is reduced. This presentation of the data can be seen as the mutagenic rate potential with operating conditions. In this situation, the FT fuel provides a $45 \%$ reduction in revertant rate (rev/hr) over the DF fuel averaged over key states 3, 4, 7 and 8 and $38 \%$ over all key states. 


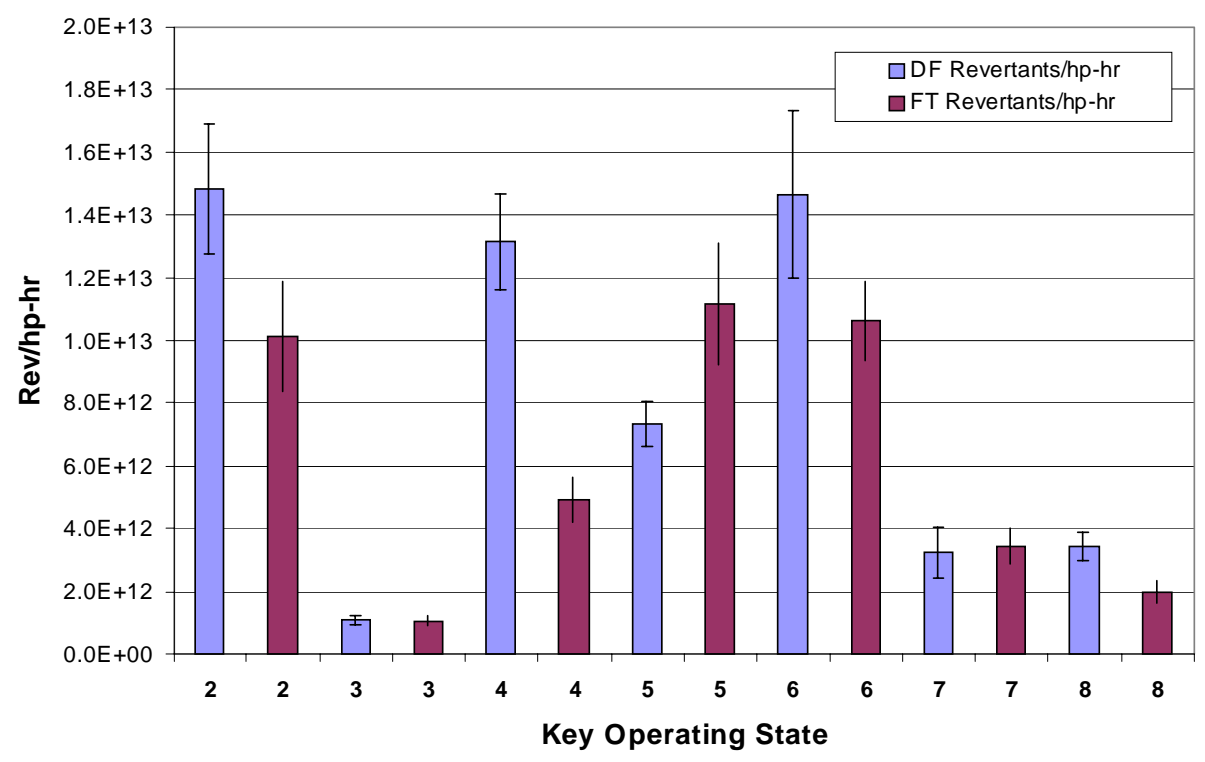

Figure 6-24. Engine revertant production rate (Revertant/hp-hr) for each key operating state and fuel type. The error bars represent the $95 \%$ confidence interval with errors due to dose response and PM measurement propagated using the root-sum-square method.

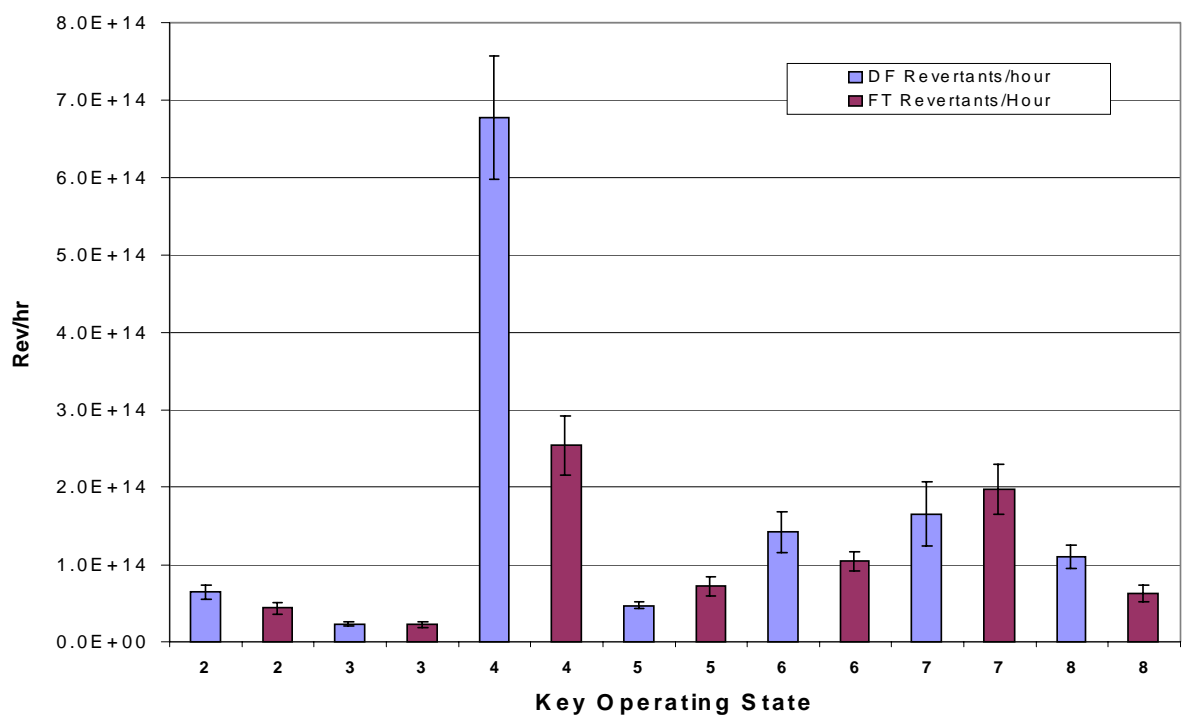

Figure 6-25. Engine revertant production rate (Revertant/hr) for each key operating state and fuel type. The error bars represent the $95 \%$ confidence interval with errors due to dose response and PM measurement propagated using the root-sum-square method. 
The result of an analysis of variance (ANOVA) of the mutagenicity data in Table 6-2 is provided in Table 6-3. As discussed above, an attempt to remove toxicity effects from the dose response slopes was employed. The highlighted cases in Table 6-2 represent dose-response slopes that exhibited some degree of remaining toxicity effect. This effect tends to bias the doseresponse slope downward thus reducing the apparent exhibited mutagenicity. Again, dosages with toxicity effects were removed until either no toxicity effects remained or 3 dosages remained (that is, enough to determine a dose-response slope). In any case, toxicity effects were minimized using this method. Also, another test comparing the remaining dose response slope to a zero slope was used to determine a mutagenic threshold. All cases in Table 6-2 exhibited a positive mutagenic response using this method.

Table 6-3. ANOVA for mutagenicity effects

\begin{tabular}{|l|c|r|l|r|r|}
\hline \multicolumn{7}{|c|}{ Summary of Effects (TPM) } \\
\hline \multicolumn{1}{|c|}{ Interaction } & SS & DF & MS Effect & F & p-level \\
Fuel & $1.5 \mathrm{E}+16$ & 1 & $1.5 \mathrm{E}+16$ & 10.232 & $\mathbf{0 . 0 0 4}$ \\
Strain & $9.0 \mathrm{E}+15$ & 1 & $9.0 \mathrm{E}+15$ & 6.316 & $\mathbf{0 . 0 1 8}$ \\
S9 & $8.0 \mathrm{E}+15$ & 1 & $8.0 \mathrm{E}+15$ & 5.576 & $\mathbf{0 . 0 2 6}$ \\
Key State & $1.3 \mathrm{E}+17$ & 6 & $2.1 \mathrm{E}+16$ & 14.998 & $\mathbf{0 . 0 0 0}$ \\
Speed & $1.8 \mathrm{E}+14$ & 1 & $1.8 \mathrm{E}+14$ & 0.124 & 0.728 \\
Load & $6.0 \mathrm{E}+16$ & 1 & $6.0 \mathrm{E}+16$ & 41.713 & $\mathbf{0 . 0 0 0}$ \\
Speed x Load & $6.8 \mathrm{E}+15$ & 1 & $6.8 \mathrm{E}+15$ & 4.782 & $\mathbf{0 . 0 3 8}$ \\
Speed & $3.2 \mathrm{E}+16$ & 1 & $3.2 \mathrm{E}+16$ & 22.247 & $\mathbf{0 . 0 0 0}$ \\
Fuel x Key State & $4.2 \mathrm{E}+15$ & 6 & $7.0 \mathrm{E}+14$ & 0.493 & 0.808 \\
Fuel x Strain & $7.4 \mathrm{E}+13$ & 1 & $7.4 \mathrm{E}+13$ & 0.052 & 0.821 \\
Key State x Strain & $3.9 \mathrm{E}+16$ & 6 & $6.5 \mathrm{E}+15$ & 4.555 & $\mathbf{0 . 0 0 3}$ \\
Fuel x S9 & $1.4 \mathrm{E}+14$ & 1 & $1.4 \mathrm{E}+14$ & 0.095 & 0.761 \\
Key State x S9 & $2.5 \mathrm{E}+16$ & 6 & $4.2 \mathrm{E}+15$ & 2.976 & $\mathbf{0 . 0 2 3}$ \\
Strain x S9 & $3.3 \mathrm{E}+16$ & 1 & $3.3 \mathrm{E}+16$ & 23.238 & $\mathbf{0 . 0 0 0}$ \\
\hline
\end{tabular}


The analysis of variance is based on 2 levels of fuel type (DF and FT), 2 levels each of Salmonella strain and S9 activation and 7 operating conditions (key states). There were 3 levels of engine speed and 4 levels of engine load within the key states. Three-way and higher order interactions were pooled to obtain an error term for testing main effects and two-way interactions. Significant differences between fuel type and key state as well as strain and activation type is indicated. From an interaction perspective, the difference among key states is consistent across fuel types. Within key states the effect speed $\mathrm{x}$ load interaction is significant, as is the effect of load in general. There is significant curvature in the speed effect (the quadratic term is significant). The mutagenicity versus engine speed and load is given in Figure 6-26 using a quadratic response surface fit.

Greater mutagenic activity can be seen in Figure 6-26 at intermediate speeds and at higher loads for each fuel type. The data trends in Figure 6-26 indicate a strong dependence on engine operation. This dependence is greater than the fuel dependence and should be considered should efforts be made in the future to reduce mutagenic emissions from compression-ignition engines.

\subsubsection{Size Dependent Particulate Matter Analysis}

The size dependent particulate matter analysis is discussed in the following two sections.

\subsubsection{Mass Distribution}

In our procedure, the measured mass size distributions obtained on the MOUDI substrates are expressed in a $\log$-normal form $\mathrm{dM} / \mathrm{d}(\log \mathrm{D})$. The mass distribution is then fitted to a bimodal distribution, following the method of Xu et al., (2002). Frequency histograms, log-normal frequency curves, the cumulative frequency and cumulative frequency curves are provided for each operating condition and each fuel type. Mass weighted particulate matter size distributions 


\title{
Dose Response vs Engine Speed and Load
}

\author{
FUEL: DFZ $=-3.212 e 8+2.692 e 7^{*} x+9.162 e 6^{*} y-4.783 e 5^{*} x^{*} x-2.544 e 5^{*} x^{*} y+1.186 e 5^{*} y^{*} y$ \\ FUEL: $F T z=-4.321 e 8+3.487 e 7^{*} x+1.937 e 7^{*} y-6.486 e 5^{*} x^{*} x-1.844 e 5^{*} x^{*} y-5.983 e 5^{*} y$ \\ $X$-axis: Speed \\ Y-axis: BMEP
}

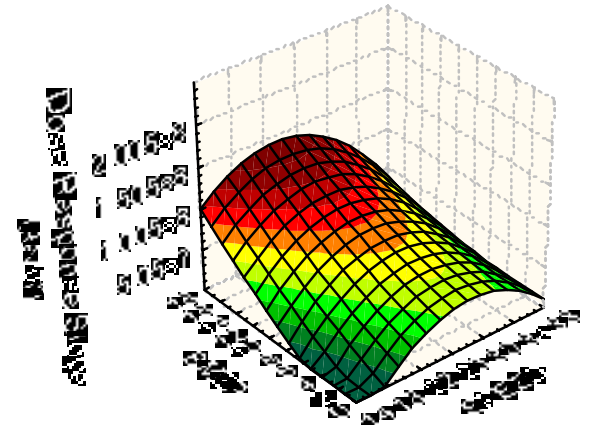

FUEL: DF2

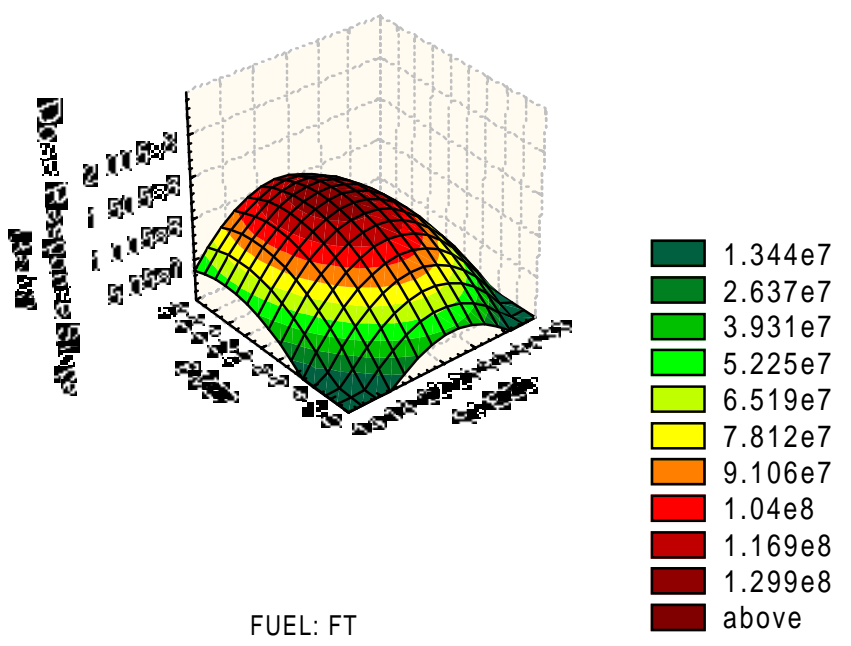

Figure 6-26. Quadratic response surface of mutagenicity (slope of revertants/ug does) as a function of engine speed and load.

from MOUDI analysis are given in Figures 6-27 and 6-28 for key operating states 2 and 4 respectively.

In Figure 6-27 (key state 2), both fuel types exhibit a mass median aerodynamic diameter (MMAD) of approximately $100 \mathrm{~nm}$ in the smaller size range. Specifically, FT fuel has an MMAD in the smaller size mode centered at $120 \mathrm{~nm}(0.12 \mu \mathrm{m})$. This is a slightly larger than DF $(\mathrm{MMAD}=92 \mathrm{~nm})$ in the smaller size mode. The DF fuel exhibits slightly more mass in the larger mode (16\% of its total mass while FT fuel has $6 \%$ of the its total mass in the larger mode). The larger mode MMAD is greater for the FT fuel than for the DF fuel. In Figure 6-28 (key state 4), again both fuel types exhibit most of the mass concentration in region centered at $100 \mathrm{~nm}$ with the FT fuel MMAD in the smaller size mode centered at $90 \mathrm{~nm}(0.09 \mu \mathrm{m})$. This is a slightly larger than DF $(M M A D=50 \mathrm{~nm})$ in the smaller size mode. The DF fuel exhibits slightly more mass in 
MOUDI Size Distribution

16rps, 2 bar bmep, Standard Diesel Fuel

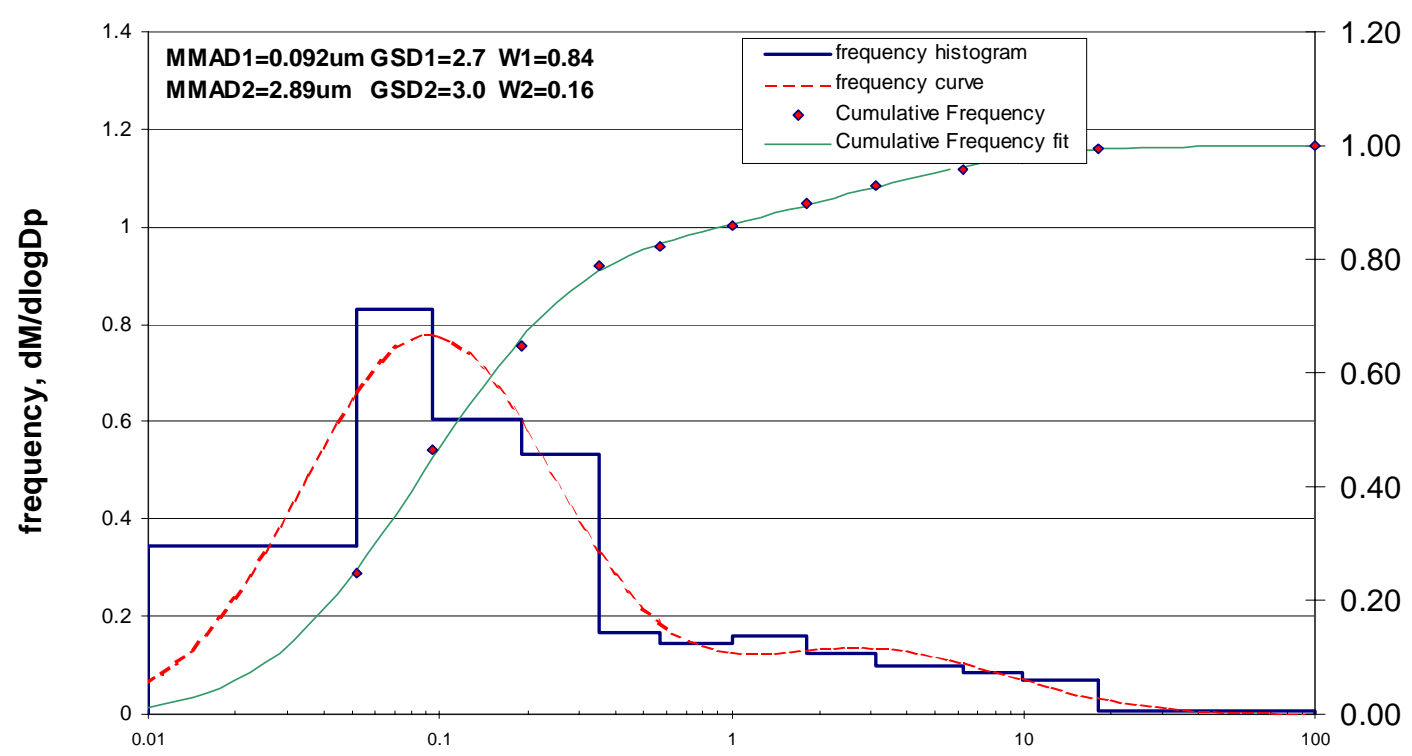

Dp, micrometers

MOUDI Size Distribution

16 rps, 2 bar bmep, F-T Fuel

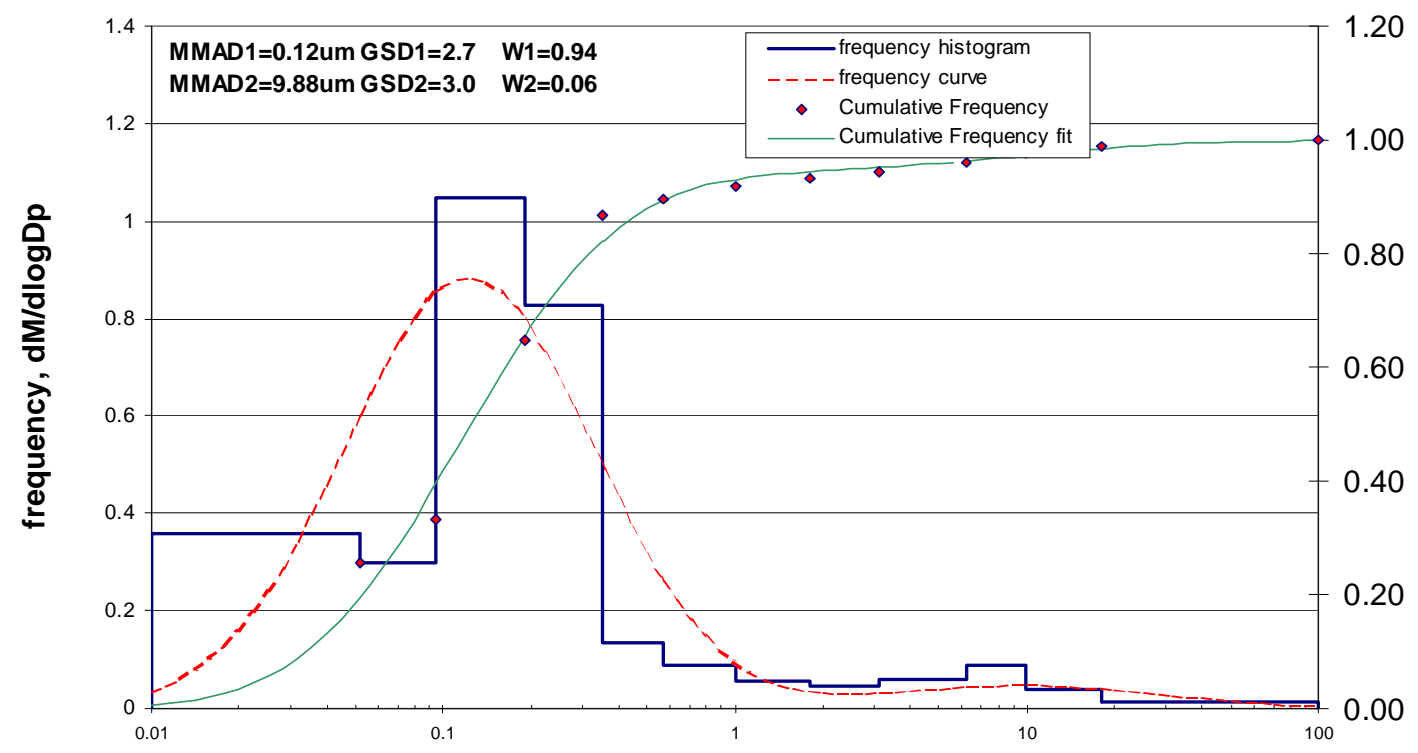

Dp, micrometers

Figure 6-27. MOUDI size distribution for key state 2 engine conditions (MMAD is the mass median aerodynamic diameter; GSD is the geometric standard deviation and $\mathrm{W}$ is the fraction of the total mass in the upper (1) or lower (2) size fraction). 
MOUDI Size Distribution

24 rps, 16 bar bmep, Standard

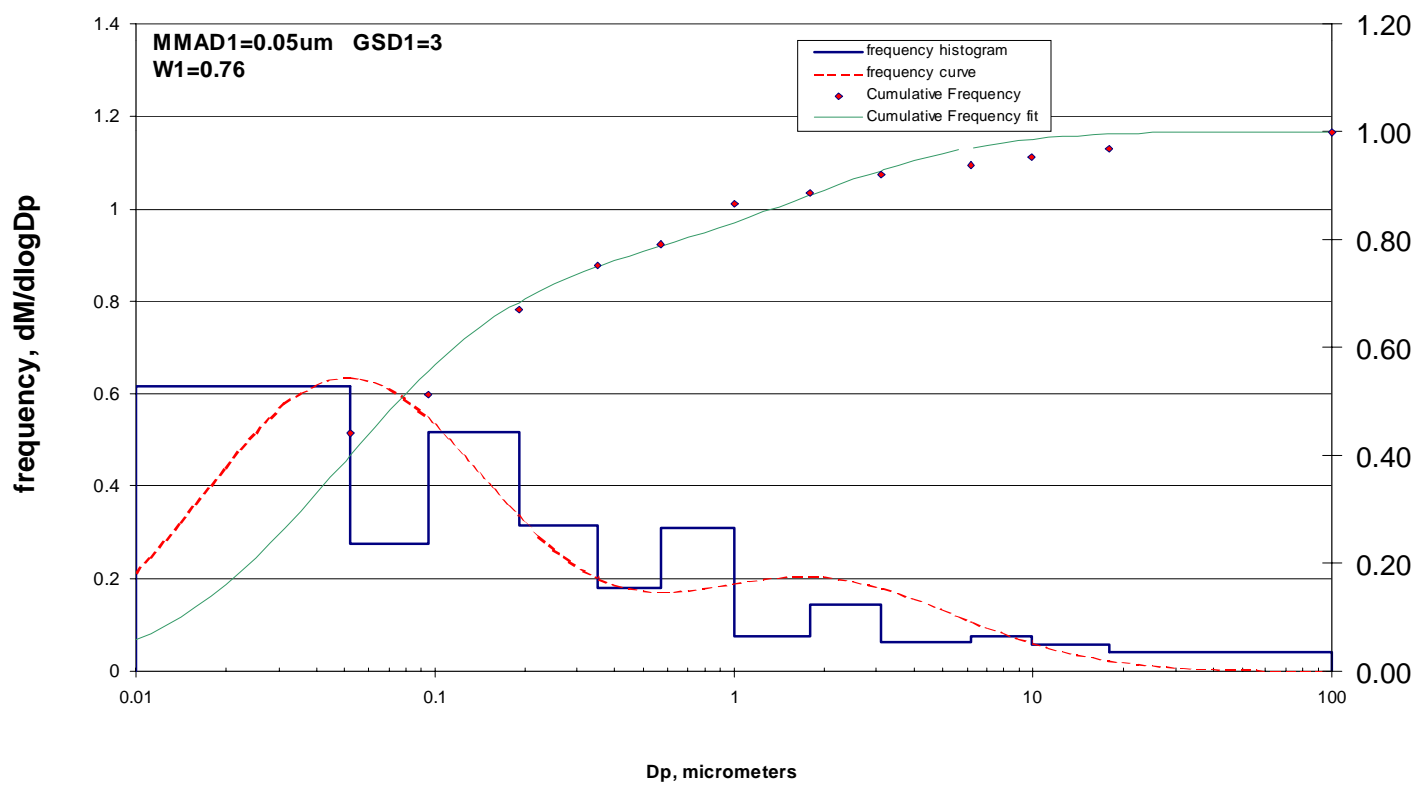

MOUDI Size Distribution 24 rps, 16 bar bmep, FT Fuel

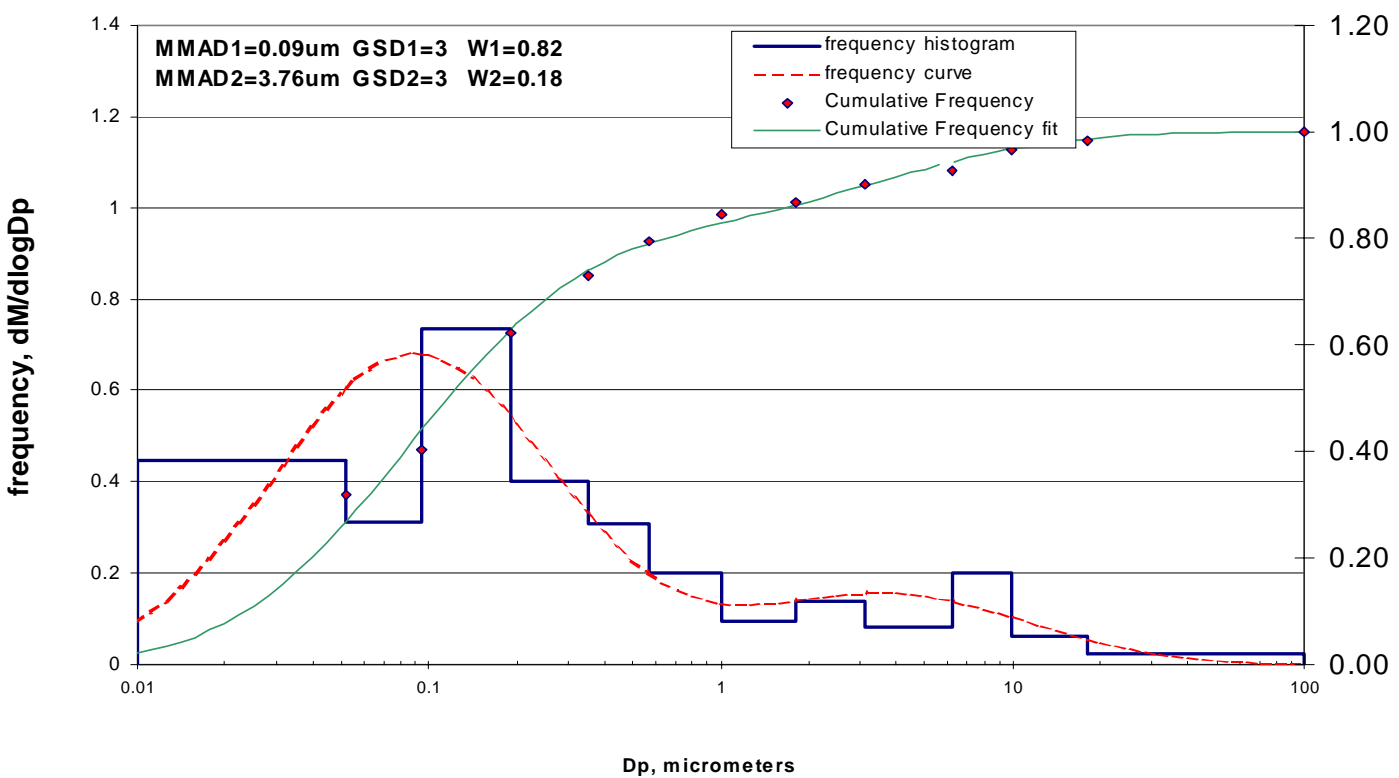

Figure 6-28. MOUDI size distribution for key state 4 engine operating conditions (MMAD is the mass median aerodynamic diameter; GSD is the geometric standard deviation and $\mathrm{W}$ is the fraction of the total mass in the upper (1) or lower (2) size fraction). 
the larger mode. The larger mode MMAD is larger in the FT fuel than the DF fuel. Overall FT fuel exhibits an overall larger MMAD for each mode with less material in the larger mode than the Federal diesel No. 2 fuel. The relative "split" or center of mass in the near100 nm particle diameter supports the decision to split the MOUDI substrates into small and large size fractions representing particles above and below $100 \mathrm{~nm}$. By general definition, but not universally established, particles below 100nm are considered ultra-fine particles and those above $100 \mathrm{~nm}$ and below 2.5 um are considered fine particles (Kittelson, 1999).

\subsubsection{Bioactivity/Comparisons}

For each engine test (sample set consisting of 3 sample replications), separate extractions were performed, on the three combined sets of stages 3 through 8 and on the three combined sets of stages 9, 10 and the afterfilter. After the extraction, the remaining DCM and SOF solution is diluted to $200 \mathrm{ml}$ and as with the total particulate matter samples, $10 \mathrm{ml}$ is taken for later chemical analysis (to determine the Soluble organic fraction (SOF)) and the remaining $190 \mathrm{ml}$ is used for bioassay analysis. The mutagenicity (revertants/ug dose) for each fuel type, engine operating condition and particle size range is given in Figure 6-29 below. Again, these are averages of the Ames test with two bacterial strains both with and without S9 activation. Each of these are the resulting slope of the dose response curve. The groups ( $2 \mathrm{sm}$ and $4 \mathrm{sm})$ are made up of substrates 9, 10 and the afterfilter. These groups represents the "Ultra-fine particles" or particles with nominal diameters less than $100 \mathrm{~nm}(0.1 \mu \mathrm{m})$. The second grouping $(2 \mathrm{lg}$ and $4 \mathrm{lg})$ consists of substrates 3-8. This grouping represents particles with nominal diameters between $100 \mathrm{~nm}$ $(0.1 \mu \mathrm{m})$ and $3.1 \mu \mathrm{m}$. The results and averages at each key state, for each fuel type, bacterial strain and activation are given in Table 6-4. 
Mutagenicity at Each Key State and PM Size Range

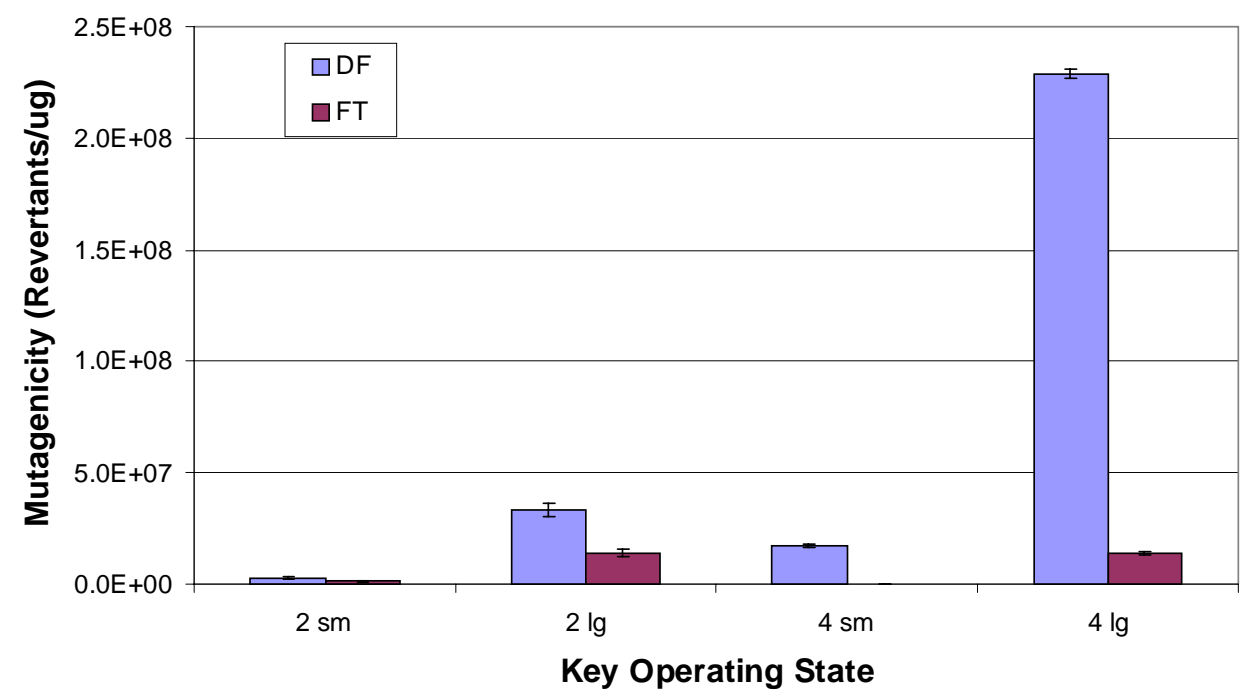

Figure 6-29. Mutagenicity at each key state, for each fuel type and DPM size range. The error bars represent the $95 \%$ confidence interval of the dose response slope.

Table 6-4. Mutagenicity (Rev/ug) and averages at each key state, for each fuel type, bacterial strain and activation for the MOUDI size fractions

\begin{tabular}{|c|c|c|c|c|c|c|c|c|c|}
\hline \multirow{3}{*}{$\begin{array}{l}\text { Key } \\
\text { State/ } \\
\text { Size }\end{array}$} & \multicolumn{4}{|c|}{ DF2 } & \multicolumn{4}{|c|}{ FT } & \multirow[b]{3}{*}{ Ave. } \\
\hline & \multicolumn{2}{|c|}{ YG1024 } & \multicolumn{2}{|c|}{ YG1029 } & \multicolumn{2}{|c|}{ YG1024 } & \multicolumn{2}{|c|}{ YG1029 } & \\
\hline & S9- & S9+ & S9- & S9+ & S9- & S9+ & S9- & S9+ & \\
\hline $2 \mathrm{sm}$ & $2.27 \mathrm{E}+06$ & $2.91 \mathrm{E}+06$ & $6.74 \mathrm{E}+05$ & $5.08 \mathrm{E}+06$ & $1.40 \mathrm{E}+06$ & $1.40 \mathrm{E}+06$ & $3.63 \mathrm{E}+05$ & $2.25 \mathrm{E}+06$ & $2.04 \mathrm{E}+06$ \\
\hline $2 \lg$ & $3.47 \mathrm{E}+07$ & $3.33 \mathrm{E}+07$ & $1.28 \mathrm{E}+07$ & $5.23 \mathrm{E}+07$ & $1.35 \mathrm{E}+07$ & $1.29 \mathrm{E}+07$ & $2.86 \mathrm{E}+06$ & $2.68 \mathrm{E}+07$ & $2.36 \mathrm{E}+07$ \\
\hline $4 \mathrm{sm}$ & $2.51 \mathrm{E}+07$ & $1.75 \mathrm{E}+07$ & $4.83 \mathrm{E}+06$ & $2.36 \mathrm{E}+07$ & $3.08 \mathrm{E}+05$ & $2.77 \mathrm{E}+05$ & $7.93 E+04$ & $2.12 \mathrm{E}+05$ & $8.98 \mathrm{E}+06$ \\
\hline \multirow[t]{2}{*}{$4 \mathrm{lg}$} & $3.15 \mathrm{E}+08$ & $2.75 \mathrm{E}+08$ & $5.85 \mathrm{E}+07$ & $2.65 \mathrm{E}+08$ & $1.31 \mathrm{E}+07$ & $1.43 \mathrm{E}+07$ & $9.11 \mathrm{E}+06$ & $1.86 \mathrm{E}+07$ & $1.21 \mathrm{E}+08$ \\
\hline & $9.43 \mathrm{E}+07$ & $8.23 \mathrm{E}+07$ & $1.92 \mathrm{E}+07$ & $8.65 \mathrm{E}+07$ & $7.06 \mathrm{E}+06$ & $7.22 \mathrm{E}+06$ & $3.10 \mathrm{E}+06$ & $1.20 \mathrm{E}+07$ & \\
\hline \multirow{2}{*}{ Ave. } & \multicolumn{2}{|c|}{$8.83 \mathrm{E}+07$} & \multicolumn{2}{|c|}{$5.29 \mathrm{E}+07$} & \multicolumn{2}{|c|}{$7.14 \mathrm{E}+06$} & \multicolumn{2}{|c|}{$7.53 \mathrm{E}+06$} & \\
\hline & \multicolumn{4}{|c|}{$7.06 \mathrm{E}+07$} & \multicolumn{4}{|c|}{$7.34 \mathrm{E}+06$} & \\
\hline
\end{tabular}

* The highlights represent dose response slopes in which there was some degree of remaining toxicity effects by the method of Bernstein, et al., 1982. 
The result of an analysis of variance (ANOVA) of the mutagenicity data in Table 6-5 is provided in Table 6-5 using the same methodology as discussed previously. The only case in Table 6-4 that exhibited a negative mutagenic response for the small particle size of key state 4 for the YG1029 bacterial strain without S9 activation.

The analysis of variance was based on 2 levels of fuel type (DF and FT), 2 levels each of Salmonella strain and S9 activation, 2 size fractions and 2 operating conditions (key states). Significant differences between fuel type, key state and particle size were indicated. Second interactions between fuel, key state and particle size were also indicated.

Table 6-5. ANOVA for mutagenicity effects of MOUDI samples

\begin{tabular}{|c|c|c|c|c|}
\hline \multicolumn{5}{|c|}{ Summary of Effects (MOUDI) } \\
\hline \multicolumn{5}{|c|}{ 1-FUEL, 2-KEYSTATE, 3-SIZE, 4-STRAIN, 5-S9 } \\
\hline Interactions & $\begin{array}{c}\text { df } \\
\text { Effect }\end{array}$ & $\begin{array}{c}\text { MS } \\
\text { Effect }\end{array}$ & $\mathrm{F}$ & p-level \\
\hline 1 & 1 & $3.2 \mathrm{E}+16$ & 23.827 & 0.003 \\
\hline 2 & 1 & $2.2 \mathrm{E}+16$ & 16.248 & 0.007 \\
\hline 3 & 1 & $3.6 \mathrm{E}+16$ & 26.651 & 0.002 \\
\hline 4 & 1 & $2.5 \mathrm{E}+15$ & 1.828 & 0.225 \\
\hline 5 & 1 & $2.1 \mathrm{E}+15$ & 1.538 & 0.261 \\
\hline 12 & 1 & $2.2 \mathrm{E}+16$ & 16.684 & 0.006 \\
\hline 13 & 1 & $2.3 \mathrm{E}+16$ & 17.235 & 0.006 \\
\hline 23 & 1 & $1.6 \mathrm{E}+16$ & 12.217 & 0.013 \\
\hline 14 & 1 & $2.6 \mathrm{E}+15$ & 1.911 & 0.216 \\
\hline 24 & 1 & $2.5 \mathrm{E}+15$ & 1.848 & 0.223 \\
\hline 34 & 1 & $2 \mathrm{E}+15$ & 1.482 & 0.269 \\
\hline 15 & 1 & $1.1 \mathrm{E}+15$ & 0.796 & 0.407 \\
\hline 25 & 1 & $4.5 \mathrm{E}+14$ & 0.335 & 0.584 \\
\hline 35 & 1 & $1.5 \mathrm{E}+15$ & 1.132 & 0.328 \\
\hline 45 & 1 & $3.9 \mathrm{E}+15$ & 2.887 & 0.140 \\
\hline
\end{tabular}


What separates this analysis from the TPM analysis is the effect of particle size. While key state interaction is still apparent, determining the effect of PM size is the primary objective in this analysis. Particle size effect is significant as indicated by the $\mathrm{f}$ ratios and p-levels in Table 6-5. Larger particles tend to exhibit a significantly larger mutagenic response than smaller size particles. This effect is demonstrated by grouping each fuel as to highlight only key state and size effects as given in Figure 6-30.

Without weighting for SOF content, the average of the dose response slope at each MOUDI key state qualitatively agrees with the key state averages from the TPM samples. TPM mutagenicity averages for key states 2 and 4 were $1.65 \times 10^{7}$ and $1.26 \times 10^{8}$ revertants per microgram respectively while the MOUDI averages are $1.28 \times 10^{7}$ and $6.5 \times 10^{7}$ respectively.

The mutagenicity versus particle size range and fuel type is given as a scatter plot in Figure 6-31. The effect of fuel type and particle size is visually demonstrated clearly in the key state 4 plot. The effect, while statistically significant, is less obvious for key state 2 operating conditions.

We can see in Figure 6-31 that the mutagenicity is not as sensitive to fuel or particle size in key state 2 as it is in key state 4 where it is very responsive to fuel type and size fraction. Common scales are used in Figure 6-31. The relative differences in mutagenic PM size affects is more apparent in Figure 6-30.

The size dependence of mutagenicity requires more discussion. When considering the heteromolecular mechanism of particle nucleation and subsequent growth by agglomerization and hydrocarbon condensation, a simplistic model of mutagenicity dependence on particle size may be developed. Simply put, as nucleation sights are formed when exhaust temperatures are still relatively high, condensation of the highest boiling point hydrocarbons is preferred. The 
Average Mutagenicity: Both Fuels at each Key State and PM Size Range

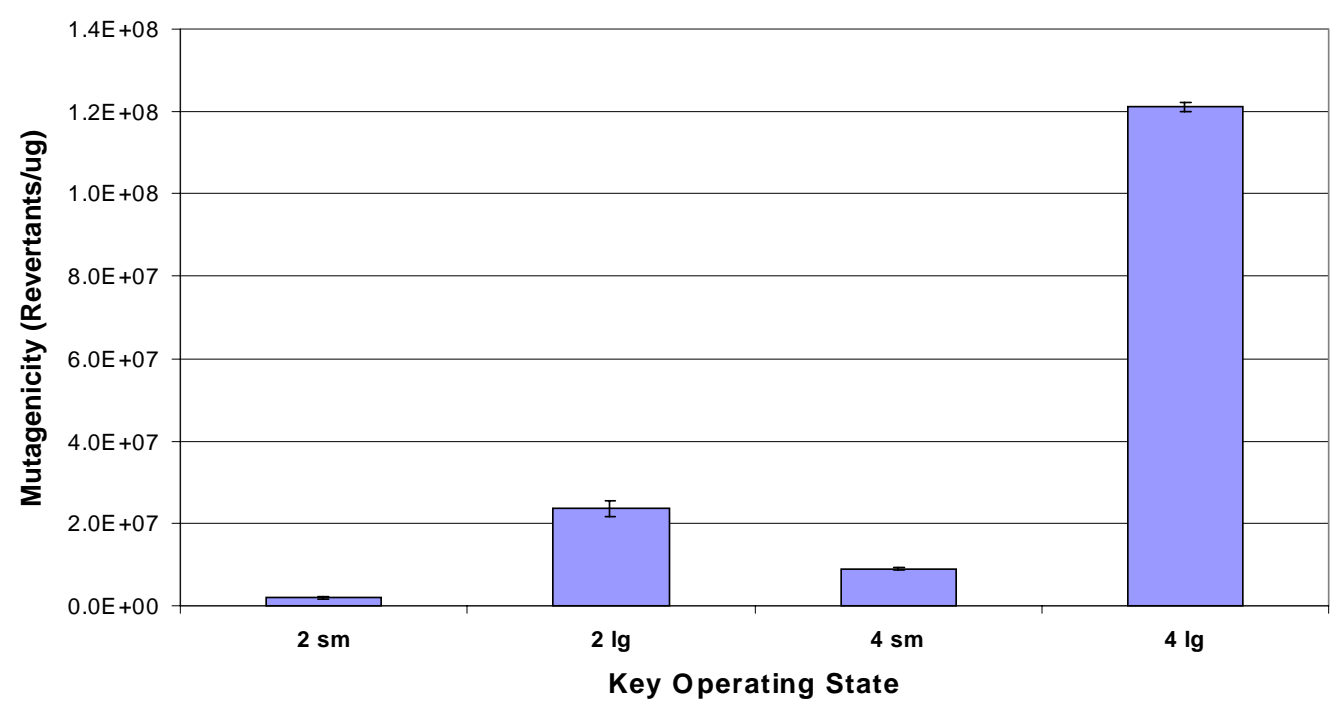

Figure 6-30. Average mutagenicity each key state and size fraction. The error bars represent the $95 \%$ confidence interval of the dose response slope.

\section{Dose Response vs Particle Size and Fuel Type (MOUDI)}

$X$-axis: Fuel Type (Diesel (DF2) or Fischer-Tropsch (FT))

Y-axis: Particle Size Range (Large (I) or Small (s))

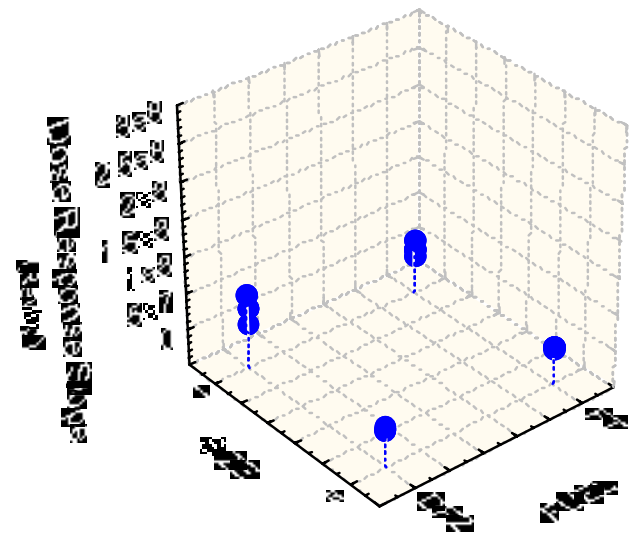

KEYSTATE: 2

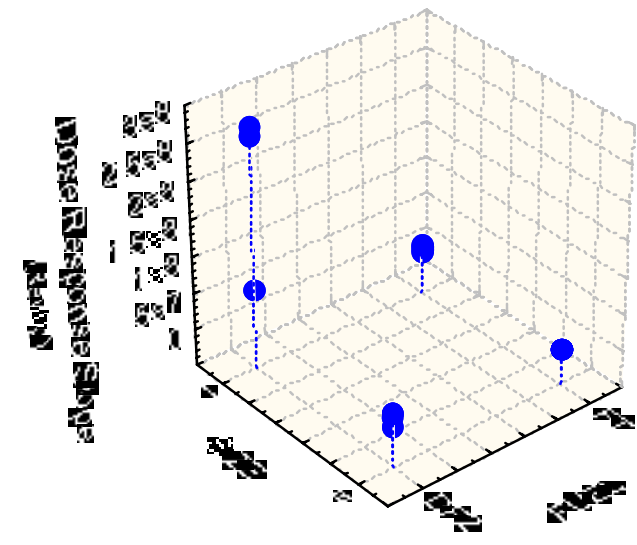

KEYSTATE: 4

Figure 6-31. Scatterplot of mutagenicity (slope of revertants/ug dose) as a function of fuel type and particle size for the MOUDI samples. 
early forming particles have a longer active growth life and once they reach equilibrium have a relatively larger size. Particles whose nuclei form later, when lower temperatures favor condensation of relatively lighter hydrocarbons, would contain a soluble organic fraction containing lower boiling point compounds and hence preferentially less mutagenic material.

This concept is indirectly supported by the work of Allen et al., (1997). In their work, size segregated atmospheric particles were collected and analyzed for polycyclic aromatic hydrocarbons $(\mathrm{PAH})$. While the source of the particles were atmospheric in nature, a combustion origin was strongly suggested. Their data indicated that PAH were preferentially distributed in the larger size fractions.

Kerminen et al., (1997) characterized the elemental and organic carbon fractions of particulate matter from diesel exhaust. Their data indicated that the organic carbon contribution to the total carbon mass was preferentially greater in large particles. Their results were really an indirect affirmation of the hydrocarbon condensation mechanism. 


\subsection{CONCLUSIONS}

The major portion of this effort investigated the mutagenicity of particulate matter derived from FT and DF fuel combustion in a single-cylinder diesel engine by relating the in-vitro mutagenic activity of the particulate to engine operating conditions and particle size using the Ames test. Mutagenicity derived from the Ames test does not necessarily equate to carcinogenicity but it is an important screening tool and indicator for potential carcinogenicity.

Total particulate matter (TPM) filter samples were taken at seven steady-state engine operating conditions for both Federal diesel No. 2 (DF) and the Fischer-Tropsch (FT) test fuels. Particulate matter from two engine conditions were also gathered on greased aluminum foil substrates using a Micro-Orifice Uniform Deposition Impactor (MOUDI) for size selective mutagenic analysis via the Ames method. Toxicity effects were screened from the dose-response analysis using the method set forth by Bernstein et al., (1982). Specific conclusions of the study are that:

- The low-load conditions generally produced the highest brake-specific TPM emissions. This is in part due to lower thermal efficiency at the low load conditions and in part due to poor fuel injection equipment (FIE) performance at low loads imparting significant carryover of unburned and partially burned fuel and oil components.

- When considering cases other than low-load conditions the relative reduction in brakespecific TPM emissions from FT fuel was $26 \%$ over the DF fuel.

- When coupled with TPM production rate (rev/hr), the FT fuel provided a $45 \%$ reduction in revertant rate (rev/hr) over the DF fuel averaged over intermediate and high-load operating conditions and $38 \%$ over all operating conditions (key states). 
- The analysis of variance was based on two levels of fuel type (DF and FT), 2 levels each of Salmonella strain and S9 activation and 7 operating conditions (key states) using 3 levels of engine speed and 4 levels of engine load within the key states. Significant differences between fuel type and key state as well as strain and activation type were indicated. From an interaction perspective, the difference among key states were consistent across fuel types. Within key states the effect speed x load interaction was significant, as was the effect of load in general. There is significant curvature in the speed effect (the quadratic term is significant).

- The measured mass weighted size distributions obtained on the MOUDI substrates, expressed in a $\log$-normal form $\mathrm{dM} / \mathrm{d}(\log \mathrm{D})$ and fitted to a bimodal distribution gave FT fuel mass distributions that were larger than DF in the smaller sized mode (120 nm vs. $92 \mathrm{~nm}$ for DF for low-speed, low-load operation.

- For intermediate-speed, high-load (key state 4) operation, the FT fuel MMAD of the ultrafine mode was at $90 \mathrm{~nm}(0.09 \mu \mathrm{m})$ which was slightly larger than that for DF $(\mathrm{MMAD}=50 \mathrm{~nm})$.

- Overall FT fuel exhibited a larger MMAD for the ultrafine (smaller size) mode with less material in the larger mode than the Federal diesel No. 2 fuel.

- Significant differences in mutagenicity between fuel type, key state and particle size was indicated as were second order interactions between fuel, key state and particle size.

- Larger particles (>100 nm) tend to exhibit a significantly greater mutagenic response per mass dosage than smaller size particles $(<100 \mathrm{~nm})$. This has implications with regard to emissions control as larger particles tend to be more efficiently removed in diesel particulate traps (Johnson, 2001). The remaining smaller particles may possibly exhibit reduced mutagenicity, which may be associated with SOF content. 
- The mutagenicity was not as sensitive to fuel or particle size in key state 2 as it is in key state 4 where it was very responsive to fuel type and size fraction.

- For all Ames tests (TPM and MOUDI), all but one of 88 dose response slopes were considered to exhibit mutagenic effects.

A study of the relationship of engine emissions and combustion using a Ricardo Proteous, single-cylinder, 4-stroke DI engine is instrumented for in-cylinder pressure measurements was conducted. The engine was run at several steady engine states at multiple timing conditions using both Federal low sulfur diesel No 2 and natural gas derived FT fuels. The emissions and performance data for each fuel at each steady state operating conditions were compared. The following conclusions may be drawn from this study:

- With the exception of CO in key state 4, THC and CO in key state 7 (36 rps, 12 bar bmep) and $\mathrm{NO}_{\mathrm{x}}$ in key state 8 (24 rps, 10 bar bmep), each operating condition displayed similar trends for each of the two test fuels implying that while the absolute emissions levels were different their trends were similar with respect to changing engine conditions.

- The FT fuel averaged about a 30\% shorter ignition delay than DF over all key states.

- There was no apparent functional relationship between $\mathrm{NO}_{\mathrm{x}}$ and the maximum heat released in the diffusion phase. Any relationship between $\mathrm{NO}_{\mathrm{x}}$ and location of the diffusion peak appeared to be a covariant relationship with timing. Further, there was no functional relationship between $\mathrm{NO}_{\mathrm{x}}$ and differences of locations of the maximum diffusion heat release rate.

- $\mathrm{NO}_{\mathrm{x}}$ was a strong function of premixed heat release rate.

- $\mathrm{NO}_{\mathrm{x}}$ was not a significant function of exhaust temperature for any key state.

- The diffusion peak of the heat release rate was consistently greater for FT fuel while the location of the diffusion peak was covariant with the location of the start of combustion as 
well as the $50 \%$ to $90 \%$ diffusion burn duration. Although the overall burn duration was very similar between fuels, the diffusion burn rate between the $50 \%$ and $90 \%$ mass fraction burned (MFB) locations was generally shorter for FT.

- Peak combustion pressures were very similar for each fuel type.

- FT $\mathrm{NO}_{\mathrm{x}}$ brake specific emissions were lower than DF at all key states except for the medium speed medium load condition at key state 8 .

- PM emissions at the low speed medium load condition key state 3, as measured by opacity, were significantly lower for FT fuel.

- Carbon monoxide (CO) brake specific emissions were lower for FT fuel at all engine conditions except at key state 4 and 7 (medium speed, high load and high-speed, moderate load respectively).

- Total hydrocarbon (THC) brake specific emissions were lower for FT fuel at all engine conditions except key state 7 (high-speed, moderate load).

- THC emissions were correlated to ignition delay. This correlation with ignition delay implyed some level of correlation with cetane number.

- It is likely that the significantly higher cetane number and lower density of the FT fuel are largely responsible for the observed differences in their combustion characteristics. 


\subsection{Recommendations}

The primary source of unburned fuel in the form of CO and THC in either FT or DF fuel combustion must primarily come from either overly rich or overly lean regions of combustion or due to flame quenching or spray cooling at the walls of the combustion chamber or piston. Rich combustion does not appear to be a strong candidate since $\mathrm{CO}$ and $\mathrm{THC}$ is quite high for the leanest conditions of key state 5 (low-speed, low-load). This conclusion is also supported by the work of Payri et al., (2000). Over mixing is a possibility as both CO and THC track well with ignition delay. Over fueling may have a bigger effect on THC than on CO. FT fuels typically have a lower boiling point than DF. The evaporation process occurs faster with FT fuel, therefore wall impingement quenching is less probable with FT fuel. The determining factors behind the differences in THC and CO levels between FT and SDF will require more analysis and perhaps a more dedicated test plan designed to isolate the effects of over mixing, over fueling and flame quenching effects. It is recommended that such an experiment be designed and performed to further understand the FT combustion process. The experiment must focus on the interactions of the fuel injection equipment and the combustion process. Injection spray patterns and injection rates may be paramount in the interactions.

A correlation between total particulate matter soluble fraction components (fuel and oil

derived) and mutagenicity data was impossible in this study due to the autocorrelation of fuel and oil solubles with operating conditions. One could envision a test in which the lube oil contribution is varied by adjusting ring clearances or by controlling and varying crankcase pressure. It is recommended that such a test be designed and performed. It is recommended that this experiment be designed and performed to provide a better understanding of the lube oil 
contribution to PM mutagenicity. It should be noted that the lube oil constituents in the SOF are dominant on a mass basis and can, in some cases, constitute over $90 \%$ of the soluble mass.

Bioactivity (mutagenicity) has been studied as a function of particle size after being directly sampled from the engine exhaust. The effect of diesel particulate afterfilters on the mutagenicity of TPM and size segregated PM should be addressed. The EPA has mandated a Federal diesel No. 2 sulfur level of no more than 15 ppm by 2007. The EPA has also mandated PM emission levels in on-highway heavy-duty diesels to be no more than $0.01 \mathrm{~g} / \mathrm{hp} \mathrm{hr}$. Particulate afterfilters will be widely distributed by 2007. It is recommended that experiments be designed and performed to develop sufficient understanding of particulate afterfilter influences on particle mutagenicity and morphology.

The Ames test is really a test of the mutagenicity of the chemical constituents of the soluble organic fraction of the diesel particulate matter. The true availability of the solubles might better be ascertained by directly presenting the diesel particulate matter to the Salmonella typhimurium. Once could envision collecting particles in an impactor coated directly with lung surfactant and/or other similar material. In this manner the particulate matter suspended in the lung surfactant could be directly introduced in vitro. This would provide an indication of the surface chemistry of the particulate matter and further clarify the effects of particle size. 


\section{References}

Abdul-Khalek, I.S., Kittelson, D.B., Graskow, B.R., Wei, Q., and Brear, F., "Diesel Exhaust

Particle Size: Measurement Issues and Trends," SAE Paper 980525, (1998).

Agee, M.A., "Convert Natural Gas Into Clean Transportation Fuels," Hart's Fuel Technology and Management, (March 1997).

Ahlvik, P., Ntziachristos, L., Keskinen, J., and Virtanen, A., "Real Time Measurements of Diesel Particle Size Distribution with an Electrical Low Pressure Impactor," SAE Paper 980410, (1998).

Allen, J.O., Dookeran, N.M, Taghizedah, K., Lafleur, A.L., Smith, K.A., and Sarofim, A.F., "Measurement of Oxygenated Polycyclic Aromatic Hydrocarbons Associated with a SizeSegregated Urban Aerosol," Environmental Science and Technology, Vol. 31, pp. 2064-2070, (1997).

Arcoumanis, C., Bae, C., Nagwaney, A., and Whitelaw, J.H., "Effect of EGR on Combustion Development in a 1.9L DI Diesel Optical Engine," SAE 950850, (1995).

Arcoumanis, C., and Megaritis, A., "Real-Time Measurement of Particulate Emissions in a Turbocharged DI Diesel Engine,” SAE 922390, (1992). 
Arcoumanis, C., Schindler, K.-P., "Mixture Formation and Combustion in the DI Diesel Engine," SAE 972681, (1997).

Atkinson, C.M., Thompson, G.J., Traver, M.L., and Clark, N.N., "In-Cylinder Combustion Pressure Characteristics of Fischer-Tropsch and Conventional Diesel Fuels in a Heavy Duty CI Engine," SAE Paper 1999-01-1472, (1999).

Bagley, S.T., Baumgard, K.J., Gratz, L.D., Johnson, J.H., and Leddy, D.G., "Characterization of Fuel and Aftertreatment Device Effects on Diesel Emissions," Health Effects Institute Research Report No. 76, (1996).

Baldwin Environmental Model 20410 Sample Gas Conditioner Instruction Manual, (1997).

Barale, R., Bulleri, M., Cornetti, G., Loprieno, N., and Wachter, W.F., "Preliminary Investigation on Genotoxic Potential of Diesel Exhaust," SAE Paper No. 920397, (1992).

Baumgard, K.J., and Johnson, J.H., "The Effect of Fuel and Engine Design on Diesel Exhaust Particle Size Distributions," SAE Paper 960131, (1986).

Bernstein, Leslie, Kaldor, John, McCann, Joyce and Pike, Malcolm C., "An Empirical Approach

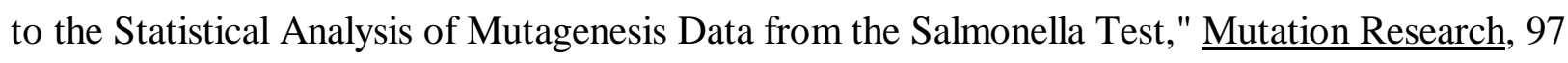
267-281 (1982). 
Boggs, D.L., Belaire, R.C., Bartunek, B., Durnhloz, M., and Ecker, H-F, “A Small Displacement DI Diesel Engine Concept for High Fuel Economy vehicles," SAE 972680, (1997).

Bond, J.A., Harkema, J.R., Henderson, R.F., Mauderly, J.L., McClellan, R.O., and Wolff, R. K., "The Role of DNA Adducts in Diesel Exhaust-Induced Pulmonary Carcinogenesis," Mutation and the Environment, Part C, pp. 259-269, (1990).

Browning, Louis H. “Technologies and Costs for On-Road Heavy-Duty Engines Meeting 2004 Emissions Standards,” SAE 973256, (1997).

Brundt, M.F.J., and Lucas G.G., “ The Effect of Crank Angle Resolution on Cylinder Pressure Analysis," SAE Paper 910041, (1991).

Brundt, M.F.J., and Emtage, A.L., "Evaluation of Burn Rate Routines and Analysis Errors," SAE Paper 970037, (1997).

Brundt, M.F.J., and Platts, K.C., "Calculation of Heat Release in Direct Injection Diesel Engines," SAE Paper 1999-01-0187, (1999).

Brundt, M.F.J., Rai, H., and Emtage, A.L., "The Calculation of Heat Release Energy from Engine Cylinder Pressure Data,” SAE Paper 981052, (1998). 
Brundt, M.F.J., and Emtage, A.L., "Evaluation of IMEP Routines and Analysis Errors," SAE Paper 960609, (1996).

Callahan, T.J., Yost, D.M., and Ryan, T.W., “Acquisition and Interpretation of Diesel Engine Heat Release Date," SAE Paper 852068, (1985).

Carson, M. M., and Roberts, M. A., Oil and Gas Journal, pp 33-38, June 19, 1995.

Cartllieri, W.P., and Herzog, P.L., "Swirl Supported or Quiescent Combustion for 1990's HeavyDuty DI Diesel Engines - An Analysis," SAE Paper 880342, (1988).

Chatterjee, S., McDonald, C., Conway, R., Windawi, H., Vertin, K., LeTavec, C.A., Clark, N.N., and Gautam, M., "Emission Reductions and Operational Experiences with Heavy-Duty Diesel Fleet Vehicles Retrofitted with Continuously Regenerated Diesel Paniculate Fillers in Southern California," SAE 2001-01-0512, (2001).

Chen, S.K., Mather, D., and Reitz, R., "Current and Advanced Design Concepts for High PowerDensity Mid-Range Truck Diesel Engines, Part II: The Development of Advanced Design Process for Combustion System Optimization,” SAE 972689, (1997).

Cheng, Y.S. and Yeh, H.C., Environmental Science and Technology, 13, 1392, (1979). 
Choi, G.N., Kramer, S.J., Tam, S.S., Srivastava, R.D., and Stiegel G.J., "Natural Gas Based Fischer-Tropsch to Liquid Fuels: Economics," Society of Petroleum Engineers 66th Western Regional Meeting, Anchorage, Alaska, May 22-24, 1996.

Christensen, R., Bo Hansen, M., Schramm, J., Binderup, M., and Jorgensen, V., "Mutagenic Activity of the Soluble Organic Fraction of Exhaust Gas Particulate from a Direct Injection Diesel Engine," SAE Paper No. 961977, (1996).

Coldren, D.R. and Moncelle, M.E. "Advanced technology fuel system for heavy duty diesel engines," SAE 973182, (1997).

Cowley, L.T., Jeune, A Le, and Lange, W.W., "Effect of Fuel Composition Including Aromatics Content on Emissions From a Range of Heavy Duty Diesel Engines," Conference Literature from “Worldwide Engine Emissions Standards and How to Meet Them” London, England. May, 1993

Crebelli, R., Conti, L., Crochi, B., Carere, A., Bertoli, C., and Del Giacomo, N., "The Effect of Fuel Composition on the Mutagenicity of Diesel Engine Exhaust," Mutation Research Letters 346, pp. 167-172, (1995).

Cuenca, R.M., "Evolution of Diesel Fuel Injection Equipment - The Last 20 Years," SAE Paper 933015, (1993). 
De Lucas, A., Durán, A, Carmona, M. And Lapuerta, M., "Characterization of soluble Organic Fraction in DPM: Optimization of the Extraction Method," SAE 1999-01-3532, (1999).

Den Ouden, C.J.J., Clark, R.H., Cowley, L.T., Stradling, R.J., Lange, W.W., and Malliard, C., "Fuel Quality Effects on Particulate Matter Emissions from Light and Heavy-Duty Diesel Engines," SAE Paper 942022, (1994).

Dent, J.C., and Suliaman, S.J., "Convective and Radiative Heat Transfer in a High Swirl Direct Injection Diesel Engine," SAE Paper 770407, (1977).

Donaldson, K. (1994): “The Effects of Ultrafine Titanium Dioxide on Epithelial Cells,” Meeting of the Aerosol Society,” Birmingham, 1994.

Ensell, M.X., Whong, W. Z., Heng, Z.C., Nath, J. and Ong, T., "In-vitro and In-vivo Transformation in Rat Tracheal Epithelial Cells Exposed to Diesel emission Particles and Related Compounds," Mutation Research 412, pp. 283-291, (1998).

Erwin, J., Ryan, T.W., and Moulton, D.S., "Diesel Fuel Component Contribution to Engine Emissions and Performance,” Final Report, NREL/TP-425-6354, (1994).

Erwin, J., and Ryan III, T.W., "The Standing of Fischer-Tropsch Diesel in an Assay of Fuel Performance and Emissions," Report for DOE Subcontract YZ-2-11215-1, (1993). 
Fluent/UNS and Rampant User's Guides, Volumes 1 through 4, Fluent Inc., April 1996.

Frenklach, M. and Wang, W., “Twenty-Third Symposium (International) on Combustion, P559, The Combustion Institute, Pittsburgh, (1990).

Gatowski, J.A, Balles, E.N., Chun, K.M., Nelson, F.E., Ekchian, J.A., and Heywood, J.B., "Heat Release Analysis of Engine Pressure Data," SAE Paper 841359, (1984).

Gautam, M., Kelly, B., Gupta, D., Clark, N., Atkinson, R., El-Gazzar, L. and Lyons, D.W., "Sampling Strategies for Characterization of the Reactive Components of Heavy Duty Exhaust Emissions," SAE 942262, (1994).

Gautam M., Smith, R.C., Miller, E., Mehta, S., Hirakouchi, N., and Shouji, T., "Split Ratio Control in Mini-Dilution Tunnels for Measurement of Steady-State and Transient Emission from Heavy-Duty Diesel Engines," Heavy Vehicle Systems, A Series of the International Journal of Vehicle Design, Vol 5, Nos 3/4, pp. 379-398, (1999).

Glavincevski, B., Gulder, O.L., and Gardner, L., "Cetane Number Estimation of Diesel Fuels from Carbon Type Structural Composition," SAE 841041, (1984).

Graskow, B.R., Kittelson, D.B., Abdul-Khalek, I.S., Ahmadi, M.R. and Morris, J.E., “Characterization of Exhaust Particulate Emissions from a Spark Ignition Engine," SAE Paper 980528, (1998). 
Gray, D., and Tomlinson, G., "Fischer-Tropsch Fuels from Coal and Natural Gas: Carbon Emissions Implications,” August 1997.

Graze, R.R., Jr., "Development of a Miniaturized Dilution-Based Diesel Engine Particulate Sampling System for Gravimetric Measurement of Particulates," SAE Paper 931190, (1993).

Griffis, L.C., Wolff, R.K., Henderson, R.F., Griffith, W.C., Mokler, B.V., and McClellan, R.O., "Clearance of Diesel Soot Particles from Rat Lung After a Subchronic Diesel Exhaust Exposure," Fundamental and Applied Toxicology, 3:99-103, (1983).

Guerrieri, D.A., Rao, V., and Caffery, P.J., "An Investigation of the Effects of Differing Filter Face Velocities on Particulate Mass Weight from Heavy-Duty Diesel Engines," SAE Paper Series 960253 (1996).

Gulder, O.L., Glavincevski, B., and Burton, G.F., "Ignition Quality Rating Methods for Diesel Fuels--A Critical Appraisal,” SAE 852080, (1985).

Hall, D.D., Stradling, R.J., Zemroch, R.J., Rickeard, D.J., Mann, N., Heinze, P., Martini, G., Hagemann, R., Rantanen, L., and Szendefi, J., "Measurement of the Number and Size Distrubution of Particle Emissions from Heavy Duty Engines," SAE Paper No. 2000-01-2000, (2000). 
Hammerle, R.H., Ketcher, D.A., Horrocks, R.W., Lepperhoff, G., Huthwohl, G., and Luers, B. (1994): “A Method for the Speciation of Diesel Fuel and the Semi-Volatile Hydrocarbon Fraction of the Diesel-Fueled Vehicle Exhaust Emissions," SAE Paper 952353, (1995).

Han, Z., Uludogan, A., Hampson, G., Reitz, R., "Mechanism of Soot and $\mathrm{NO}_{\mathrm{x}}$ Emission Reduction Using Multiple-Injection in a Diesel Engine," SAE Paper 960633, (1996).

Hawker, P., Hüthwohl, G., Henn, J., Koch, W., Lüders, H., Lüers, B., and Stommel, P., "Effect of Continuously Regenerating Diesel Particulate Filter on Non-Regulated Emissions and Particle Size Distribution,” SAE Paper 980189, (1998).

Heywood, John B., "INTERNAL COMBUSTION ENGINE FUNDAMENTALS,” McGraw-Hill, 1988.

Hikosaka, Noboru, "A View of the Future of Automotive Diesel Engines," SAE 972682, (1997).

Hilliard J.C., and Wheeler, R.W., "Catalyzed Oxidation of Nitric Oxide to Nitrogen Dioxide," Combustion and Flame 29, 15-19, (1977).

Horiba Model FIA-236 Flame Ionization Analyzer Instruction Manual, March 1997.

Horiba Model VIA-510 Non-dispersive Infrared Analyzer Instruction Manual, August 1997. 
Illinois Instruments Model 6000 Precision Oxygen Analyzer User’s Manual, 1997.

International Agency for Research on Cancer, "Diesel and Engine Exhausts and Some Nitroarenes, IARC Monographs on the Evaluation of Carcinogenic Risks to Humans," Vol. 46, IARC, Lyon, France, (1989).

Johansen, K., Gabrielsson, P., Stavnsbjerg, P., Flemming, B., Andersen, E., and Autrup, H., "Effect of Upgraded Diesel Fuels and Oxidation Catalysts on Emission Properties, Especially PAH and Genotoxicity," SAE Paper No. 973001, (1997).

Johnson, T.V., "Diesel Emission Control in Review," SAE 2001-01-0184, (2001).

Kado, N.Y., Langley, D., and Eisenstadt, E., “A Simple Modification of the Salmonella LiquidIncubation Assay: Increased Sensitivity for Detecting Mutagens in Human Urine," Mutation Research 121:125-132, (1983).

Kakwani, R.M., and Kamo, R., “Combustion Characteristics of Dry Coal-Powder-Fueled Adiabatic Diesel Engine,” DOE/MC/23258-2693 (DE89000978), (1989).

Karim, G.A., and Khan, M.O., "An Examination of Some of the Errors Normally Associated with the Calculation of Apparent Rates of Heat Release in Engines," SAE Paper 710135, (1971). 
Kays, W. M. and Crawford, M.E., "CONVECTIVE HEAT AND MASS TRANSFER,” Third Edition, McGraw-Hill, Inc., (1993).

Kerminien, V-M., Makela, T.E., Ojanen, C.H., Hillamo, R.E., Vilhunen, J.K., Rantanen, L., Havers, N., Bohlen von, A., and Klockow, D., Characterization of the Particulate Phase in the Exhaust from a Diesel Car," Environmental Science and Technology, Vol. 31, pp. 1883-1889, (1997).

Khair, M.K., “Technical and Synergistic Approaches Towards the Twenty-First Century Diesel Engine," SAE 972687, (1997).

Kidoguchi, Y., Yang, C., and Miwa, K., "Effects of fuel Properties on Combustion and Emission Characteristics of a Direct-Injection Diesel Engine," SAE 2000-01-1851 (2000).

Kittelson, David B., Ambs, Jeffrey L., and Hadjkacem, Hassan. "Particulate Emissions from Diesel Engines: Influence of In-Cylinder Surface," SAE 900645, (1990).

Kittelson, David B., and Johnson, John H., “An Examination of the Sources of Variability in Particle Emission Measurements by the Transient Test Method for Heavy-Duty Diesel Engines," Phase I Final Report, prepared for Engine Manufacturers Association Calibration Task Force and Coordinating Research Council Smoke and Particulate Panel, September 25, 1990. 
Kittelson, D.B., Arnold, M., and Winthrop, F.W., "Review of Diesel Particulate Matter Sampling Methods - Final Report,” University of Minnesota, Minneapolis, MN, (1999).

Kittleson, D.B., "Engines and Nanoparticles: A Review," Journal of Aerosol Science, Vol. 29, pp. 575-588, (1998).

Kohketsu, S., Mori, K., Sakai, K., and Hakozaki, T., "EGR Technologies for a Turbocharged and Intercooled Heavy-Duty Diesel Engine,” SAE 970340, (1997).

Krieger, R.B., Siewert, R.M., Pinson, J.A., Gallopoulos, N.E., Hilden, D.L., Monroe, D.R., Rask, R.B., Solomon, A.S.P., and Zima, P., "Diesel Engines: One Option to Power Future Personal Transportation Vehicles," SAE 972683, (1997).

Krishna, G., Ong, T., Whong, W.Z. and Nath, J., "Mutagenicity Studies of Ambient Airborne Particles: Comparison of Solvent Systems,” Mutation Research, 124:113-120, (1983).

Lancaster, D.R., Krieger, R.B, and Lienesch, J.H., "Measurement and analysis of Engine Pressure Data," SAE Paper 750026, (1975).

Lange, W.W., "The Effect of Fuel Properties on Particulate Emissions in Heavy Duty Truck Engines Under Transient Operating Conditions," SAE 912425, (1991). 
LeFeurve, T., Myers, P.S., and Uyehara, O.A., "Experimental Instantaneous Heat Fluxes in a Diesel Engine and Their Correlation," SAE Paper 690464, (1969).

Lenonardy, A., Birtscher, H., Siegemann, H.C., "Size-Dependent Measurement of Aerosol Photoemission from Particles in Diesel Exhaust," Atmospheric Environment, Vol. 26A, No. 18, pp. 3287-3290, (1992).

Li, X., Chippior, W. L., Gulder, O.L., "Effects of Fuel Properties on Exhaust Emissions of a Single Cylinder DI Diesel Engine,” SAE 962116, (1996).

Lindeburg, M.R., “MECHANICAL ENGINEERING REFERENCE MANUAL,” Professional Publications Inc., (1994).

Mid-Atlantic Research Institute, LLC. (MARI), Real-Time Particulate Mass Monitor RPM 100, (2002).

Maricq, M.M., Chase, R.E. and Podsiadlik, D.H., "Vehicle Exhaust Particle Size Distributions: A Comparison of Tailpipe and Dilution Tunnel Measurements," SAE Paper 1999-01-1461, (1999).

Maron, D.N., Ames, B.N., "Revised Methods for the Salmonella Mutagenicity Test," Mutation Research 113:173-215, (1983). 
Marple, V.A., Rubow, K.L., and Behm, S.M., "A Microoriface Uniform Deposit Impactor

(MOUDI): Description, Calibration and Use," Aerosol Science and Technology 14:434-446 (1991).

Matthews, R.D., Sawyer, R.F., and Schefer, R.W., "Interferences in Chemiluminescent

Measurement of $\mathrm{NO}$ and $\mathrm{NO}_{2}$ Emissions from Combustion Systems," Environmental Science and Technology, Vol. 11, No. 12, November 1977.

Mauderly, J., Schlesinger, R., and Neas, L., "Measurement Needs Related to Health Effects," HEI Report, (1995).

Mayer, A., Egil, H., Burtscher, H., Czerwinski, J., and Gehrig, D., 'Particle Size Distribution Downstream Traps of Different Design,” SAE Paper 950373, (1995).

McMillian, M.H. and Gautam, M., "Consideration for Fischer-Tropsch Derived Liquid Fuels as an Fuel Injection Emission Control Parameter," SAE 982489, (1998).

McMillian, M.H. and Gautam, M., "Combustion and Emission Characteristics of Fischer-Tropsch and Standard Diesel Fuel in a Single-Cylinder Diesel Engine," SAE 2001-01-3517, (2001).

Mills, G.A, Howart, S., Howard, A.G., "The Effects of Diesel Fuel Aromaticity on Polynuclear Aromatic Hydrocarbon Exhaust Emissions," Journal of the Institute of Energy, Vol. 273, (1983). 
Montreuil, C.N., Ball, J.C., Gorse, R.A. and Young, W.C., "Solvent Extraction Efficiencies of Mutagenic Components from Diesel Particles," Mutation Research, 282:89-92, (1992).

Morel, T., and Keribar, R., "A Model for Predicting Spatially and Time Resolved Convective Heat Transfer in Bowl-in-Piston Combustion Chambers," SAE Paper 850204, (1985).

Mori, Kazutoshi, "Worldwide Trends in Heavy-Duty Diesel Engine Exhaust Emission Legislation and Compliance Technologies," SAE 970753, (1997).

Morita, T., and Okamura, H., "Analysis of Crankshaft Three-Dimensional Vibrations in a Rotating Coordinate System,” SAE Paper 951292, (1995).

Mtui, P.J., and Hill, P.G., "Ignition Delay and Combustion Duration with Natural Gas Fueling of Diesel Engines,” SAE Paper 961933, (1996).

Nikula, K.J, Finch, G.L, Westhouse, R.A., Seagrave, J., Mauderly, J.L. Lawson, D.R., and Gurevich, M., "Progress in Understanding the Toxicity of Gasoline and Diesel Engine Exhaust Emissions,"SAE Paper 1999-01-2250, (1999).

NIOSH (1988) Current Intelligence Bulletin 50, Carcinogenic Effects of Exposure to Diesel Exhaust. DHHS (NIOSH) Publication No. 88-116. U.S.G.P.O 1988, 548-159:81504. 
Nussear, D.L., Gautam, M., Hong-Guang, G., Clark, N., and Wallace, W.E., "Respirable Particulate Genotoxicant Distribution in Diesel Exhaust and Mine Atmospheres, SAE Paper No. 921752, (1992).

Ogawa, T., Araga, T., Masanori, O., and Fujimoto, Y., "Fuel Effects on Particulate Emissions from D.I. Engine - Chemical Analysis and Characterization of Diesel Fuel," SAE Paper 952351, (1995).

Opris, C.N., Gratz, L.D., Bagley, S.T., Baumgard, K.J., Leddy, D.G., and Johnson, J.H. (1993): "The Effect of Fuel Sulfur Concentration on Regulated and Unregulated Heavy-Duty Diesel Emissions," SAE Paper 930730, (1993).

Pagan, J., "Study of Particle Size distribution Emitted by a Diesel Engine," SAE Paper 1999-011141, (1999).

Pataky, G.M., Baumgard, K.J., Gratz, L.D., Bagley, S.T., Leddy, D.G., and Johnson, J.J., 'Effects of an Oxidation Catalytic Converter on Regulated and Unregulated Diesel Emissions," SAE Paper 940243, (1994).

Payri, F., Arregle, J., Fenollosa, C., Belot, G., Delage, A., Schaberg, P., Myburgh, I., and Botha, J., "Characterization of the Injection-Combustion Process in a Common Rail D.I. Diesel Engine Running with Sasol Fischer-Tropsch Fuel," SAE 2000-01-1803, (2000). 
Perry, Robert H., Green, Don W., Maloney, James O., 'PERRY'S CHEMICAL ENGINEERS'

HANDBOOK," McGraw-Hill, Seventh Edition, (1997).

Peus Systems PGD 15/63 Gas Divider Manual, September, (1998).

Phillips Petroleum Company, Certificate of Analysis for 0.05\% Sulfur Diesel Fuel Type 2, Lot D-163 and 10\% Aromatic Diesel Fuel, Lot W-785-X.

Pittsburgh Energy Technology Center, Office of Fossil Energy, U.S. Department of Energy, “Liquid Transportation Fuels From Coal, Part 2: Indirect Liquefaction,” Issue 4, (Fall 1991).

Plee, S.L., MacDonald, J.S., "Some Mechanisms Affecting the Mass of Diesel Exhaust Particulate Collected following a Dilution Process," SAE Paper 800186, (1980).

Randolf, A.L., "Methods of Processing Cylinder Pressure Transducer Signals to Maximize Data Accuracy," SAE 900170, (1980).

Ricart, L.M., Xin, J., Bower, G.R., Reitz, R.D., "In-Cylinder Measurement and Modeling of Liquid Fuel Spray Penetration in a Heavy-Duty Diesel Engine," SAE Paper 970154, (1977).

Rickeard, D.J., Bateman, J.R., Kwon, Y.K., McAughey, J.J., and Dickens, C.J., "Exhaust Particulate Size Distribution: Vehicle and Fuel Influences in Light Duty Vehicles," SAE Paper 961980, (1996). 
Ryan, Thomas W. And Montalvo, Daniel A., "Emissions Performance of Fischer-Tropsch Diesel Fuels," Conference Paper: 1997 AIChE Spring Meeting, Houston, TX, March 9-13, 1997.

SAE Handbook 1990, "Engines, Fuels, Lubricants, Emissions, and Noise, Volume 3, Society of Automotive Engineers," Warrendale, PA, (1990).

Sawyer, R.F., Johnson, J.H., "Diesel Emissions and Control Technology. In: Diesel Exhaust: A Critical Analysis of Emissions, Exposure, and Health Effects (A special Report of the Institute's Diesel Working Group) pp. 65-81, Health Effects Institute, Cambridge, MA, (1995).

Schaberg, P.W., Myburgh, I.S., Botha, J.J., Roets, P.N.,Viljoen, C.L., Dancuart, L.P., and Starr, M.E., "Diesel Exhaust Emissions Using Sasol Slurry Phase Distillate Process Fuels," SAE 972898, (1997).

Schaberg, P.W., Myburgh, I.S., Botha, J.J. and Khalek, I.A., "Comparative Emissions Performance of Sasol Fischer-Tropsch Fuel in Current and Older Technology Heavy-Duty Engines," SAE 2000-01-1912, (2000).

Scheepers, P. T. J. and Bos, R. P., "Combustion of diesel fuel from a toxicological perspective, II. Toxicity,” International Archives of Occupational and Environmental Health, April 29, 1992. 
Scheepers, P. T. J. and Bos, R. P., "Combustion of diesel fuel from a toxicological perspective, I. Origin of Incomplete Combustion Products," International Archives of Occupational and Environmental Health, April 29, 1992.

Shibuya. M., Miyamato, N., Ogawa, H., Arai, K., and Esmilaire, O., "Influence of Molecular Structure of Aromatic Fuels on Diesel Combustion and Emissions," Bulletin of the Faculty of Engineering, Hokkaido University, No. 164, (1993).

Sihling, K., and Woschni, G., "Experimental Investigation of the Instantaneous Heat Transfer in the Cylinder of a High Speed Diesel Engine,” SAE Paper 790833, (1979).

Silvis, W.M., Harvey, R.N., and Dageforde, A.F., “A CFV Type Mini-Dilution Sampling System for Vehicle Exhaust Emissions Measurement," SAE Paper 1999-01-0151, (1999).

Stavinoha, L.L., Alfaro, E.S., Dobbs, H.H., Villahermosa, L.A., and Heywood, J.B., "Alternative Fuels: Gas to Liquids as Potential $21^{\text {st }}$ Century Truck Fuels," SAE 2000-01-3422 (2000).

Stiegel, G.J. and Srivastava, R.D., "Natural Gas Conversion Technologies,” Chemistry and Industry, Number 21, pp. 837-834, 7 November, 1994.

Theobald, M.A., and Alkidas, A.C., "On the Heat-Release Analysis of Diesel Engines: Effects of Filtering on Pressure Data," SAE Paper NO. 872059, (1987).

ThermoEnvironmental Model 42C Instruction Manual, (1995). 
Tidona, R.J., Nuzami, A.A., and Cernansky, N.P., "Reducing interference Effects in the Chemiluminescent Measurement of Nitric Oxides from Combustion Systems," JAPCA 38:806911, (1988).

Tosaka, S., Fujiwara, Y., and Murayama, T., "The Effect of Fuel Properties on Diesel Engine Exhaust Particulate Formation," SAE 890421 (1989).

Ullman, T.L., Mason, R.L. and Montalvo, D.A., "Effects of Fuel Aromatics, Cetane Number, and Cetane Improver on Emissions from a 1991 Prototype Heavy-Duty Diesel Engine," SAE 902171 (1990).

Ullman, T.L., Spreen, K.B., and Mason, R.L., "Effects of Cetane Number on Emissions from a 1998 Prototype Heavy-Duty Diesel Engine," SAE 9502511 (1995).

Van Beckhoven, L.C. (1991) "Effects of Fuel Properties on Diesel engine Emissions: A Review of Information Available to the EEC-MVEG Group, SAE Paper 910608, (1991).

Venkataraman, C., and Friedlander, S.K., "Size Distribution of Polycyclic Aromatic Hydrocarbons and Elemental Carbon, 2. Ambient Measurements and Effects on Atmospheric Processes," Environmental Science and Technology, Vol. 28, pp. 563-572, (1994).

Venkataraman, C., Lyons, J.M., and Friedlander, S.K., "Size Distribution of Polycyclic Aromatic Hydrocarbons and Elemental Carbon, 1. Sampling, Measurement Methods, and Source Characterization," Environmental Science and Technology, Vol. 28, pp. 555-562, (1994). 
Venkatesan, C.P., and Abraham, J., "An Investigation of the Dependence of NO and Soot

Emissions from a Diesel Engine on Heat Release Rate Characteristics - I," SAE 2000-01-0509 (2000).

Wahiduzzaman, S., Morel, T., Timar, J., and DeWitt, D.P., "Experimental and Analytical Study of Heat Radiation in a Diesel Engine," SAE Paper 870571, (1987).

Wallace, W., Keane, M., Xing S.-G., Harrison, J., Gautam, M., Ong, T.-M., "Mutagenicity of Diesel Exhaust Soot Dispersed in Phospholipid Surfactants," Environmental Hygiene II, pp. 7-10, Eds. Seenayer, N.H. and Hadnagy, W., Springer-Verlag, Heildelberg, (1990).

Walsh, Michael P., "Global Trends in Diesel Emissions Regulation - A 2001 Update," SAE 2001-01-0183, (2001).

Watenabe, M., Ishidate, M., and Nohmi, T., "Sensitive Method for the Detection of Mutagenic Nitroarenes and Aromatic Amine: New Derivation of Salmonella typhimurium Tester Strains Possessing Elevated O-acetyltransferase Levels," Mutation Research, 234, 337-348, (1990).

Weidmann, K., Menrad, H., Reders, K., and Hutcheson, R.C., "Diesel Fuel Quality Effects on Exhaust Emissions," SAE 881649 (1988).

West Virginia University, MAE 363 Class Notes, Spring Semester, (1998). 
White, Frank M., "HEAT AND MASS TRANSFER,” First Edition, Addison Wesley Publishing Co., (1988).

Willeke, K. and Baron, P.A., editors Aerosol Measurement: Principles, Techniques and Applications. Van Nostrand Reinhold, New York (1993).

Xu, Z., Gautam, M., and Mehta, S., "Cumulative Frequency Fit for Particle Size Distrubution," Accepted for Publication in the Journal of Applied Occupational and Environmental Hygiene (2002).

Yoda, K., and Uchida, K., “A New Proportional Collection System for Extremely Low Emission Measurement in Vehicle Exhaust," SAE Paper 1999-01-1460, (1999).

Zabielski, M.F., Seery, D.J., and Dodge, L.G., "Influence of Mass Transport and Quenching on Nitric Oxide Chemiluminescent Analysis," Environmental Science and Technology, Vol. 18, No. 2, (1984).

Zhang, Y., and Van Gerpen, J.H., "Combustion Analysis of Esters of Soybean Oil in a Diesel Engine," SAE Paper 960765, (1996). 


\section{Appendix A. Flow and Mixing Analysis of a Diesel Engine Mini-Dilution Tunnel Using FLUENT/UNS 4.1}

Introduction

A computational fluid dynamic (CFD) flow and mixing analysis was performed on the mini-dilution tunnel to insure uniform mixing prior to sampling points for both particulate and $\mathrm{CO} 2$ measurement. FLUENT/UNS is a general purpose computational fluid dynamic (CFD) computer program for modeling fluid flow, heat transfer, and chemical reactions (Fluent, 1996). It enables knowledgeable engineers and scientists to apply computer simulation methods to solve practical design problems. This project involved using FLUENT/UNS 4.1 (herein after referred to as Fluent) as a tool to predict the mixing of engine exhaust and air in a mini-dilution tunnel prior to exiting the tunnel. Eight base cases were run which covered the operating limits of flow in the tunnel. In addition, three separate runs for cases 2 and 8 runs were conducted to investigate the effects of the iterative scheme. The geometry of the dilution tunnel is provided in Figure A-1.

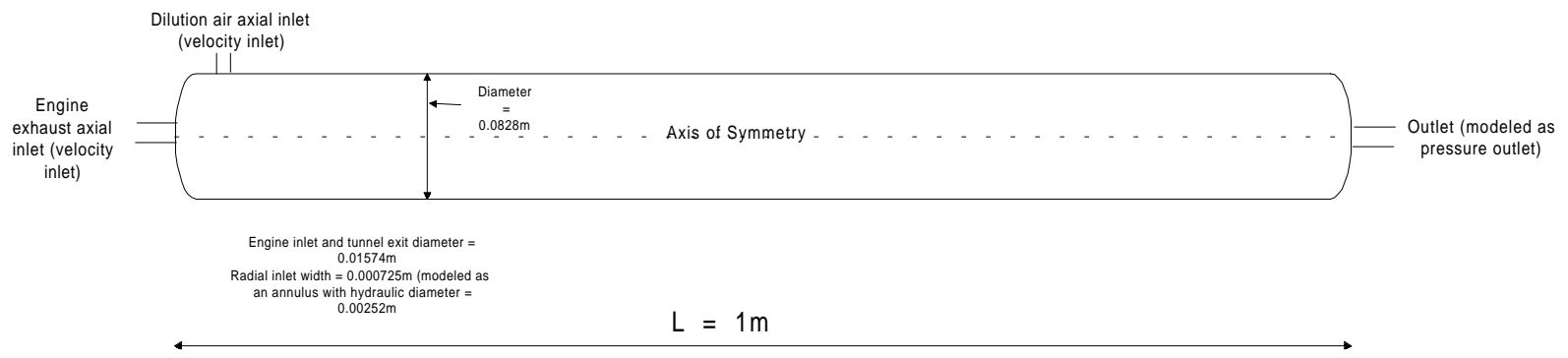

Figure A-1. Mini-dilution tunnel geometry.

The dimensions are equivalent to a schedule 10 stainless steel pipe with 3/4" (0.049" wall) tubing for the engine tunnel inlet and the tunnel outlet. The dilution air annulus flow area is equivalent to $4 \times 3 / 8$ " ( $0.035 "$ wall) tubes directed radially equally spaced around the tunnel. 
Because of the annular nature of the dilution air inlet, its actual hydraulic diameter $\mathrm{D}_{\mathrm{H}}=$ $4 \mathrm{~A} / \mathrm{P}=0.00252$ meters. The engine inlet temperature was considered to be $700 \mathrm{~K}$ for each case and the inlet air and temperature at infinity was considered to be $294 \mathrm{~K}$ in each case. The velocity inlet condition equivalents are given below in table A-1.

Table A-1. Velocity Inlet Flow Conditions

\begin{tabular}{|c|c|c|c|}
\hline \multicolumn{2}{|c|}{ Exhaust } & \multicolumn{2}{c|}{ Dilution Air } \\
\hline \multirow{2}{*}{ Flow (scfh) } & Velocity $(\mathbf{m} / \mathbf{s})$ & Flow $(\mathbf{s c f h})$ & Velocity $(\mathbf{m} / \mathbf{s})$ \\
\hline \multirow{2}{*}{40} & 1.62 & 560 & 23.36 \\
\cline { 3 - 4 } & & 200 & 8.34 \\
\hline \multirow{2}{*}{20} & \multirow{2}{*}{0.81} & 280 & 11.68 \\
\cline { 3 - 4 } & & 100 & 4.17 \\
\hline
\end{tabular}

\section{The Grid}

The grid was generated using an unstructured grid generator called "Geomesh." The grid is a structured grid with non constant cell size. The cell size is much finer near the walls and near the inlets and exits of the tunnel. In all cases, the grid cell size on the horizontal walls at $y_{p}=$ $0.00115 / 2$ meters which gives $\mathrm{y}^{+}=6.5$. This provides adequate resolution of the boundary layer at a point within the turbulent logarithmic region. The logarithmic sublayer lies between $30<y^{+}<300$. The required cell size in my scheme would lie between $0.007 \mathrm{~m}$ and $0.1 \mathrm{~m}$. The chosen grid size could have been coarser, thus saving computational time. The chosen cell size near the wall may have affected heat transfer at the wall but would not have affected overall gas mixing significantly for these cases. Consideration was given to minimize grid size gradients throughout the grid domain. 


\section{Boundary Conditions}

An axis symmetry boundary conditions was used to mirror the centerline of the tunnel for all cases. Table A-2 below gives the general boundary conditions used for the 8 base cases. For the inlet flows an "Intensity and Hydraulic Diameter" specification is used (turned on) in the Fluent code. As such initial inputs of turbulence intensity and hydraulic diameter are required. The turbulence intensities were calculated from the Reynolds number as given by Equation A-1 below.

$$
I=0.16\left(R e_{D_{H}}\right)^{-1 / 8}
$$

This correlation is derived for internal flows and is used as an initial estimate for better (faster) convergence in the fluent code. Since the turbulence intensity at the inlets is totally dependent on the upstream flow history, using this equation based on fully developed upstream conditions is valid. Following these inputs to Fluent, the turbulent kinetic energy (k) and the turbulent dissipation $(\epsilon)$ are calculated in the code by Equations A-2 and A-3 below.

$$
\begin{aligned}
& \epsilon=C_{\mu}^{3 / 4} \frac{k^{3 / 2}}{L} \\
& k=\frac{3}{2}\left(u_{\text {avg }} I\right)^{2}
\end{aligned}
$$

Where $\mathrm{C}_{\mu}$ is an empirical constant, $\mathrm{L}$ is the turbulence length scale, and $\mathrm{u}_{\mathrm{avg}}$ is the average velocity. 
Table A-2: Base Case Boundary Conditions

\begin{tabular}{|c|c|c|c|c|}
\hline \multirow[b]{2}{*}{ Case \# } & \multicolumn{4}{|c|}{ Table A-2: Boundary Conditions for Base Cases } \\
\hline & $\mathrm{V}_{\text {inlet }} 1$ (radial) & $\mathbf{V}_{\text {inlet }} 2$ (axial) & Walls & $\begin{array}{c}\text { Pressure } \\
\text { Outlet }\end{array}$ \\
\hline 1 & $\begin{array}{c}\mathrm{D}_{\mathrm{H}}=0.01574 \mathrm{~m} \text { and the } \\
\text { turbulence length scale }= \\
0.07 \mathrm{D}_{\mathrm{H}} \\
\mathrm{v}_{\mathrm{y}}=-23.36 \mathrm{~m} / \mathrm{s} \\
\text { Turbulence Intensity }(\mathrm{I})= \\
5.7 \%, \mathrm{v}_{\mathrm{x}}=0 \mathrm{~m} / \mathrm{s}\end{array}$ & $\begin{array}{c}\mathrm{D}_{\mathrm{H}}=0.00252 \mathrm{~m} \text { and the } \\
\text { turbulence length scale = } \\
0.07 \mathrm{D}_{\mathrm{H}} \\
\mathrm{v}_{\mathrm{y}}=0 \mathrm{~m} / \mathrm{s}, \mathrm{v}_{\mathrm{x}}=1.62 \mathrm{~m} / \mathrm{s} \mathrm{I}= \\
5.7 \%\end{array}$ & $\Delta \mathrm{Q}=0$ & $\begin{array}{c}\mathrm{I}=5 \%, \text { Backflow } \\
\text { turbulence length } \\
\text { scale }=1.1 \mathrm{e}-3, \\
\mathrm{P}=75000 \mathrm{~Pa}, \\
\text { Backflow total } \\
\text { temperature }(\mathrm{Tb})= \\
325 \mathrm{~K}\end{array}$ \\
\hline 2 & $\begin{array}{c}\mathrm{D}_{\mathrm{H}}=0.01574 \mathrm{~m} \text { and the } \\
\text { turbulence length scale }= \\
0.07 \mathrm{D}_{\mathrm{H}} \\
\mathrm{v}_{\mathrm{y}}=-23.36 \mathrm{~m} / \mathrm{s}, \mathrm{I}=5.7 \% \\
\mathrm{v}_{\mathrm{x}}=0 \mathrm{~m} / \mathrm{s}\end{array}$ & $\begin{array}{c}\mathrm{D}_{\mathrm{H}}=0.00252 \mathrm{~m} \text { and the } \\
\text { turbulence length scale }= \\
0.07 \mathrm{D}_{\mathrm{H}} \\
\mathrm{v}_{\mathrm{y}}=0 \mathrm{~m} / \mathrm{s}, \mathrm{v}_{\mathrm{x}}=1.62 \mathrm{~m} / \mathrm{s} \mathrm{I}= \\
5.7 \%\end{array}$ & $\begin{array}{l}\text { Used fluent mixed radiation and } \\
\text { external convection model. } \mathrm{h} \\
\text { external was specified by } \\
\text { spreadsheet as }(.0762 \mathrm{~W} / \mathrm{m} 2 \mathrm{~K}) \text {. } \\
\text { Fluent calculates the external } \\
\text { radiation and internal convective } \\
\text { effects }\end{array}$ & $\begin{array}{c}\mathrm{I}=5 \%, \text { Backflow } \\
\text { turbulence length } \\
\text { scale }=1.1 \mathrm{e}-3 \\
\mathrm{P}=75000 \mathrm{~Pa} \\
(\mathrm{~Tb})=325 \mathrm{~K}\end{array}$ \\
\hline 3 & $\begin{array}{c}\mathrm{D}_{\mathrm{H}}=0.01574 \mathrm{~m} \text { and the } \\
\text { turbulence length scale }= \\
0.07 \mathrm{D}_{\mathrm{H}} \\
\begin{array}{c}\mathrm{v}_{\mathrm{y}}=-8.34 \mathrm{~m} / \mathrm{s}, \mathrm{I}=6.4 \%, \mathrm{v}_{\mathrm{x}} \\
=0 \mathrm{~m} / \mathrm{s}\end{array}\end{array}$ & $\begin{array}{c}\mathrm{D}_{\mathrm{H}}=0.00252 \mathrm{~m} \text { and the } \\
\text { turbulence length scale = } \\
0.07 \mathrm{D}_{\mathrm{H}} \\
\mathrm{v}_{\mathrm{y}}=0 \mathrm{~m} / \mathrm{s}, \mathrm{v}_{\mathrm{x}}=1.62 \mathrm{~m} / \mathrm{s} \mathrm{I}= \\
5.7 \%\end{array}$ & $\Delta \mathrm{Q}=0$ & $\begin{array}{c}\mathrm{I}=5 \%, \text { Backflow } \\
\text { turbulence length } \\
\text { scale }=1.1 \mathrm{e}-3 \\
\mathrm{P}=75000 \mathrm{~Pa} \\
(\mathrm{~Tb})=325 \mathrm{~K}\end{array}$ \\
\hline 4 & $\begin{array}{c}\mathrm{D}_{\mathrm{H}}=0.01574 \mathrm{~m} \text { and the } \\
\text { turbulence length scale = } \\
0.07 \mathrm{D}_{\mathrm{H}} \\
\mathrm{v}_{\mathrm{y}}=-8.34 \mathrm{~m} / \mathrm{s}, \mathrm{I}=6.4 \%, \mathrm{v}_{\mathrm{x}} \\
=0 \mathrm{~m} / \mathrm{s}\end{array}$ & $\begin{array}{c}\mathrm{D}_{\mathrm{H}}=0.00252 \mathrm{~m} \text { and the } \\
\text { turbulence length scale }= \\
0.07 \mathrm{D}_{\mathrm{H}} \\
\mathrm{v}_{\mathrm{y}}=0 \mathrm{~m} / \mathrm{s}, \mathrm{v}_{\mathrm{x}}=1.62 \mathrm{~m} / \mathrm{s} \mathrm{I}= \\
5.7 \%\end{array}$ & $\begin{array}{l}\text { Used fluent mixed radiation and } \\
\text { external convection model. h } \\
\text { external was specified by my } \\
\text { spreadsheet program }(.0761 \mathrm{~W} / \mathrm{m} 2 \\
\text { K). Fluent calculates the external } \\
\text { radiation and internal convective } \\
\text { effects }\end{array}$ & $\begin{array}{c}\mathrm{I}=5 \%, \text { Backflow } \\
\text { turbulence length } \\
\text { scale }=1.1 \mathrm{e}-3 \\
\mathrm{P}=75000 \mathrm{~Pa} \\
(\mathrm{~Tb})=325 \mathrm{~K}\end{array}$ \\
\hline 5 & $\begin{array}{c}\mathrm{D}_{\mathrm{H}}=0.01574 \mathrm{~m} \text { and the } \\
\text { turbulence length scale }= \\
0.07 \mathrm{D}_{\mathrm{H}} \\
\mathrm{v}_{\mathrm{y}}=-11.67 \mathrm{~m} / \mathrm{s}, \mathrm{I}=6.2 \% \\
\mathrm{v}_{\mathrm{x}}=0 \mathrm{~m} / \mathrm{s}\end{array}$ & $\begin{array}{c}\mathrm{D}_{\mathrm{H}}=0.00252 \mathrm{~m} \text { and the } \\
\text { turbulence length scale }= \\
0.07 \mathrm{D}_{\mathrm{H}} \\
\mathrm{v}_{\mathrm{y}}=0 \mathrm{~m} / \mathrm{s}, \mathrm{v}_{\mathrm{x}}=0.81 \mathrm{~m} / \mathrm{s} \mathrm{I}= \\
6.3 \%\end{array}$ & $\Delta \mathrm{Q}=0$ & $\begin{array}{c}\mathrm{I}=5 \%, \text { Backflow } \\
\text { turbulence length } \\
\text { scale }=1.1 \mathrm{e}-3 \\
\mathrm{P}=75000 \mathrm{~Pa} \\
(\mathrm{~Tb})=325 \mathrm{~K}\end{array}$ \\
\hline 6 & $\begin{array}{c}\mathrm{D}_{\mathrm{H}}=0.01574 \mathrm{~m} \text { and the } \\
\text { turbulence length scale }= \\
0.07 \mathrm{D}_{\mathrm{H}} \\
\mathrm{v}_{\mathrm{y}}=-11.67 \mathrm{~m} / \mathrm{s}, \mathrm{I}=6.2 \% \\
\mathrm{v}_{\mathrm{x}}=0 \mathrm{~m} / \mathrm{s}\end{array}$ & $\begin{array}{c}\mathrm{D}_{\mathrm{H}}=0.00252 \mathrm{~m} \text { and the } \\
\text { turbulence length scale = } \\
0.07 \mathrm{D}_{\mathrm{H}} \\
\mathrm{v}_{\mathrm{y}}=0 \mathrm{~m} / \mathrm{s}, \mathrm{v}_{\mathrm{x}}=0.81 \mathrm{~m} / \mathrm{s} \mathrm{I}= \\
6.3 \%\end{array}$ & $\begin{array}{l}\text { Used fluent mixed radiation and } \\
\text { external convection model. h } \\
\text { external was specified by my } \\
\text { spreadsheet program }(.0762 \mathrm{~W} / \mathrm{m} 2 \\
\text { K). Fluent calculates the external } \\
\text { radiation and internal convective } \\
\text { effects }\end{array}$ & $\begin{array}{c}\mathrm{I}=5 \%, \text { Backflow } \\
\text { turbulence length } \\
\text { scale }=1.1 \mathrm{e}-3 \\
\mathrm{P}=75000 \mathrm{~Pa} \\
(\mathrm{~Tb})=325 \mathrm{~K}\end{array}$ \\
\hline 7 & $\begin{array}{c}\mathrm{D}_{\mathrm{H}}=0.01574 \mathrm{~m} \text { and the } \\
\text { turbulence length scale }= \\
0.07 \mathrm{D}_{\mathrm{H}} \\
\begin{array}{c}\mathrm{v}_{\mathrm{y}}=-4.17 \mathrm{~m} / \mathrm{s}, \mathrm{I}=7.1 \%, \mathrm{v}_{\mathrm{x}} \\
=0 \mathrm{~m} / \mathrm{s}\end{array}\end{array}$ & $\begin{array}{c}\mathrm{D}_{\mathrm{H}}=0.00252 \mathrm{~m} \text { and the } \\
\text { turbulence length scale = } \\
0.07 \mathrm{D}_{\mathrm{H}} \\
\mathrm{v}_{\mathrm{y}}=0 \mathrm{~m} / \mathrm{s}, \mathrm{v}_{\mathrm{x}}=0.81 \mathrm{~m} / \mathrm{s} \mathrm{I}= \\
6.3 \%\end{array}$ & $\Delta \mathrm{Q}=0$ & $\begin{array}{c}\mathrm{I}=5 \%, \text { Backflow } \\
\text { turbulence length } \\
\text { scale }=1.1 \mathrm{e}-3 \\
\mathrm{P}=75000 \mathrm{~Pa} \\
(\mathrm{~Tb})=325 \mathrm{~K}\end{array}$ \\
\hline 8 & $\begin{array}{c}\mathrm{D}_{\mathrm{H}}=0.01574 \mathrm{~m} \text { and the } \\
\text { turbulence length scale }= \\
0.07 \mathrm{D}_{\mathrm{H}} \\
\begin{array}{c}\mathrm{v}_{\mathrm{y}}=-4.17 \mathrm{~m} / \mathrm{s}, \mathrm{I}=7.1 \%, \mathrm{v}_{\mathrm{x}} \\
=0 \mathrm{~m} / \mathrm{s}\end{array}\end{array}$ & $\begin{array}{c}\mathrm{D}_{\mathrm{H}}=0.00252 \mathrm{~m} \text { and the } \\
\text { turbulence length scale = } \\
0.07 \mathrm{D}_{\mathrm{H}} \\
\mathrm{v}_{\mathrm{y}}=0 \mathrm{~m} / \mathrm{s}, \mathrm{v}_{\mathrm{x}}=0.81 \mathrm{~m} / \mathrm{s} \mathrm{I}= \\
6.3 \%\end{array}$ & $\begin{array}{l}\text { Used fluent mixed radiation and } \\
\text { external convection model. } \mathrm{h} \\
\text { external was specified by my } \\
\text { spreadsheet program }(.076 \mathrm{~W} / \mathrm{m} 2 \\
\text { K). Fluent calculates the external } \\
\text { radiation and internal convective } \\
\text { effects }\end{array}$ & $\begin{array}{l}\mathrm{I}=5 \%, \text { Backflow } \\
\text { turbulence length } \\
\text { scale }=1.1 \mathrm{e}-3 \\
\mathrm{P}=75000 \mathrm{~Pa} \\
(\mathrm{~Tb})=325 \mathrm{~K}\end{array}$ \\
\hline
\end{tabular}


In all cases, the axial velocity inlet, which represent the engine exhaust flow, contains the following species and their respective mass fractions $\left(\mathrm{H}_{2} \mathrm{O}: 0.03, \mathrm{CO}_{2}: 0.09, \mathrm{O}_{2}: 0.136\right.$ and $\left.\mathrm{N}_{2}: 0.746\right)$.

The pressure outlet boundary condition represented the effects of a down stream pump, in the dilution tunnel system, so that the outlet pressure used was that expected at half the pump suction or 75,000 Pa absolute. The backflow temperature used was that expected at the outlet of the converged solution. For all cases $325 \mathrm{~K}$ was used. This value was used by fluent to minimize convergence difficulties in the event that backflow does occur during calculations.

The wall boundary conditions were chosen as either adiabatic or as mixed convective and radiative. In the latter case, fluent requires a specified external convective heat transfer coefficient. In order to specify the external heat transfer coefficient, a spreadsheet was developed using Microsoft Excel. The spreadsheet calculated the linear heat loss rate from piping or tubing with or without insulation or refractory. It took into consideration external radiation effects and assumed an inside wall temperature equal to the internal gas temperature or will calculate either a laminar, transient or turbulent internal heat transfer coefficient. Also, external natural and forced convective heat transfer coefficients were automatically calculated. The spreadsheet was easily modified to conduct parametric studies of different insulating materials, thicknesses and casing emissivities. Temperature dependence on external air parameters for thermal conductivity, prandtl number, coefficient of volumetric expansion, and absolute viscosity is handle by linear regression of tabulated data. The spreadsheet model assumed that the flow is single phase, there were no heat sources in the fluid or the pipe and that the external fluid temperature was equal to the temperature at infinity for radiative heat transfer effects. The effective absorptivity or emissivity of the surroundings was handled by adjusting the pipe (dilution tunnel) or insulation 
surface emissivity value. The external surface temperature was assumed not to exceed $1000^{\circ} \mathrm{F}$ as this was a limitation imposed by the regressive estimates placed on some of the thermodynamic variables. Higher external surface temperatures could have been calculated and used but more error would have been expected in the calculations. The piping or tubing was also assumed to be horizontal for calculating the natural convective external heat transfer coefficient and for considering external forced convection. The values provided by the Excel spreadsheet program were not strong functions of flow, hence a constant value was chosen per flow condition based on the spreadsheet output. For physical properties, default values were used in all cases. Generally the default values are constant values derived form the Fluent library. In all cases the ideal gas law was used to calculate the fluid density at each time step.

\section{The Numerical Scheme}

Fluent solves the governing partial differential equations for the conservation of mass. Momentum, and scalars such as energy, turbulence and chemical species in a control-volume formulation. The governing equations are discretized and solved sequentially. Since they are coupled, several iterations of a solution loop must be performed before a converged solution is obtained. Each iteration consists of the following steps:

1. The $\mathrm{u}, \mathrm{v}$, and $\mathrm{w}$ momentum equations are each solved in turn using current values for pressure, in order to update the velocity field.

2. Since the velocities obtained may not satisfy the continuity equation locally, a "poisson type" equation for the pressure correction is derived for the continuity equation and the linearized momentum equation. The pressure correction equation is then solved to obtain the necessary corrections to the pressure and velocity fields such that continuity is achieved.

3. The $\mathrm{k}$ and $\epsilon$ equations are solved using the updated velocity field. 
4. Any auxiliary equations are solved using the previously updated values of the other variables. In this case the energy equation is calculated for temperature only since there are no reacting species within the dilution tunnel.

5. Fluid properties are updated.

6. When interphase coupling is to be included, the source terms in the appropriate continuous phase equations may be updated.

7. A check for convergence is made.

The control volume formulation consists of integrating the resulting discretized algebraic equations (derived for the governing differential equations) over each control volume (cell). Consider the equation for transport of the scalar quantity $\phi$ given below as Equation A-4.

$$
\frac{\partial}{\partial x}(\rho u \phi)=\frac{\partial}{\partial x} \Gamma \frac{\partial \phi}{\partial x}+S_{\phi}
$$

Where $\rho$ is the density, $u$ is the velocity $\Gamma$ is the diffusion coefficient and $S_{\phi}$ is the source term. Equation A-4 is integrated about the control volume (cell) and discretized to yield Equation A-5 below.

$$
J_{e} \phi_{e}-J_{w} \phi_{w}=\left(\Gamma_{e} \frac{\phi_{E}-\phi_{P}}{\Delta x_{e}}-\Gamma_{w} \frac{\phi_{P}-\phi_{W}}{\Delta x_{w}}\right) A+S_{\phi} \Delta V
$$

Where $\mathrm{J}$ is the mass flux.

Fluent stores discrete values of the scalar quantity at the cell centers P, E, and W. Since face values of $\phi$ are required for the convection terms in (A-4), they must be interpolated for the cell center values. This is accomplished using either a first order upwind scheme, a power-law 
scheme or a second-order upwind scheme. The diffusion terms are central difference and are always second order accurate. The final form of the discretized equation may be written as

$$
a_{P} \phi_{P}=\sum a_{n b} \phi_{n b}+b
$$

When first order accuracy is selected, the face value of $\phi$ is assumed to be that of the upstream cell. This scheme may be derived from the exact solution to a one dimensional convection-diffusion equation for $\phi$ as given below

$$
\frac{\partial}{\partial x}(\rho u \phi)=\frac{\partial}{\partial x} \Gamma \frac{\partial \phi}{\partial x}
$$

where the values of $\rho u$ and $\Gamma$ are constant across the interval. This equation can be integrated to yield

$$
Y=\frac{\phi(x)-\phi_{0}}{\phi_{L}-\phi_{0}}=\frac{\exp \left(P e \frac{x}{L}\right)-1}{\exp (P e)-1}
$$

where

$\phi_{0}=\phi$ at $\mathrm{x}=0$

$\phi_{\mathrm{L}}=\phi$ at $\mathrm{x}=\mathrm{L}$

and $\mathrm{Pe}$ is the Peclet number $\mathrm{Pe}=\rho \mathrm{L} / \Gamma$.

The variation between $\mathrm{x}=0$ and $\mathrm{x}=1$, normalized for the overall length $(\mathrm{L})$, is given in Figure A-2 below for a range of Peclet numbers. Figure A-2 shows that for large Pe, the value of $\phi$ at $\mathrm{x}=\mathrm{L} / 2(0.5)$ is approximately equal to the upstream value. This implies that for convection dominated flow, interpolation should be done using the upwind scheme. As an example, the 


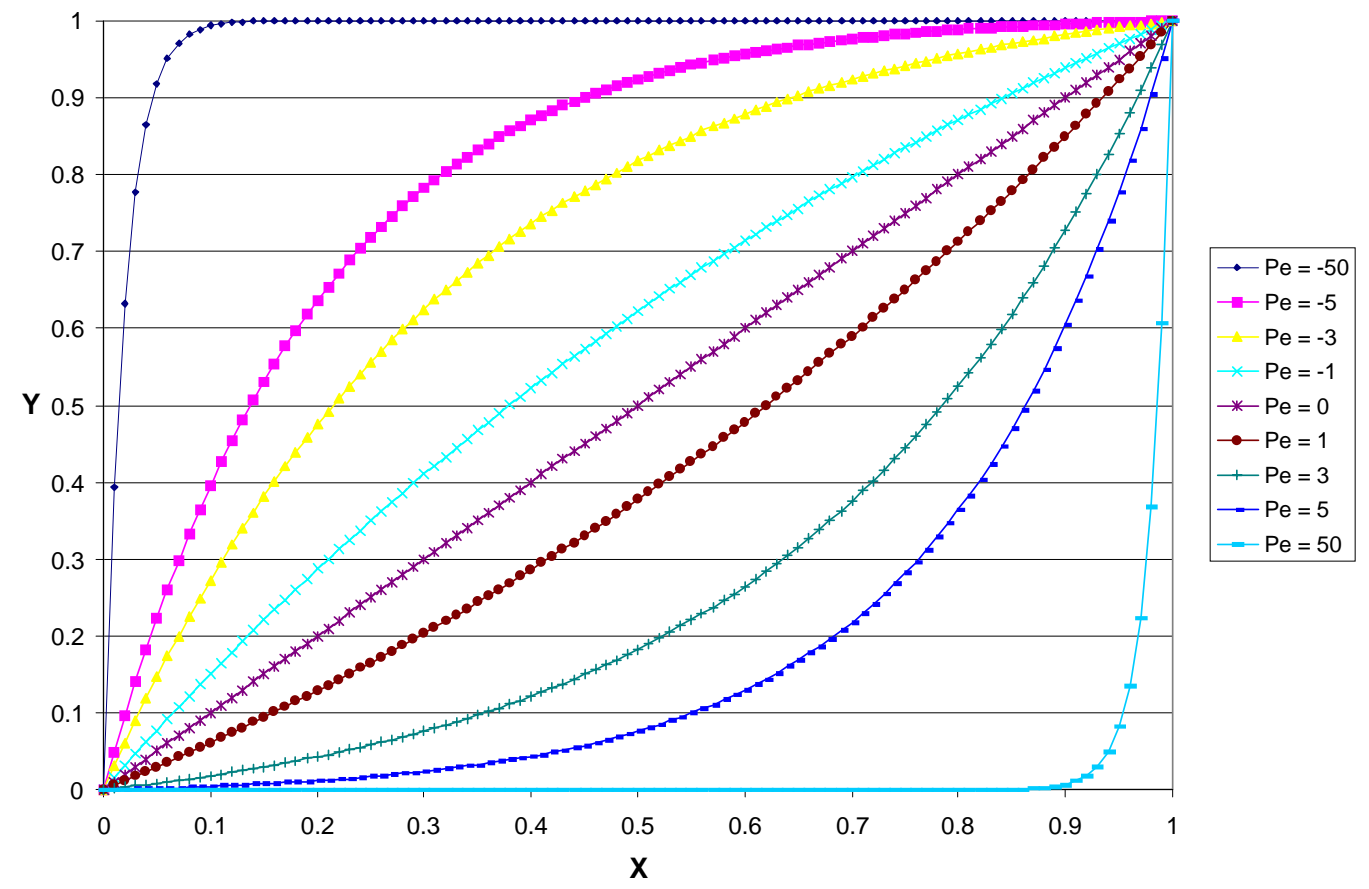

Figure A-2. Variation of function Y with Peclet Number

Pe is estimated using a technique given in Lindeberg, 1994, which considers $\mathrm{CO}_{2}$ and air as a binary diffusion pair. As such, and even increasing the estimated diffusion rate of $\mathrm{CO}_{2}$ in air by an order of magnitude to account for turbulence, the estimated grid Pe is around 250. Therefore, an upwinding numerical scheme is essential in these cases.

Fluent also has the option for a power-law and second order upwinding discretization schemes. The optional power law scheme interpolates the face value of a variable using the exact solution to the one-dimensional convection-diffusion equation (A-4) depending on the range of the Peclet number. The second order accuracy scheme computes the face value of the function using a Taylor series about a cell centroid:

$$
\phi_{e}=\phi_{p}+\nabla \phi_{p} \Delta s
$$


Here, $\phi_{\mathrm{p}}$ and $\nabla \phi_{\mathrm{p}}$ are the values of $\phi$ and its gradient in the upstream cell and $\Delta \mathrm{s}$ is the displacement vector from the cell centroid to the face centroid. This formulation requires the determination of the gradient in each cell. This gradient is computed using the divergence theorem, which in discrete form is written as

$$
\nabla \phi=\frac{1}{V} \sum(\phi A)
$$

The face values of $\phi$ are computed by averaging $\phi$ from the two cell adjacent to the face. Finally, the gradient is limited so that no new maxima or minima are introduced ${ }^{3}$.

\section{Results and Discussion}

\section{Base Cases}

Due to the small sizes of soot material entering the tunnel (estimated 95\% less than $1 \mu \mathrm{m}$ ), their relative slip with respect to the continuous phase is essentially zero. Hence, $\mathrm{CO}_{2}$ is used as a mixing tracer gas since it is highly concentrated in the engine inlet to the dilution tunnel. In all cases mixing is very rapid. $\mathrm{CO}_{2}$ profiles at the pressure outlet (tunnel outlet) for all cases from Table A-1 show a constant $\mathrm{CO}_{2}$ outlet profile at the pressure boundary. They also include wall heat transfer. Centerline mass fractions also show that in all cases the $\mathrm{CO}_{2}$ concentration approaches a constant value within 0.1 meters of the tunnel inlet. Figure A-3 (case 8) provides a typical $\mathrm{CO}_{2}$ centerline profile.

\section{Temperature}

Wall heat flux was "turned on" for cases 2, 4, 6, and 8 and a zero heat flux (adiabatic) condition was used for cases $1,3,5$, and 7 . To illustrate the heat transfer effects, temperature 


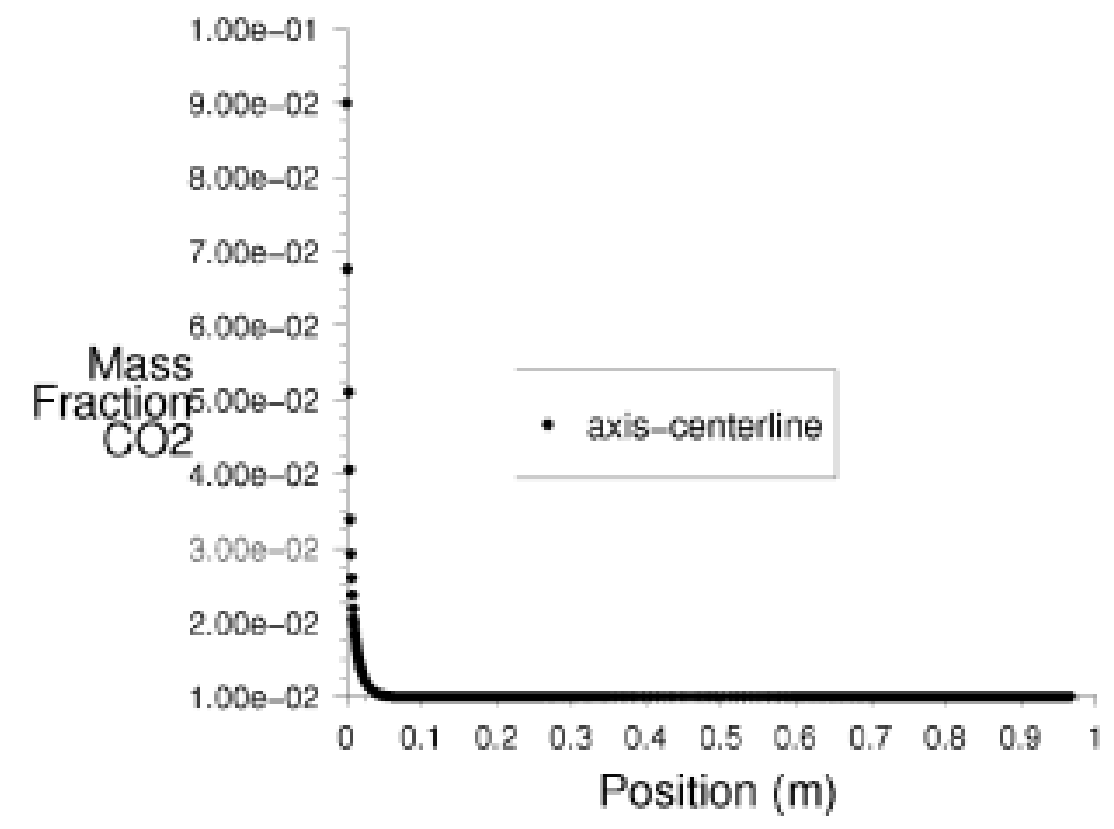

Mass fraction of $\mathrm{co2}$

Case 8b

Figure A-3. Typical $\mathrm{CO}_{2}$ axial concentration along the dilution tunnel centerline.

contours for case 8 near the inlet and over the entire dilution tunnel are given in Figures A-4 and A-5 respectively. Case 8 shows a changing profile in the axial direction. Cases 8 is chosen as an illustration because is the one of the lowest flow cases and hence show the greatest temperature effects. These are representative of the type of results for each condition. In all cases, the axial temperatures show a rapid convergence within 0.1 meters to a constant axial temperature decline rate as a function of axial distance. 


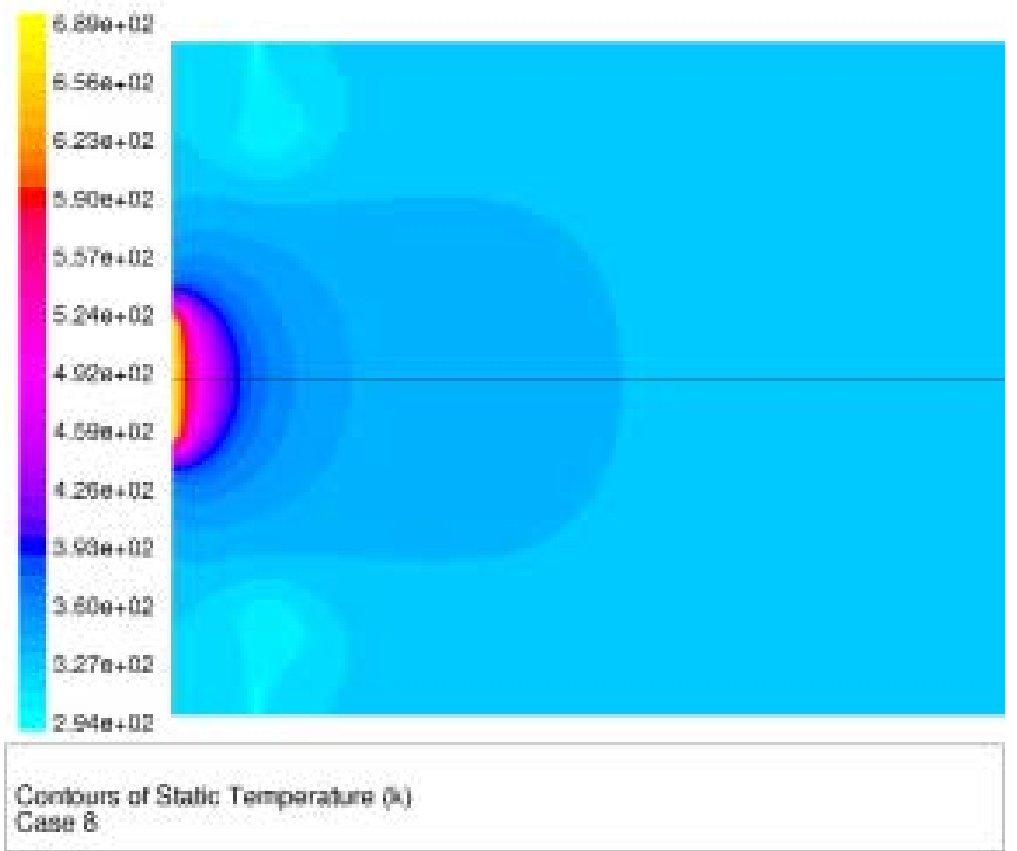

Figure A-4. Temperature contours near the inlet of the dilution tunnel.

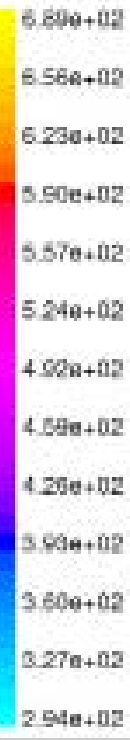

Figure A-5. Temperature contours over the entire dilution tunnel length. 


\section{Velocity}

Representative contours for velocity magnitude at the outlet of the dilution tunnel for three runs of case 8 are given in Figure A-6. A plot of the velocity magnitude for the pressure outlet for case 8 is given in Figure A-7. The outlet velocity profile mimics that which would be expected for a turbulent pipe flow.

\section{Discretization Effects}

For cases 2 and 8, which are high and low flow cases respectively, three separate sets of data are presented. Cases 2 and 8 are run using 1st order discretization, cases $2 \mathrm{~b}$ and $8 \mathrm{~b}$ are 2 nd order discretization and cases $2 \mathrm{c}$ and $8 \mathrm{c}$ were power law discretizations. Throughout the data, cases for temperature and $\mathrm{CO}_{2}$ concentration showed only slight differences between discretization types. The difference in converged temperature across the pressure outlet for each discretization case was minor. Due to the convective domination in this part of the tunnel, the suspected source of differences in values came from numerical diffusion. All practical schemes for solving fluid flow contain a finite amount of numerical diffusion. Numerical diffusion is attributed to truncation errors due to discretized nature of the equations. Numerical diffusion is minimized when flow is aligned with the grid. The flow in this case was very strongly aligned with the grid. As such, the scheme with the least theoretical numerical diffusion gave the solution with least error. We expect to see the least diffusion and greatest stability with the second order method. Stability for all cases was strong. The number of iterations and the convergence time were fairly stable between schemes. These values are given below in Table A-3. 


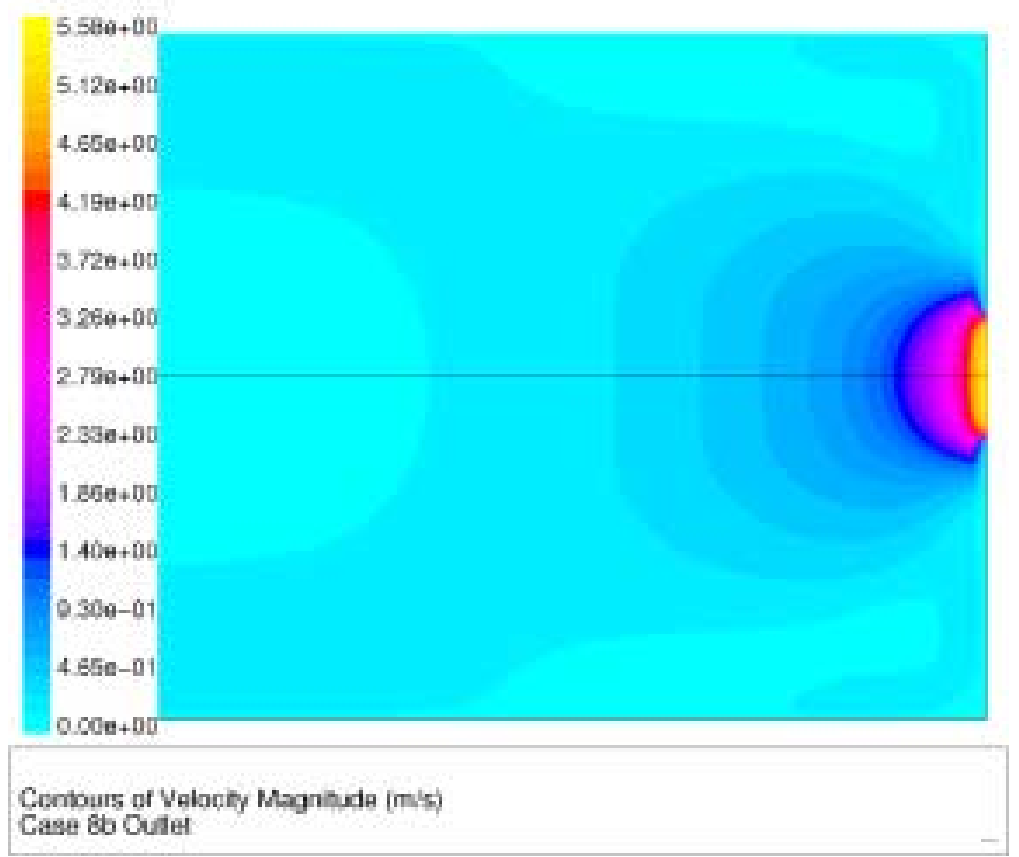

Figure A-6. Velocity contours near the outlet of the dilution tunnel.

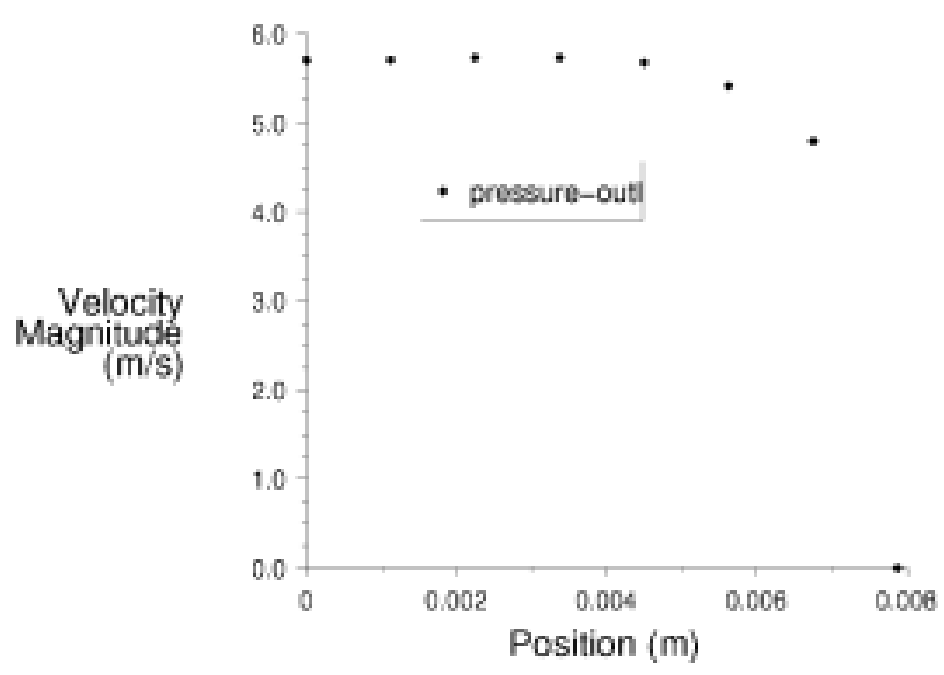

Valocity Magnituda Case 80

Figure A-7. Velocity profile at the outlet of the dilution tunnel. 
Table A-3: Number of Iterations and CPU Time for Each Case

\begin{tabular}{|c|c|c|}
\hline Case Number & CPU Time & \# of Iterations \\
\hline 1 & Not recorded & Not recorded \\
\hline 2 & $23: 16$ & 196 \\
\hline $2 \mathrm{~b}$ & $21: 06$ & 200 \\
\hline $2 \mathrm{c}$ & $23: 26$ & 201 \\
\hline 3 & $14: 23$ & 118 \\
\hline 4 & $14: 21$ & 118 \\
\hline 5 & $15: 08$ & 130 \\
\hline 6 & $15: 28$ & 130 \\
\hline 7 & $18: 14$ & 137 \\
\hline 8 & $18: 00$ & 134 \\
\hline $8 \mathrm{~b}$ & $18: 24$ & 140 \\
\hline $8 \mathrm{c}$ & $19: 13$ & 145 \\
\hline
\end{tabular}

\section{Conclusions}

The following are conclusions from the results of this effort:

- Mixing is rapid and reaches a steady state value within $0.1 \mathrm{~m}$ of the inlet as determined by $\mathrm{CO}_{2}$ concentrations.

- Heat transfer effects are well managed using 2" of fiberglass matting over the entire dilution tunnel as evidenced by the low flow case 8 .

- The discretization schemes all converged rapidly and monotonically. For these base cases, significant differences in discretization schemes were not outwardly apparent. Minor differences in converged values may be attributed to truncation error (numerical diffusion due to the convective nature of the flow). Hence, 2nd order is considered more accurate. 


\section{Appendix B: Engine Low-Speed Data Acquisition and Control Procedures}

Where convenient, calculated values are derived using the Microsoft Excel spreadsheet. However, because an average value over the sample time is required for measuring particulate emissions in the dilution tunnel, most calculations are done in Paragon TNT. This allows use of counter/timer/reset blocks within Paragon to be used to initialize and integrate key values over the duration of the emission sample, while still locking minimum and maximum values.

Paragon TNT employs an architecture, which partitions program functions into multiple servers and multiple clients. This allows TNT's client and server subsystems to function independently or in combination. Paragon TNT also provides open links to third party software such as relational databases, spreadsheets and statistical analysis packages through dynamic data exchange (DDE). From the viewpoint of other Paragon TNT subsystems, the DDE subsystem is considered a "client;" however, from the viewpoint of a third party package, it is a "server." This means that any third party system such as MS Excel can initiate a conversation with the DDE subsystem and then perform data exchange in real time. Hence, the Excel spreadsheet is used as the "final line" for low-speed data acquisition. Given below are data acquisition features inputted into Paragon TNT or Excel for data analysis and documentation purposes.

\section{Run Number}

Manually entered by the operator (dsl_run\#.xls) into a Paragon TNT operator interface screen.

\section{C/H Ratio and Correction factor}

Obtained by chemical analysis of fuel. Manually entered by the operator into a Paragon TNT operator interface screen. Correction factor accounts for species other than carbon and hydrogen. 


\section{Heat of Combustion $\left(\mathbf{q}_{\text {fuel }}\right)$}

Obtained by combustion calorimeter given as (cal/g). Manually entered by the operator into a Paragon TNT operator interface screen.

\section{Specific Gravity $\left(\rho_{\text {fuel }}\right)$}

Manually entered by the operator into a Paragon TNT operator interface screen.

\section{Test Conditions}

Usually part of the run number but may represent a subset of the run number or any special conditions. Manually entered by the operator into a Paragon TNT operator interface screen.

\section{Summations}

The number of summations used by the engine analyzer for high-speed data acquisition. This is used for documentation only. Manually entered by the operator into a Paragon TNT operator interface screen.

\section{Desired speed, torque, intake pressure, intake temp. and exhaust back pressure} All are manually entered and represent the ideal desired conditions into a Paragon TNT operator interface screen.

\section{8. $\quad$ Speed $\left(S_{\text {eng }}\right)$}

Actual average value of the engine speed (rev/sec) from flywheel ${ }^{\circ} \mathrm{CA}$ measurement which is calculated as a rolling average over the past 30 seconds of data from the calculation block in Paragon (SA-255).

Values may be reported as actual values, values averaged over a rolling 30 seconds, characterized values or as integrated values over the sample time (used when particulate samples 
are taken). A characterized values is a value that has been linearly, first or second order, least squares fitted to some "known" value.

\section{Torque (WT-259Z)}

Value of the engine torque in Nm which is given by the calculation block in Paragon (WT-259Z). This information comes from a characterization block in Paragon which allows for calibration and correction of the output value from a calibrated load cell on the engine dynamometer.

\section{Engine Intake Pressure $\left(\mathbf{P}_{\text {surge }}\right)$}

The calculation block in Paragon (PT-129) gives the value of the engine intake pressure in $\mathrm{KPaG}$. It is measured at the downstream end of the surge tank just upstream of the engine using a Rosemount 1144 pressure transmitter.

\section{Intake Air Temp $\left(\mathbf{T}_{\text {in }}\right)$}

Value of the engine air temperature $\left({ }^{\circ} \mathrm{C}\right)$ comes from the calculation block in Paragon (TE-130A). It is measured at the engine intake manifold.

\section{Exhaust Backpressure $\left(\mathbf{P}_{\text {back }}\right)$}

The calculation block in Paragon (PT-377) gives value of the engine exhaust backpressure (kpag) and is measured using a Rosemount model 1151 pressure transmitter.

\section{BMEP (bar)}

Brake Mean Effective Pressure data taken directly from calculation block "ENBMEP" in Paragon which is given by:

$$
\mathrm{ENBMP}=(\mathrm{W} 259 \mathrm{Z})\left(\frac{1}{\mathrm{~V}_{\mathrm{DISP}}}\right)\left(\frac{2 \mathrm{rev}}{\text { cycle }}\right)\left(\frac{2 \pi \mathrm{rad}}{\mathrm{rev}}\right)\left(\frac{10^{-2}}{\mathrm{~Pa}}\right)
$$


Where the displaced volume $\left(\mathrm{V}_{\text {DISP }}\right)$ is $0.001997 \mathrm{~m}^{3}$ or $1.997 \mathrm{dm}^{3}$. The last term of Equation B-1 (Heywood, 1988) converts Pa to bar. $\mathrm{V}_{\mathrm{DISP}}$ is in $\mathrm{dm}^{3}$ units.

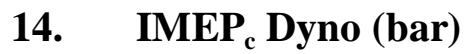

The indicated mean effective pressure is calculated in Excel as:

$$
\mathrm{IMEP}_{\text {dyno }}=\mathrm{BMEP}-\mathrm{FMEP}
$$

\section{FMEP $_{c}$}

$\mathrm{FMEP}_{\mathrm{c}}$ values are determined experimentally at each operating state by equilibrating the engine, eliminating fuel, and providing aspirated air. The motoring torque values are then determined and converted to FMEP. These values can be manually entered into Paragon for processing in the $\mathrm{IMEP}_{\mathrm{dyno}}$ calculations.

\section{Power $(\mathrm{kW})$}

The power in kilowatts is calculated from the engine speed and torque. This is read directly into excel from the "ENPWKW" Paragon calculation block. The calculation is given by:

$$
\text { Power }(\mathrm{kW})=(\mathrm{WT}-259 \mathrm{~A})(\mathrm{ST}-255)\left(\frac{2 \pi \mathrm{rad}}{\mathrm{rev}}\right)\left(\frac{1 \mathrm{~kW}}{1000 \mathrm{~W}}\right)
$$

\section{Power (hp)}

The power in horsepower is calculated in the Paragon calculation block "ENPWHP" and is simply the power in $\mathrm{kW}$ multiplied by the conversion factor of $1.34 \mathrm{hp} / \mathrm{kW}$.

\section{BSFC (g/kW-hr)}

The brake specific fuel consumption in $\mathrm{g} / \mathrm{kW}-\mathrm{hr}$ is calculated in the Paragon calculation block "ENBFKW" by using the following: 


$$
\mathrm{BSFC}=\left(\frac{\dot{\mathrm{m}}_{\mathrm{f}}}{\text { ENPFKWA }}\right)\left(\frac{3600 \mathrm{sec}}{\mathrm{hr}}\right)
$$

Where the fuel mass flow rate is given by F218Z and is the characterized value of the fuel flow rate $(\mathrm{g} / \mathrm{sec})$ given below.

\section{9. $\quad$ BSFC (g/hp-hr)}

Is calculated in Paragon by dividing BSFC in $\mathrm{g} / \mathrm{kW}-\mathrm{hr}$ by $1.34 \mathrm{hp} / \mathrm{kW}$. This is also averaged and taken as "ENBFHP."

20. Vol. Eff. (\%)

This is calculated in Paragon as "ENVLEF." It measures the ratio of the actual amount of air used by the engine relative to the amount theoretically needed. The actual amount of air is calculated by F120Z (explained below).

$$
\text { ENVLEF }=\eta=\frac{m_{\text {air }_{\text {act }}}}{m_{\text {air }_{\text {theo }}}}(100 \%)
$$

by:

$$
\mathrm{m}_{\text {air }}=\frac{\left(\mathrm{P}_{\text {surge }}+\mathrm{P}_{\mathrm{b}}\right)\left(\frac{28.95 \mathrm{~g}_{\text {Air }}}{\mathrm{gmol}}\right)}{\mathrm{R}_{\mathrm{u}}\left(\mathrm{T}_{\text {intake }}+273.15\right)}\left(\mathrm{V}_{\text {disp }}\right)\left(\mathrm{S}_{\text {eng }}\right)\left(\frac{1 \text { cycle }}{2 \mathrm{rev}}\right)
$$

Where $\mathbf{R}_{\mathbf{u}}=0.008314 \mathrm{kPa} \mathrm{m}^{3} / \mathrm{gmol} \mathrm{K}, \mathbf{P}_{\mathbf{b}}$ is the mean local barometric pressure $(97.82 \mathrm{kPa})$ and $\mathrm{V}_{\text {disp }}=0.001997 \mathrm{~m}^{3}$.

\section{Thermal eff. (\%)}

The thermal efficiency is defined as: 


$$
\eta=\frac{\text { Power }(\mathrm{kw})}{\dot{\mathrm{m}}_{\text {fuel }} \mathrm{q}_{\text {fuel }}\left(0.004188 \frac{\mathrm{kW}}{\mathrm{cal} / \mathrm{sec}}\right)} 100 \%
$$

Where $\mathrm{q}_{\text {fuel }}$ is in $(\mathrm{cal} / \mathrm{g})$ and $\mathrm{M}_{\text {fuel }}(\mathrm{F} 218 \mathrm{Z})$ is in $(\mathrm{g} / \mathrm{sec})$ units.

\section{Air/Fuel Ratio}

Calculated in Paragon as "ARFLRT" from the characterized and averaged values of the air mass flow rate and fuel mass flow rate as:

$$
\frac{\dot{\mathrm{m}}_{\text {air }}}{\dot{\mathrm{m}}_{\text {fuel }}}=\frac{\mathrm{F} 120 \mathrm{Z}}{\mathrm{F} 218 \mathrm{Z}}
$$

\section{Fueling}

This is calculated in the Paragon as the Paragon calculation block "FLING" as the volume of fuel per injection $\left(\mathrm{mm}^{3} /\right.$ injection $)$ as

$$
\mathrm{V}_{\text {fuel }}=\left(\frac{\dot{\mathrm{m}}_{\text {fuel }} \cdot\left(2 \frac{\mathrm{rev}}{\text { cycle }}\right)}{\rho_{\text {fuel }} \cdot \mathrm{S}_{\mathrm{eng}}}\right) \cdot\left(1000 \frac{\mathrm{mm}^{3}}{\mathrm{ml}}\right)
$$

\section{Smoke Opacity (\%)}

Is taken from Paragon directly from the opacity monitor (AT-366) as \% opacity and is measured using a Telonic Berkeley Celesco Model 107 In-line Smokemeter.

\section{Air Rate $(\mathrm{g} / \mathrm{sec})$}

Actual average value of the inlet engine air flow rate which is characterized from flow calibration in the Paragon calculation block "F120Z." The measurement is made from an "Alcock Viscous Air Flow Meter." The equation for the viscosity correction factor $(\gamma)$ was derived from second-order regression of the viscosity data in the air properties table 
of the Alcock Viscous Air Flow Meter operating instructions. The following equation shows how the air mass flow rate is calculated.

$$
\dot{\mathrm{m}}_{\mathrm{air}}=\alpha \cdot \Delta \mathrm{P} \cdot \gamma_{\mathrm{visc}} \cdot\left[\frac{\left(\mathrm{P}_{\mathrm{fm}}+\mathrm{P}_{\mathrm{ba}}\right)}{\mathrm{P}_{\mathrm{atm}}}\right] \cdot\left[\frac{\mathrm{T}_{\mathrm{std}}}{\left(\mathrm{T}_{\mathrm{abs}}+\mathrm{T}_{\mathrm{fm}}\right)}\right]
$$

Where $\alpha$ is a calibration factor determined during flow proving. The viscous correction factor $\left(\gamma_{\text {visc }}\right)$ is calculated as:

$$
\gamma_{\text {visc }}=1.05525-0.00288 \cdot \mathrm{T}+6.29018 \times 10^{-6} \cdot \mathrm{T}^{2}
$$

Where the temperature $\left({ }^{\circ} \mathrm{C}\right)$ is measured at the flowmeter (TE-118). $\Delta \mathrm{P}$ is measured by Rosemount model 3051 differential pressure transmitter. $\mathrm{P}_{\mathrm{fm}}$ is measured by a Rosemount model 1144 pressure transducer.

\section{Fuel Flow Rate (g/sec)}

Actual average value of the inlet fuel engine flow rate which is and characterized for calibration from Paragon (F218Z). It is calculated from the rate of change in holding weight of a small fuel reservoir in the gravimetric fuel flow unit. The weight of fuel in the reservoir decreases as fuel is consumed. When the fuel weight reaches a specified minimum, a solenoid opens a valve and admits mor fuel to the reservoir, thus causing the holding weight to increase. The solenoid closes when the weight of fuel reaches a specified maximum. Calculation of fuel flow rate begins by identifying and isolating those portions of holding weight data for which the fill valve is closed. The cumulative mass of fuel consumed between consecutive observations is then calculated. The time between successive calculations depends on the time for a given mass of fuel to be consumed.

\section{Exhaust Pressure (KPaG)}

Value of the exhaust pressure is given by a calculation block in Paragon (PT-377). 


\section{Intake Pressure (KPaG)}

A calculation block in Paragon (PT-129) gives value of the intake pressure and is measured by a Rosemount model 1144 pressure transmitter.

\section{Flow Element Pressure (KPaG)}

A calculation block in Paragon (PT-122) gives value of the flow element pressure and is measured by a Rosemount model 1144 pressure transmitter.

\section{Exhaust Temperature $\left({ }^{\circ} \mathrm{C}\right)$}

A calculation block in Paragon (TA-350) gives value of the exhaust temperature. It is measured at the exhaust manifold.

\section{Intake Temperature $\left({ }^{\circ} \mathrm{C}\right)$}

A calculation block in Paragon (TE-130) gives value of the intake temperature. It is measured at the exhaust manifold.

\section{Flow Element Temperature $\left({ }^{\circ} \mathrm{C}\right)$}

A calculation block in Paragon (TE-118) gives value of the Alcock laminar flow element temperature.

\section{Surge Tank Temperature $\left({ }^{\circ} \mathrm{C}\right)$}

A calculation block in Paragon (TE-126) gives value of the surge tank temperature, just downstream of the air heater.

\section{Oil Temperature $\left({ }^{\circ} \mathrm{C}\right)$}

A calculation block in Paragon (TE-071) gives value of the oil temperature.

\section{Coolant In Temperature $\left({ }^{\circ} \mathrm{C}\right)$}

A calculation block in Paragon (TE-077) gives value of the coolant inlet temperature. 


\section{Coolant Out Temperature $\left({ }^{\circ} \mathrm{C}\right)$}

A calculation block in Paragon (TE-059) gives value of the coolant outlet temperature.

37. Sample Time (sec)

This is the measured time over which the gas and particulate samples are taken. It is read from a counter in Paragon (CNT).

\section{Horsepower-hour (hp-hr)}

This is calculated in Paragon as the average horsepower multiplied by the sample time.

\section{Absolute Humidity $\left(\mathrm{g} / \mathrm{m}^{3}\right)$}

Read from Paragon (XT-512). It is used for corrections to gaseous and particulate emissions measurement. It is measured by a Vaisela model HMP 233 humidity analyzer.

\section{Total Std. Dry Engine Volume (std. $\left.\mathbf{m}^{3}\right)$}

Used in engine specific volume calculations. Calculate in Paragon as:

$$
\mathrm{V}_{\text {eng }}=\left(\frac{\left[\left(\mathrm{M}_{\text {air }}+\mathrm{M}_{\text {fuel }}\right) \cdot(100)\right] \cdot(\mathrm{Ru}) \cdot\left(\frac{\mathrm{T}_{\text {std }}}{\mathrm{P}_{\text {std }}}\right) \cdot(\text { Sample Time })}{\left(100-\mathrm{CO}_{2 \mathrm{ex}}-\mathrm{O}_{2}-(\mathrm{High} \mathrm{CO}) \cdot(28)+(\mathrm{High} \mathrm{CO}) \cdot(28)+\left(\mathrm{O}_{2}\right) \cdot(32)+\left(\mathrm{CO}_{2 \mathrm{ex}}\right) \cdot(44)\right)}\right)
$$

Where the denominator is a calculation of the average exhaust gas molecular weight (Dry). The first term in the denominator is a difference equation for the nitrogen concentration.

\section{Total Engine Mass (g)}

This is the total engine mass "ENTLMS" calculated in Paragon as the sum of the air and fuel into the engine multiplied by the sample time (CNT).

\section{Total Engine Sample Volume $\left(\mathbf{m}^{3}\right)$}

Calculated in Paragon as 


$$
\text { Total Engine Sample Volume }=\frac{\text { Total Std. Dry Engine Vol. }}{\text { Split Ratio }}
$$

Where the Split Ratio is given below.

\section{Total Engine Sample Mass (g)}

Calculated in Paragon as:

$$
\text { Total Engine Sample Mass }=\frac{\text { Total Engine Mass }}{\text { Split Ratio }}
$$

Where the Split Ratio is given below.

\section{Split Ratio}

The total tunnel mass flow rate calculated based on pump speed, pump upstream pressure and temperature (FMTLMFZ). Both methods are characterized for calibration and averaged. The first calculation goes as:

$$
\text { Split Ratio }=\frac{\left(\mathbf{M}_{\text {air }}+\mathbf{M}_{\text {fuel }}\right) \cdot \text { Dilution Ratio }}{\mathrm{M}_{\text {tunnel }}}
$$

The FMTLMFZ calculation, done in Paragon, is already in $\mathrm{g} / \mathrm{sec}$ units and is calculated as:

$$
\mathrm{M}_{\text {tun }}=\left(\text { Pump Speed } \cdot\left(2.724 \times 10^{-4} \frac{\mathrm{g}_{\text {air }}}{\mathrm{m}^{3}}\right) \cdot \mathrm{K}\left(\frac{\mathrm{m}^{3}}{\mathrm{stroke}}\right) \cdot\left[\frac{\mathrm{T}_{\text {std }}}{\left(\mathrm{T}_{\text {pump }}+\mathrm{T}_{\mathrm{abs}}\right)}\right] \cdot\left[\frac{\left(\mathrm{P}_{\text {std }}+\mathrm{P}_{\text {pump }}\right)}{\mathrm{P}_{\text {std }}}\right]\right.
$$

Where $\mathrm{K}$ is a mid-value calibration constant and $\mathrm{T}_{\text {std }}$ and $\mathrm{P}_{\text {std }}$ are standard temperature (288.7 K) and pressure (406.9 in $\mathrm{H}_{2} \mathrm{O}$ ), respectively. This value is linearized via flow proving. 


\section{Dilution Ratio}

The ratio of $\mathrm{CO}_{2}$ levels in the tunnel and in the raw engine exhaust is used to calculate dilution ratio. This is calculated as:

$$
\text { Dilution Ratio }=[\mathrm{WCF}] \cdot\left[\frac{\left(\mathrm{CO}_{2_{\mathrm{ex}}}-\mathrm{CO}_{2_{\mathrm{back}}}\right)}{\left(\mathrm{CO}_{2_{\mathrm{tun}}}-\mathrm{CO}_{2_{\text {back }}}\right)}\right]
$$

Where $\mathrm{CO}_{2 \text { back }}$ is the $\mathrm{CO}_{2}$ in the background ambient air. WCF is the water correction factor, which is discussed later in this chapter. The first term in the equation is a correction used to account for the fact that the measurement is done on dry samples. It accounts for the missing water vapor. This correction is described below. The dilution ratio is typically measured using $\mathrm{CO}_{2}$, $\mathrm{NO}$ or some other chemically stable species in the exhaust which can be easily measured. $\mathrm{CO}_{2}$ was used in this work due to the ease of measurement and the availability of analytical instrumentation.

\section{Tunnel Inlet Temperature $\left({ }^{\circ} \mathrm{C}\right)$}

Calculated in Paragon and measured in the sample line prior to the tunnel inlet (TE-501).

\section{Dilution Air Temperature $\left({ }^{\circ} \mathrm{C}\right)$}

Calculated in Paragon and measured in the dilution air line prior to the dilution tunnel (TE-520).

\section{Filter Face Temperature $\left({ }^{\circ} \mathrm{C}\right)$}

Calculated in Paragon and measured at the filter face downstream of the dilution tunnel. (TE-516).

\section{Maximum Filter Face Temperature $\left({ }^{\circ} \mathrm{C}\right)$}

Calculated in Paragon and measured at the filter face downstream of the dilution tunnel (TE-516). 
50. Minimum Filter Face Temperature $\left({ }^{\circ} \mathrm{C}\right)$

Calculated in Paragon and measured at the filter face downstream of the dilution tunnel (TE-516).

\section{Bypass Line Temperature $\left({ }^{\circ} \mathrm{C}\right)$}

Calculated in Paragon and measured in the bypass line after the dilution tunnel right before it branches to the sample filter. Used to monitor temperatures to stabilize prior to switching to the sample filter line (TE-528).

\section{Dilution Air Mass Flow (g/s)}

The dilution air flow as measured using a Sierra mass flow controller and characterized and averaged by Paragon function block (FY-521Z).

\section{Tunnel Mass Flow (g/s)}

The total tunnel mass flow rate is measured using a Sierra mass flow controller and characterized and averaged by Paragon function block (FY-511Z). It is linearized via flow proving.

\section{Pump Speed (Hz)}

Raw value (readin value) from Paragon (ST-517).

\section{Sample Filter Delta $P$ (inches of $\mathrm{H}_{2} \mathrm{O}$ )}

Raw value (read-in value) from Paragon (PDT-508).

\section{6. $\mathrm{NO}_{\mathrm{x}}$ Analyzer}

The $\mathrm{NO}_{\mathrm{x}}$ measurement is taken in the raw exhaust. The $\mathrm{NO}_{\mathrm{x}}$ values are presented in three ways: Average (\%), Mass (g) and Ave. (g/hp-hr). The average values are given by Paragon as a rolling average over the past 30 seconds of measurement. The Mass value is the total mass of $\mathrm{NO}_{\mathrm{x}}$ measured during the sampling period. It is calculated as: 


$$
\mathrm{M}_{\mathrm{NO}_{\mathrm{x}}}=\mathrm{K}_{\mathrm{H}} \cdot\left[\mathrm{NO}_{\mathrm{x}}-\mathrm{NO}_{\mathrm{x}_{\text {back }}} / 10^{6}\right] \cdot\left(1913 \mathrm{~g} / \mathrm{m}^{3}\right) \cdot(\text { Total Std. Dry Engine Vol. })
$$

Where $1913 \mathrm{~g} / \mathrm{m}^{3}$ is the density of $\mathrm{NO}_{\mathrm{x}}$ and $\mathrm{K}_{\mathrm{H}}$ is the humidity correction factor. Both of these values are given in the Code of Federal Regulations CFR 40, 86.1342-90. The Ave. ( $\mathrm{g} / \mathrm{hp}-\mathrm{hr}$ ) is the total mass $\mathrm{M}_{\mathrm{NOx}}$ as measured and calculated above, divided by the Horsepower-hour calculated in Paragon. The Ave. (g/hp-hr) is the value commonly reported in the literature. This value may also be averaged (integrated over the particulate sampling time).

\section{Low CO Analyzer}

The Low CO values are presented in three ways: Average (\%), Mass (g) and Ave. (g/hp-hr). The average values are given by Paragon as a rolling average over the past 30 seconds of measurement. The Mass value is the total mass of Low CO measured during the sampling period or the instantaneous value. It is calculated as:

$$
\mathrm{M}_{\text {LowCO }}=\left[\left(\text { LowCO }_{\text {ave }}-\mathrm{CO}_{\text {back }}\right) / 10^{6}\right] \cdot\left(1164 \mathrm{~g} / \mathrm{m}^{3}\right) \cdot(\text { Total Std. Dry Engine Vol. }) \cdot(\mathrm{WCF})
$$

Where $1164 \mathrm{~g} / \mathrm{m}^{3}$ is the density of CO given in the Code of Federal Regulations CFR 40, 86.1342-90. The Ave. (g/hp-hr) is the total mass $\mathrm{M}_{\text {LowCO }}$ as measured and calculated above, divided by the Horsepower-hour calculated in paragon. The Ave. (g/hp-hr) is the value commonly reported in the literature.

\section{High CO Analyzer}

The High CO values are presented in three ways: Average (\%), Mass (g) and Ave. (g/hp-hr). The average values are given by Paragon as a rolling average over the past 30 seconds of measurement. The Mass value is the total mass of High CO measured during the sampling period. It is calculated as: 


$$
\mathrm{M}_{\mathrm{HighCO}}=\left[\left(\mathrm{HighCO}_{\mathrm{ave}} / 100\right)-\left(\mathrm{CO}_{\text {back }} / 10^{6}\right)\right] \cdot\left(1164 \mathrm{~g} / \mathrm{m}^{3}\right) \cdot(\text { Total Std. Dry Engine Vol. }) \cdot(\mathrm{WCF})
$$

Where $1164 \mathrm{~g} / \mathrm{m}^{3}$ is the density of CO given in the Code of Federal Regulations CFR 40, 86.1342-90. The Ave. (g/hp-hr) is the total mass $\mathrm{M}_{\mathrm{HighCO}}$ as measured and calculated above, divided by the Horsepower-hour calculated in paragon. The Ave. (g/hp-hr) is the value commonly reported in the literature.

\section{9. $\mathrm{CO}_{2}$ Ex Analyzer}

The $\mathrm{CO}_{2}$ Ex values are presented in three ways: Average (\%), Mass (g) and Ave. (g/hp-hr). The average values are given by Paragon as a rolling average over the past 30 seconds of measure. The Mass value is the total mass of $\mathrm{CO}_{2}$ Ex measured during the sampling period. It is calculated as:

$$
\mathrm{M}_{\mathrm{CO}_{2} \mathrm{Ex}}=\left[\left(\mathrm{CO}_{2} \mathrm{Ex}_{\text {ave }} / 100\right)-\left(\mathrm{CO}_{2 \mathrm{back}} / 10^{6}\right)\right] \cdot\left(1830 \mathrm{~g} / \mathrm{m}^{3}\right) \cdot(\text { Total Std. Dry Engine Vol. }) \cdot(\mathrm{WCF})
$$

Where $1830 \mathrm{~g} / \mathrm{m}^{3}$ is the density of $\mathrm{CO}_{2}$ given in the Code of Federal Regulations CFR 40, 86.1342-90. The Ave. (g/hp-hr) is the total mass $\mathrm{M}_{\mathrm{CO} 2 \mathrm{Ex}}$ as measured and calculated above, divided by the Horsepower-hour calculated in Paragon. The Ave. (g/hp-hr) is the value commonly reported in the literature.

\section{0. $\mathrm{CO}_{2}$ Tun Analyzer}

The $\mathrm{CO}_{2} \mathrm{Ex}$ values are presented in three ways: Average (\%), Mass (g) and Ave. (g/hp-hr). The average values are given by Paragon as a rolling average over the past 30 seconds of measurement. The measurement is taken in the dilution tunnel. The Mass value is the total mass of $\mathrm{CO}_{2} \mathrm{Ex}$ measured during the sampling period. It is calculated as:

$$
\mathrm{M}_{\mathrm{CO}_{2} \mathrm{Tun}}=\left[\left(\mathrm{CO}_{2} \mathrm{Tun}_{\text {ave }} / 100\right)-\left(\mathrm{CO}_{2 \mathrm{baok}} / 10^{6}\right)\right] \cdot\left(1830 \mathrm{~g} / \mathrm{m}^{3}\right) \cdot(\text { Total Std. Dry Engine Vol.) } \cdot \text { (Dilution Ratio) }
$$

Where $1830 \mathrm{~g} / \mathrm{m}^{3}$ is the density of $\mathrm{CO}_{2}$ given in the Code of Federal Regulations CFR 40, 86.1342-90. The Ave. (g/hp-hr) is the total mass $\mathrm{M}_{\mathrm{CO} 2 \mathrm{Ex}}$ as measured and calculated 
above, divided by the Horsepower-hour calculated in Paragon. The Ave. (g/hp-hr) is the value commonly reported in the literature.

\section{THC Analyzer}

The THC values are presented in three ways: Average (ppm), Mass (g) and Ave. (g/hp-hr). The average values are given by Paragon as a rolling average over the past 30 seconds of measurement. The measurement is taken in the dilution tunnel. The Mass value is the total mass of THC measured during the sampling period. It is calculated as:

$$
\mathbf{M}_{\mathrm{THC}}=\left[\left(\mathrm{THC}_{\mathrm{ave}}-\mathrm{THC}_{\mathrm{back}}\right) / 10^{6}\right] \cdot\left(574.6 \mathrm{~g} / \mathrm{m}^{3}\right) \cdot(\text { Total Std. Dry Engine Vol. })
$$

Where $574.6 \mathrm{~g} / \mathrm{m}^{3}$ is the density of HC given in the Code of Federal Regulations CFR 40,

86.1342-90. The Ave. (g/hp-hr) is the total mass $\mathrm{M}_{\mathrm{THC}}$ as measured and calculated above, divided by the Horsepower-hour calculated in Paragon. The Ave. (g/hp-hr) is the value commonly reported in the literature.

\section{2. $\mathrm{O}_{2}$ Analyzer}

The $\mathrm{O}_{2}$ values are presented in three ways: Average (\%), Mass (g) and Ave. (g/hp-hr). The average values are given by Paragon as a rolling average over the past 30 seconds of measurement. The Mass value is the total mass of $\mathrm{O}_{2}$ measured during the sampling period. It is calculated as:

$$
\mathrm{M}_{\mathrm{O}_{2}}=\left[\left(\mathrm{O}_{2 \mathrm{ave}} / 100\right)\right] \cdot\left(1330 \mathrm{~g} / \mathrm{m}^{3}\right) \cdot(\text { Total Std. Dry Engine Vol. }) \cdot(\mathrm{WCF})
$$

Where $1330 \mathrm{~g} / \mathrm{m}^{3}$ is the density of $\mathrm{O}_{2}$ given in the Code of Federal Regulations CFR 40, 86.1342-90. The Ave. ( $\mathrm{g} / \mathrm{hp}-\mathrm{hr})$ is the total mass $\mathrm{M}_{\mathrm{O} 2}$ as measured and calculated above, divided by the Horsepower-hour calculated in Paragon. The Ave. (g/hp-hr) is the value commonly reported in the literature. 


\section{Background Values (ppm)}

The background values of $\mathrm{CO}, \mathrm{CO}_{2}, \mathrm{THC}$ and $\mathrm{NO}_{\mathrm{x}}$ are entered manually into Paragon and read into Excel through the Paragon TNT operator interface screen. These values are used as background correction to the test values given above. They are obtained by running engine/dilution air to the analyzers and reading a background value each run day.

\section{4. $\mathbf{K}_{\mathrm{H}}$}

This is the calculated humidity correction factor given by Code of Federal Regulations CFR 40, 86.1342-90. It is calculated in paragon as:

$$
\mathrm{K}_{\mathrm{H}}=\frac{1}{\left[1-0.00182 \cdot\left(\text { Absolute Humidity }\left(\mathrm{g} / \mathrm{m}^{3}\right)-10.71\right)\right]}
$$

\section{Carbon Mass Balance}

The carbon mass balance calculation provides a measure closure between inlet carbon (fuel-bound carbon) and measured gaseous carbon contained in the exhaust $\mathrm{CO}_{2}, \mathrm{CO}$ and THC. The inlet fuel carbon mass flow rate is calculated as:

$$
\dot{\mathrm{m}}_{\mathrm{C}_{\text {fuel }}}=\left[\frac{12}{(12+(1 / \mathrm{C} / \mathrm{H}))}\right] \cdot \dot{\mathrm{m}}_{\text {fuel }} \cdot(\text { Sample Time })
$$

The outlet gaseous carbon mass flow rate is calculated as:

$$
\dot{\mathrm{m}}_{\mathrm{C}_{\mathrm{gas}}}=\left[\dot{\mathrm{m}}_{\mathrm{CO}_{2}} \mathrm{Ex} \cdot(12 / 44)\right]+\left[\left(\dot{\mathrm{m}}_{\mathrm{CO}_{\text {high }}}\right) \cdot(12 / 28)\right]+\left[\left(\dot{\mathrm{m}}_{\mathrm{THC}}\right) \cdot(12 / 16)\right]
$$

The agreement should be no better than about $99 \%$ due to some carbon in the particulate phase. The percent accounted for is given by:

$$
\% \text { accounted }=\frac{\mathrm{M}_{\mathrm{C}_{\text {gas }}}}{\mathrm{M}_{\mathrm{C}_{\text {fuel }}}}
$$




\section{Particulate Mass (Post Processed)}

These calculations will be post processed after physically conditioning the particulate samples and weighing them to determine the particulate mass. First the filters are conditioned and pre-weighed, then either conditioned again or put directly into the dilution tunnel. A background sample is also taken to account for background from dilution air etc. The corresponding datasheet file for that particular run must be opened without accepting the relink option and the "Filter Particulate Mass" and "Background Mass" manually entered onto the paragon. The "Corrected Mass" is calculated in Excel as:

$$
\mathrm{M}_{\mathrm{P}_{\text {Corr }}}=\frac{\left[\left(\mathrm{M}_{\mathrm{p}}-\mathrm{M}_{\text {back }}\right) \cdot(\text { Split Ratio })\right]}{[1+0.0018 \cdot(\text { Absolute Humidity }-10.71)]}
$$

Although the CFR-40 does not specify any further correction be made to the particulate mass, Nussear (1992) utilized a humidity correction factor (denominator term) which was developed by Mack Trucks and found to be in good correlation for a variety of engine types and laboratories. This corrected mass is related back to the total engine throughput by the split ratio. Also provided, is the $\mathrm{PM} \mathrm{(g/hp-hr).} \mathrm{This} \mathrm{value} \mathrm{is} \mathrm{given} \mathrm{by:}$

$$
\mathrm{PM}=\frac{\mathrm{M}_{\mathrm{P}_{\text {Cor }}}}{\text { horsepower - hour }}
$$

\section{Water}

The mass production rate of water is calculated using the carbon-hydrogen ratio of the fuel and the fuel flow rate. Since the molecular weight of atomic hydrogen is approximately equal to 1 , the inverse of the $\mathrm{C} / \mathrm{H}$ is the number of hydrogen atoms per mole of fuel. The factor of 9 is introduced to account for one oxygen atom per 2 hydrogen atoms 
and hence half of the molecular weight of water per gram of hydrogen in the fuel ( 9 grams of water per 1 mole of atomic $\mathrm{H}$ ).

The total water mass is given by:

$$
\mathrm{M}_{\mathrm{tot}_{\mathrm{H}_{2} \mathrm{O}}}=\frac{\frac{1}{(\mathrm{C} / \mathrm{H})} \cdot[\text { Fuel Rate }(\mathrm{g} / \mathrm{s})]}{\left[12+\frac{1}{(\mathrm{C} / \mathrm{H})}\right]} \cdot(\text { Sample Time })
$$

The volume water production rate at standard conditions is given by:

$$
\mathrm{V}_{\mathrm{H}_{2} \mathrm{O}}=\frac{\mathrm{M}_{\mathrm{H}_{2} \mathrm{O}} \cdot \mathrm{R}_{\mathrm{u}} \cdot \mathrm{T}_{\text {std }}}{\mathrm{MW}_{\text {water }} \cdot \mathrm{P}_{\text {std }}}
$$

The total volume of water at standard conditions produced during the sample time is given by:

$$
\mathrm{V}_{\mathrm{H}_{2} \mathrm{O}}=\frac{\mathrm{M}_{\mathrm{H}_{2} \mathrm{O}} \cdot \mathrm{R}_{\mathrm{u}} \cdot \mathrm{T}_{\text {std }}}{\mathrm{MW}_{\text {water }} \cdot \mathrm{P}_{\text {std }}} \cdot(\text { Sample Time })
$$

The $\mathrm{CO}_{2}$ measurements and several others are taken on a dry basis, meaning the sample is passed through a condenser or refrigerator/dryer unit to remove moisture that might interfere with the true response of the analyzer. Therefore, since it is necessary to represent the dilution ratio on a wet basis to account for the mass of water produced due to combustion. A conversion factor must be used to adjust the dry concentrations to their corresponding wet concentrations. The equation below is the "Water Correction Factor" and utilizes the Fuel to Air ratio, which is calculated from mass fuel and airflow measurements.

$$
\text { Water Correction Factor }=1-\left[\left(\frac{\dot{\mathrm{m}}_{\mathrm{tot}_{\mathrm{H}_{2} \mathrm{O}}}}{\left.\dot{\mathrm{m}}_{\text {air }}+\dot{\mathrm{m}}_{\mathrm{f}}\right)}\right)\left(\frac{\mathrm{MW}_{\text {exhaust }}}{\mathrm{MW}_{\mathrm{H}_{2} \mathrm{O}}}\right)\left(\frac{1}{100}\right)\right]
$$


This conversion factor is slightly different from the approach taken by (MacDonald et al., 1980). The $\mathrm{Mw}_{\mathrm{H} 2 \mathrm{O}}$ is 18 , while the $\mathrm{Mw}_{\text {exhaust }}$ is given as:

$$
\mathrm{M}_{\mathrm{W}_{\mathrm{air}}}=\left[\left(100-\mathrm{CO}_{2 \mathrm{ex}}-\mathrm{CO}-\mathrm{O}_{2}\right) 28+(\mathrm{CO}) 28+\left(\mathrm{O}_{2}\right) 32+\left(\mathrm{CO}_{2 \mathrm{ex}}\right) 44\right]
$$




\section{Appendix C. Uncertainty Analysis Calculations}

\section{PM Uncertainty}

The following equation was used to determine the uncertainty in particulate matter mass measurement in the mini-dilution tunnel.

$$
\mathrm{P}_{\text {corr }}=\frac{(\mathrm{SR})\left(\mathrm{P}_{\text {mass }}\right)}{1-(.0126)(\mathrm{H}-10.71)}
$$

Where:

$\mathrm{P}_{\text {mass }}=$ measured filter particulate mass in milligrams.

$\mathrm{P}_{\text {corr }}=$ filter particulate mass corrected to total engine particulate production $(\mathrm{g} / \mathrm{hp}-\mathrm{hr})$.

$\mathrm{SR}=$ split ratio (total engine exhaust mass divided by total sample mass without dilution air). $\mathrm{H}=$ absolute humidity (grams water per gram of dry air).

Equation 1 accurately represents the subject mini-tunnel design yet is different from that expressed in CFR 40, Part 86, Subpart $\mathrm{N}$ for diesel fuels. The CFR states that this is acceptable provided good engineering practices are followed. Also, there is no particulate background correction in the equation due to careful filtering of the inlet engine air and the diluent air in the dilution tunnel. The denominator of Equation 1 provides a humidity correction factor for PM, which was developed by engineers at Mack Trucks and has been found to be in good correlation for a variety of engine types and laboratories (Nussear, 1993). Using the RMS method, the uncertainty in $\mathrm{P}_{\text {mass }}$ may be written as

$$
\Delta \mathrm{P}_{\text {corr }}=\left[\left(\Delta \mathrm{SR} \frac{\partial \mathrm{P}_{\text {corr }}}{\partial \mathrm{SR}}\right)^{2}+\left(\Delta \mathrm{P}_{\text {mass }} \frac{\partial \mathrm{P}_{\text {corr }}}{\partial \mathrm{P}_{\text {mass }}}\right)^{2}+\left(\Delta \mathrm{H} \frac{\partial \mathrm{P}_{\text {corr }}}{\partial \mathrm{H}}\right)^{2}\right]^{1 / 2}
$$

where: 


$$
\frac{\partial P_{\text {corr }}}{\partial H}=-\frac{P_{\text {mass }} S R(0.0126)}{(1-[.0126(H-10.71)])^{2}}
$$

$$
\frac{\partial P_{\text {corr }}}{\partial S R}=\frac{P_{\text {mass }}}{1-[.0126(H-10.71)]}
$$

$$
\frac{\partial \mathrm{P}_{\text {corr }}}{\partial \mathrm{P}_{\text {mass }}}=\frac{\mathrm{SR}}{1-[.0126(\mathrm{H}-10.71)]}
$$

and

$\Delta \mathrm{P}_{\text {mass }}=$ uncertainty of gravimetric particulate measurement.

$\Delta \mathrm{H}=$ uncertainty of absolute humidity measurement.

The split ratio (SR) is defined as

$$
\mathrm{SR}=\frac{\left(\dot{\mathrm{m}}_{\text {air }}+\dot{\mathrm{m}}_{\text {fuel }}\right)}{\dot{\mathrm{m}}_{\text {tunnel }}} \mathrm{DR}
$$

Where DR is the dilution ratio (defined below), $\mathrm{m}_{\text {air }}$ and $\mathrm{m}_{\text {fuel }}$ are the mass flow of air and fuel into the engine respectively. The split ratio uncertainty is defined as

$$
\Delta \mathrm{SR}=\left[\left(\Delta \dot{\mathrm{m}}_{\text {air }} \frac{\partial \mathrm{SR}}{\partial \dot{\mathrm{m}}_{\text {air }}}\right)^{2}+\left(\Delta \dot{\mathrm{m}}_{\mathrm{f}} \frac{\partial \mathrm{SR}}{\partial \dot{\mathrm{m}}_{\mathrm{f}}}\right)^{2}+\left(\Delta \dot{\mathrm{m}}_{\mathrm{t}} \frac{\partial \mathrm{SR}}{\partial \dot{\mathrm{m}}_{\mathrm{t}}}\right)^{2}+\left(\Delta \mathrm{DR} \frac{\partial \mathrm{SR}}{\partial \mathrm{DR}}\right)^{2}\right]^{1 / 2}
$$

where:

$$
\frac{\partial \mathrm{SR}}{\partial \dot{\mathrm{m}}_{\text {air }}}=\frac{\mathrm{DR}}{\dot{\mathrm{m}}_{\mathrm{t}}}
$$




$$
\begin{gathered}
\frac{\partial \mathrm{SR}}{\partial \dot{\mathrm{m}}_{\mathrm{f}}}=\frac{\mathrm{DR}}{\dot{\mathrm{m}}_{\mathrm{t}}} \\
\frac{\partial \mathrm{SR}}{\partial \dot{\mathrm{m}}_{\mathrm{t}}}=\frac{-\left(\dot{\mathrm{m}}_{\text {air }}+\dot{\mathrm{m}}_{\text {fuel }}\right)}{\dot{\mathrm{m}}_{\mathrm{t}}^{2}} \text { (DR) } \\
\frac{\partial \mathrm{SR}}{\partial \mathrm{DR}}=\frac{\dot{\mathrm{m}}_{\text {air }}+\dot{\mathrm{m}}_{\mathrm{f}}}{\dot{\mathrm{m}}_{\mathrm{t}}}
\end{gathered}
$$

These error uncertainties are defined as:

$\Delta \dot{m}_{\text {air }}=$ uncertainty error in engine intake air mass flow.

$\Delta \dot{m}_{\mathrm{f}}=$ uncertainty error in engine intake fuel mass flow.

$\Delta \dot{m}_{\mathrm{t}}=$ uncertainty error in total dilution tunnel mass flow.

$\Delta \mathrm{DR}=$ uncertainty error in dilution ratio.

The uncertainty in air and tunnel mass flow may be determined by flow calibration (flow proving); however, it is important to understand their uncertainties in order to determine the accuracy required in flow calibration. The equation for calculating air mass flow is given by

$$
\dot{\mathrm{m}}_{\mathrm{air}}=\alpha \Delta \mathrm{P} \gamma_{\mathrm{visc}}\left(\frac{\mathrm{P}_{\mathrm{air}}+99.3}{101.3}\right)\left(\frac{273.15}{\mathrm{~T}_{\text {air }}+273.15}\right)
$$

where $\gamma_{\text {visc }}$ is the viscosity correction given by $\gamma_{\text {visc }}=1.05525-00288 \mathrm{~T}_{\text {air }}+0.00000629 \mathrm{~T}_{\text {air }}$ and $\alpha$ is a calibration factor.

The error in air mass flow is given below.

$$
\Delta \dot{\mathrm{m}}_{\text {air }}=\left[\left(\Delta(\Delta \mathrm{P}) \frac{\partial \mathrm{SR}}{\partial \Delta \mathrm{P}}\right)^{2}+\left(\Delta \mathrm{P}_{\text {air }} \frac{\partial \mathrm{SR}}{\partial \mathrm{P}_{\text {air }}}\right)^{2}+\left(\Delta \mathrm{T}_{\text {air }} \frac{\partial \mathrm{SR}}{\partial \mathrm{T}_{\text {air }}}\right)^{2}\right]^{1 / 2}
$$


Where:

$$
\begin{gathered}
\frac{\partial \dot{\mathrm{m}}_{\text {air }}}{\partial(\Delta \mathrm{P})}=\alpha \gamma_{\text {visc }}\left(\frac{\mathrm{P}_{\text {air }}+99.3}{101.3}\right)\left(\frac{273.15}{\mathrm{~T}_{\text {air }}+273.15}\right) \\
\frac{\partial \dot{\mathrm{m}}_{\text {air }}}{\partial\left(\mathrm{P}_{\mathrm{a}}\right)}=\alpha \Delta \mathrm{P} \gamma_{\text {visc }}\left(\frac{1}{101.3}\right)\left(\frac{273.15}{\mathrm{~T}_{\text {air }}+273.15}\right) \\
\frac{\partial \dot{\mathrm{m}}_{\text {air }}}{\partial\left(\mathrm{T}_{\mathrm{a}}\right)}=(1.05525) \alpha \Delta \mathrm{P}\left(\frac{\mathrm{P}_{\text {air }}+99.3}{101.3}\right)\left(\frac{-273.15}{\left(\mathrm{~T}_{\text {air }}+273.15\right)^{2}}\right) \\
-(0.00288) \alpha \Delta \mathrm{P}\left(\frac{\mathrm{P}_{\text {air }}+99.3}{101.3}\right)\left(\frac{\left(\mathrm{T}_{\mathrm{a}}+273.15\right)(273.15)-273.15 \mathrm{~T}_{\mathrm{a}}}{\left(\mathrm{T}_{\text {air }}+273.15\right)^{2}}\right) \\
+(0.00000629) \alpha \Delta \mathrm{P}\left(\frac{\mathrm{P}_{\text {air }}+99.3}{101.3}\right)\left(\frac{\left(\mathrm{T}_{\mathrm{a}}+273.15\right)(2)(273.15) \mathrm{T}_{\mathrm{a}}-273.15 \mathrm{~T}_{\mathrm{a}}^{2}}{\left(\mathrm{~T}_{\text {air }}+273.15\right)^{2}}\right)
\end{gathered}
$$

Where $\Delta \mathrm{P}, \mathrm{P}_{\mathrm{a}}$ and $\mathrm{T}_{\mathrm{a}}$ are direct measurements whose errors are discussed below. The equation for calculating tunnel mass flow is given by

$$
\dot{\mathrm{m}}_{\text {tun }}=(\mathrm{PS})(.0586)\left(\frac{288.7}{\mathrm{~T}_{\mathrm{p}}+273.15}\right)\left(\frac{406.9+\mathrm{P}_{\mathrm{p}}}{406.9}\right)
$$

Where PS is pump speed and the constant is a conversion factor. $T_{p}$ and $P_{p}$ are the temperature and pressure of tunnel gases entering the pump. They are directly measured and their errors are also discussed below. The error in tunnel mass flow is given by

$$
\left.\Delta \dot{\mathrm{m}}_{\text {tun }}=\left[(\Delta \mathrm{PS}) \frac{\partial \mathrm{SR}}{\partial \mathrm{PS}}\right)^{2}+\left(\Delta \mathrm{T}_{\mathrm{p}} \frac{\partial \mathrm{SR}}{\partial \mathrm{T}_{\mathrm{p}}}\right)^{2}+\left(\Delta \mathrm{P}_{\mathrm{p}} \frac{\partial \mathrm{SR}}{\partial \mathrm{P}_{\mathrm{p}}}\right)^{2}\right]^{1 / 2}
$$


Where:

$$
\begin{aligned}
\frac{\partial \dot{\mathrm{m}}_{\mathrm{t}}}{\partial \mathrm{T}_{\mathrm{p}}} & =(\mathrm{PS})(.0586)\left(\frac{288.7}{\mathrm{~T}_{\mathrm{p}}+273.15}\right)\left(\frac{1}{406.9}\right) \\
\frac{\partial \dot{\mathrm{m}}_{\mathrm{t}}}{\partial \mathrm{PS}} & =(.0586)\left(\frac{288.7}{\mathrm{~T}_{\mathrm{p}}+273.15}\right)\left(\frac{406.9+\mathrm{P}_{\mathrm{p}}}{406.9}\right) \\
\frac{\partial \dot{\mathrm{m}}_{\mathrm{t}}}{\partial \mathrm{T}_{\mathrm{p}}} & =-(\mathrm{PS})(.0586)\left(\frac{288.7}{\mathrm{~T}_{\mathrm{p}}+273.15}\right)\left(\frac{406.9+\mathrm{P}_{\mathrm{p}}}{406.9}\right)
\end{aligned}
$$

The equation representing dilution ratio is given by

$$
\mathrm{DR}=\frac{\mathrm{CO}_{2 \mathrm{ex}}-\mathrm{CO}_{2 \text { back }}}{\mathrm{CO}_{2 \text { tun }}-\mathrm{CO}_{2 \text { back }}} \mathrm{WCF}
$$

Where WCF is the water correction factor given by

$$
\mathrm{WCF}=-1.9\left(\frac{\dot{\mathrm{m}}_{\mathrm{f}}}{\dot{\mathrm{m}}_{\mathrm{a}}}\right)
$$

The error in dilution ratio is given by

$$
\Delta \mathrm{DR}=\left[\left(\Delta \mathrm{WCF} \frac{\partial \mathrm{DR}}{\partial \mathrm{WCF}}\right)^{2}+\left(\Delta \mathrm{CO}_{2 \mathrm{ex}} \frac{\partial \mathrm{DR}}{\partial \mathrm{CO}_{2 \mathrm{ex}}}\right)^{2}+\left(\Delta \mathrm{CO}_{2 \text { tun }} \frac{\partial \mathrm{DR}}{\partial \mathrm{CO}_{2 \text { tun }}}\right)^{2}+\left(\Delta \mathrm{CO}_{2 \text { back }} \frac{\partial \mathrm{DR}}{\partial \mathrm{CO}_{2 \text { back }}}\right)^{2}\right]^{1 / 2}(\mathrm{C}-24)
$$

The error in the water correction factor used to account for the fact that $\mathrm{CO}_{2}$ measurements are done on a dry basis. It is given by

$$
\Delta \mathrm{WCF}=\left[\left(\Delta \dot{\mathrm{m}}_{\text {fuel }} \frac{\partial \mathrm{WCF}}{\partial \dot{\mathrm{m}}_{\text {fuel }}}\right)^{2}+\left(\Delta \dot{\mathrm{m}}_{\text {air }} \frac{\partial \mathrm{WCF}}{\partial \dot{\mathrm{m}}_{\text {air }}}\right)^{2}\right]^{1 / 2}
$$


Where:

$$
\begin{gathered}
\frac{\partial \mathrm{DR}}{\partial \mathrm{WCF}}=\frac{\mathrm{CO}_{2 \mathrm{ex}}-\mathrm{CO}_{2 \text { back }}}{\mathrm{CO}_{2 \text { tun }}-\mathrm{CO}_{2 \text { back }}} \\
\frac{\partial \mathrm{DR}}{\partial \mathrm{CO}_{2 \mathrm{ex}}}=\frac{\mathrm{WCF}}{\mathrm{CO}_{2 \text { tun }}-\mathrm{CO}_{2 \text { back }}} \\
\frac{\partial \mathrm{DR}}{\partial \mathrm{CO} \mathrm{O}_{\text {tun }}}=-\mathrm{WCF} \frac{\mathrm{CO}_{2 \text { ex }}-\mathrm{CO}_{2 \text { back }}}{\left(\mathrm{CO}_{2 \text { tun }}-\mathrm{CO}_{2 \text { back }}\right)^{2}} \\
\frac{\partial \mathrm{DR}}{\partial \mathrm{CO} \mathrm{Oback}_{\text {back }}}=\mathrm{WCF} \frac{\mathrm{CO}_{2 \text { ex }}-\mathrm{CO}_{2 \text { tun }}}{\left(\mathrm{CO}_{2 \text { tun }}-\mathrm{CO}_{2 \text { back }}\right)^{2}}
\end{gathered}
$$

And regarding the water correction factor:

$$
\begin{gathered}
\frac{\partial(\mathrm{WCF})}{\partial \dot{\mathrm{m}}_{\text {air }}}=1.9 \frac{\dot{\mathrm{m}}_{\mathrm{f}}}{\left(\dot{\mathrm{m}}_{\text {air }}\right)^{2}} \\
\frac{\partial(\mathrm{WCF})}{\partial \dot{\mathrm{m}}_{\mathrm{f}}}=\frac{-1.9}{\dot{\mathrm{m}}_{\text {air }}}
\end{gathered}
$$

At this point, before proceeding with a full discussion of the error analysis, it is important to discuss the relative errors of engine air mass flow and tunnel mass flow. Table C-1 below provides the estimated errors in $\Delta \mathrm{P}_{\mathrm{a}}, \mathrm{P}_{\mathrm{a}}, \mathrm{T}_{\mathrm{a}}, \mathrm{T}_{\mathrm{p}}, \mathrm{P}_{\mathrm{p}}$ and the total RMS error for $\Delta \mathrm{m}_{\mathrm{a}}$ and $\Delta \mathrm{m}_{\text {tun }}$. This methodology for determining instrument measurement error is followed throughout this analysis. 
Further errors are reported on a total error basis to avoid complexity. Again, all errors are calculated similarly to those in Table C-1.

Table C-1. Engine Air and Tunnel Flow Measurement Errors

\begin{tabular}{|c|c|c|c|c|c|c|}
\hline \multirow[b]{2}{*}{ Uncertainty } & \multicolumn{6}{|c|}{ Device } \\
\hline & $\begin{array}{l}\text { Error } \\
\text { Type }\end{array}$ & $\begin{array}{c}\Delta \mathbf{P}_{\mathrm{a}} \\
\text { (Rosemount } \\
\text { 3051) }\end{array}$ & $\begin{array}{c}P_{\mathrm{a}} \\
\text { (Rosemount } \\
\text { 1144) }\end{array}$ & \begin{tabular}{|c|}
$\mathbf{T}_{\mathrm{a}}$ (Type K \\
Thermo- \\
couple \\
field \\
calibrated) \\
\end{tabular} & $\begin{array}{c}\mathbf{P}_{\mathrm{p}} \\
\text { (Rosemount } \\
\text { 3051) }\end{array}$ & $\begin{array}{c}\mathbf{T}_{\mathrm{p}}(\mathrm{Type} \mathrm{K} \\
\text { Thermocouple } \\
\text { field } \\
\text { calibrated) }\end{array}$ \\
\hline & & $\begin{array}{l}\text { Range }=254 \\
\mathrm{mmH}_{2} \mathrm{O}\end{array}$ & $\begin{array}{l}\text { Range }= \\
200 \mathrm{kpag}\end{array}$ & & $\begin{array}{l}\text { Range }= \\
500 \mathrm{inH}_{2} 0\end{array}$ & \\
\hline $\begin{array}{l}\text { Accuracy } \\
\text { (Includes } \\
\text { stability, } \\
\text { accuracy and } \\
\text { temperature } \\
\text { effects) }\end{array}$ & Bias & $\begin{array}{l}.19 \% \text { of span } \\
\text { range (includes } \\
\text { linearity hys- } \\
\text { teresis and } \\
\text { repeatability per } \\
\text { manufacturer) }\end{array}$ & $\begin{array}{l}.2598 \% \text { of } \\
\text { span range } \\
\text { (includes } \\
\text { linearity and } \\
\text { repeatability) }\end{array}$ & $\begin{array}{l}0.1^{\circ} \mathrm{C} \text { field } \\
\text { calibrated } \\
\text { with RTD } \\
\text { device }\end{array}$ & $\begin{array}{l}.19 \% \text { of span } \\
\text { range (includes } \\
\text { linearity } \\
\text { hysteresis and } \\
\text { repeatability } \\
\text { per } \\
\text { manufacturer) } \\
\end{array}$ & $\begin{array}{l}0.1^{\circ} \mathrm{C} \text { field } \\
\text { calibrated with } \\
\text { RTD device }\end{array}$ \\
\hline Linearity & Bias & & & & & \\
\hline Hysteresis & Bias & & $\begin{array}{l}.0725 \% \text { of } \\
\text { span range } \\
\text { (Determined } \\
\text { from } \\
\text { calibration) } \\
\end{array}$ & & & \\
\hline \begin{tabular}{|l} 
Non- \\
Repeatability \\
\end{tabular} & Random & & & & & \\
\hline DAS Error & $\begin{array}{l}\text { Bias and } \\
\text { Random } \\
\text { (Calculated } \\
\text { separately) } \\
\end{array}$ & $.266 \mathrm{mmH}_{2} \mathrm{O}$ & $.209 \mathrm{kpag}$ & $\begin{array}{l}1^{\circ} \mathrm{C} \text { random } \\
\text { error }\end{array}$ & $.523 \mathrm{inH}_{2} \mathrm{O}$ & $1{ }^{\circ} \mathrm{C}$ random error \\
\hline $\begin{array}{l}\text { RMS Total } \\
\text { Error }\end{array}$ & $\begin{array}{l}\text { Bias + 1.96 } \\
\text { Random }\end{array}$ & $0.551 \mathrm{mmH}_{2} \mathrm{O}$ & $.5785 \mathrm{kpag}$ & $2.06^{\circ} \mathrm{C}$ & $1.084 \mathrm{inH}_{2} \mathrm{O}$ & $2.06^{\circ} \mathrm{C}$ \\
\hline
\end{tabular}

From these errors the uncertainty in engine air mass flow and tunnel mass flow are used in the RMS uncertainty determination.

\section{Flow Calibration Uncertainty}

After determining the uncertainties in engine mass airflow and tunnel mass airflow it became important to determine the errors involved with flow calibration and to look at their 
sensitivities so that flow calibration error could be minimized. Flow calibration was critical to measurement of engine air and dilution tunnel total flow accuracy. A flow calibration error analysis and sensitivity analysis was done in the same manner as Kline, 1985.

Flow calibrations for the dilution tunnel was performed using a certified high precision subsonic flow Venturi with total accuracy of $\pm 0.5 \%$. Dilution tunnel flow uncertainty was actually on the order of $0.72 \%$ when considering the errors in pump speed, temperature, and pressure. A better calibration was not available on site, therefore, total tunnel mass flow uncertainty was limited to approximately $0.88 \%$ (derived by summing the total variances). Engine air mass flow calibration was performed using sonic flow nozzles. Engine air mass flow measurement uncertainty was on the order of $1.53 \%$ when considering the errors in flowmeter, temperature, and pressure. It was therefore desirable to have a flow calibration error low enough so as not to introduce more than $10 \%$ uncertainty to the total engine air mass flow error uncertainty. Flow calibration uncertainty using the sonic nozzles of less than $0.7 \%$ met this criterion. The flow equation (in cubic feet per hour units) used with the Singer "American Sonic Flow Prover" is given by

$$
\dot{\mathrm{V}}=\frac{v}{\mathrm{Mw}} 3600\left[\frac{\mathrm{g}_{\mathrm{c}} \mathrm{kMw}}{\mathrm{R}}\left(\frac{2}{\mathrm{k}+1}\right)^{\left(\frac{\mathrm{k}+1}{\mathrm{k}-1}\right)}\right]^{1 / 2}\left(\frac{\mathrm{P}_{\mathrm{b}}+\mathrm{P}}{\sqrt{\mathrm{T}}}\right) \mathrm{A}_{\mathrm{noz}} \mathrm{C}_{\mathrm{d}}
$$

Where:

$v=$ molar volume.

$\mathrm{g}_{\mathrm{c}}=$ local gravitational acceleration .

$\mathrm{M}_{\mathrm{w}}=$ molecular weight of air.

$\mathrm{R}=$ universal gas constant.

$\mathrm{k}=$ ratio of specific heats of air. 
$\mathrm{P}_{\mathrm{b}}=$ local barometric pressure (psia).

$\mathrm{P}=$ upstream pressure at sonic flow nozzle (psig).

$\mathrm{T}=$ upstream temperature at sonic flow nozzle $\left({ }^{\circ} \mathrm{F}\right)$.

$\mathrm{A}_{\text {noz }}=$ nozzle throat area.

$\mathrm{C}_{\mathrm{d}}=$ discharge coefficient.

Errors were considered for each variable and "constant" with the exception of the universal gas constant. The nozzle area was considered constant and the nozzle flow error was provided by a Singer accuracy certification in which a bell flow prover was used as the primary standard. Test conditions with the bell flow prover were $60^{\circ} \mathrm{F}$ and 24.696 psia using dry air. These conditions were very similar to our typical airflow proving conditions. Nominal values and errors are given in Table C-2.

Total flow calibration error is given by:

$$
\begin{gathered}
\Delta \dot{\mathrm{V}}=\left[\left(\Delta \mathrm{P} \frac{\partial \dot{\mathrm{V}}}{\partial \mathrm{P}}\right)^{2}+\left(\Delta \mathrm{P}_{\mathrm{b}} \frac{\partial \dot{\mathrm{V}}}{\partial \mathrm{P}_{\mathrm{b}}}\right)^{2}+\left(\Delta \mathrm{T} \frac{\partial \dot{\mathrm{V}}}{\partial \mathrm{T}}\right)^{2}+\left(\Delta \mathrm{g}_{\mathrm{c}} \frac{\partial \dot{\mathrm{V}}}{\partial \mathrm{g}_{\mathrm{c}}}\right)^{2}+\left(\Delta v \frac{\partial \dot{\mathrm{V}}}{\partial \mathrm{v}}\right)^{2}+\right. \\
\left.\left(\Delta \mathrm{Mw} \frac{\partial \dot{\mathrm{V}}}{\partial \mathrm{Mw}}\right)^{2}+\left(\Delta \mathrm{k} \frac{\partial \dot{\mathrm{V}}}{\partial \mathrm{k}}\right)^{2}+\left(\Delta \mathrm{C}_{\mathrm{d}} \frac{\partial \mathrm{DR}}{\partial \mathrm{C}_{\mathrm{d}}}\right)^{2}\right]^{1 / 2}
\end{gathered}
$$

Error sensitivities formulas used in determining calibration flow error are provided below in Equations C-34 through C-41. 
Table C-2. Nominal Values, Errors, and Uncertainty Sources for Flow Calibration

\begin{tabular}{|c|c|c|c|c|}
\hline $\begin{array}{l}\text { Variable or } \\
\text { "Constant" }\end{array}$ & $\begin{array}{c}\text { Nominal } \\
\text { Value }\end{array}$ & Units & Error & Description \\
\hline$v$ & 379.52 & $\begin{array}{l}\mathrm{ft} 3 / \mathrm{lb}- \\
\text { mole }\end{array}$ & .01 & $\begin{array}{l}\text { Value was interpolated and error was given from the } \\
\text { source tables "Tables of Thermal Properties of Gases," } \\
\text { U.S. Department of Commerce National Bureau of } \\
\text { Standards, Circular } 564 \text { at standard conditions of one } \\
\text { atmosphere and } 60^{\circ} \mathrm{F} \text {. }\end{array}$ \\
\hline $\mathbf{g}_{\mathrm{c}}$ & 32.15385 & $\begin{array}{l}\text { Lbm- } \\
\text { ft/lbf-sec }\end{array}$ & .00005 & $\begin{array}{l}\text { Value provided by and error estimated from "Bouguer } \\
\text { Gravity map of West Virginia," published by the West } \\
\text { Virginia Geological and Economic Survey, 1987. The } \\
\text { base values were provided by the International Gravity } \\
\text { Standardization Net of } 1971 \text { (Morelli, 1974) and the } 1967 \\
\text { Geodetic Reference System formula for theoretical } \\
\text { gravity (International Association of Geodesy, 1971). }\end{array}$ \\
\hline $\mathbf{M}_{\mathrm{w}}$ & 28.9645 & $\mathrm{Lb} / \mathrm{lb}-\mathrm{mol}$ & .035 & $\begin{array}{l}\text { Value and error estimated from the source tables "Tables } \\
\text { of Thermal Properties of Gases," U.S. Department of } \\
\text { Commerce National Bureau of Standards, Circular } 564 .\end{array}$ \\
\hline $\mathbf{k}$ & $\begin{array}{l}\text { Variable } \\
(1.398)\end{array}$ & None & .000608 & $\begin{array}{l}\text { Error from the source tables "Tables of Thermal } \\
\text { Properties of Gases," U.S. Department of Commerce } \\
\text { National Bureau of Standards, Circular } 564 \text { which gives } \\
\text { the error as } .0003 \text { in Cp/R or .0001 in Cp. Interpolation } \\
\text { between temperatures and pressures was done by a first } \\
\text { order linear estimate using the equation k }=1.4016534- \\
0.000005 T-0.000063 P \text { with } \mathrm{R}^{2}=0.98462 \text {. A } 95 \% \\
\text { uncertainty estimate is .0006 for the fit. RSS error is } \\
\text { therefor } 0.000608 \text {. }\end{array}$ \\
\hline $\mathbf{P b}$ & $\begin{array}{l}\text { Variable } \\
(14.2)\end{array}$ & Psia & $\begin{array}{l}.02 \% \text { of } \\
\text { range } \\
(.00284)\end{array}$ & $\begin{array}{l}\text { Value of error from calibration source (Instrument is a } \\
\text { Secondary Standard) }\end{array}$ \\
\hline $\mathbf{P}$ & Variable & Psig & $\begin{array}{l}.04 \% \text { of } \\
\text { range } \\
(.02)\end{array}$ & $\begin{array}{l}\text { Value of error from calibration source (Instrument is a } \\
\text { Secondary Standard) }\end{array}$ \\
\hline $\mathbf{T}$ & Variable & ${ }^{\circ} \mathrm{F}$ & $\begin{array}{l}.7502 \% \\
\text { of } \\
\text { reading } \\
\left({ }^{\circ} \mathrm{R}\right)\end{array}$ & $\begin{array}{l}\text { Type K Thermocouple and readout calibrated and error } \\
\text { estimated }\end{array}$ \\
\hline $\mathbf{C}_{\mathrm{d}}$ & Variable & Constant & $0.5 \%$ & Conservative estimate based on other flow nozzle data. \\
\hline
\end{tabular}




$$
\begin{aligned}
& \frac{\partial \dot{\mathrm{V}}}{\partial \mathrm{P}}=\frac{v 3600}{\mathrm{Mw}}\left(\frac{1}{\sqrt{\mathrm{T}}}\right)\left[\frac{\mathrm{kMw}}{\mathrm{R}}\left(\frac{2}{\mathrm{k}+1}\right)^{\left(\frac{\mathrm{k}+1}{\mathrm{k}-1}\right)} \mathrm{g}_{\mathrm{c}}\right]^{1 / 2} \mathrm{~A}_{\mathrm{noz}} \mathrm{C}_{\mathrm{d}} \\
& \frac{\partial \dot{\mathrm{V}}}{\partial \mathrm{T}}=-\left(\frac{v 3600}{\mathrm{Mw}}\right)\left(\frac{\mathrm{P}_{\mathrm{b}}+\mathrm{P}}{2 \mathrm{~T}^{3 / 2}}\right)\left[\frac{\mathrm{kMw}}{\mathrm{R}}\left(\frac{2}{\mathrm{k}+1}\right)^{\left(\frac{\mathrm{k}+1}{\mathrm{k}-1}\right)} \mathrm{g}_{\mathrm{c}}\right]^{1 / 2} \mathrm{~A}_{\mathrm{noz}} \mathrm{C}_{\mathrm{d}} \\
& \frac{\partial \dot{\mathrm{V}}}{\partial \mathrm{P}_{\mathrm{b}}}=\frac{v 3600}{\mathrm{Mw}}\left(\frac{1}{\sqrt{\mathrm{T}}}\right)\left[\frac{\mathrm{kMw}}{\mathrm{R}}\left(\frac{2}{\mathrm{k}+1}\right)^{\left(\frac{\mathrm{k}+1}{\mathrm{k}-1}\right)} \mathrm{g}_{\mathrm{c}}\right]^{1 / 2} \mathrm{~A}_{\mathrm{noz}} \mathrm{C}_{\mathrm{d}} \\
& \frac{\partial \dot{\mathrm{V}}}{\partial v}=\frac{3600}{\mathrm{Mw}}\left(\frac{\mathrm{P}_{\mathrm{b}}+\mathrm{P}}{\sqrt{\mathrm{T}}}\right)\left[\frac{\mathrm{kMw}}{\mathrm{R}}\left(\frac{2}{\mathrm{k}+1}\right)^{\left(\frac{\mathrm{k}+1}{\mathrm{k}-1}\right) \mathrm{g}_{\mathrm{c}}}\right]^{1 / 2} \mathrm{~A}_{\mathrm{noz}} \mathrm{C}_{\mathrm{d}} \\
& \frac{\partial \dot{V}}{\partial g_{c}}=\frac{\frac{v 3600}{\mathrm{Mw}}\left(\frac{\mathrm{P}_{\mathrm{b}}+\mathrm{P}}{\sqrt{\mathrm{T}}}\right)\left[\frac{\mathrm{kMw}}{\mathrm{R}}\left(\frac{2}{\mathrm{k}+1}\right)\left(\frac{\mathrm{k}+1}{\mathrm{k}-1}\right) \mathrm{g}_{\mathrm{c}}\right]^{1 / 2} \mathrm{~A}_{\mathrm{noz}}}{2\left[\frac{\mathrm{kMw}}{\mathrm{R}}\left(\frac{2}{\mathrm{k}+1}\right)^{\left(\frac{\mathrm{k}+1}{\mathrm{k}-1}\right)} \mathrm{g}_{\mathrm{c}}\right]^{1 / 2}} \\
& \frac{\partial \dot{\mathrm{V}}}{\partial \mathrm{k}}=\frac{-\left(\frac{v 3600}{\mathrm{Mw}}\right)\left(\frac{\mathrm{P}_{\mathrm{b}}+\mathrm{P}}{\sqrt{\mathrm{T}}}\right)\left[\frac{\mathrm{g}_{\mathrm{c}} \mathrm{Mw}}{\mathrm{R}}\left(\frac{2}{\mathrm{k}+1}\right)\left(\frac{\mathrm{k}+1}{\mathrm{k}-1}\right)\left(\ln \left(\frac{2}{\mathrm{k}+1}\right)^{2 \mathrm{k}}+(\mathrm{k}+1)\right)\right] \mathrm{A}_{\mathrm{noz}}}{2(\mathrm{k}-1)^{2}\left[\frac{\mathrm{kMw}}{\mathrm{R}}\left(\frac{2}{\mathrm{k}+1}\right)^{\left(\frac{\mathrm{k}+1}{\mathrm{k}-1}\right)} \mathrm{g}_{\mathrm{c}}\right]^{1 / 2}}
\end{aligned}
$$




$$
\begin{aligned}
\frac{\partial \dot{\mathrm{V}}}{\partial \mathrm{Mw}} & =\left\{-\left(\frac{v 3600}{\mathrm{Mw}^{2}}\right)\left(\frac{\mathrm{P}_{\mathrm{b}}+\mathrm{P}}{\sqrt{\mathrm{T}}}\right)\left[\frac{\mathrm{kMw}}{\mathrm{R}}\left(\frac{2}{\mathrm{k}+1}\right)^{\left(\frac{\mathrm{k}+1}{\mathrm{k}-1}\right)} \mathrm{g}_{\mathrm{c}}\right]^{1 / 2} \mathrm{~A}_{\text {nox }}\right\} \\
& \left.+\left\{\frac{\frac{v 3600}{\mathrm{Mw}}\left(\frac{\mathrm{P}_{\mathrm{b}}+\mathrm{P}}{\sqrt{\mathrm{T}}}\right)\left[\frac{\mathrm{kg}_{\mathrm{c}}}{\mathrm{R}}\left(\frac{2}{\mathrm{k}+1}\right)^{\left(\frac{\mathrm{k}+1}{\mathrm{k}-1}\right)^{1 / 2} \mathrm{~A}_{\mathrm{noz}}}\right.}{\mathrm{R}}\right]_{\mathrm{d}}\left(\frac{2}{\mathrm{k}+1}\right)^{\left(\frac{\mathrm{k}+1}{\mathrm{k}-1}\right) \mathrm{g}_{\mathrm{c}}}\right]^{1 / 2} \\
\frac{\partial \dot{\mathrm{V}}}{\partial \mathrm{C}_{\mathrm{d}}} & =\frac{v 3600}{\mathrm{Mw}}\left[\frac{\mathrm{g}_{\mathrm{c}} \mathrm{kMw}}{\mathrm{R}}\left(\frac{2}{\mathrm{k}+1}\right)^{\left.\left(\frac{\mathrm{k}+1}{\mathrm{k}-1}\right)\right]^{1 / 2}\left(\frac{\mathrm{P}_{\mathrm{b}}+\mathrm{P}}{\sqrt{\mathrm{T}}}\right) \mathrm{A}_{\mathrm{noz}}}\right.
\end{aligned}
$$

As an example of the benefit of this analysis, we consider engine air flow prooving. Typical flow proving had previously used a pressure transmitter with a $500 \mathrm{psi}$ and using a constant $\mathrm{k}$ value of 1.4. In that case, error in $\mathrm{k}$ is typically 0.02 . This introduced significant error into the calibration flow calculation. Also, the wide span range of the pressure transducer introduced further error. Respaning the transmitter and using the calculated $\mathrm{k}$ value reduced the typical calibration error from $1.6 \%$ to $0.6 \%$. This arrangement was used for a further flow provingWith these errors reduced, the bulk of the residual uncertainty then resided in the calculated $\mathrm{k}$ value. If any further improvements could have been made it would have to be either an improvement in the fitted $\mathrm{k}$ value or in the temperature measurement. This is a good demonstration of the benefit of a thorough sensitivity analysis in identifying error sources in flow measurement. 


\section{Gaseous Emissions Uncertainty}

Exhaust gas measurements are taken both from raw engine exhaust and from the dilution tunnel. Measurements taken at the dilution tunnel $\left(\mathrm{NO}_{\mathrm{x}}\right.$ and $\left.\mathrm{THC}\right)$ were at one time subject to errors from dilution ratio (DR) which increases their errors. The equations (g/hp-hr) that govern these measurements are given by

$$
\begin{gathered}
\text { NOx }\left(\frac{\mathrm{g}}{\mathrm{hp}-\mathrm{hr}}\right)=\frac{\left[\frac{1}{1-0.0182(\mathrm{H}-10.71)}\right]\left(\frac{\mathrm{NO}_{\mathrm{x}}-\mathrm{NO}_{\text {xback }}}{1,000,000}\right)(1,913)(\mathrm{DEV})(\mathrm{DR})}{\mathrm{hp}-\mathrm{hr}} \\
\operatorname{THC}\left(\frac{\mathrm{g}}{\mathrm{hp}-\mathrm{hr}}\right)=\frac{\left(\frac{\mathrm{THC}_{\mathrm{x}}-\mathrm{THC}_{\text {back }}}{1,000,000}\right)(574.6)(\mathrm{DEV})(\mathrm{DR})}{\mathrm{hp}-\mathrm{hr}}
\end{gathered}
$$

For measurements taken in the tunnel, the general uncertainty equation is given by

$$
\begin{aligned}
\Delta \mathrm{E}_{\mathrm{s}}\left(\frac{\mathrm{g}}{\mathrm{hp}-\mathrm{hr}}\right)=\left[\left(\Delta \mathrm{H} \frac{\partial \mathrm{E}_{\mathrm{s}}}{\partial \mathrm{H}}\right)^{2}+\left(\Delta \mathrm{E} \frac{\partial \mathrm{E}_{\mathrm{s}}}{\partial \mathrm{E}}\right)^{2}+\left(\Delta \mathrm{E}_{\mathrm{b}} \frac{\partial \mathrm{E}_{\mathrm{s}}}{\partial \mathrm{E}_{\mathrm{b}}}\right)^{2}+\left(\Delta \mathrm{DEV} \frac{\partial \mathrm{E}_{\mathrm{s}}}{\partial \mathrm{DEV}}\right)^{2}\right. \\
\left.+\left(\Delta \mathrm{DR} \frac{\partial \mathrm{E}_{\mathrm{s}}}{\partial \mathrm{DR}}\right)^{2}+\left(\Delta \mathrm{hphr} \frac{\partial \mathrm{E}_{\mathrm{s}}}{\partial \mathrm{hphr}}\right)^{2}\right]^{1 / 2}
\end{aligned}
$$

The first term is only used in $\mathrm{NO}_{\mathrm{x}}$ uncertainty determination and error in sample time is neglected.

$\mathrm{E}_{\mathrm{s}}$ represents any specific gaseous emissions measurement.

These error uncertainties are defined as:

$\Delta \mathrm{H}=$ uncertainty error in specific humidity.

$\Delta \mathrm{E}=$ uncertainty error in emission measurement.

$\Delta \mathrm{E}_{\mathrm{b}}=$ uncertainty error in emission background measurement. 
$\triangle \mathrm{DEV}=$ uncertainty error in Dry Engine Volume.

$\Delta \mathrm{DR}=$ uncertainty error in dilution ratio.

$\Delta \mathrm{hp}-\mathrm{hr}=$ uncertainty error in horsepower-hour.

The sensitivities are given by:

$$
\begin{gathered}
\frac{\partial \mathrm{E}_{\mathrm{s}}}{\partial \mathrm{DEV}}=\frac{\left[\frac{1}{1-0.0182(\mathrm{H}-10.71)}\right]\left(\frac{\mathrm{E}_{\mathrm{s}}-\mathrm{E}_{\mathrm{b}}}{1,000,000}\right)(1,913)(\mathrm{DR})}{\mathrm{hp}-\mathrm{hr}} \\
\frac{\partial \mathrm{E}_{\mathrm{s}}}{\partial \mathrm{DR}}=\frac{\left[\frac{1}{1-0.0182(\mathrm{H}-10.71)}\right]\left(\frac{\mathrm{E}_{\mathrm{s}}-\mathrm{E}_{\mathrm{b}}}{1,000,000}\right)(1,913)(\mathrm{DEV})}{\mathrm{hp}-\mathrm{hr}} \\
\frac{\partial \mathrm{E}_{\mathrm{s}}}{\partial \mathrm{E}}=\frac{\left[\frac{1}{1-0.0182(\mathrm{H}-10.71)}\right]\left(\frac{1}{1,000,000}\right)(1,913)(\mathrm{DEV})(\mathrm{DR})}{\mathrm{hp}-\mathrm{hr}} \\
\frac{\partial \mathrm{E}_{\mathrm{s}}}{\partial \mathrm{E}_{\mathrm{b}}}=\frac{\left[\frac{1}{1-0.0182(\mathrm{H}-10.71)}\right]\left(\frac{1}{1,000,000}\right)(1,913)(\mathrm{DEV})(\mathrm{DR})}{\mathrm{hp}-\mathrm{hr}} \\
\frac{\partial \mathrm{E}_{\mathrm{s}}}{\partial \mathrm{hphr}^{2}}=\frac{-\left[\frac{1}{1-0.0182(\mathrm{H}-10.71)}\right]\left(\frac{\mathrm{E}_{\mathrm{s}}-\mathrm{E}_{\mathrm{b}}}{1,000,000}\right)(1,913)(\mathrm{DEV})(\mathrm{DR})}{(\mathrm{hp}-\mathrm{hr})^{2}}
\end{gathered}
$$

Also, specific only to $\mathrm{NO}_{\mathrm{x}}$ measurement is the sensitivity due to humidity correction given by: 


$$
\frac{\partial \mathrm{E}_{\mathrm{s}}}{\partial \mathrm{H}}=\frac{-\left[\frac{0.0182}{(1-0.0182(\mathrm{H}-10.71))^{2}}\right]\left(\frac{\mathrm{E}_{\mathrm{s}}-\mathrm{E}_{\mathrm{b}}}{1,000,000}\right)(1,913)(\mathrm{DEV})(\mathrm{DR})}{(\mathrm{hp}-\mathrm{hr})}
$$

Note that the constant is 574.6 in the case of THC. All of these constants are provided by CFR 40, Part 86, Subpart N. The error in dilution ratio is calculated above. The uncertainty in dry engine volume (DEV) must be determined from the defining equation:

$$
\mathrm{DEV}=\frac{2.37\left(\dot{\mathrm{m}}_{\mathrm{a}}+\dot{\mathrm{m}}_{\mathrm{f}}\right)(\text { Sample Time })}{\left(100-\mathrm{CO}_{2 \mathrm{ex}}-\mathrm{O}_{2}-\mathrm{CO}\right) 28+\mathrm{CO} \cdot 28+\mathrm{O}_{2} \cdot 32+\mathrm{CO}_{2 \mathrm{ex}} \cdot 44}
$$

The uncertainty is given by:

$$
\begin{gathered}
\Delta \mathrm{DEV}=\left[\left(\Delta \dot{\mathrm{m}}_{\mathrm{a}} \frac{\partial \mathrm{DEV}}{\partial \dot{\mathrm{m}}_{\mathrm{a}}}\right)^{2}+\left(\Delta \dot{\mathrm{m}}_{\mathrm{f}} \frac{\partial \mathrm{DEV}}{\partial \dot{\mathrm{m}}_{\mathrm{f}}}\right)^{2}+\left(\Delta \mathrm{CO}_{2 \mathrm{ex}} \frac{\partial \mathrm{DEV}}{\partial \mathrm{CO}_{2 \mathrm{ex}}}\right)^{2}+\right. \\
\left.\left(\Delta \mathrm{O}_{2} \frac{\partial \mathrm{DEV}}{\partial \mathrm{O}_{2}}\right)^{2}+\left(\Delta \mathrm{CO} \frac{\partial \mathrm{DEV}}{\partial \mathrm{CO}}\right)^{2}\right]^{1 / 2}
\end{gathered}
$$

Where:

$$
\begin{gathered}
\frac{\partial \mathrm{DEV}}{\partial \dot{\mathrm{m}}_{\mathrm{a}}}=\frac{2.37 \text { (Sample Time) }}{\left(100-\mathrm{CO}_{2 \mathrm{ex}}-\mathrm{O}_{2}-\mathrm{CO}\right) 28+\mathrm{CO} \cdot 28+\mathrm{O}_{2} \cdot 32+\mathrm{CO}_{2 \mathrm{ex}} \cdot 44} \\
\frac{\partial \mathrm{DEV}}{\partial \mathrm{CO}_{2 \mathrm{ex}}}=\frac{(-16)(2.37)\left(\dot{\mathrm{m}}_{\mathrm{a}}+\dot{\mathrm{m}}_{\mathrm{f}}\right)(\text { Sample Time })}{\left(2800-16 \mathrm{CO}_{2 \mathrm{ex}}-4 \mathrm{O}_{2}\right)^{2}}
\end{gathered}
$$




$$
\begin{gathered}
\frac{\partial \mathrm{DEV}}{\partial \mathrm{O}_{2}}=\frac{(-4)(2.37)\left(\dot{\mathrm{m}}_{\mathrm{a}}+\dot{\mathrm{m}}_{\mathrm{f}}\right)(\text { Sample Time })}{\left(2800-16 \mathrm{CO}_{2 \mathrm{ex}}-4 \mathrm{O}_{2}\right)^{2}} \\
\frac{\partial \mathrm{DEV}}{\partial \dot{\mathrm{m}}_{\mathrm{f}}}=\frac{2.37(\text { Sample Time })}{\left(100-\mathrm{CO}_{2 \mathrm{ex}}-\mathrm{O}_{2}-\mathrm{CO}\right) 28+\mathrm{CO} \cdot 28+\mathrm{O}_{2} \cdot 32+\mathrm{CO}_{2 \mathrm{ex}} \cdot 44} \\
\frac{\partial \mathrm{DEV}}{\partial \mathrm{CO}}=0
\end{gathered}
$$

The uncertainty in horsepower-hour (hp-hr) must be determined from the defining equation:

$$
\mathrm{hp}-\mathrm{hr}=(0.008495)(\mathrm{ES})(\mathrm{ET})
$$

Where ES is engine speed and ET is engine torque. The uncertainty in hp-hr is given by:

$$
\Delta \mathrm{hp}-\mathrm{hr}=\left[\left(\Delta \mathrm{ES} \frac{\partial \mathrm{hp}-\mathrm{hr}}{\partial \mathrm{ES}}\right)^{2}+\left(\Delta \mathrm{ET} \frac{\partial \mathrm{hp}-\mathrm{hr}}{\partial \mathrm{ET}}\right)^{2}\right]
$$

Where:

$$
\begin{aligned}
& \frac{\partial \mathrm{hp}-\mathrm{hr}}{\partial \mathrm{ES}}=(0.008495)(\mathrm{ET}) \\
& \frac{\partial \mathrm{hp}-\mathrm{hr}}{\partial \mathrm{ET}}=(0.008495)(\mathrm{ES})
\end{aligned}
$$

Raw engine exhaust measurements include high $\mathrm{CO}$, low $\mathrm{CO}, \mathrm{O}_{2}$ and $\mathrm{CO}_{2 \mathrm{ex}}$. These measurements are not subject to errors in dilution ratio (DR). The general equation is given as:

$$
\mathrm{E}_{\mathrm{s}}=\left(\frac{\mathrm{E}-\mathrm{E}_{\mathrm{b}}}{10^{6}}\right)(1,164)(\mathrm{DEV})(\mathrm{WCF})
$$


The first term can vary slightly depending on whether $\mathrm{E}$ is in parts per million (ppm) or percent (\%) units. The second term (a constant) is 1,164 for $\mathrm{CO}, 1,330$ for $\mathrm{O}_{2}$ and 1,830 for $\mathrm{CO}_{2}$. The sensitivities for DEV and WCF are calculated above. The uncertainty in the raw gas measurements is given by:

$$
\Delta \mathrm{E}_{\mathrm{s}}=\left[\left(\Delta \mathrm{E} \frac{\partial \mathrm{E}_{\mathrm{s}}}{\partial \mathrm{E}}\right)^{2}+\left(\Delta \mathrm{E}_{\mathrm{b}} \frac{\partial \mathrm{E}_{\mathrm{s}}}{\partial \mathrm{E}_{\mathrm{b}}}\right)^{2}+\left(\Delta \mathrm{DEV} \frac{\partial \mathrm{E}_{\mathrm{s}}}{\partial \mathrm{DEV}}\right)^{2}+\left(\Delta \mathrm{WCF} \frac{\partial \mathrm{E}_{\mathrm{s}}}{\partial \mathrm{WCF}}\right)^{2}\right]^{1 / 2}
$$

The sensitivities are given by:

$$
\begin{aligned}
\frac{\partial \mathrm{E}_{\mathrm{s}}}{\partial \mathrm{E}_{\mathrm{b}}} & =-(\text { constant })(\mathrm{DEV})(\mathrm{WCF}) \\
\frac{\partial \mathrm{E}_{\mathrm{s}}}{\partial \mathrm{E}} & =-(\text { constant })(\mathrm{DEV})(\mathrm{WCF}) \\
\frac{\partial \mathrm{E}_{\mathrm{s}}}{\partial \mathrm{WCF}} & =-(\text { constant })\left(\frac{\mathrm{E}-\mathrm{E}_{\mathrm{b}}}{10^{6}}\right)(\mathrm{DEV}) \\
\frac{\partial \mathrm{E}_{\mathrm{s}}}{\partial \mathrm{DEV}} & =- \text { (constant) }\left(\frac{\mathrm{E}-\mathrm{E}_{\mathrm{b}}}{10^{6}}\right)(\mathrm{WCF})
\end{aligned}
$$

\section{Sensitivity Analysis}

A spreadsheet program was written using Microsoft Excel ${ }^{\mathrm{TM}}$, allowing easy variation of parameters and easy graphical representation of sensitivities. The overall results of this analysis are presented in Table C-3. Table C-3 provides a description of each spreadsheet calculation. The spreadsheets are used for "what if" analysis, identification of error sources and their total contribution to error as well as their sensitivity. Identifying sensitivity is also very useful for control purposes. 
Table C-3. Spreadsheet Calculation Descriptions

\begin{tabular}{|c|c|}
\hline Spreadsheet Calculation Title & Description \\
\hline Flow Calibration Error Analysis & $\begin{array}{l}\text { Used to determine source error in flow calibrations. It demonstrates sensi- } \\
\text { tivities and error location. } \mathrm{P}_{\text {baro }}, \mathrm{P}_{\text {noz }}, \mathrm{T}_{\text {noz }} \text { and nozzle designations are entered } \\
\text { into the spreadsheet during flow calibration. The spreadsheet calculates } \\
\text { flow, } \mathrm{k} \text {, nozzle area, sensitivities etc. Errors and ranges of the test equipment } \\
\text { are checked prior to each run. }\end{array}$ \\
\hline Tunnel Flow Sensitivity & $\begin{array}{l}\text { This spreadsheet was developed to look strictly at sensitivities of dilution } \\
\text { ratio and measured tunnel } \mathrm{CO}_{2} \text { as functions of tunnel and dilution air parame- } \\
\text { ters. This was done because during initial shake down of the tunnel, severe } \\
\text { dilution ratio drift was observed when operating at modest dilution ratios. } \\
\text { The spreadsheet identified dilution air temperature and pressure as important } \\
\text { control factors. A heat exchanger was installed on the dilution air line as } \\
\text { well as a precision pressure regulator. This improved drift greatly. It also } \\
\text { showed that control of pump speed from dilution ratio was impractical due to } \\
\text { the extreme sensitivity of dilution ratio to pump speed. Instead, pump mass } \\
\text { flow is used as the set point for pump speed and the controller was detuned } \\
\text { to allow greater stability. As a result, mass flow is approached manually. } \\
\text { Once it is set, it is very stable provided dilution ratios are below about 30:1. }\end{array}$ \\
\hline $\begin{array}{l}\text { Diesel Dilution Tunnel PM } \\
\text { Measurement Uncertainty }\end{array}$ & $\begin{array}{l}\text { Used to determine source errors, overall error and sensitivities related to } \\
\text { measured tunnel particulate mass related to engine specific conditions } \\
\text { (g/hphr). Its usefulness is well demonstrated in that it identified source errors } \\
\text { and their relative importance. This lead to purchase of a high accuracy gas } \\
\text { divider so that each potential gas span range may be spanned to reduce error. } \\
\text { It identified the need to select the operating space so that gas measurements } \\
\text { are near the top end of their span ranges. It also showed the need to } \\
\text { minimize } \mathrm{CO}_{2} \text { measurement error in order to reduce DR uncertainty. }\end{array}$ \\
\hline $\mathrm{NO}_{\mathrm{x}}$ Measurement Uncertainty & $\begin{array}{l}\text { Used to determine source errors, overall error and sensitivities related to } \\
\text { measured tunnel } \mathrm{NO}_{\mathrm{x}} \text { related to engine specific conditions (g/hphr). Its } \\
\text { usefulness is well demonstrated in that it identified source errors and their } \\
\text { relative importance. This lead to purchase of a high accuracy gas divider so } \\
\text { that each potential gas span range may be spanned to reduce error. It identi- } \\
\text { fied the need to select the operating space so that gas measurements are near } \\
\text { the top end of their span ranges. }\end{array}$ \\
\hline THC Measurement Uncertainty & $\begin{array}{l}\text { Used to determine source errors, overall error and sensitivities related to } \\
\text { measured tunnel THC related to engine specific conditions ( } \mathrm{g} / \mathrm{hphr} \text { ). Its } \\
\text { usefulness is demonstrated above. }\end{array}$ \\
\hline $\mathrm{CO}_{2}$ Measurement Uncertainty & $\begin{array}{l}\text { Used to determine source errors, overall error and sensitivities related to } \\
\left.\text { measured tunnel } \mathrm{CO}_{2} \text { related to engine specific conditions ( } \mathrm{g} / \mathrm{hphr}\right) \text {. Its } \\
\text { usefulness is demonstrated above. }\end{array}$ \\
\hline High CO Measurement Uncertainty & $\begin{array}{l}\text { Used to determine source errors, overall error and sensitivities related to } \\
\text { measured tunnel High CO related to engine specific conditions (g/hphr). Its } \\
\text { usefulness is demonstrated above. }\end{array}$ \\
\hline Low CO Measurement Uncertainty & $\begin{array}{l}\text { Used to determine source errors, overall error and sensitivities related to } \\
\text { measured tunnel Low CO related to engine specific conditions }(\mathrm{g} / \mathrm{hphr}) \text {. Its } \\
\text { usefulness is demonstrated above. }\end{array}$ \\
\hline Instrument Errors & $\begin{array}{l}\text { This spreadsheet is used to calculate the errors in instrument measurements. } \\
\text { It calculates the total errors as RMS sums of bias and random errors in each } \\
\text { instrument. It also includes calibration source error measurement. As an } \\
\left.\text { example } \mathrm{CO}_{2} \text { tunnel measurement includes error from calibration gas ( } 1 \%\right) \text {, } \\
\text { gas divider uncertainty }(0.4 \%) \text { instrument error (random and bias) and DAS } \\
\text { error (random and bias). The total error cells in this spread sheet is linked to } \\
\text { the measurement uncertainty spreadsheets. }\end{array}$ \\
\hline
\end{tabular}


The "Measurement Uncertainty" spreadsheets were also linked through Dynamic Data Exchange protocol to the Paragon control and data acquisition system. This allowed a "real time" estimate of measurement error during engine testing. Changes in gas composition and hence ranges were handled analytically using "if" statements in the spreadsheets which search the instrument error spreadsheet for the proper errors. This provides a point source error estimation, which were used in considering the uncertainty overall engine measurements. Nominal uncertainty ranges for emissions parameters are given below in Table C-4.

Table C-4. Nominal Measurement Uncertainties

\begin{tabular}{|c|c|}
\hline Emission Measurement Type & $\begin{array}{c}\text { Approximate Uncertainty (g/bhp-hr) (Actual } \\
\text { value depends on range used, concentration, etc.) }\end{array}$ \\
\hline Particulate (PM) & $2.8 \%-10 \%$ \\
\hline $\mathrm{NO}_{\mathrm{x}}$ & $2 \%-8 \%$ \\
\hline $\mathrm{THC}$ & $2 \%-8 \%$ \\
\hline $\mathrm{CO}_{2 \mathrm{ex}}$ & $2 \%-8 \%$ \\
\hline $\mathrm{CO}_{2 \mathrm{tun}}$ & $2 \%-8 \%$ \\
\hline $\mathrm{High} \mathrm{CO}$ & $2 \%-8 \%$ \\
\hline Low CO & $2 \%-8 \%$ \\
\hline
\end{tabular}

Uncertainties are monitored in real time during test runs. Generally, however, engine air mass flow measurement uncertainty is on the order of $\pm 1.53 \%$ when considering the errors in flowmeter, temperature, and pressure. Re-spanning the transmitter and using the calculated value of $\mathrm{k}$ reduced the typical calibration air flow error from $1.6 \%$ to $0.6 \%$. 


\section{Appendix D: Annotated Example of Ames Test Data Analysis Using MathCAD}

\section{Setup}

Specify Data Set ID \# and Test Condition Information:

$$
\begin{aligned}
& \text { Set }:=34 \\
& \text { KeyState }:=\text { "2" } \\
& \text { EngineSpeed }:=16 \\
& \text { BMEP }:=2 \\
& \text { Fuel }:=\text { "FT" } \\
& \text { S9 }:=\text { "+" } \\
& \text { Strain }:=\text { "YG1024" }
\end{aligned}
$$

Input Dose and Revertant count data:

Number of Doses:

$r:=5$

Dose index variable:

$\mathrm{i}:=1 . . \mathrm{r}$

Number of Replicates:

$\mathrm{n}:=4$

Replicate index variable:

$\mathrm{j}:=1 . . \mathrm{n}$

Dose Data:

$$
\mathrm{d}:=\left(\begin{array}{c}
0 \\
1.48 \\
4.44 \\
13.3 \\
40
\end{array}\right) \cdot 10^{-6}
$$

Revertant Count Data: $\mathrm{N}_{\mathrm{i}, \mathrm{j}}$

$$
\mathrm{N}:=\left(\begin{array}{cccc}
14 & 16 & 22 & 13 \\
30 & 49 & 72 & 56 \\
65 & 84 & 128 & 109 \\
136 & 126 & 201 & 224 \\
271 & 269 & 435 & 415
\end{array}\right)
$$

Plot revertant count vs dose for an initial visual assessment... 


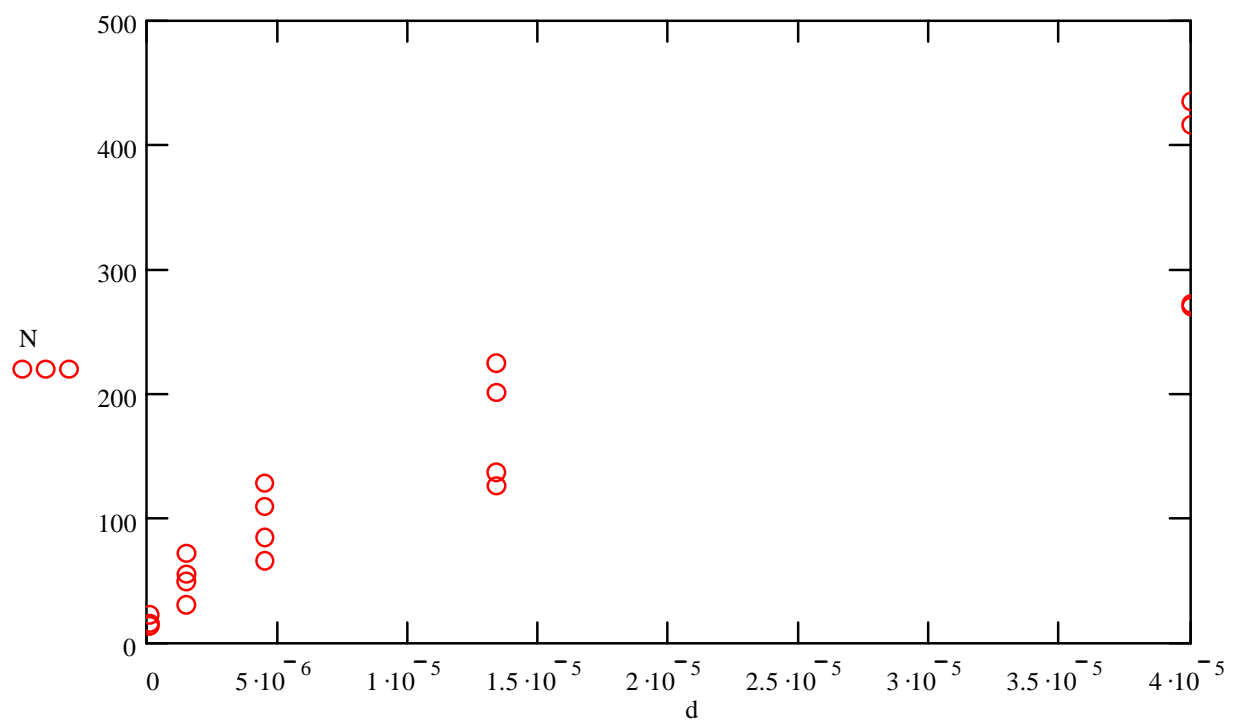

Notice that the number of revertants increases with dose, but that the shape of the "curve" is concave downward, suggesting some toxicity effect. For use later, define a function to evaluate the log factorial of $n$ :

$$
\operatorname{LF}(n):=\mid \begin{aligned}
& 0 \text { if } n \leq 1 \\
& \sum_{i=1}^{n} \ln (i) \text { otherwise }
\end{aligned}
$$

\section{Summary of the equations used in the data analysis}

Let us use generalized Poisson \#1. The "expected" or "mean" revertant count is a linear function of dose (except for toxicity),

$E\left(N_{i, j}\right)=\mu_{i}=\left(\beta_{0}+\beta_{1} \cdot d_{i}\right)$

The probability density function for the revertant counts at the ith dose:

$P\left(N_{i, j}\right)=\frac{\xi \cdot\left(\xi+\eta \cdot N_{i, j}\right)^{n-1} \cdot e^{-\left(\xi+\eta \cdot N_{i, j}\right)}}{N_{i, j} !}$

The unknown parameters are

$\beta_{0}$

$\beta_{1}$

and

$\gamma$

where: 
$\eta=1-\frac{1}{\sqrt{\gamma}}$

$\xi=\frac{\mu_{\mathrm{i}}}{\sqrt{\gamma}}$

We can write $\mathrm{x}$ and $\mathrm{h}$ in terms of the unknown parameters...

$$
\begin{aligned}
& \xi\left(\beta_{0}, \beta_{1}, \gamma, d\right):=\frac{\left(\beta_{0}+\beta_{1} \cdot d\right)}{\sqrt{\gamma}} \\
& \eta(\gamma):=1-\frac{1}{\sqrt{\gamma}}
\end{aligned}
$$

The probability of revertant count $\mathrm{n}$ at dose $\mathrm{d}$ is:

$$
P\left(n, d, \beta_{0}, \beta_{1}, \gamma\right):=\frac{\xi\left(\beta_{0}, \beta_{1}, \gamma, d\right) \cdot\left(\xi\left(\beta_{0}, \beta_{1}, \gamma, d\right)+\eta(\gamma) \cdot n\right)^{n-1} \cdot e^{-\left(\xi\left(\beta_{0}, \beta_{1}, \gamma, d\right)+\eta(\gamma) \cdot n\right)}}{n !}
$$

The log-probability is:

$\operatorname{LP}\left(\mathrm{n}, \mathrm{d}, \beta_{0}, \beta_{1}, \gamma\right):=\ln \left(\xi\left(\beta_{0}, \beta_{1}, \gamma, \mathrm{d}\right)\right)+(\mathrm{n}-1) \cdot \ln \left(\left(\xi\left(\beta_{0}, \beta_{1}, \gamma, \mathrm{d}\right)+\eta(\gamma) \cdot \mathrm{n}\right)\right)-\left(\xi\left(\beta_{0}, \beta_{1}, \gamma, \mathrm{d}\right)+\eta(\gamma) \cdot \mathrm{n}\right)-\operatorname{LF}(\mathrm{n})$

The "likelihood" of a sample of independently and identically distributed random variables is simply the product of the pdf's at each sample point, therefore the log-likelihood of a sample of revertant count $\mathrm{N}$ 's is given by:

$$
\operatorname{LL}\left(\beta_{0}, \beta_{1}, \gamma, r_{1}, r_{2}\right):=\sum_{i=r_{1}}^{r_{2}} \sum_{j=1}^{n} \operatorname{LP}\left(N_{i, j}, d_{i}, \beta_{0}, \beta_{1}, \gamma\right)
$$

Notice that the log-likelihood is a function of the unknown parameters $b_{0}, b_{1}$ and $\gamma$. The $r_{1}$ and $r_{2}$ arguments are for convenience, allowing specification of which doses to use. We can derive estimates of the unknown parameters by finding those values that maximize the likelihood of the sample by actually maximizing the log-likelihood. The anlysis starts with "stage 1" by evaluating whether to drop the rth dose from the data set because of toxic effects. Using the procedure of Bernstein et al., 1982, we fit two models to the data. The first assumes that the mean revertant count is a linear function of dose up to and including the largest (rth) dose. The second model is similar except it allows the rth dose to have its own mean, possibly not following the linear trend. If the second model fits significantly better and the average count at the rth dose is "below" the linear trend, we conclude the rth data set is affected by toxicity and toss it out. 


\section{Calculation}

Step 1: Fit parameters to whole set $r$, and model to $r-1+$ ur, then define a function for the loglikelihood of the entire data set with linear dose-revertant relationship:

$\operatorname{LLx}\left(\beta_{0}, \beta_{1}, \gamma\right):=\operatorname{LL}\left(\beta_{0}, \beta_{1}, \gamma, 1, \mathrm{r}\right)$

In order to estimate the parameters, we need initial estimates:

$\gamma:=1$

$\beta_{0}:=$ intercept $\left(\mathrm{d}, \mathrm{N}^{\langle{ }\rangle}\right)$

$\beta_{0}=29.05$

$\beta_{1}:=\operatorname{slope}\left(\mathrm{d}, \mathrm{N}^{\langle 1\rangle}\right)$

$\beta_{1}=6.261 \times 10^{6}$

The log-likelihood with the initial estimates is:

$\operatorname{LLx}\left(\beta_{0}, \beta_{1}, \gamma\right)=-293.168$

Now, iterate a solution to maximize the likelihood...

Given

$\gamma>0$

$\beta_{0}>0$

$\beta_{1}>-1000$

$\left(\begin{array}{c}\beta^{\prime}{ }_{0} \\ \beta^{\prime}{ }_{1} \\ \gamma\end{array}\right):=\operatorname{Maximize}\left(\operatorname{LLx}, \beta_{0}, \beta_{1}, \gamma\right)$

The revised parameter estimates are:

$\beta_{0}^{\prime}=34.406$

$\beta^{\prime}{ }_{1}=8.641 \times 10^{6}$

$\gamma^{\prime}=13.926$

The maximized likelihood is:

$\mathrm{LL}_{1}:=\operatorname{LLx}\left(\beta_{0}{ }_{0}, \beta^{\prime}{ }_{1}, \gamma^{\prime}\right)$

Now fit the second model to same data (with separate mean for dose r).

Define the likelihood function:

$\operatorname{LLx}\left(\beta_{0}, \beta_{1}, \gamma, \mu_{\mathrm{r}}\right):=\operatorname{LL}\left(\beta_{0}, \beta_{1}, \gamma, 1, \mathrm{r}-1\right)+\sum_{\mathrm{i}=\mathrm{r}}^{\mathrm{r}} \sum_{\mathrm{j}=1}^{\mathrm{n}} \operatorname{LP}\left(\mathrm{N}_{\mathrm{i}, \mathrm{j}}, \mathrm{d}_{\mathrm{i}}, \mu_{\mathrm{r}}, 0, \gamma\right)$ 
Use mean of rth dose and previous estimates for initial values:

$$
\begin{aligned}
& \gamma:=\gamma \\
& \beta_{0}:=\beta^{\prime}{ }_{0} \\
& \beta_{0}=34.406 \\
& \beta_{1}:=\beta^{\prime}{ }_{1} \\
& \beta_{1}=8.641 \times 10^{6} \\
& \mu_{\mathrm{r}}:=400 \\
& \operatorname{LLx}\left(\beta_{0}, \beta_{1}, \gamma, \mu_{\mathrm{r}}\right)=-98.69 \\
& \text { Given } \\
& \gamma>0 \\
& \mu_{\mathrm{r}}>0 \\
& \beta_{0}>0 \\
& \beta_{1}>-1000 \\
& \left(\begin{array}{c}
\beta_{0} \\
\beta_{1} \\
\gamma^{\prime} \\
\mu_{\mathrm{r}}
\end{array}\right):=\operatorname{Maximizd}\left(\operatorname{LLx}, \beta_{0}, \beta_{1}, \gamma, \mu_{\mathrm{r}}\right) \\
& \beta^{n_{0}}=26.961 \\
& \beta^{n_{1}}=1.214 \times 10^{7} \\
& \gamma^{\prime \prime}=10.429 \\
& \mu{ }_{\mathrm{r}}=342.504
\end{aligned}
$$

\section{Parameter estimates}

Maximized likelihood:

$$
\begin{aligned}
& \mathrm{LL}_{2}:=\operatorname{LLx}\left(\beta_{0}{ }_{0}, \beta_{1}{ }_{1}, \gamma^{\prime \prime}, \mu_{\mathrm{r}}\right) \\
& \mathrm{LL}_{2}=-95.085
\end{aligned}
$$

This graph compares the fit of the two different models 


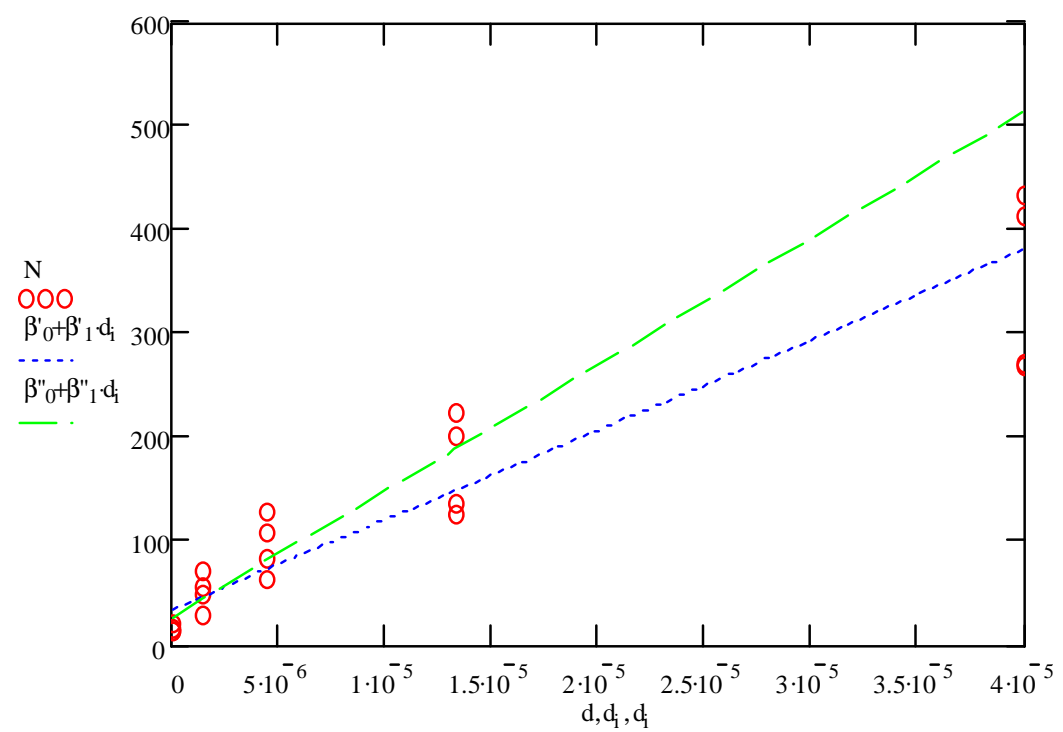

They are:

$\mu^{\prime \prime}=342.504$

$\beta_{0}+\beta_{1} \cdot d_{\mathrm{r}}=512.711$

Now we get to the actual "test." The second model, having one extra parameter, will tend to fit better than the first. The question is, "is it significantly better." We can for a test statistic consider that the difference in the log-likelihoods, under a null-hypothesis of no difference between the two models, will follow a chi-square distribution. In addition, the mean count at the rth dose must fall below the trend established by the remaining doses.

We see above that the mean revertant count at the high dose (343) is less than the expected count from the reduced model (513), therefore we need to do the chi-square test:

$\beta^{\prime}{ }_{1}=8.641 \times 10^{6}$

(dose-response, full model)

$\chi 2:=2 \cdot\left(\mathrm{LL}_{2}-\mathrm{LL}_{1}\right)$

$\chi 2=5.7$

$1-\operatorname{pchisq}(\chi 2,1)=0.017$

$\beta^{n_{1}}=1.214 \times 10^{7}$

(dose-response, w/o rth dose)

The p-value (1-pchisq) is $<0.05$. so we conclude that data from the highest dose DOES NOT follow the linear trend. We throw it out and proceed to the next step. In this stage, we repeat the process we just used, except in this case, we are examining data at the (r-1)th dose to determine whether we should omit it from the dose-response analysis also. In this regard, this is a 
"step-wise" process. The calculations for the second step will now be carried out without any extra annotation. The process is similar to what we just did above.

Step 2: Fit parameters to set r-1, and model to $\mathrm{r}-2+\mathrm{ur}-1$

$\operatorname{LLx}\left(\beta_{0}, \beta_{1}, \gamma\right):=\operatorname{LL}\left(\beta_{0}, \beta_{1}, \gamma, 1, \mathrm{r}-1\right)$

First we need initial estimates:

$$
\begin{aligned}
& \gamma:=\gamma^{\prime \prime} \\
& \beta_{0}:=\beta^{n_{0}} \\
& \beta_{0}=26.961 \\
& \beta_{1}:=\beta_{1} \\
& \beta_{1}=1.214 \times 10^{7} \\
& \operatorname{LLx}\left(\beta_{0}, \beta_{1}, \gamma\right)=-71.691 \\
& \gamma>0 \\
& \beta_{0}>0 \\
& \beta_{1}>-1000 \\
& \left(\begin{array}{c}
\beta_{0}^{\prime} \\
\beta_{1}^{\prime} \\
\gamma
\end{array}\right):=\operatorname{Maximizd}\left(L L x, \beta_{0}, \beta_{1}, \gamma\right) \\
& \beta^{\prime}{ }_{0}=25.866 \\
& \beta^{\prime}{ }_{1}=1.211 \times 10^{7} \\
& \gamma^{\prime}=8.239 \\
& \mathrm{LL}_{3}:=\operatorname{LLx}\left(\beta_{0}^{\prime}, \beta^{\prime}{ }_{1}, \gamma^{\prime}\right) \\
& \mathrm{LL}_{3}=-71.519
\end{aligned}
$$

Now fit to same data but with separate mean for dose $r-1 \ldots$

$$
\begin{aligned}
& \operatorname{LLx}\left(\beta_{0}, \beta_{1}, \gamma, \mu_{\mathrm{r}}\right):=\operatorname{LL}\left(\beta_{0}, \beta_{1}, \gamma, 1, \mathrm{r}-2\right)+\sum_{\mathrm{i}=\mathrm{r}-1}^{\mathrm{r}-1} \sum_{\mathrm{j}=1}^{\mathrm{n}} \operatorname{LP}\left(\mathrm{N}_{\mathrm{i}, \mathrm{j}}, \mathrm{d}_{\mathrm{i}}, \mu_{\mathrm{r}}, 0, \gamma\right) \\
& \gamma:=\gamma^{\prime} \\
& \beta_{0}:=\beta_{0}^{\prime} \\
& \beta_{0}=25.866 \\
& \mu_{\mathrm{r}}:=\frac{\mathrm{N}_{\mathrm{r}-1,1}+\mathrm{N}_{\mathrm{r}-1,2}+\mathrm{N}_{\mathrm{r}-1,3}+\mathrm{N}_{\mathrm{r}-1,4}}{4} \\
& \beta_{1}:=\beta_{1}^{\prime} \\
& \beta_{1}=1.211 \times 10^{7} \\
& \operatorname{LLx}\left(\beta_{0}, \beta_{1}, \gamma, \mu_{\mathrm{r}}\right)=-71.127
\end{aligned}
$$




$$
\begin{aligned}
& \text { Given } \\
& \gamma>0 \\
& \mu_{\mathrm{r}}>0 \\
& \beta_{0}>0 \\
& \beta_{1}>-1000 \\
& \left(\begin{array}{l}
\beta_{0} \\
\beta^{\prime \prime} \\
\gamma^{\prime \prime} \\
\mu_{\mathrm{r}}
\end{array}\right):=\operatorname{Maximizd}\left(\mathrm{LLx}, \beta_{0}, \beta_{1}, \gamma, \mu_{\mathrm{r}}\right) \\
& \beta_{n_{0}}=20.088 \\
& \beta_{{ }_{1}}=1.803 \times 10^{7} \\
& \gamma^{\prime \prime}=5.97 \\
& \mu_{\mathrm{r}}=169.245 \\
& \mathrm{LL}_{4}:=\operatorname{LLx}\left(\beta_{0}{ }_{0}, \beta^{\prime \prime}, \gamma^{\prime \prime}, \mu_{\mathrm{r}}\right) \\
& \mathrm{LL}_{4}=-69.082
\end{aligned}
$$

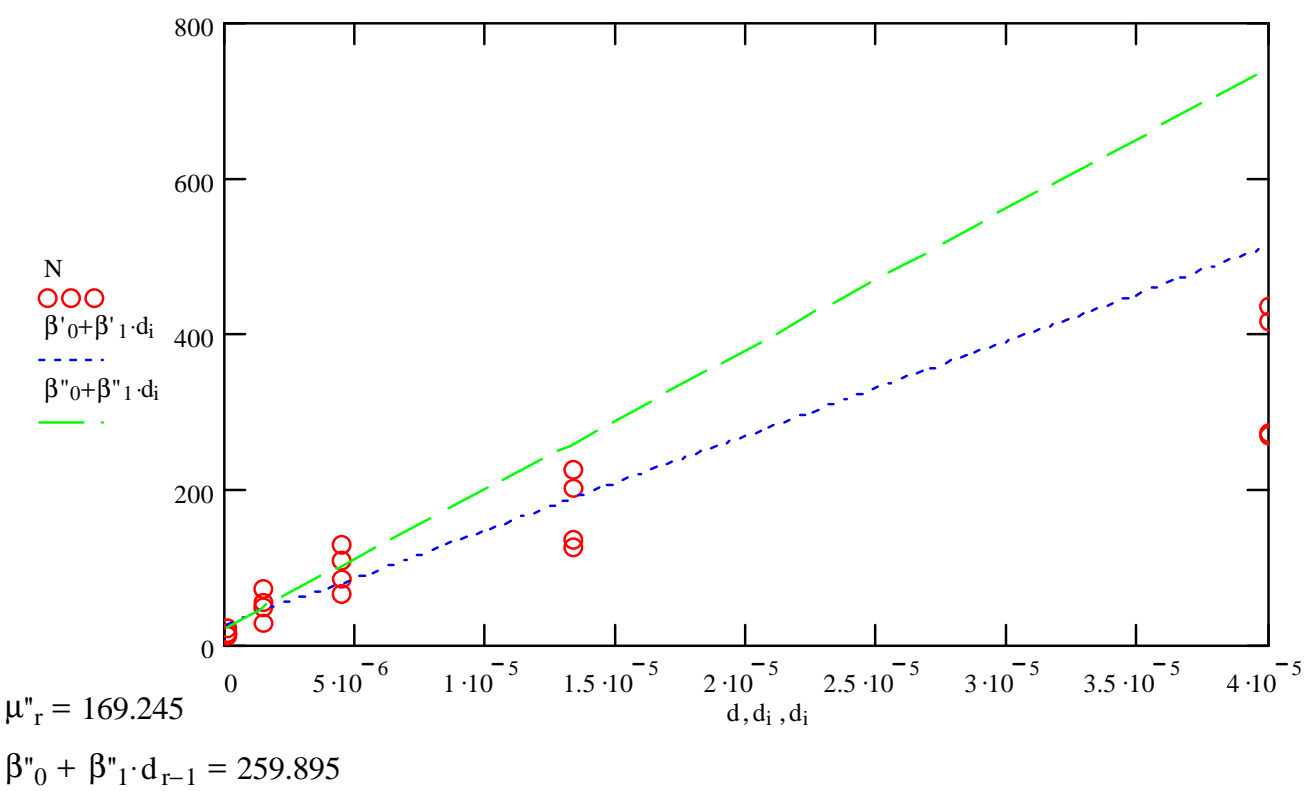

The mean revertant count at the $\mathrm{r}-1$ dose is not greater than or equal to the expected count from the reduced model, therefore the data fail to meet the criterion of equation (11) and we must do the chi-square test in equation (12):

$$
\begin{aligned}
& \chi 2:=2 \cdot\left(\mathrm{LL}_{4}-\mathrm{LL}_{3}\right) \\
& \chi 2=4.876 \\
& 1-\text { pchisq }(\chi 2,1)=0.027 \\
& \beta^{\prime}{ }_{1}=1.211 \times 10^{7}
\end{aligned}
$$


Dose-response including (r-1)th dose

$\beta^{\prime \prime}=1.803 \times 10^{7}$

Dose-response without (r-1)th dose

So we conclude that data from the $\mathrm{r}-1$ dose DOES NOT follow the linear trend, and omit it from analysis. After throwing out the (r-1)th dose, there are only 3 doses remaining. This is an insufficient number of doses to proceed with the stepwise process, therefore we stop the step-wise process here. Our final estimate of the mutagenicity slope is:

Dose-response without (r-1)th dose

$\beta^{\prime \prime}=1.803 \times 10^{7}$

It is also enlightening to routinely compare the final slope with that derived from only the control and the first non-zero dose (i.e. doses $1 \& 2$ )

$$
\frac{\operatorname{mean}\left(\mathrm{N}_{2,1}, \mathrm{~N}_{2,2}, \mathrm{~N}_{2,3}, \mathrm{~N}_{2,4}\right)-\operatorname{mean}\left(\mathrm{N}_{1,1}, \mathrm{~N}_{1,2}, \mathrm{~N}_{1,3}, \mathrm{~N}_{1,4}\right)}{\mathrm{d}_{2}-\mathrm{d}_{1}}=2.399 \times 10^{7}
$$

We see that $b_{1}$ is a good bit less than this two-point slope, thus providing some suspicion that there still are still toxicity effects remaining. The next step is to check the goodness-of-fit to the model selected in the step-wise procedure above. Certain types of lack-of-fit could be attributed to toxicity effects in the remaining data. This goodness of fit test essentially compares the revertant count at the control (zero) dose with the trend established by the remaining non-zero dose data.

\section{GOODNESS OF FIT TEST}

$$
\begin{aligned}
& \mathrm{LL}_{\text {Alt }}:=\operatorname{LL}\left(\beta^{\prime \prime}{ }_{0}, \beta^{\prime \prime}{ }_{1}, \gamma^{\prime \prime}, 1, \mathrm{r}-2\right) \\
& \mathrm{LL}_{\text {Alt }}=-48.188
\end{aligned}
$$

The likelihood of the model selected above

$$
\begin{aligned}
& \mathrm{r}_{\text {keep }}:=3 \\
& \mathrm{LL}_{\text {Model }}:=\mathrm{LL}_{\text {Alt }}
\end{aligned}
$$

The number of doses kept.

Define the likelihood function for the separate control mean model...

$$
\operatorname{LL} 3\left(\mu_{0}, \beta_{0}, \beta_{1}, \gamma\right):=\sum_{j=1}^{n} \operatorname{LP}\left(N_{1, j}, d_{1}, \mu_{0}, 0, \gamma\right)+\sum_{i=2}^{r_{k e e p}} \sum_{j=1}^{n} \operatorname{LP}\left(N_{i, j}, d_{i}, \beta_{0}, \beta_{1}, \gamma\right)
$$

Initial estimates:

$\beta_{0}:=\beta_{0}^{\prime}$

$\beta_{0}=25.866$ 


$$
\begin{aligned}
& \beta_{1}:=\beta_{1}^{\prime} \\
& \beta_{1}=1.211 \times 10^{7} \\
& \gamma:=\gamma \\
& \mu_{0}:=20 \\
& \operatorname{LL} 3\left(\mu_{0}, \beta_{0}, \beta_{1}, \gamma\right)=-50.023 \\
& \text { Given } \\
& \gamma>0 \\
& \mu_{0}>0 \\
& \beta_{0}>0 \\
& \beta_{1}>-1000 \\
& \left.\begin{array}{l}
\mu^{\prime \prime \prime}{ }_{0} \\
\beta^{\prime \prime \prime \prime}{ }_{0} \\
\beta^{\prime \prime \prime \prime}{ }_{1} \\
\gamma^{\prime \prime \prime \prime}
\end{array}\right):=\operatorname{Maximize}\left(\mathrm{LL}_{3}, \mu_{0}, \beta_{0}, \beta_{1}, \gamma\right) \\
& \mathrm{LL}_{\mathrm{CF}}:=\operatorname{LL} 3\left(\mu^{\prime \prime \prime \prime}{ }_{0}, \beta^{\prime \prime \prime \prime}{ }_{0}, \beta^{\prime \prime \prime \prime}{ }_{1}, \gamma^{\prime \prime \prime}\right) \\
& \operatorname{LL}_{\mathrm{CF}}=-47.503
\end{aligned}
$$

Next, we compare the likelihoods of the two models...

$\chi 2_{\mathrm{CF}}:=2 \cdot\left(\mathrm{LL}_{\mathrm{CF}}-\mathrm{LL}_{\mathrm{Model}}\right)$

$\chi 2_{\mathrm{CF}}=1.37$

$1-\operatorname{pchisq}\left(\chi 2_{\mathrm{CF}}, 1\right)=0.242$

The chi-square value is not large, so we DO NOT reject the hypothesis that the control data are on the same trend as the other remaining doses. In other words, there is no conclusive evidence of significant lack-of-fit.

Another test that the authors recommend is a test for mutagenic effect. In the step-wise procedure above, we threw out data that exhibited toxicity and came up with an estimate of the dose-response slope of revertants per unit dose, but nowhere did we test that value to see if it differed significantly from zero. If it is not significantly different from zero, the dose does not effect the number of revertants and the substance can not be mutagenic. The procedure for testing for nonzero slope essentially involves comparing the likelihood of the selected model with that of a model where $b_{1}=0$. This test compares the zero slope model for cases with at $r$ doses, $r-1$ doses, and $r-2$ doses. It proceeds as follows:

\section{Chi Square for Mutagenic Response}

No Slope Model for $r$ doses.

define likelihood function:

$\operatorname{LLo}(\mu, \gamma):=\operatorname{LL}(\mu, 0, \gamma, 1, \mathrm{r})$ 
initial estimates:

$\mu:=100$

$\gamma:=1$

$\operatorname{LLo}(\mu, \gamma)=-1.241 \times 10^{3}$

solve...

Given

$\gamma>0$

$\mu>0$

$\left(\begin{array}{l}\mu \\ \psi\end{array}\right):=\operatorname{Maximizd}(L L o, \mu, \gamma)$

Solution...

$\operatorname{LL0}:=\operatorname{LLo}(\mu, \psi)$

LLO $=-118.32$

Compare likelihoods...

$\mathrm{X} 2_{\mathrm{M}}:=2\left(\mathrm{LL}_{1}-\mathrm{LL} 0\right)$
$\mathrm{X} 2_{\mathrm{M}}=40.77$
$\sqrt{\mathrm{X} 2_{\mathrm{M}}}=6.385$

No Slope Model for $\mathrm{r}-1$ doses...

$\operatorname{LLo}(\mu, \gamma):=\operatorname{LL}(\mu, 0, \gamma, 1, \mathrm{r}-1)$

$\mu:=100$

$\gamma:=1$

$\operatorname{LLo}(\mu, \gamma)=-448.757$

Given

$\gamma>0$

$\mu>0$

$\left(\begin{array}{l}\mu \\ \psi\end{array}\right):=\operatorname{Maximize}(L L o, \mu, \gamma)$

$\operatorname{LL0}:=\operatorname{LLo}(\mu, \psi)$

LLO $=-86.298$

$\mathrm{LL}_{3}=-71.519$

$\mathrm{X} 2_{\mathrm{M}}:=\max \left[\mathrm{X} 2_{\mathrm{M}},\left(\mathrm{LL}_{3}-\mathrm{LL} 0\right)\right]$

$\mathrm{X} 2_{\mathrm{M}}=40.77$

$\sqrt{\mathrm{X} 2_{\mathrm{M}}}=6.385$

No Slope Model for $\mathrm{r}-2$ doses...

$\operatorname{LLo}(\mu, \gamma):=\operatorname{LL}(\mu, 0, \gamma, 1, \mathrm{r}-2)$ 


$$
\begin{aligned}
& \mu:=100 \\
& \gamma:=1 \\
& \operatorname{LLo}(\mu, \gamma)=-329.934 \\
& \text { Given } \\
& \gamma>0 \\
& \mu>0 \\
& \left(\begin{array}{c}
\mu \\
\psi
\end{array}\right):=\operatorname{Maximizd}(\operatorname{LLo}, \mu, \gamma) \\
& \operatorname{LL0}:=\operatorname{LLo}(\mu, \psi) \\
& \operatorname{LLO}=-58.73 \\
& \mathrm{LL}_{\mathrm{Alt}}=-48.188 \\
& \sqrt{3.841}=1.96 \\
& \mathrm{X} 2_{\mathrm{M}}:=\max \left[\mathrm{X} 2_{\mathrm{M}},\left(\mathrm{LL}_{\mathrm{Alt}}-\mathrm{LL} 0\right)\right] \\
& \mathrm{X} 2_{\mathrm{M}}=40.77 \\
& \sqrt{\mathrm{X} 2_{\mathrm{M}}}=6.385
\end{aligned}
$$

A Chi-square of 40.77 is quite large, even without computing its p-valve (actually the square-root of a 1 degree of freedom chi-square follows a normal or $\mathrm{z}$-distribution, and $\mathrm{z}(1, .975)=1.96$ $<<6.385$ ), we conclude that $b_{1}$ does not equal zero and that the substance is mutagenic in this case. 